\title{
Morfología de un pensamiento. Aprender, desaprender y reaprender
}

\section{Adris Díaz}

Universidad de Monterrey, México

\section{Resumen}

El aprendizaje-servicio es una metodología que invita al estudiante a entretejer de manera armónica y holística la teoría con la praxis. Al poner en práctica este aprendizaje, se evidencian los riesgos por el rechazo y/o la incertidumbre a la que los estudiantes se enfrentan, así como los beneficios del fortalecimiento de sus competencias y habilidades, pertinentes para su futuro profesional. El objetivo del estudio es mostrar el desarrollo de la práctica en la aplicación de la teoría, en función del servicio a una comunidad vulnerable. El mismo se desarrolla con estudiantes de diferentes semestres de la carrera de Sociología Urbana y para su cumplimiento se analizan distintos puntos de vista sobre cómo se fue construyendo el conocimiento, de acuerdo a las características particulares de las dos comunidades, ambas en el estado de Nuevo León, México. Es un estudio cualitativo, que busca por medio de un análisis descriptivo, abrir un espacio a la reflexión, tras descubrir los aciertos y desaciertos como una oportunidad para rediseñar un curso en el servicio y crear adaptaciones metodológicas. Revela, además, la importancia de la investigación formativa como componente vital para el desarrollo de competencias para el futuro profesional.

\section{Palabras clave}

Aprendizaje-servicio, investigación formativa, competencias, habilidades. 


\title{
Morphology of a thought. Learning, unlearning and relearning
}

\begin{abstract}
Service-learning is a methodology that invites the student to interweave theory and practice in a harmonic and holistic way. By putting this type of learning into practice, the risks due to the rejection and the uncertainty faced by students are exposed, as are the benefits of strengthening their competences and skills, which are so relevant to their professional future. The objective of this study is to show the development of practice in the application of theory with the aim of offering a service to a vulnerable community. The project was carried out with students from the Urban Sociology degree. This qualitative study seeks to open a space for reflection, through a descriptive analysis, after considering the successes and failures as an opportunity to redesign a course in the Service and produce methodological adaptations. This was done with the purpose of making students face reality in a solidary manner and improving their abilities as responsible, committed and proactive citizens. This study also reveals the importance of Research Training as a vital component for the development of competences in the future professional.
\end{abstract}

\section{Keywords}

Service-learning, formative research, competences, abilities. 


\section{Introducción}

¿Qué hacer ante la necesidad de querer cambiar el paradigma educativo? Uno de los retos actuales en relación con la educación tradicional es la forma de trasmitir el conocimiento, donde es ya obsoleto el querer memorizar toda la información. Es una necesidad apremiante que los estudiantes aprendan haciendo, es decir, que tengan la oportunidad de poder combinar de una manera sistémica los objetivos de aprendizaje con la práctica cotidiana a través de su aplicación en el servicio. Se precisa de un proceso de enseñanza-aprendizaje donde el alumno pueda darle significado a la información que recibe, vinculando el contenido con nuevas experiencias prácticas.

Partiendo de esta premisa es importante que los cursos se caractericen por ser motivadores, retadores y sobre todo vivenciales, donde el estudiante tenga la garantía de aprender y actuar al mismo tiempo en compañía del profesor -que a su vez urge que tenga un espíritu proactivo, creativo y retador-. En todo este proceso de enseñanza-aprendizaje, como plantea Weiner (Vázquez y Manassero, 1989), la motivación para el alumno dependerá de sus expectativas, de sus éxitos y sus fracasos, del valor $y / o$ incentivo que le conceda a sus resultados finales. Ante este panorama, los elementos intrínsecos -según Weiner (Vázquez y Manassero, 1989)consisten en las expectativas y el esfuerzo que el alumno es capaz de realizar aunado a su motivación; que a su vez está estrechamente combinada con el valor académico y la autoestima. La combinación de todos estos elementos, es decir, la expectativa, la motivación, el esfuerzo, el incentivo académico y la autoestima, incita al aprendizaje y los resultados académicos. En todo ello, el maestro es un eslabón importante de esta cadena.

Existen varios factores que contribuyen a ofrecer entornos y acciones en función de una enseñanza pasada, como la proporcionada por la educación tradicional. Gutiérrez y Prieto (1993) llegaron a la conclusión que la educación tradicional no es productiva:

Arroja apuntes mal tomados, mal digeridos, mal expresados $y$, consecuentemente, mal utilizados [...] La humanización del aprendizaje significa una manera de humanizar la vida, las relaciones sociales, las prácticas cotidianas, el trabajo profesional y la propia posición ante la realidad (p.4 y p.10).

Hoy, la persistente necesidad del cambio no apela al mejoramiento de las cosas, sino a su riqueza y a una veloz perspectiva de mirar con un pensamiento complejo y transdisciplinario el mundo que nos rodea. Desde este mismo enfoque, es necesario resolver los problemas que se nos presentan a través de la creatividad, la innovación y la injerencia en la vida práctica, donde la libertad de actuación sea su motor impulsor. No hay prácticamente otra opción, por colosal que sea, que enfrente con mayor eficacia el complejo mundo en el que habitamos. La elección de vivir 
momentos de emergencias repetidas aporta a la sanidad espiritual de nuestros contemporáneos, lo que no es más que la adaptación modernizada y ajustada al nuevo ambiente social.

En este sentido, el enfoque educativo desde el servicio, exige concebir al alumno como un ente proactivo, creativo e innovador, con alto compromiso social, apto para la resolución de problemas, crítico y con un buen desempeño en el trabajo en equipo en alianza con la sociedad. Ello posibilita desarrollar un saber y una actitud capaz de ver en una misma dirección, la vida académica, con la social y la futura vida profesional. El objetivo no es olvidar el pasado, porque este sería un error rotundo, ya que como expresa Robinson (2012) son tiempos éstos de grandes dificultades. $Y$ dado que la situación es nueva, debemos pensar de una forma nueva y actuar de una forma nueva.

En cuanto a la argumentación anunciada por Robinson (2012), la tarea inmediata es transferida a la educación, pues la estratagema de esconderse detrás de los parámetros de la educación tradicional ya no es una opción válida y mucho menos confiable. Emprender esta tarea del cambio, estimula -tanto en los profesores, como en los estudiantes- un estado de inquietud permanente. Sin embargo, la mirada cultural, creativa e innovadora y experiencial de la educación, demuestra ser menos dañina ante los desafíos actuales y prometedores del futuro. De algún modo existen estudios con experiencias prácticas y sugerencias didácticas, que apuntan de una u otra forma a mitigar el impacto en ocasiones y previsoramente devastador para las futuras generaciones, en su inserción al mundo laboral.

No continuar bajo el régimen de la educación tradicional nos obliga abandonar nuestra zona de confort. Según Robinson (2012):

El énfasis en la linealidad, la conformidad y la estandarización [...] hoy no funciona porque la vida real es orgánica, adaptable y diversa. [...] La educación no es un proceso lineal de preparación para el futuro: su cometido es cultivar las aptitudes y las sensibilidades con las que podamos vivir la mejor vida en la actualidad y crearnos para todos el mejor de los futuros (p. 29).

En la actualidad, para Casassus (2002):

La educación es percibida como una acumulación de pequeños bloques de conocimientos sancionados por una prueba y organizados en una secuencia jerárquica que va aportando y acumulando nuevas informaciones, la suma de las cuales me permitirá tener un conocimiento del todo (p.56).

No se pretende borrar los existentes campos del conocimiento, sino interrelacionarlos.

Hay que reformar el pensamiento en general y sus paradigmas si se quiere revertir el pensar educativo y sus estrategias. Hay que cambiar las estructuras existentes no sólo del pensamiento, sino en plena 
conjunción con la práctica social y sin perder el sentido cultural en que toma cuerpo y se despliega como sistema complejo (Pupo, 2014, p. 153).

Lo que se requiere, entonces, es propiciar un aprendizaje activo en los alumnos.

En fin, independientemente que la entidad educativa diseñe su propio modelo pedagógico, cada maestro deberá crear y/o adaptar sus estrategias didácticas, para que el aprendizaje sea satisfactorio, revelador y significativo para el alumno. La riqueza de un modelo estará en la versatilidad de los métodos de enseñanza utilizados, en la combinación de las técnicas y/o estrategias didácticas, que ayuden a la integración del aprendizaje. La enseñanza, vista en diferentes perspectivas y desde una visión más compleja e incluso interdisciplinaria -si así se desea- para la definición y el conocimiento de las competencias a desarrollar y/o potenciar en los alumnos. Un recurso que ha quedado definido como un escape al pasado, en el orden educativo, es la estrategia formativa del aprendizaje-servicio.

Las prácticas del aprendizaje-servicio tienen impactos educativos, y es el maestro, en su papel de facilitador y/o mediador, quién debe hacer uso de su creatividad, para crear situaciones de enseñanza que no solo posibiliten la adquisición del conocimiento, sino también la interrelación del contenido con la práctica. Ello facilita un ejercicio intelectual y de servicio provechoso para el desarrollo académico de los estudiantes y la solución de problemas para la comunidad.

Ante el desafío de un mundo globalizado y cada vez más complejo, urge que los cursos replanteen sus estrategias didácticas y así dar respuesta desde la academia a los problemas existentes en la sociedad. En este andar necesario y emergente, la habilidad del aprendizaje-servicio constituye una plataforma ideal, para gestionar el conocimiento fuera del salón de clase. También contribuye a la formación educacional y profesional por excelencia, fortificando además una cultura solidaria, responsable, de cooperación y de reciprocidad. El aprendizaje-servicio ayuda a los estudiantes a convivir con la comunidad a través del servicio, aprenden de la acción, es decir, los impulsa a correlacionar el ejercicio con los conocimientos adquiridos.

Al poner en vía práctica este tipo de aprendizaje, se evidencian algunos riesgos. Por una parte, por el rechazo y/o la incertidumbre a la que los estudiantes se enfrentan. En gran medida se debe al desconocimiento y el miedo al fracaso. Situaciones lógicas, generadas de la convivencia; la dificultad de lidiar con lo inexplorado y las problemáticas ajenas a ellos. Por otro lado, la aceptación y/o resistencia por parte de la comunidad. En fin, existen riesgos que se expresan a lo largo del trabajo, así como beneficios que se hacen palpable en su implementación.

\section{Metodología}

El objetivo del estudio está en detallar 
los contextos y estrategias que se utilizan en el curso de Sociología Urbana. Es un estudio cualitativo, con un enfoque etnográfico. Combina la observación participante y no participante, con la finalidad de analizar e interpretar cada tiempo empleado en la aplicación de la metodología del aprendizaje-servicio y en la investigación formativa. Además, se identifican discursos, tensiones y escenarios que fueron vividos desde una representación dialógica fundada desde múltiples miradas.

Para su cumplimiento, se analizan los distintos puntos de vista sobre cómo se fue construyendo el conocimiento de acuerdo a las características particulares de las dos comunidades: ambas en el estado de Nuevo León, México. Vivencia sucedida en el semestre de primavera de 2018. Para la comprensión de la calidad académica, se trabajó con tres Indicadores: conocimiento, habilidades y compromiso social.

Se intercedió en dos comunidades marginales:

- Arboleda de las mitras, en el municipio de Santa Catarina colindante con uno de los municipios más rico de América Latina. Es una comunidad organizada, cuenta con un comité vecinal con más de 16 años de trabajo. Aquí se hacen

\footnotetext{
1 Entiéndase como descriptores específicos para medir un fenómeno social, información observable y concreta que proporciona medida y datos acerca de procesos inobservables, definibles a un nivel de mayor abstracción (Forner y Latorre, 1996).
}

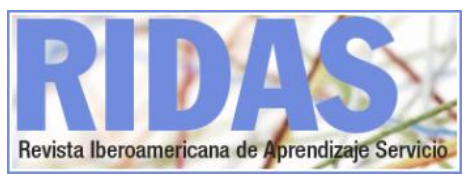

evidentes, los importantes pasos avanzados en su infraestructura, con la creación de parques, canchas, comedor, calles pavimentadas, iluminarias, etc.

\section{- Unidad Lomas Modelos}

Ampliación Norte, en el municipio de Monterrey. Es una comunidad con habitantes de procedencia indígena (Otomí) 2 . Es un territorio fragmentado, abandonado por las instancias del gobierno. Posee pocos y deteriorados espacios públicos. No están organizados, aunque si afirman su identidad como una fortaleza. Disponen del apoyo de la asociación Tirando Esquina A.C., quién ha trabajado por tres años en potenciar actividades culturales, dirigidas especialmente a niños y jóvenes.

En general, y al margen de estas problemáticas, los estudiantes se enfrentaron a problemas urbanos que fueron analizados en clases y visualizados en la comunidad. Para cubrir los espacios urbanos, se crearon dos grupos de trabajos que accionaron en sinergia con otros estudiantes universitarios.

Para evaluar la calidad de los proyectos (servicio) y los artículos científicos (aprendizaje), se analiza el protagonismo de los estudiantes, el servicio ofrecido a la comunidad y el vínculo entre el servicio y los contenidos curriculares así como los espacios de reflexión.

2 Pueblo indígena originario de México. 
Figura 1. Esquema de estudio

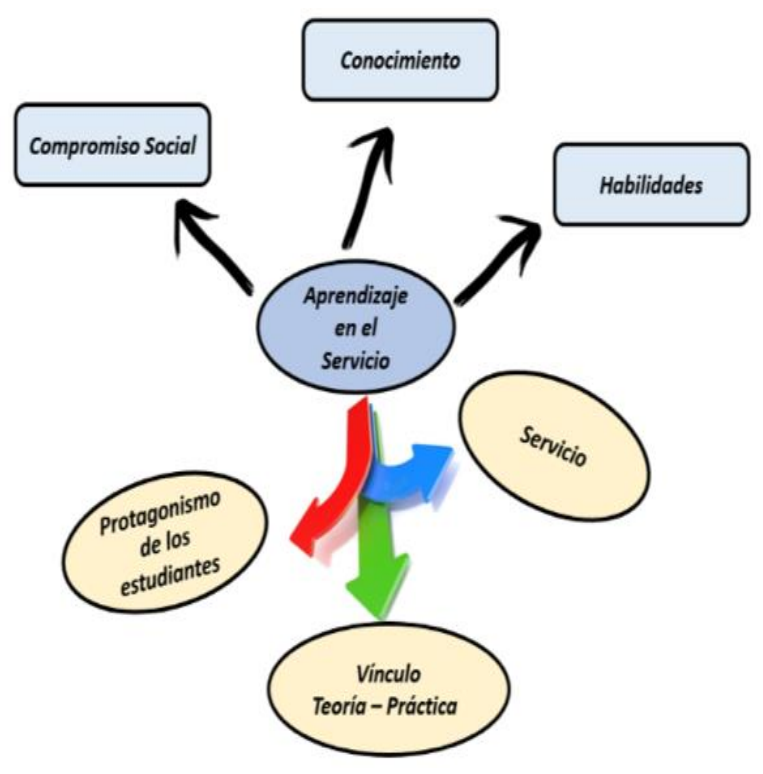

Fuente: elaboración propia

\section{Desarrollo}

El impacto del aprendizaje-servicio ha sido estudiado por diversos autores que han descrito las bondades de la metodología para el aprendizaje. Han enumerado un conjunto de atributos, que son rasgos distintivos $\mathrm{y} / \mathrm{o}$ característicos. Entre ellos citamos la compresión, la aplicación del conocimiento, el pensamiento crítico y reflexivo. Igualmente, el interés por investigar, el beneficio por producir un cambio social, el desarrollo de prácticas ciudadanas participativas, el desarrollo interpersonal, el crecimiento espiritual y la habilidad para trabajar en equipo. Investigaciones más recientes, hacen una declaración del impacto del aprendizaje-servicio, como el desarrollo de competencias, actitudes y habilidades en los estudiantes universitarios (Eyler y Giles, 1999;

Furco, 2005; Tapia, 2006).

Lejos de preparar a los estudiantes para un trabajo en particular, el aprendizajeservicio los dispone para resolver los problemas de su comunidad. Les ofrece la posibilidad de explorar las interconexiones entre la teoría del aula y la práctica, enfocada a las necesidades comunitarias (Herrero, 2002). Facilitar un enfrentamiento solidario del alumno con la realidad condiciona sus habilidades como ciudadanos responsables, comprometidos y proactivos e identifica las competencias investigativas adquiridas de la investigación formativa y el servicio.

Ante estos grandes retos urge plantearse nuevas interrogantes. Descubrir diferentes procesos y estructuras, sistematizar experiencias que ayuden a comprender el proceso de institucionalización, en el cual se encuentran sumergidas las universidades, en el sentido más abarcador y lo acontecido en un curso desde el punto de vista específico. Así mismo, con sus procesos administrativos e institucionales, que impactan de manera directa en la aplicación de la metodología del aprendizaje-servicio, para generar la toma de decisiones oportunas, con las capacidades estratégicas académicas. Los recursos humanos - maestros y alumnos- son componentes esenciales para su implementación. Al ser identificados como el mayor determinante del éxito o fracaso de su aplicación, la universidad de Monterrey ha puesto mucho énfasis en su capacitación. De igual modo, en la 
coordinación con la comunidad, la distribución de los recursos y del tiempo, como factores clave del éxito de su aplicación.

\section{Discusión y Resultados}

El análisis de este estudio se enfoca en dos momentos (ver figura 1): (I) de la implementación a la práctica; y (II) evaluación de los proyectos.

\section{De la implementación a la práctica}

Según Montero (2001):

La profesión de la enseñanza no tiene un cuerpo codificado de conocimientos y habilidades compartidos, una cultura compartida. La ausencia de este cuerpo de conocimientos compartidos -una de las marcas de las profesiones- cuestiona la pertinencia de utilizar el término profesión para la enseñanza. La consideración de la experiencia práctica como la fuente más importante de adquisición de conocimientos y habilidades situación que configura un saber vulgar técnico, o artesanal pero nunca un saber científico, base del saber profesional- ha conducido durante mucho tiempo a la irreverencia de la formación para la comunidad académica y los propios profesores (p. 87).

El conocimiento interpretado como los conceptos, teorías, hechos, modelos y procedimientos (datos interrelacionados, teoría con la práctica) tiene como objetivo estudiar el crecimiento y transformación de las ciudades. Se realiza a través del análisis de las principales teorías que explican el fenómeno, la observación de la realidad actual del proceso de urbanización y el estudio de algunas de las consecuencias de estos procesos.

Para su cumplimiento, se implementaron diversas estrategias didácticas donde se incluye el ensayo y artículos científicos. Igualmente la elaboración de mapas y redes conceptuales y el taller reflexivo con expertos en el tema comunitario. Además del uso del aprendizaje por proyecto, medio para plasmar los avances del servicio y el contenido. El panel es usado como recurso de comprobación del aprendizaje, a través de tarjetas de conocimiento. De gran utilidad resultaron los estudios de casos, las entrevistas/encuestas y grupo de enfoque para la realización del diagnóstico. Se incorporaron actividades extras que exigían profundizar en cada uno de los contenidos. Estás consistían en lecturas necesarias para comprender los temas y las respuestas a interrogantes, en cuyos argumentos estuvieran las vivencias en la comunidad. Todo ello, creó un vínculo directo entre la teoría y la práctica.

Se estudió la bibliografía para pensar y examinar la comunidad, desde el punto de vista sociológico. Ello facilitó la introducción del sustento teórico del proyecto de servicio.

\section{Incidentes críticos}

- En relación con el conocimiento, a los estudiantes les era muy difícil poder mezclar la teoría con 
la práctica y peor aún, fusionar aquellos conceptos que ya habían recibido en cursos anteriores, denotándose una marcada fragmentación del conocimiento.

- Estimular que los alumnos estudien, conceptúen, diseñen, interactúen, gestionen y ejecuten, equivalía a una bomba de tiempo, porque los sacaba de su rutina académica, de su zona de confort.

- Era evidente la falta de la práctica de lectura, en sí, no todos los estudiantes están preparados para enfrentar el conocimiento por sí mismos, es decir, ser responsables de su autoaprendizaje. Precisan de un maestro, no como un mediador y/o facilitador como lo sugiere el aprendizaje activo, sino como una fuente de enciclopedia viva en el salón de clases. En este sentido, hubo un reclamo de los métodos tradicionales de estudio porque estos les trasferían confianza y seguridad.

- Por otro lado, no haber trabajado con la metodología de proyecto, se convirtió en un déficit muy importante, porque aunque en el curso los estudiantes tenían claro que hacer en cada momento, era visto como un trabajo más, que nada tenía que ver con el contenido.

Todos estos elementos, de desconocimiento, de indecisión e incluso de miedo se convirtieron en factores de riesgo, creando cierta incertidumbre en los estudiantes y en el propio maestro.

La evaluación sumativa e informal, las reflexiones que se hacían del servicio en la comunidad y en el salón de clases, así como la retroalimentación de cada uno de los trabajos, ayudó de alguna forma a comprobar los avances y detectar aquellas áreas de oportunidad con las cuales se necesitaba trabajar concienzudamente. Para esto, se emplearon técnicas como la revisión de documentos, la observación, la entrevista, la revisión del portafolio de campo y la presentación de avances investigativos.

Las habilidades, entendidas como la capacidad y aptitud que se adquiere a vincularse con la práctica, destrezas que se fueron potenciando en la travesía del curso. El definir las competencias a adquirir $\mathrm{y} / \mathrm{o}$ fortalecer es una necesidad significativa, los estudiantes deben saber que se espera de ellos y cuáles serían las vías para lograrlo. Se potenciaron:

- Habilidades comunicativas: para el trabajo en comunidad se precisa tener la capacidad para observar, escuchar, vislumbrar, comprender e interrelacionar las ideas y plasmar de una manera sencilla las propuestas en el proyecto. Por lo que es sumamente importante saber comunicarse, tanto por vía oral como escrita. En este sentido, el portafolio de campo, las entrevistas, el grupo focal, la presentación de las acciones del proyecto, sus avances y resultados a la comunidad se 
convirtieron en una herramienta primordial.

- Flexibilidad/adaptabilidad: estas destrezas son imprescindibles para el trabajo, donde el alumno debe aprender a trabajar en equipo y adaptarse a las disímiles situaciones que se pueda presentar, los tiempos de la comunidad y de la academia son muy diferentes.

- Investigar y analizar: la carrera de Sociología requiere que sus alumnos desarrollen estas competencias, que se forme como investigador social cuyo propósito es estudiar a la sociedad, mediante esta práctica se hacen competente para su futura vida profesional.

- Trabajo en equipo: esta es una habilidad que los estudiantes despliegan con mayor facilidad ya que es una de las estrategias didácticas mayor empleada, con la salvedad que no siempre se logra obtener un trabajo colaborativo de alto desempeño.

- Relaciones interpersonales/ actitud positiva: el servir a otros requiere de mucha dedicación, el ser una persona trabajadora, responsable y confiable ante los ojos del comunitario, del equipo de trabajo y colaboradores; ser entusiastas y con una actitud positiva, donde se emplee lo negativo, es decir los malos desenlaces no para criticar sino para aprender del error y buscar nuevas vías de solución.
- Deseo de aprender: aunque esta habilidad debe ser una prioridad, por la responsabilidad que tienen el alumno de aprender, es una preferencia que coexista una necesidad de conocer cosas nuevas, a la cual tendrán que inmiscuirse quiera o no quiera en el momento de tener que resolver ciertas situaciones problemas, por ende se precisa ampliar los conocimientos incluso saltando las barreras formativas que el propio curso presente.

- Creatividad: el tener que imaginar, intuir, innovar y diseñar nuevas acciones en dependencia de los resultados obtenidos del diagnóstico, contribuyo a incentivar de alguna manera esta competencia para la solución de problemas, para el acercamiento con la comunidad, para la gestión de los tiempos, la organización del trabajo en equipo. Asimismo la entrega, presentación final del proyecto de servicio y el artículo científico.

\section{Incidentes críticos}

- A pesar de estar motivados por la necesidad de involucrarse con una experiencia nueva, se creó cierto rechazo, tradúzcase en trabajo fuera de la universidad, en horarios extras. El horario y los tiempos disponibles de la comunidad, impiden que las visitas de los estudiantes al campo, no siempre coincidan. La información tiende a tergiversarse o trasmitirse de manera limitada, 
independientemente que el empleo del portafolio ayudaba a concretar y sistematizar las experiencias.

- No tenían la capacidad de la observación, no eran capaces de relacionar las ideas -lo visualizado por ellos y por la propia comunidad-. En ocasiones se señalaba a los miembros de la comunidad lo que ellos debían inferir por sí mismos. En sus inicios no registraban lo observado, escuchado y el accionar de los vecinos, dejando todo a la espontaneidad de sus memorias.

- En la aplicación del aprendizajeservicio se requiere un tiempo extra para culminar con eficacia el trabajo y en ocasiones los alumnos observan esta extensión en el tiempo como una mala planificación del trabajo, por un lado, o como esfuerzo adicional, por otro. El tiempo es un detonador, es una preocupación tanto para el alumno como para el maestro.

- La flexibilidad mental del alumno, es también un punto neurálgico en este proceso de enseñanzaaprendizaje, visto como la capacidad que tienen para enfrentar un nuevo desafío intelectual, debemos de partir del hecho de que los estudiantes rompen con esquemas educativos, a los que por años han venido estrechamente ligados. Son entonces, las desconfianzas e indecisiones, debilidades que de una forma influyen en los resultados académicos y de servicio, independientemente de su grado de motivación.

- Al inicio del curso hicieron mucha resistencia a involucrase en el proceso de investigación, porque lo desconocían o apenas estaban aprendiéndolos. Los alumnos no están preparados para asumir el error, experimentar e indagar en un entorno real, el dejarlos de alguna manera solos en relación con la toma de decisiones, sobre qué hacer y cómo hacerlo es un gran reto.

- El trabajo en equipo a veces se torna deficiente, porque no se toman decisiones colaborativas. Precisa ocuparse en fortalecer las funciones de liderazgo y la toma de decisiones. Algunas veces las decisiones erradas y/o limitadas, entorpecen la labor. Éste es un elemento que debe quedar bien organizado desde el inicio del curso, previniendo cómo concebirse, cómo evaluarse y definiendo que se espera de él.

- Necesitan ser optimistas y poseer una alta capacidad para resolver los problemas, reconocer sus consecuencias y actuar con responsabilidad ante ellas. Sin embargo, no siempre confían en sí mismos, divagan acerca de si lo que hacen está bien o puede ser lo más adecuado para otros.

- A su vez no están preparados para actuar de manera 
interdisciplinaria. Ésta forma de trabajar los asusta, porque de una u otra forma se suma a la indecisión del trabajo en la comunidad. Eso, por un lado y por otro, la desconfianza en torno a la información derivada de sus propios resultados investigativos. Ésta indagación, debe ser proporcionada a los alumnos de otros cursos, para el sustento de su proyecto de servicio. El temor a equivocarse se hace evidente.

El Compromiso social, entendido como una competencia enfocada en la identificación de una situación problema $y$ al mejoramiento y/o apoyo a los asuntos sensibles a la comunidad. Independientemente de que están compulsados a servir al otro, esta exigencia propia del aprendizajeservicio, mezcla de una manera integral el principio de voluntariedad y el interés por ayudar a personas en situaciones vulnerables. El compromiso, es ante todo una actitud que se forma y contribuye a reforzar el trabajo en equipo. La sensibilidad ante los problemas y/o necesidades del entorno y a su mejoramiento. La empatía, la responsabilidad y una actitud humilde, abierta, generan un estado de satisfacción personal.

\section{Incidentes críticos}

- Independientemente de los beneficios tanto para la comunidad, como para el alumno, ofrece trabajar con personas en estado de vulnerabilidad, se transfiere el temor al fracaso. El actuar a destiempo e inadecuadamente, los inmoviliza. Esta situación genera una co-dependencia, en tanto su compromiso y acciones, en alguna medida dependen de la responsabilidad del "otro" (comunidad, consejos de vecinos, asociaciones, etc.).

\section{Evaluación de los proyectos.}

En este apartado, se examinan las etapas del proyecto -inicio, planificación, ejecución, seguimiento y cierre-. Incluye la investigación formativa como componente vital para el desarrollo de competencias, lo cual tiene como referente el protagonismo de los estudiantes y el servicio ofrecido a la comunidad. Del mismo modo, se valora el vínculo entre el servicio y los contenidos curriculares, así como los espacios de reflexión (ver figura 1).

Gaitán y Jaramillo (2003) explican que suele identificarse a la docencia -en su sentido más tradicional- con un proceso de transmisión de información. Ello hace recaer toda la responsabilidad del proceso, en el docente y en su saber. Éste planteamiento relega el papel del estudiante, a ser un receptor pasivo de la información transmitida. Con el fin de modificar esta tendencia, es preciso comprender la pertinencia de los contenidos y su vínculo con la experiencia práctica. Así como el papel del docente en la búsqueda de la mejor vía, para adaptar la enseñanza a las urgencias actuales.

El curso de Sociología Urbana fue diseñado para estar en el cuadrante $\mathrm{IV}_{3}$

3 Plataforma computacional donde se registra el 
del aprendizaje-servicio por lo que la planificación de las actividades, tanto de aprendizaje como de servicio, brinda al estudiante una alta calidad en las acciones, un mayor significado en lo aprendido y por ende un diseño y ejecución de proyecto con un alto impacto para la comunidad.

El vínculo teoría-práctica involucra esencialmente a tres actores: el alumno, el docente y la propia comunidad.

El docente, como mediador del proceso de EA, de alguna manera exige a que se renuncie paulatinamente al ser el centro y controlador de toda la información, a tener un amplio conocimiento de los temas ya que estos no se quedaran en el mero papel sino que se implementará en función del beneficios a otros; y en una unión perfecta al conocimiento debe de estar la actitud y la destrezas para enfrentar las dificultades que puedan aparecer en su aplicación. Un elemento esencial y primordial es la motivación que debe tener el maestro; un docente motivado, flexible y consciente de los beneficios de la metodología del aprendizajeservicio logra que los estudiantes posean un acompañamiento eficaz y un aprendizaje significativo. El maestro en todo momento debe ser receptivo a las impaciencias, opiniones y gestiones propuestas por los estudiantes y la propia comunidad.

El alumno de acuerdo al modelo pedagógico de la universidad y las exigencias de la propia metodología del

curso con módulos de contenidos y herramientas de comunicación flexibles y sencillas de emplear. aprendizaje-servicio es el máximo responsable de su aprendizaje, quien tiene el compromiso de identificar una problemática social, y buscar una solución a través de la aplicación de un proyecto de servicio, incorporando los conocimientos adquiridos en el curso a una realidad vulnerable específica, logrando asumir un mayor compromiso ciudadano y cívico asociado a un desarrollo personal y social con un alto nivel protagónico capaz de liderar proceso de participación y comunicación en la comunidad.

En cambio la comunidad se convierte en un área de aprendizaje por un lado, no como un simple laboratorio, sino como el espacio de interacción de enseñanzas en dónde los alumnos aprenden y la propia comunidad también, en esa rica y en ocasión delicada conexión existe un denominador común y son los objetivos de aprendizaje.

Procedimiento de las etapas desde la experiencia del curso.

\section{Inicio:}

Esta fase es decisiva en el ciclo de vida del proyecto, donde se involucra la motivación por parte del docente a los alumnos, en caso del curso se empleó el uso del video que evidenciaba resultados del trabajo en comunidad con entrevistas a vecinos y alumnos con experiencias en el trabajo, se invitó a vecinos y asociaciones vinculados con la comunidad, identificados como líderes, para que ilustraran sus fortalezas y debilidades como comunidad y sus acciones a corto, mediano y largo plazo. En la plataforma 
Blackboard se almacena información que explícita de manera didáctica la metodología, y se estimuló a los estudiantes a trabajar de manera interdisciplinaria con la invitación a colaborar con los estudiantes del curso Soluciones Interdisciplinaria de Diseño, con la participación de la maestra en el curso.

Existieron diversas vías que motivaron el trabajo en la comunidad. Se generaron más y eficientes encuentros, que contribuyeron a una mejor coordinación. Un mayor conocimiento de la realidad y a una revelación de las problemáticas y/o necesidades, favorecieron desde el inicio del curso, el reconocimiento de las opciones en las que se podría trabajar desde los objetivos de aprendizaje. Se delimitaron a su vez, el ámbito de acción y los equipos de trabajo.

No obstante, los estudiantes mostraron preocupación porque las visitas de la comunidad al salón de clases lo consideraron -en un inicio- como una pérdida del tiempo. Objetaron que les restaba espacio al contenido, sin interiorizar que éste método de enseñanza-aprendizaje les exigía un compromiso mayor y responsabilidad hacia su autoaprendizaje.

\section{Diagnóstico:}

\section{Los encuentros descriptos}

anteriormente, se convirtieron en alternativas de ayuda, para identificar y comprender el impacto de los problemas en la comunidad. Luego de definir las prioridades a estudiar, se fue a la comunidad a observar la situación problema. Para explicar objetivamente lo que sucede en la práctica, es importante reconocer que se parte de percepciones subjetivas, aún cuando éstas puedan mal interpretar la realidad. En este sentido, cobra especial valor la observación no participante para validar el problema e identificar el alcance de los objetivos del proyecto de servicio con los de aprendizaje.

Lo anterior sólo puede lograrse con el diseño de instrumentos de recogidas de información. En ambas comunidades, se emplearon además de la observación, reseñas geo-histórica de la comunidad, historias de vidas, narraciones y relatos. De igual modo, las entrevistas en profundidad con líderes y comunitarios. Se utilizaron encuesta y enfoques grupales para descubrir las causas que favorecían la problemática a analizar. Los resultados de éstos permitieron profundizar en el conocimiento del problema a enfrentar y generaron la información disponible para el diseño del proyecto, así como para su puesta en práctica.

Para evaluar la realidad, se contó además con el apoyo del diagnóstico participativo y/o comunitario, que ayudó a comprender detalladamente la situación, logrando identificar los problemas y establecer las prioridades de servicio.

Amparados en un enfoque mixto en ambas comunidades -a través de la comparación de las técnicas aplicadasse produjo una reflexión epistemológica. Ello permitió un acercamiento a la realidad, desde diferentes perspectivas, descubriendo las inquietudes, causas y consecuencias de un mismo fenómeno. Estos análisis 
derivaron en el diagnóstico de los proyectos de servicio y en la producción de artículos científicos.

El que los alumnos tuvieran que incursionar -por primera vez- en un proceso de investigación, para luego diseñar un proyecto y minimizar una problemática, les provocó una actitud catastrofista, es decir, esta dosis de desconfianza fue un impedimento que debió ser tratado con la intensificación de la motivación, como único camino posible. Ello sólo podía ser viable con el cotejo del contenido, el servicio y con la retroalimentación del proceso. Tal razonamiento condiciona la necesidad de realizar de manera continua y sistemática, la reflexión de cada momento y la comprobación del entendimiento del contenido.

Al curso fueron invitados especialistas sobre el tema de proyectos sociocomunitarios, con la finalidad de compartir sus experiencias y dar retroalimentación a los diagnósticos realizados, con la intención de trasmitir confianza y seguridad a los estudiantes. El analizar -de manera simultánea- Ios hallazgos de ambas comunidades, en complicidad directa con los temas del curso, fue revelador. Además de descubrir las similitudes, a pesar de existir en espacios morfológicamente diferentes y con situaciones muy diversas, los estudiantes fueron capaces de manifestar el hallazgo de teorías, conceptos y problemáticas urbanas análogas.

El diagnostico les ayudó a cambiar su percepción sobre la población que vive en comunidades vulnerables y marginadas. Pudieron reconocer las tendencias y los sesgos en la investigación. Ejercieron un pensamiento abstracto y a la vez flexible. Una reflexión abierta e interdisciplinaria, para sistematizar las experiencias de la comunidad e interpretar las teorías adecuadas a la realidad, diseñar, aplicar, interpretar y tabular la información recabada.

En relación con el diagnóstico, corresponde satisfacer dos puntos importantes. El que se relaciona con la valoración de la realidad, o sea, identificar y describir en detalle la situación problema y el que se vincula con el contenido, es decir, lo que se ha develado en los alumnos a través del contenido de estudio. Se trata de dos asuntos distintos, que trasfieren un mismo resultado: el aprendizaje.

\section{Diseño y planificación:}

Es esencial para el proyecto delimitar alcance, población beneficiada, localización, temporalización, objetivo general y especifico. Definir la meta, la descripción de los recursos y la forma de solucionarlo, evita los obstáculos. Toda labor social necesita ser planificada y esta proyección deberá ser flexible, descentralizada, interdisciplinaria, autogestionada y sobre todo participativa. En el proceso, los estudiantes fortalecen ciertas competencias como diseñar, planificar la propuesta de su proyecto de servicio, redactar e interpretar textos y datos.

Al trabajar con la comunidad se necesita paciencia, tolerancia y respeto del tiempo de los comunitarios. Y en este sentido, se privilegia lo académico por encima del servicio. El alumno 
valora como más importante su intuición que el servicio, por lo tanto, privilegiar la validez de ambas, en este caso, puede conllevar a no satisfacer las necesidades del comunitario, ni del alumno, cuando no se está capacitado y no existe una adecuada planificación del servicio. Entonces, hay un fin último, que es diseñar proyectos que estén acorde a los tiempos, disponibilidad y recursos. En esta fase se deben agenciar por igual: el tiempo, el riesgo al cambio, los reajustes y las trasformaciones que pueden ocurrir al proyecto.

\section{Ejecución:}

Esta etapa es decisiva puesto que obliga poner en práctica todo lo estudiado y planificado. La implementación de las acciones, se hicieron con la anuencia de los comunitarios, en especial con sus líderes. También con el apoyo de otros alumnos y asociaciones buscando especialmente que lo investigado $y$ diseñado, tenga continuidad en el tiempo, revele una realidad diferente y un compromiso ciudadano.

Desarrollaron experiencias dialógicas y de intervención con otros estudiantes y la propia comunidad, denotándo un sentido de pertenencia académica y comunitaria, no obstante aún persistía cierto temor a incursionar y aplicar las acciones.

Consecuentemente en las comunidades se generaron espacios de diálogo para la comprensión de la situaciónproblema, se propuso un conjunto de actividades orientadas a cubrir un lugar más de cultura e instrucción para la resolución del problema y un aprovechamiento óptimo de los recursos existentes. Hubo una retroalimentación de los elementos culturales, sociales y académicos que aproximó a los alumnos a un proceso de autoaprendizaje continuo.

5. Seguimiento y cierre: Investigación formativa como componente vital para el desarrollo de competencias.

Se culminó con la entrega y presentación de dos proyectos a las comunidades.

- Realidad Teórica: Visión teóricapráctica respecto a la cotidianidad y retos comunitarios en la urbe regiomontana. Se contribuyó con un sustento teórico y científico, que define la necesidad de la comunidad Unidad Lomas Modelo en cuanto al uso de los espacios públicos y el derecho de la infancia. Como aporte, se considera la sinergia entre la escuela primaria y el proyecto Tirando Esquina A.C., quienes realizan una labor comunitaria en el área.

- Contrastes urbanos: Una mirada desde el punto de vista teóricopráctico en la sinergia sobre la cuestión infraestructural y superestructural de la dualización y segregación urbana en la ciudad de Monterrey. Examina dos fenómenos presentes en la colonia Arboledas de las Mitras. Los resultados obtenidos permitieron una propuesta de solución, para el cambio de un muro perimetral en Arboleda, se lograron ofertas de cursos, tanto 
para la casa de la cultura "La Cima" y el CESADE (Centro de Salud y Desarrollo), con el fin de trabajar en el reciclaje y crear conciencia sobre el cuidado y conservación del medio ambiente.

La metodología del aprendizajeservicio, según los propios alumnos, les ayudó a tener una visión contextualizada y más amplia de la situación que acontece en la ciudad, sobre todos en comunidades marginadas, segregadas y de un alto nivel de desigualdad económica. En el cierre, los alumnos se sentían con una mayor seguridad, desarrollaron estrategias comunicacionales comunitarias, se adaptaron a los medios de presentación que la comunidad le ofrecía ayudándolos analizar vías alternativas y la utilización adecuada de técnicas de información y comunicación. Con esta modalidad de estudio se adquirieron competencias y habilidades necesarias para nuestra futura vida profesional.

Además el trabajar con la comunidad, espacio urbano rico en interacciones sociales, modo de producción de ideologías y comportamientos, ofrece un panorama diferente a lo que en teoría se puede conocer, ayuda a ver lo estudiando de una manera compleja e interactiva. Acercarnos de manera directa con las personas que se estudia ayuda a eliminar miedos y prejuicios y adquirir mucho más experiencias. El hecho de unir la práctica con la teoría fue uno de los aprendizajes más significativos, no obstante, existe ciertas limitantes en el aprendizaje en el servicio como el poco tiempo que ofrece la academia (4 meses), el definir líderes en la comunidad que fueran enlaces efectivos para el buen desempeño de las acciones a realizar, entre otras. Sin embargo, un aprendizaje en el servicio planificado de una manera eficiente es lo más pertinente en el contacto con una comunidad y para el aprendizaje y autoaprendizaje de los estudiantes.

En el cierre los alumnos se sentían con una mayor seguridad, desarrollaron estrategias comunicacionales comunitarias, se adaptaron a los medios de presentación que la comunidad le ofrecía ayudándolos analizar vías alternativas y la utilización adecuada de técnicas de información y comunicación. El que la comunidad acogiera su proyecto, aprobara y congratulará su aporte fue muy significativo para su aprendizaje y autoestima coadyuvando a elevar su confianza en cuanto a sus conocimientos y forma de actuación ofreciéndoles el desarrollo de respuestas comunicacionales y de servicios efectivas.

Aldana y Joya (2011) mencionan que el desarrollo de las competencias investigativas resulta de gran importancia en la formación de los futuros profesionales, pues, aunque es bien entendido que en este nivel de formación el objetivo no es formar investigadores, si es prioritario formar profesionales con actitudes positivas hacia la investigación, de forma que se conviertan en sus usuarios y la adopten como una manera de enfrentar los problemas cotidianos y de la ciencia.

Al finalizar el curso, los estudiantes 
entregaron un artículo científico contentivo de los resultados investigativos. Se les dio la libertad de escoger el tema, de cuya labor, resultaron tres trabajos.

La investigación formativa en sentido general contribuyó a la adquisición de nuevos conocimientos $\mathrm{y} / \mathrm{o}$

fortalecimiento de otros anteriormente asimilados. Valoramos como un logro la interrelación indisoluble entre la teoría y la praxis, ofreciéndoles a los estudiantes una actitud autónoma, crítica y reflexiva. Al respecto, según Lara (2006):

\section{La Investigación Formativa es entendida como el proceso mediante el cual se busca la generación de una cultura que promueva el desarrollo autónomo del pensamiento, el debate, la crítica argumentada, el trabajo colaborativo e interdisciplinario, la circulación y la exposición de ideas (p.162).}

Los alumnos adquirieron las competencias destacadas por Ollarves y Salguero (2009). Destacamos la observación, la interpretación y el análisis crítico mediante el desarrollo de destrezas al preguntar, registrar y describir los contextos. Escribir los textos acerca de situaciones problemáticas propias de los ambientes de aprendizajes, proponer soluciones a los problemas detectados, y la utilización adecuada de los conceptos y métodos de investigación. Resolver y argumentar razones sobre las relaciones que se establecen dentro de la cultura académica y las alternativas dadas a los problemas investigados, sistematizar los datos y la información para presentarlos a través de los informes de investigación.

La investigación en todo momento fue un proceso premeditado que buscaba desarrollar en los estudiantes las competencias previstas.

\section{Conclusiones}

El mundo de hoy requiere de respuestas emergentes a los problemas actuales y en este accionar la educación suele estar evocando en un camino lento y pedregoso. Con el fin de modificar esta tendencia es preciso comprender la pertinencia de los contenidos y su vínculo con la experiencia práctica, así como el papel del docente en la búsqueda de la mejor vía para adaptar la enseñanza a las urgencias actuales, además de visualizar al alumno como el intermediario directo de este vínculo didáctico: academia-comunidad.

El aprendizaje-servicio busca de manera directa influir en los desencadenados problemas que se viven hoy e invita al alumno a investigar, reflexionar y ejecutar gestiones y trabajos acordes al contenido de la instrucción, en función de producir un impacto en las comunidades vulnerables, dotándolas de nuevos conocimientos y saberes para la resolución de sus problemas, y apoyándolas para convertirla en un escenario mutuo de aprendizaje, donde la comunidad aprende y el alumno también.

Luego de analizar en detalle el proceso en el cual se desarrolló el diseño, la 
aplicación y la ejecución del proyecto de servicio, así como la investigación formativa -necesaria e imprescindible para la mejor y más eficaz implementación del servicio a ofrecer-, podemos concluir que la metodología del aprendizaje-servicio ayuda a formar a estudiantes comprometidos con su entorno con una mayor visión de análisis y critica de los problemas que lo rodean. Contribuye a vincular la teoría con la práctica y éste acercamiento fomenta en los estudiantes, la pasión por lo que estudian.

La academia debe buscar estrategias para que, de manera inter $y$ trasdiscipinaria, los estudiantes encuentren espacios propicios de reflexión, de investigación e intervención conjunta en la comunidad, convocando a la creación de espacios que no afecten sus restantes actividades académicas sino que la enriquezca. Es un reto que los estudiantes cambien sus hábitos y maneras de estudiar; es una necesidad que el estudiante se haga responsable de su autoaprendizaje con la capacidad de aplicar en la práctica, lo aprendido en clase. El maestro debe aprender a salir de su zona de confort y también enfrentarse en conjunto con sus alumnos, a la resolución de las problemáticas existentes en la vida real e incentivarlos a investigar y a cuestionar con fundamento, todo lo que lo rodea, a ser críticos y autocríticos.

No cabe duda que hubo un cambio en los estudiantes. En sus inicios fue incertidumbre, miedo al cambio, al fracaso y al error. Al final, el desenlace fue pertinente, logrando elevar su autoestima, el desarrollo del pensamiento creativo, la identificación de problemas y/o necesidades. Igualmente se consiguió el análisis de paradigmas de investigación y técnicas de recogidas de información, para descubrir las raíces del problema estudiado. La búsqueda de información, el procesamiento y la triangulación de la misma. La síntesis de la pesquisa y la lectura de los contenidos a través de las fuentes bibliográficas sugeridas. La invitación a expertos en los temas del curso y a líderes comunitarios, aportó una mayor riqueza en la compresión de los contenidos y un mejor vínculo entre la teoría y la praxis.

El aprendizaje-servicio, en conjunto con las estrategias para la investigación formativa, el contexto, la motivación, la relación entre los actores involucrados en el servicio, favorece el fortalecimiento de ciertas competencias y habilidades válidas para el aprendizaje y la vida profesional del estudiante.

Debemos tener presente, como explican Gutiérrez y Prieto (1993), que:

La primera función de una universidad es la de promover el aprendizaje, no la docencia, no la investigación, no la extensión. En cada una de ellas lo primordial es abrir caminos al aprendizaje, es ofrecer medios para desarrollarse como ser humanos (p.9).

Y en este andar la mezcla atinada y concientizada de la curiosidad, la estimulación, el atrevimiento y el estímulo académico aunado a la autoestima incita el conocimiento y los 
resultados académicos, como bien señala Weiner (Vázquez y Manassero, 1989).

Los alumnos a través del aprendizajeservicio aprenden de una manera experiencial, a su vez, desaprenden con la salida de su zona de comodidad académica y reaprenden con la familiaridad con nuevos paradigmas de investigación, gestión, colaboración e innovación. En fin, se precisa desde la universidad, desde el salón de clases y la propia comunidad crear entornos favorables al alumno, ambientes que incentiven el aprendizaje, contribuya a que amen lo que estudian y lo prepare para su vida profesional.

\section{Referencias bibliográficas}

Aldana, G. y Joya, N. (2011). Actitudes hacia la investigación científica en docentes de metodología de la investigación. Tabula Rasa, 14, 295309. Recuperado de http://www.scielo.org.co/pdf/tara/n14/ n14a12.pdf

Casassus, J. (2002). Cambios paradigmáticos en Educación. Revista Brasileira de Educação, 20, 48-153. Recuperado de http://www.scielo.br/pdf/rbedu/n20/n2 $0 \mathrm{a} 04$

Eyler, J. y Giles, D. (1999). Where's the learning in service-learning?. San Francisco, Estados Unidos: Jossey-Bass Publishers.

Forner, A. y Latorre, A. (1996). Diccionario terminológico de investigación psicopedagógica. Barcelona, España: EUB
Furco, A. (2005). Impacto de los proyectos de aprendizaje servicio. Aprendizaje y servicio solidario en la Educación Superior y en los sistemes educativos latinoamericanos. Actas del 70 Seminario Internacional Aprendizaje y Servicio Solidario, Buenos Aires (Argentina), 19-26. Recuperado de http://www.clayss.org.ar/seminario/ant eriores/actas/2005_Actas7.pdf

Gaitán, C. y Jaramillo, J. (2003). Formación Docente en la Educación Superior. Modelo educativo para la formación pedagógico-didáctica. Bogotá, Colombia: CEJA.

Gutiérrez, P. y Prieto, C. (1993). ¿Qué significa aprender? Revista Chasqui, 47, 4-10. Recuperado de https://issuu.com/chasqui/docs/quesignifica-aprender

Herrero, M. (2002). El problema del agua. Un desafío para incorporar nuevas herramientas pedagógicas al aula Universitaria (tesis doctoral). Universidad de Buenos Aires, Buenos Aires, Argentina.

Lara, G. (2006). Investigación formativa. Una visión integral para profesiones de la salud. Revista Ciencias de la Salud, 4(especial), 161176. Recuperado de https://revistas.urosario.edu.co/index.p $\mathrm{hp} / \mathrm{revsalud/article/view/549}$

Ollarves, Y. y Salguero, L. (2009). Una propuesta de competencias investigativas para los docentes universitarios. Laurus: revista de Educación, 15(30), 118-137.

Recuperado de http://www.redalyc.org/articulo.oa?id= 


\section{6}

Montero, L. (2001). La construcción del conocimiento profesional docente.

Rosario, Argentina: Homo Sapiens Ediciones.

Pupo, R. (2014). Filosofía, educación, cultura y pluralidad discursiva ensayística. (Hacia una visión cultural y compleja del saber humano). Tepic, México: Centro Universitario ISIC, A.C.

Robinson, K. (2012). El elemento.

Ciudad de México, México: Urano.

Tapia, M. N. (2006). Aprendizaje y servicio solidario en las instituciones educativas y las organizaciones juveniles. Buenos Aires, Argentina: Ciudad Nueva.

Vázquez, A. y Manassero, M. A. (1989). La teoría de la atribución y el rendimiento escolar. Educació i cultura: revista mallorquina de pedagogía, 7 , 225-241. Recuperado de http://redined.mecd.gob.es/xmlui/bitstr eam/handle/11162/6586/01220023016 9.pdf? sequence $=1$ \&isAllowed $=y$ 


\title{
El aprendizaje-servicio: una forma para impulsar la participación en los jóvenes
}

\author{
Alejandra Martínez. \\ Universidad Autónoma de Querétaro, México
}

\section{Resumen}

Este escrito da cuenta de un proyecto de intervención realizado con hombres y mujeres jóvenes de nivel secundario con los que se trabajó impulsando procesos participativos, a fin de darles voz y posibilitar la construcción colectiva del conocimiento de su realidad, involucrándolos para que identificaran, ordenaran, jerarquizaran y priorizaran los problemas y obstáculos que les aquejan e impiden su desarrollo, para que posteriormente propusieran e implementaran alternativas de solución dirigidas a su comunidad, detonando así ciudadanías juveniles que redunden en procesos democráticos, autónomos y solidarios. El proyecto utilizó la metodología del aprendizaje-servicio, con la cual se brindaron herramientas que les permitiera repensarse como sujetos de derechos, cuyos resultados muestran la importancia que tiene la participación para la construcción de ciudadanías juveniles.

\section{Palabras clave}

Aprendizaje-servicio, jóvenes, participación. 


\title{
Service-learning: a way to encourage young people's participation
}

\begin{abstract}
This article reports on an intervention project carried out with secondary school students with whom we worked to promote participatory processes. The project sought to give these students a voice and facilitate the collective construction of knowledge of their reality, involving them in identifying, ordering and prioritizing the problems and obstacles that affect them and prevent their development, so that they can later propose and implement alternative solutions in their community, thus promoting citizenship and resulting in democratic, autonomous and solidary processes. The project used the service-learning methodology, which provided the young people with tools that allowed them to rethink themselves as legal subjects. The project results show the importance of participation in the construction of youth citizenship.
\end{abstract}

\section{Keywords}

Service-learning, youth, participation. 


\section{Introducción}

Sensibles ante las problemáticas que vive y padece la población juvenil, se realizó un proyecto fundamentado en la metodología del aprendizaje-servicio, al cual se le apostó por ser una herramienta que puede detonar en los jóvenes acciones más allá de lo personal, para llevarlo al ámbito público, condición necesaria para la construcción de ciudadanía.

La metodología del aprendizajeservicio, al ser parte de los nuevos discursos educativos en materia de ciudadanía activa, trabaja en la construcción de ciudadanos comprometidos con la sociedad, y corresponsables en la transformación social, adquiriendo aprendizajes que les sean significativos al llevarlos a la práctica.

El proyecto surge ante la necesidad de cuestionar y repensar las estrategias metodológicas y los modelos educativos pasivos que invisibilizan a los jóvenes, que no les permiten expresar sus ideas, sino solo responder a órdenes. Por lo que se hace necesario crear espacios y mecanismos reales para la participación juvenil, que incidan en la construcción de ciudadanos comprometidos con sus decisiones, e involucrados con su país y su comunidad.

Frente a un país convulsionado, en el que se está cuestionando la efectividad real de la participación, es importantísimo estudiar lo que sucede en la población juvenil al promoverles sentimientos de pertenencia a una colectividad, de empatía por sus semejantes, cuando se trabaja en la construcción de su autonomía, libertad, y trabajo comunitario, para observar si es posible crear otro tipo de ciudadanía en el que se concreten transformaciones que mejoren las relaciones individuales y comunitarias a largo plazo.

\section{Marco teórico}

\subsection{El aprendizaje-servicio}

En los últimos años se han plasmado una diversidad de discursos respecto a la ciudadanía, los cuales proponen nuevas formas de articularse ante los desafíos de las democracias actuales. De estos discursos surge el de la ciudadanía activa, el cual ha sido considerado como una medida utilizada entre las nuevas generaciones para superar los problemas de las sociedades democráticas. Este discurso se basa en dos premisas. La primera afirma que "la ciudadanía tiene la obligación cívica de implicarse y participar en la marcha de los asuntos de la comunidad de pertenencia adquiera nueva importancia" (Benedicto y Morán, 2002, p.7), y la segunda en la que los ciudadanos quieren, de acuerdo con Inglehart (Benedicto y Morán, 2002) hacer oír su voz sobre todo aquello que les afecta directamente.

Si bien estos posicionamientos demandan mayor protagonismo y presencia de la ciudadanía en el ámbito público, diversos grupos coinciden que hasta el momento el Estado ha sido el acaparador de la concepción de ciudadanía, convirtiendo a la 
colectividad en meros espectadores sin capacidad de intervenir (Benedicto y Morán, 2002).

En el caso de la juventud, la construcción de una ciudadanía activa, participativa y democrática tiene una serie de complejidades, ya que principalmente se confía en la adquisición de procesos de aprendizaje que les permitan adquirir capacidades y competencias para participar. Sin embargo, estos jóvenes desde siempre han sido tutelados, por lo que se encuentran en situación de dependencia, dificultando su incorporación a la esfera pública, careciendo de los recursos necesarios para ejercer de manera efectiva su ciudadanía, lo que ha dado como consecuencia una falta de interés por todo lo relacionado con la esfera institucional (Benedicto y Morán, 2002).

\section{La quiebra de los modelos} estandarizados sobre lo que significa ser adulto, el incremento del periodo de dependencia familiar y las dificultades con las que se encuentran para completar sus transiciones han introducido grandes dosis de indeterminación y confusión entre los grupos juveniles que observan cómo se consolida su situación de cuasiciudadanía, pero sin posibilidad de lograr acceder plenamente a ella (Benedicto y Morán, 2002).

En una sociedad más afín a la democracia representativa que a la democracia participativa, es de gran importancia preparar a niños y jóvenes para la participación ciudadana, la cual constituye una tarea educativa capital y al mismo tiempo delicada (Batlle,
2007). Por lo que, en un reconocimiento de las diversas situaciones de desigualdad que vive la juventud, una medida para evitar que se les siga relegando es darles voz, enseñarles a participar, para que ello no afecte de manera negativa en su vida democrática, pero si tenga una incidencia en el desarrollo de un entorno político e institucional en el que tengan oportunidades reales de participación, ejerciendo su influencia en los asuntos de su comunidad y en la solución de sus propios problemas (Benedicto y Morán, 2002).

De esta propuesta surge la educación para la ciudadanía, la cual tiene como finalidad garantizar que los jóvenes se conviertan en buenos ciudadanos, activos y responsables, capaces de contribuir al desarrollo y bienestar de la sociedad en la que viven, que sepan exigir sus derechos, que cumplan con sus deberes con la comunidad y contribuyen al bien común, que colaboren en el mantenimiento de un espacio democrático que posibilite la participación activa, la toma de decisiones y la realización de proyectos cívicos (Batlle, 2007).

Bajo estas circunstancias, se reconoce que la metodología más adecuada para la educación para la ciudadanía es aprender a través de la acción, implicándose y generando compromiso. En resumen, la educación para la ciudadanía se lleva a cabo cuando los jóvenes aprenden a participar de manera directa en la sociedad, mejorando su entorno, ejerciendo su condición de ciudadanos activos (Batlle, 2007). 
De estas perspectivas surge el aprendizaje-servicio como metodología orientada a la educación para la ciudadanía que tiene como base las pedagogías activas, combinando dos elementos: el aprendizaje basado en la experiencia y el servicio a la comunidad. La propuesta se basa en que, al volverse una experiencia vivida se afirma que aprender, sirve; y servir, enseña, convirtiendo el entorno y la comunidad en destinarios de esos aprendizajes (Batlle, 2007).

El aprendizaje-servicio acorta esa brecha y posibilita que los jóvenes aprendan a ser ciudadanos comprometidos al aprender a participar en sociedad, siendo las instituciones educativas formales y no formales quienes podrían brindarles la oportunidad de practicarlo (Batlle, 2007).

Los proyectos de aprendizaje-servicio representan una nueva oportunidad de educar para la ciudadanía fortaleciendo las relaciones entre la institución educativa y su entorno, estableciendo acuerdos y alianzas entre los diferentes agentes de la comunidad educativa. El objetivo es trabajar conjuntamente en la construcción de un tejido social crítico, responsable y comprometido, reflexionando sobre la necesidad de una comunidad en la que la escuela trabaje en, con y para su entorno.

El aprendizaje-servicio es una metodología que ofrece a los alumnos oportunidades de implicarse de manera activa en la mejora de su entorno, alentando su participación democrática y de compromiso social. También es una propuesta educativa que combina procesos de aprendizaje y de servicio a la comunidad en un único proyecto bien articulado en el que los participantes aprendan a la vez que trabajan las necesidades reales del entorno con la finalidad de mejorarlo (Gijón y Rubio, 2010).

El hacer servicio a la comunidad es uno de los métodos más eficaces de aprendizajes, ya que los chicos le dan sentido a lo que estudian al aplicar sus conocimientos y habilidades a través de una práctica solidaria.

Esta propuesta es importante ya que el servicio mejora el aprendizaje, por lo tanto lo aprendido se pueda transferir a la realidad en forma de acción y permite dar un servicio de calidad a la comunidad. El servicio motiva y dota de sentido al aprendizaje, le aporta experiencia vital, lo vuelve significativo y permite extraer nuevos aprendizajes. El mensaje de fondo es claro y contundente: aprender, sirve; y servir, enseña (Gijón y Rubio, 2010).

Los proyectos de aprendizaje-servicio "se fundamentan en una propuesta de educación para la ciudadanía basada en la participación activa, responsable, cooperativa y solidaria que pretende contribuir a la mejora de la calidad de vida de la sociedad" (Gijón y Rubio, 2010, p.113). Su contribución principal es la de posibilitar que los jóvenes se vuelvan ciudadanos comprometidos, favoreciendo así "una educación para la ciudadanía que debe llevarse a cabo en, con y para la comunidad, convirtiendo la relación escuela y entorno en un binomio indisociable" (Gijón y Rubio, 2010, p.114). 
En el planteamiento que realizan Gijón y Rubio (2010) afirman que los proyectos de aprendizaje-servicio suponen:

1. Un método para la educación formal y no formal, para todas las edades y que debe contar con un tiempo y espacio precisos.

2. Un servicio para aprender y colaborar en el marco de reciprocidad.

3. Un proceso de adquisición de conocimientos y competencias para la vida.

4. Un método de pedagogía activa y reflexiva.

5. Un trabajo en red que coordine las instituciones educativas y las entidades sociales que intervienen en la realidad.

6. Un impacto formativo y transformador.

El aprendizaje-servicio es una metodología que brinda la oportunidad de transmitir aprendizajes para educar a los jóvenes en la ciudadanía, ya que les favorece la construcción de valores como la responsabilidad, el compromiso o la solidaridad, además de permitirles enfrentarse a situaciones problemáticas desde su propia experiencia, ofreciéndoles la oportunidad de participar activamente en la sociedad, contribuyendo en la mejora de su calidad de vida, tomando conciencia, analizando e implicándose en diversos retos, yendo más allá de las propuestas informativas tradicionales de educación para la ciudadanía, practicando valores para vivirlos en la propia piel (Gijón y Rubio, 2010).
Si bien existen algunos obstáculos para la promoción de la participación ciudadana, como que la educación para la ciudadanía en la escuela no contempla que:

[...] participar en proyectos y actividades que supongan un beneficio a la comunidad es una herramienta esencial de formación para cualquier joven [...] Se trata de un recurso que debería garantizarse en el proceso de formación de todos los jóvenes y que, hoy por hoy, no está asegurado (Batlle, 2007, p.59).

Por lo tanto, es importante destacar que en momentos como los actuales, es necesario desarrollar en la juventud un concepto de ciudadanía amplio "que afronte el reto de la inclusión frente a la exclusión, de la diversidad frente a la homogeneidad, de la paridad frente a la exclusividad, de los derechos frente a los privilegios, de la participación frente a la inactividad" (Cabrera, 2000,p.70).

Es entonces que los proyectos de aprendizaje-servicio deben ser vistos como una herramienta coadyuvante en la formación ciudadana, ya que ponen énfasis en la pertenencia a una comunidad y en el ejercicio de una ciudadanía activa.

\subsection{La importancia de la participación} juvenil en los espacios escolares

Bajo la perspectiva de que la ciudadanía se aprende, se vuelven esenciales las instituciones familiares, escolares y los medios de comunicación para transmitir una conciencia 
ciudadana para el mejoramiento de sus condiciones personales, familiares y sociales. Hart (1993) sostiene este argumento afirmando que "la participación democrática y la confianza y la capacidad para participar sólo se pueden adquirir gradualmente por medio de la práctica; no pueden enseñarse como una abstracción"(p.5).

La escuela al ser un lugar donde permanecen los jóvenes una gran cantidad de tiempo, es donde se les pude brindar la oportunidad de aprender a participar, para coadyuvar en su formación ciudadana, venciendo los prejuicios arraigados que tienen los docentes de que la participación vendrá con la mayoría de edad, creyendo que su deber es formarles para cuando sean adultos, ignorando la importancia de una preparación temprana.

Sin embargo, a pesar de que la escuela forma parte de los trayectos de vida de los jóvenes, ha sido incapaz de atender las crecientes demandas sociales y ofrecerles alternativas, por lo que, si bien se ha erigido como fiscal, juez y jurado, no se ha asumido como parte de la problemática de la juventud (Reguillo, 1997).

La interacción en la escuela se organiza mediante lo que se ha llamado "estructuras de participación". Durante las clases se distinguen diversas situaciones y formas de comunicación en términos de quiénes interactúan y de qué manera lo hacen, en torno a determinadas tareas o actividades. La escuela típica es asimétrica; el docente inicia, dirige, controla, comenta, da turnos; a la vez exige y aprueba o desaprueba la respuesta verbal o no verbal de los alumnos.

Participar en tal situación requiere un aprendizaje especial por parte de los niños. Implica la capacidad de seguir la lógica de la interacción y de entender "qué quiere el docente" en cada momento, es decir, de reconstruir las reglas de interacción (Rockwell, 1997, p.23).

Es así que una de las principales funciones de la escuela ha sido la de formar ciudadanos, aspiración presente en la enseñanza escolar explicita, ejecutada a través de los discursos de los docentes quienes son fundamentales para la formación escolar, ya que tienen a su cargo no solo la formación moral y cívica, sino también la transmisión de contenidos no intencionales, implícitos, sobre la manera en cómo se estructura y se ejerce el poder. De igual forma, brindan orientaciones valorativas de la ideología dominante, los cuales tienen permeabilidad en los contenidos académicos. Pero a la vez, se dan procesos de resistencia y de lucha, así como de apropiación de la cultura (Rockwell, 1997).

La participación que tienen los jóvenes en los espacios escolares se ha observado que es reducida y controlada por las personas adultas (Rosano, 2013) sin reconocérseles como sujetos de derechos, negándoles su práctica; por lo que es necesario promover en estos espacios "experiencias significativas de interacción en la que puedan aprender a argumentar y 
discutir, a escuchar y respetar los puntos de vista de los demás y a negociar sus intereses en conjunción con los de otros" (Corona, 2007, p.39).

La participación en la escuela se vuelve fundamental, sobre todo porque las formas de interacción influyen en la transmisión de conocimientos, debido a que entre estudiantes esta acción se realiza de manera horizontal, entre ellos se explican y comentan el contenido curricular que intenta transmitir la escuela, convirtiendo el aprendizaje en un actividad social y colectiva, más que individual (Rockwell, 1997).

Sin duda, fomentar la participación de los jóvenes al interior de las aulas no es sencillo, ya que implica "confiar en ellos, trabajar con ellos, estar a su lado, aprender a ponernos detrás para dejarlos actuar, y después saber ponernos delante para reflexionar y valorar" (Bosch y González-Monfort, 2012, p.421). Lo anterior busca que aprendan la libertad y la responsabilidad que les llevará a la participación responsable.

La escuela debería facilitar que la juventud sea protagonista de su formación, y que lo sea participando activamente en la vida escolar, con lo que podrán adquirir autonomía y responsabilidad, y así incrementar su participación en todos aquellos aspectos que sea posible dejar en sus manos (Bosch y González-Monfort, 2012).

La escuela secundaria en particular se vuelve un lugar idóneo para instrumentar acciones para la construcción de la ciudadanía juvenil, tanto porque es el nivel educativo donde existe menor deserción escolar, donde hay una mayor eficiencia terminal, así como una mayor matriculación, convirtiéndose en el espacio académico por excelencia en el que asisten la mayor cantidad de jóvenes.

Además, la escuela secundaria se organiza como una gran comunidad, donde las diversas experiencias y contextos de donde provienen los chicos les da la posibilidad de interactuar con un otro que posee un conjunto de significados dados a ciertas prácticas y actividades, y por tanto representaciones, las cuales son oportunidades para experimentar aquello que posteriormente les será de utilidad, pudiéndose volver la escuela en un gran laboratorio social.

Sumado a ello, encontramos que la edad puede ser un factor de vulnerabilidad para los jóvenes que asisten a la escuela secundaria, ya que se encuentran expuestos a diversas problemáticas; sin embargo, al ser una edad temprana, existen mayores posibilidades de instrumentar acciones preventivas y de incidencia.

De ahí surge la importancia de impulsar procesos participativos que den voz a los jóvenes, impulsando su formación ciudadana que desde siempre se ha encontrado en el abandono, sin nunca ser considerados para dar solución a sus propias problemáticas. Dichos procesos participativos sirven para conocer la forma en que los jóvenes perciben su realidad, delineando sus propias necesidades, sus aspiraciones y su proyecto de vida, ampliando sus 
oportunidades de desarrollo, al ser constructores de un orden democrático que les garantice igualdad de derechos. Resulta más que necesario que incidan en la toma de decisiones que les afectan, construyendo el mundo en el que habitan. No se trata de imponer formas de participación, sino de facilitar procesos organizativos que tengan como objetivo, una visión comunitaria, de acción colectiva que construyan una ética que busque generar solidaridad social y bienestar individual.

\section{Metodología}

\subsection{Tipo de estudio}

La metodología instrumentada en el proyecto de intervención fue de corte cualitativo. Para la obtención de información se utilizó el método de estudio de caso, el cual es definido según Denny (Rodríguez, Gil y García, 1999) como:

\section{[...] un examen completo e intenso de una faceta, una cuestión o quizás los acontecimientos que tienen lugar en un marco geográfico a lo largo del tiempo [...] y también implica un proceso de indagación detallado, comprehensivo, sistemático y en profundidad de un caso en particular ( $p .91$ ).}

\subsection{Objetivos}

Los objetivos del proyecto de intervención fueron:

\subsubsection{General}

- Describir los efectos de un programa participativo creado e impulsado por jóvenes de un grupo de secundaria.

\subsubsection{Específicos}

- Describir las preocupaciones e inquietudes que tienen los jóvenes de un grupo de secundaria.

- Impulsar la participación de un grupo de jóvenes de secundaria, a través de la creación e instrumentación de un proyecto de intervención.

\subsection{Población}

La población con la que se trabajó fue un grupo de mujeres y hombres jóvenes estudiantes de una escuela secundaria pública en la ciudad de Querétaro, México, con edades que oscilaron entre los 13 y los 15 años de edad, siendo un total de 22 mujeres y 21 hombres.

La secundaria a la que asisten los jóvenes, se caracteriza por estar ubicada en una colonia con altos niveles de delincuencia, en la que se registran violentos robos de vehículos, de comercios, extorsiones, altos índices de violencia, uso de armas de fuego, etc., encontrándose dentro de las 10 colonias que presentan mayor índice delictivo en la ciudad (López, 2015).

Al conocer el contexto social y escolar en el que se desarrollan los jóvenes participantes en el proyecto, se comprende de mejor manera sus realidades, así como los retos a los que

Martínez, A. (2020). El aprendizaje-servicio: una forma para impulsar la participación en los jóvenes. RIDAS, Revista Iberoamericana de Aprendizaje Servicio, 9, 22-42. DOI10.1344/RIDAS2020.9.2 
se enfrentan día con día.

\subsection{Procedimiento}

El proyecto de intervención tuvo como finalidad el facilitar procesos participativos, en el que los jóvenes se involucraran para dar respuesta a las problemáticas que habían identificado. Bajo esta perspectiva, se eligió el aprendizaje-servicio como propuesta pedagógica y de intervención social para la realización del proyecto propuesto, debido a que diversas experiencias han arrojado evidencia que esta metodología permite a los jóvenes realizar proyectos estructurados, con una intencionalidad pedagógica, aplicando sus conocimientos a las necesidades sentidas en su entorno, lo cual les puede posibilitar la obtención de nuevos conocimientos que fortalezcan o desarrollen actitudes de participación, solidaridad, cooperación, reciprocidad, como bases esenciales en la construcción de su ciudadanía.

La implementación de este proyecto de intervención se dividió en tres fases que permitieran el cumplimiento de su propósito:

- Fase 1: Diagnóstico participativo de la problemática

a. Identificación y análisis de las problemáticas que los jóvenes identifican.

- Fase 2: Intervención formativa y de motivación

a. Diseño y planeación de la intervención. b. Transmisión de conocimientos y comprensión de aprendizajes clave.

c. Motivación personal e institucional para el desarrollo del proyecto.

d. Transmisión y formación en la importancia de la participación juvenil.

- Fase 3: Intervención participativa (ejecución)

a. Diseño y planeación de proyectos:

b. Implementación del proyecto.

\subsubsection{Fase 1: Diagnóstico participativo de la problemática}

En esta primera fase los jóvenes identificaron y analizaron las principales problemáticas que les afectan en el contexto en el que se desenvuelven, a través de la instrumentación de un diagnóstico participativo.

Al realizar el diagnóstico, es necesario tener una mirada analítica inicial sobre la realidad en la que se va a actuar, identificando el problema o problemas que serán el objeto del proyecto (Chamorro, Balbi y Márquez, 2007).

El diagnóstico participativo fue la herramienta elegida, ya que impulsa la participación de los jóvenes, dándoles voz e influyendo en su involucramiento en ésta y en las fases de planificación y ejecución, así como para que comprendan mejor su situación, identificando los problemas y 
obstáculos que impiden su desarrollo, así como la determinación de sus prioridades.

Este método facilita la construcción en colectivo del conocimiento de la realidad, permitiendo identificar, ordenar y jerarquizar los problemas que les aquejan, siendo una práctica democrática orientada a la formación ciudadana.

El diagnóstico participativo, tal como se observa en la tabla 1 , se realizó durante cuatro sesiones, obteniendo un análisis mucho más certero de lo que los jóvenes consideran que son las problemáticas que viven en el entorno en el que se encuentran. El darles la voz es una cuestión fundamental para el reconocimiento de su ciudadanía, y para posteriormente involucrarlos en la solución a estas problemáticas, de ahí la relevancia que el diagnóstico aplicado rescate la participación como punto nodal del acercamiento con la juventud.

Tabla 1. Sesiones del diagnóstico participativo

\begin{tabular}{|c|c|c|}
\hline Sesión & Objetivo & Instrumento \\
\hline 1 & $\begin{array}{c}\text { Conocer el contexto } \\
\text { social y escolar de } \\
\text { los jóvenes. }\end{array}$ & $\begin{array}{l}\text { Mapa de la } \\
\text { Comunidad }\end{array}$ \\
\hline 2 & $\begin{array}{l}\text { Conocer las } \\
\text { preocupaciones y } \\
\text { prioridades que } \\
\text { tienen los jóvenes, } \\
\text { así como los } \\
\text { factores que } \\
\text { influyen en la } \\
\text { realidad observada. }\end{array}$ & $\begin{array}{l}\text { Priorización de } \\
\text { Problemas }\end{array}$ \\
\hline 3 & $\begin{array}{l}\text { Indagar los } \\
\text { estereotipos y los } \\
\text { efectos que en } \\
\text { materia de estigma } \\
\text { y discriminación } \\
\text { viven los jóvenes. }\end{array}$ & Personaje típico \\
\hline
\end{tabular}

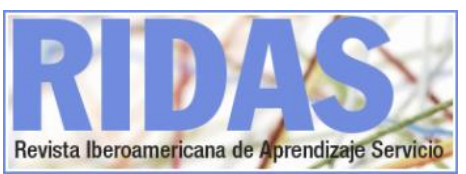
problemáticas que viven los jóvenes, así como los factores que influyen en su capacidad de elección y las alternativas de acción que están visibilizando en relación con sus prácticas cotidianas.

Historieta en 5 cuadros

4

Conocer las principales dudas que tienen en su vida, y de las cuales no han encontrado respuesta.

Fuente: elaboración propia

\subsubsection{Fase 2: Intervención formativa y de motivación}

En esta fase se trabajó en los siguientes puntos con los jóvenes:

\section{a. Diseño y planeación de la intervención}

En este punto se realizó el diseño y la planeación de la intervención a instrumentar, la cual se estructuró con base en los resultados obtenidos en la Fase 1 llamada Diagnóstico participativo de la problemática. En esta fase se planteó la creación de contenidos, de actividades y los tiempos de implementación necesarios para que los jóvenes obtuvieran aprendizajes para posteriormente llevarlos a la práctica, siendo este un elemento básico del aprendizaje-servicio, que es la intención pedagógica.

Tapia (2010) lo resume de la siguiente

Martínez, A. (2020). El aprendizaje-servicio: una forma para impulsar la participación en los jóvenes. RIDAS, Revista Iberoamericana de Aprendizaje Servicio, 9, 22-42. DOI10.1344/RIDAS2020.9.2 
manera: "Cuando la intencionalidad pedagógica y la intencionalidad social se enlazan en una actividad compleja y superadora, eso es aprendizajeservicio" (pp.24-25).

Fue necesario que los jóvenes contaran con conocimientos que les permitieran la elección de un tema, para posteriormente replicarlo en la Fase 3, llamada Intervención participativa, la cual se enfoca en la ejecución del proyecto de intervención.

b. Conocimiento y comprensión de aprendizajes clave

Para que los jóvenes obtuvieran los aprendizajes clave necesarios, se realizó la planeación de un total de 42 sesiones de 50 minutos cada una, desarrollando 21 sesiones con el grupo de varones y 21 sesiones con el grupo de mujeres.

c. Motivación personal e institucional para el desarrollo del proyecto

Lo relacionado con el componente de motivación se realizó con los jóvenes a lo largo de toda esta fase, trabajando en las sesiones en la creación de vínculos para que se apropiaran del proyecto, haciendo suyo el espacio de trabajo, impulsándolo desde dos aspectos, las implicaciones personales y las implicaciones sociales.

Cada uno de los temas tratados en la fase de intervención formativa contuvieron componentes que brindaban conocimientos a partir de las problemáticas que los jóvenes detectaron en la Fase 1. La intencionalidad es que la identificación e implicación en los temas, les motivó a obtener mayores aprendizajes y a la necesidad de realizar un servicio para otros jóvenes de su comunidad escolar, generando compromiso y responsabilidad en cada uno de ellos.

\section{d. Transmisión y formación de la participación juvenil}

Bajo el entendido que la participación juvenil es uno de los puntos nodales en los proyectos de aprendizaje-servicio, se consideró importante que durante todas las fases a desarrollar se realizaran acciones que la impulsaran, apuntalando a que los jóvenes la aprendieran, para que posteriormente tuvieran elementos para instrumentarla, sobre todo en la Fase 3, que es la referida a la ejecución de los proyectos.

La intencionalidad que se buscaba con el impulso de la participación era la modificación de la conceptualización que este grupo de jóvenes tenían sobre ella, la cual, como se ha revisado previamente, es condicionante para el ejercicio de la ciudadanía y la democracia.

\subsubsection{Fase 3: Intervención participativa (ejecución)}

Los pasos a realizar durante esta fase fueron:

\section{a. Diseño y planeación del proyecto}

En este apartado se trabajó en el diseño y la planeación del proyecto. Natura y Centro Latinoamericano de Aprendizaje y Servicio Solidario (2013) hace énfasis en la importancia de esta 
parte, ya que menciona que "el diseño de un proyecto de aprendizaje-servicio es el proceso de elaboración de la propuesta de trabajo que articula una intencionalidad pedagógica y una intencionalidad social" (p.38).

A partir de los aprendizajes intencionados que se les transmitieron a los jóvenes en la Fase 2, los cuales fueron diseñados en función de los resultados obtenidos en la Fase 1 , definieron la estructura general de su proyecto, basándose en los contenidos revisados previamente, esperando que estos conocimientos se volvieran significativos al momento de llevarlos a la práctica.

Por lo tanto, en la Fase 3 se impulsó la participación juvenil para la construcción de ciudadanía en los jóvenes involucrados, ya que al planear y ejecutar sus proyectos, éstos tendrían una implicación en su vida personal, y en su formación como jóvenes comprometidos con sí mismos, con su comunidad escolar y con su entorno, a partir de las problemáticas que detectaron y las respuestas críticas y creativas que les surgieron para atenderlo.

El objetivo fue que los jóvenes se apropiaran de sus procesos de aprendizaje y fueran los protagonistas en todas las etapas del proyecto. Definieron con quien trabajar, el tema a abordar, y el proyecto a realizar, con base en los contenidos de los aprendizajes revisados en la fase previa, buscando siempre garantizar tanto la consolidación de los aprendizajes, como el brindar un servicio que diera respuesta a las problemáticas detectadas en la fase de diagnóstico. Este fue un proceso dialéctico, ya que no se contempló como un continuo lineal, sino como un diálogo permanente para la construcción y deconstrucción de los proyectos que estaban planeando.

Los jóvenes desarrollaron los siguientes puntos para poder instrumentar sus proyectos, teniendo en consideración que debían ser ejecutados en un plazo máximo de sesiones, y con los recursos que tenían a su alcance:

1. Nombre del proyecto.

2. Nombre del equipo.

3. Integrantes del equipo.

4. Objetivo.

5. Actividades a desarrollar.

6. Tiempo de ejecución.

7. Beneficiarios.

8. Tiempo de ejecución.

9. Materiales.

El desarrollo de esta fase duró un total de 12 sesiones, cada una de ellas con una duración de 100 minutos.

\section{b. Implementación del proyecto}

Para la implementación del proyecto, cada equipo definió sus tiempos de planeación y de ejecución, diseñando y ajustando los cambios que consideraron pertinentes, por lo que solo se les brindaron lineamientos genéricos, dándoles un seguimiento pedagógico y operativo personalizado a cada equipo. En esta parte, fue importante que los jóvenes eligieran la problemática que deseaban abordar, así como las 
soluciones que consideraban que podrían darle a la misma, dándole un peso importante a su voz, impulsando así la participación juvenil.

La Fundación Esplai, en su publicación Ciudadanía Comprometida.Tejiendo propuestas de Aprendizaje Servicio (2013) lo enfatiza de la siguiente manera:

\section{La participación y el} protagonismo de niños y niñas y jóvenes es vital para la elaboración de un proyecto de aprendizaje-servicio. La participación activa es clave para aprender desde la experiencia a ser sujetos activos y de transformación del entorno donde viven y a comprometerse socialmente (p.7).

El desarrollo de esta fase duró un total de 5 sesiones, cada una de ellas con una duración de 100 minutos. En suma, la fase en total tuvo una duración de 17 sesiones.

Figura 1. Esquema de estudio

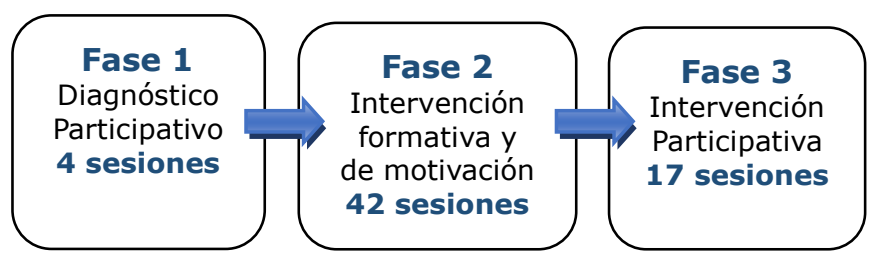

Fuente: elaboración propia

\subsubsection{Fase 4: Evaluación}

\section{Resultados}

\section{Fase 1: Diagnóstico participativo de}

\section{la problemática}

La Fase 1 tuvo como objetivo general analizar y describir las preocupaciones e inquietudes que tienen los jóvenes de una escuela secundaria. Para lograr dicho objetivo se implementaron cuatro sesiones de trabajo, en las cuales se utilizaron diversas técnicas para explorar las prácticas de riesgo y los factores de vulnerabilidad a los que se enfrentan los jóvenes.

A continuación, se describen los resultados más representativos:

- Los resultados muestran que los jóvenes viven en situaciones de vulnerabilidad que los ponen en riesgo, tanto por el nivel de violencia ejercido por sus pares, como por el acceso y consumo de drogas, así como por la exposición a un ejercicio de la sexualidad realizado en la clandestinidad.

- Las preocupaciones que los jóvenes identifican como más graves, son el bullying, las adicciones, los embarazos, la violencia, los problemas familiares, el cutting, la violencia sexual y los suicidios. Mientras que los que afirman que más frecuentemente padecen son el bullying, las adicciones, los embarazos, la violencia, el cutting y los problemas familiares.

- Los jóvenes mostraron los estereotipos y los efectos que en materia de estigma y discriminación viven en sus 
vidas, encontrando que varias de sus respuestas son un reflejo de una construcción desigual basada en el género.

- Para finalizar, las principales preocupaciones que actualmente vive este grupo de jóvenes son los embarazos, la violencia y las adicciones; mientras que las principales interrogantes que tiene este grupo de jóvenes son en materia de sexualidad.

\section{Fase 2: Intervención formativa y de motivación}

El objetivo de la Fase 1 fue conocer las principales problemáticas que los jóvenes identifican, con la finalidad de contar con los elementos suficientes y así poder instrumentar la Fase 2.

Lo que resultó evidente en las sesiones realizadas en la Fase 1 es que había tres temas latentes, las adicciones, la violencia y la sexualidad, siendo este último el que estuvo de manifiesto en todas y cada una de las sesiones, reafirmándolo con la última sesión en el que todas las preguntas formuladas por los jóvenes hacían referencia a dicho tema.

Este análisis determinó que la elección del principal problema a abordar fuera el de la sexualidad, con la finalidad de dar respuesta a la demanda formulada por el grupo. Ya con la temática elegida, se desarrolló la Fase 2, la cual estuvo dividida en dos apartados, a) Diseño y planeación de la intervención y b)Conocimiento y comprensión de aprendizajes clave.
A continuación se describe el desarrollo de cada apartado.

\section{a. Diseño y planeación de la intervención}

Se planificaron 21 sesiones abordando temas primordiales para una educación integral en sexualidad, como lo es la salud sexual, la salud reproductiva, el conocimiento del cuerpo, el derecho al placer, las relaciones sexo-afectivas, la violencia de género y en el noviazgo, hasta temas actuales, como es lo referente al ejercicio de la sexualidad a través de las redes sociales.

Los contenidos educativos abordados en esta fase se apegaron al carácter laico establecido en el artículo $3^{\circ}$ de la Constitución Política de los Estados Unidos Mexicanos, y estuvieron sustentados en los derechos humanos, así como en fundamentos científicos sobre la sexualidad, la salud reproductiva, y los derechos sexuales y reproductivos de la población juvenil.

El abordaje en esta fase se basó en el Acuerdo 592 en el que se materializa el Plan de Estudios 2011 de la Educación Básica de la Secretaría de Educación Pública, documento rector que define las competencias para la vida, el perfil de egreso, los estándares curriculares y los aprendizajes esperados que constituyen el trayecto formativo de los estudiantes, y que contribuyen a su formación como ciudadanos democráticos, críticos y creativos (Secretaría de Educación Pública, 2011).

La intervención formativa tuvo una intencionalidad pedagógica, al tener 
una vinculación curricular basada en la asignatura de Formación Cívica y Ética, desarrollando una mayor comprensión de los contenidos académicos que se trabajaron en las siguientes fases.

Las sesiones tuvieron como finalidad promover valores solidarios, de comprensión de tolerancia, de respeto, de igualdad y equidad, formando un espíritu crítico e informado, que posibilite una ciudadanía activa, crítica y sexual, para ir bordando en la construcción y consolidación de un quehacer democrático, apuntalando entre otras cosas, a la reducción de desventajas por motivo de género, de edad y por orientación sexual.

b. Conocimiento y comprensión de aprendizajes clave

Con la finalidad de que los contenidos abordados en las sesiones tuvieran una clara intencionalidad pedagógica (requisito indispensable de la metodología del aprendizaje-servicio), se utilizaron como base algunos de los bloques temáticos de la asignatura de Formación Cívica y Ética para segundo año de nivel secundaria, con la finalidad de que los jóvenes asumieran posturas y compromisos éticos vinculados con su desarrollo personal y social, teniendo como marco de referencia los derechos humanos y la cultura política democrática.

La asignatura de Formación Cívica y Ética en la educación básica está encaminada al logro de las competencias cívicas y éticas, que permiten a los alumnos tomar decisiones, elegir entre opciones de valor, encarar conflictos y participar en asuntos colectivos. Su desarrollo demanda un ejercicio práctico, tanto en situaciones de su vida diaria como ante problemas sociales que representan desafíos de complejidad creciente. Asimismo, los aprendizajes logrados mediante el desarrollo de las competencias pueden ser utilizados en múltiples situaciones y así enriquecer la perspectiva de los jóvenes sobre sí mismos y el mundo en que viven. Por lo tanto, se eligió que las sesiones propuestas para la Fase 2 tuvieron como base esta asignatura.

Tabla 2. Temas abordados en la Fase 2 de Intervención Formativa y de Motivación

\begin{tabular}{|c|c|}
\hline Sesión & Tema de la sesión \\
\hline 1 & ¿Qué es la participación? \\
\hline 2 & Prácticas narrativas de la sexualidad. \\
\hline 3 & Sentando las bases del proyecto. \\
\hline 4 & ¿Qué es la sexualidad? \\
\hline 5 & $\begin{array}{l}\text { Lo que me gusta y no me gusta de ser } \\
\text { hombre/ mujer. }\end{array}$ \\
\hline 6 & Las características. \\
\hline 7 & $\begin{array}{l}\text { Compartiendo experiencias sobre } \\
\text { participación. }\end{array}$ \\
\hline 8 & $\begin{array}{c}\text { Sensibilización sobre relaciones en el } \\
\text { noviazgo, relaciones de género y } \\
\text { sexualidad. }\end{array}$ \\
\hline 9 & $\begin{array}{l}\text { Sensibilización sobre violencia de género, } \\
\text { violencia sexual, diversidad sexual, VIH. }\end{array}$ \\
\hline 10 & $\begin{array}{l}\text { Sensibilización sobre proyecto de vida, } \\
\text { migración, violencia de género, embarazo } \\
\text { en la adolescencia. }\end{array}$ \\
\hline 11 & $\begin{array}{c}\text { Sensibilización sobre las desigualdades de } \\
\text { género, prevención, discriminación, } \\
\text { suicidio. }\end{array}$ \\
\hline 12 & Cuerpo. Autocuidado. \\
\hline 13 & Placer y autoerotismo. \\
\hline 14 & Sexo seguro y sexo protegido. \\
\hline 15 & Embarazo adolescente. \\
\hline 16 & Infecciones de transmisión sexual. \\
\hline 17 & Violencia en el noviazgo. \\
\hline 18 & Diversidad sexual. \\
\hline
\end{tabular}




\begin{tabular}{|c|c|}
\hline 19 & $\begin{array}{c}\text { Las nuevas tecnologías y el ejercicio de la } \\
\text { sexualidad. }\end{array}$ \\
\hline 20 & Derechos sexuales y reproductivos. \\
\hline 21 & Cierre del proceso. \\
\hline
\end{tabular}

Fuente: elaboración propia

En estas sesiones se brindó información y herramientas para que los jóvenes trabajaran en asumirse como sujetos de una sexualidad socialmente construida, brindándoles la posibilidad de elección, fortaleciendo su autonomía, y motivando su participación, para sentar las bases de un futuro involucramiento en acciones colectivas.

\section{Fase 3: Intervención participativa (ejecución)}

La Fase 3 tuvo como objetivo que los jóvenes se apropiaran de sus procesos de aprendizaje y fueran los protagonistas del proyecto, ya que como ya se había mencionado, fueron ellos quienes definieron con quien trabajar, el tema a abordar, y el proyecto a realizar, con base en los contenidos de los aprendizajes revisados en la Fase 2, apuntalando a crear una propuesta de servicio que diera respuesta a las problemáticas detectadas en la Fase 1.

La Fase 3 estuvo compuesta por dos subfases, la primera consistió en diseñar y planear el proyecto a realizar por parte de los jóvenes, mientras que la segunda consistió en la implementación del proyecto de aprendizaje-servicio. A continuación se describe cada una de las subfases:

\section{Diseño y planeación de proyectos}

La primera parte de esta subfase se llevó a cabo en un total de 12 sesiones, en las que se definieron los equipos, los temas, los objetivos y actividades, así como las dificultades encontradas durante el desarrollo del proceso.

Al concluir las sesiones de la primera subfase de la Fase 3 en la que se llevó a cabo el diseño y planeación del proyecto de aprendizaje-servicio, se prosiguió la ejecución de la segunda subfase que era la referida a la implementación del proyecto. Durante cinco sesiones se trabajó con los jóvenes para que lo implementaran.

\section{a. Los proyectos desarrollados}

Finalmente solo cinco proyectos pudieron ser concluidos y estar listos para realizar el servicio. A continuación se describe el tema de cada proyecto elegido, el tipo de proyecto realizado y el número de jóvenes que integraba cada equipo.

Tabla 3. Equipos que concluyeron sus proyectos y realizaron el servicio

\begin{tabular}{|c|c|c|c|}
\hline Equipo & $\begin{array}{l}\text { Tema del } \\
\text { proyecto }\end{array}$ & $\begin{array}{l}\text { Tipo de } \\
\text { proyecto }\end{array}$ & Integrantes \\
\hline 1 & $\begin{array}{l}\text { Sexo seguro y } \\
\text { sexo protegido }\end{array}$ & $\begin{array}{l}\text { Realización de } \\
\text { una canción }\end{array}$ & 11 varones \\
\hline 2 & $\begin{array}{c}\text { Métodos } \\
\text { anticonceptivos }\end{array}$ & $\begin{array}{l}\text { Realización de } \\
\text { una canción }\end{array}$ & 3 varones \\
\hline 3 & $\begin{array}{l}\text { Diversidad } \\
\text { sexual }\end{array}$ & $\begin{array}{l}\text { Realización de } \\
\text { una canción }\end{array}$ & 1 chica \\
\hline 4 & $\begin{array}{c}\text { Infecciones de } \\
\text { transmisión } \\
\text { sexual }\end{array}$ & $\begin{array}{l}\text { Realización de } \\
\text { una canción }\end{array}$ & 2 chicos \\
\hline 5 & $\begin{array}{l}\text { Diversidad } \\
\text { sexual }\end{array}$ & $\begin{array}{l}\text { Realización de } \\
\text { una canción }\end{array}$ & 7 chicas \\
\hline
\end{tabular}

Fuente: elaboración propia

Martínez, A. (2020). El aprendizaje-servicio: una forma para impulsar la participación en los jóvenes. RIDAS, Revista Iberoamericana de Aprendizaje Servicio, 9, 22-42. DOI10.1344/RIDAS2020.9.2 


\section{b. El servicio realizado}

Después de un arduo trabajo con la realización de sus proyectos, los equipos decidieron que el servicio que realizarían iba a estar dirigido a los jóvenes de todos los grupos de la secundaria, con la finalidad de enseñarles, darles a conocer $\mathrm{e}$ informarles todo lo que ellos y ellas habían trabajado y aprendido.

La evaluación del servicio realizado fue de tipo cuantitativo, cuyo foco primordial estaba puesto en la implementación del proyecto por parte de los jóvenes. Los resultados son los siguientes:

- Se impactó a 17 grupos, seis grupos de primer año, seis grupos de segundo año y cinco grupos de tercer año. Estos grupos corresponden a toda la población de la secundaria del turno vespertino.

- Cada grupo aproximadamente tiene una población de 45 estudiantes, por lo que cerca de 765 personas fueron beneficiarias del proyecto de aprendizaje-servicio.

La realización de este tipo de proyectos, sin duda, les brindó a los jóvenes involucrados perspectivas distintas en torno a la participación, así como un afianzamiento de los aprendizajes obtenidos durante el desarrollo del proyecto, así como habilidades para su vida y para el ejercicio de su sexualidad.

La experimentación de proyectos de esta naturaleza debería estar disponibles para que más jóvenes se involucren en acciones comunitarias, con beneficios para la sociedad. Sin lugar a dudas, los proyectos de aprendiza-servicio son una opción viable, con resultados positivos en las juventudes.

\section{Conclusiones}

Según datos ya revisados en este documento, la secundaria es el momento en el que la mayoría de los jóvenes en México se encuentran matriculados, con un rango de edad que va de los 12 a los 14 años. Esta cuestión es una gran área de oportunidad para trabajar con ellos y ellas en su involucramiento en la vida democrática, para participar de manera más activa en las decisiones que les afectan, por lo que la metodología del aprendizaje-servicio se vuelve una posibilidad de explorar el fomento de la ciudadanía, a través de la participación juvenil.

A partir de la experiencia de haber llevado implementado un proyecto de aprendizaje-servicio, resultaron una serie de reflexiones. La utilización de aprendizaje-servicio como metodología debe tomar en cuenta la opinión de la población con la que se trabaja, ya que la participación no sólo implica que las personas se involucren, sino también que se tome en consideración su opinión y que ésta sea aplicada, para así evitar simulaciones. Por lo que los proyectos de aprendizaje-servicio que tienen definidas previamente las actividades y el servicio a desarrollar, en realidad no están promoviendo la participación real y efectiva, sino solo

Martínez, A. (2020). El aprendizaje-servicio: una forma para impulsar la participación en los jóvenes. RIDAS, Revista Iberoamericana de Aprendizaje Servicio, 9, 22-42. DOI10.1344/RIDAS2020.9.2 
se están imponiendo los designios, los deseos y las perspectivas adultocentristas.

Por otro lado, se debe evitar creer que con el solo hecho de realizar el servicio se está cumpliendo con el objetivo de la metodología, ya que su ejercicio también debe implicar una reflexión mucho más amplia y profunda sobre la construcción de la ciudadanía.

Al elegir la metodología de aprendizajeservicio, se tienen que tener en consideración las dificultades o pocas habilidades que tienen los grupos, sobre todo bajo la perspectiva que a niños, niñas, adolescentes y jóvenes no se les ha dado la oportunidad de participar, por lo que, al comenzar un proyecto participativo, deben planearse actividades en las que inicialmente se les brinden las herramientas que les faciliten dicha participación.

\section{El proyecto implementado no} contempló estas consideraciones, por lo que los principales problemas a los que se enfrentaron los jóvenes durante la aplicación de la metodología, fue lo referente a la resolución no violenta de conflictos, que repercutió en el trabajo en equipo. Por lo tanto, la metodología de aprendizaje-servicio no solo debería enfocarse en transmitir aprendizajes con una intencionalidad pedagógica, sino que también tendría que considerar el trabajar en el desarrollo de habilidades, que les posibilite a los jóvenes aprovechar de mejor manera la metodología, para que ésta no corra el riesgo de volverse un factor o un obstáculo en sus procesos.

Por tanto, la recomendación es que para obtener mejores resultados, la metodología debería de dedicar un tiempo dentro de la planeación a enseñar procesos participativos, sobre todo en contextos en donde las infancias y las juventudes han sido invisibilizadas, sometidas a verticalidad y autoritarismo, donde poco se les ha dado la oportunidad de tomar la palabra, y menos de ejecutar y liderear acciones. Además de ello, la escuela debería de estar propiciando experiencias y espacios de participación para la puesta en marcha de proyectos como éste, y así no se vería limitada por esta cuestión.

Si bien, para este proyecto se realizaron diversas evaluaciones para dar cuenta del proceso del aprendizajeservicio, no se contemplaron maneras de comprobar que al concluir la intervención en los jóvenes se observaran cambios en sus prácticas ciudadanas. Por lo tanto haría falta crear procesos en los que se evalúe la formación ciudadana, para que sea posible determinar este tipo de cambios.

Otra de las cuestiones que es importante destacar, es que la realización de este proyecto no estuvo vinculado directamente a una materia académica, por lo que se volvió un reto que los jóvenes participaran sin esperar nada a cambio. Esto sin duda, es uno de los grandes retos para el fomento a la participación juvenil, y a la metodología por sí misma, ya que los proyectos que utilizan el aprendizajeservicio y que se encuentran vinculados a lo académico contienen una participación limitativa, ya que al estar de por medio una calificación, quedan a 
la espera de lo que los adultos ordenen, limitando su participación.

En el caso de los proyectos propuestos y creados por alumnado de la secundaria ha sido claramente identificable que la tardanza en la implementación de los proyectos tuvo un claro componente de desigualdad, ya que se han puesto de manifiesto sus propias deficiencias académicas y materiales. La desigualdad social y económica se traduce en mayores vulnerabilidades.

Por otro lado, de los muchos trabajos que se han realizado en materia de aprendizaje-servicio, son pocas las experiencias que retoman el tema de la sexualidad como tema nodal del aprendizaje y del servicio, por lo que debería de promoverse dicha metodología, ya que les permitiría a los jóvenes asumirse como facilitadores para brindar educación sexual en su comunidad.

\section{Referencias bibliográficas}

Batlle, R. (2007). Juventud, ciudadanía y Aprendizaje-Servicio. ¿Qué jóvenes y cuál ciudadanía? Fundació Catalana de I'Esplai (Ed.) Documentos para el debate. Educación y Ciudadanía.

Recuperado de http://roserbatlle.net/wpcontent/uploads/2009/03/educacion-yciudadania-fundacion-esplai-2007.pdf

Benedicto, M. y Morán, M.L. (2002). La construcción de una ciudadanía activa entre los jóvenes. Recuperado de http://www.injuve.es/sites/default/files /LA\%20CONSTRUCCION.pdf
Bosch, D. y González-Monfort, N. (2012). ¿Cómo perciben los alumnos su participación en los centros de secundaria? Una investigación sobre las representaciones sociales de los alumnos. En N. de Alba, F. García y A. Santisteban (Eds.), Educar para la participación ciudadana en la enseñanza de las Ciencias Sociales (pp.421-429). Sevilla, España: Díada Editora.

Cabrera, F. (2000). Hacia una nueva concepción de ciudadanía en una sociedad multicultural. En M. Bartolomé (coord.) Identidad y ciudadanía: un reto a la educación intercultural, Recuperado de https://www.academia.edu/18229991/ Hacia_una_nueva_concepci\%C3\%B3n de_la_ciudadan $\%$ C3\%ADa_en_una_soc iedad_multicultural

Chamorro, N., Balbi, J. y Márquez, S. (2007). Aprendizaje Servicio Solidario: una propuesta pedagógica. Montevideo, Uruguay: Centro de Voluntariado del Uruguay.

Corona, Y. (2007). Desarrollos conceptuales sobre ciudadanía y niñez. Anuario de investigación 2006 UAM-X, 27- 41. Recuperado de https://programainfancia.uam.mx/pdf/ publicaciones/corona_desarrollos.pdf

Fundación Esplai. (2013). Ciudadanía comprometida. Tejiendo propuestas de Aprendizaje Servicio (ApS). Recuperado de https://fundacionesplai.org/wpcontent/uploads/2014/10/Teixintterminado.pdf

Gijón M. y Rubio, L. (2010). Escuela y 
entorno: el aprendizaje servicio. En J.M. Puig (Coord.), Entre todos. Compartir la educación para la ciudadanía (pp. 107122). Barcelona, España: ICEHORSORI.

Hart, R. (1993). La participación de los niños. De la participación simbólica a la participación auténtica. Ensayos Innocenti , 4. Nueva York, Estados Unidos: Fondo de las Naciones Unidas para la Infancia (UNICEF) Oficina Regional para América Latina y el Caribe.

López, P. (22 de julio de 2015). Difunden las 10 zonas más conflictivas en Querétaro. Quadratin. Recuperado de

https://queretaro.quadratin.com.mx/Da n-a-conocer-top-ten-de-zonasconflictivas-en-Queretaro/

Natura y Centro Latinoamericano de Aprendizaje y Servicio Solidario. (2013). Manual para docentes y estudiantes solidarios. Buenos Aires, Argentina: Centro Latinoamericano de Aprendizaje y Servicio Solidario (CLAYSS). Recuperado de Recuperado de

http://www.clayss.org/04_publicacione s/Natura2013.pdf

Reguillo, R. (1997). Culturas Juveniles, producir la identidad un mapa de interacciones. Revista de Estudios sobre Juventud, 2(5), 12-31.

Rockwell, E. (1997). De huellas, bardas y veredas: una historia cotidiana en la escuela. En E. Rockwell (Coord.) La Escuela Cotidiana (pp.13-57). México D.F, México: Fondo de Cultura
Económica.

Rodríguez, G., Gil, J. y García, E. (1999). Metodología de Investigación Cualitativa. Málaga, España: Aljibe.

Rosano, S. (2013). Son cosas de niños. La participación como derecho y la educación inclusiva: reflexión en torno al papel de las niñas y niños en la escuela. Revista Latinoamericana de Educación Inclusiva, 7(1), 151-167. Recuperado de https://dialnet.unirioja.es/descarga/arti culo/4268756.pdf

Secretaría de Educación Pública. (2011). Acuerdo Número 592 por el que se establece la articulación de la Educación Básica. Recuperado de http://www.sipi.siteal.iipe.unesco.org/si tes/default/files/sipi_normativa/acuerdo _592_articulacion_educacion_basica_pr imaria.pdf

Tapia, M. N. (2010). La propuesta pedagógica del "Aprendizaje Servicio": una perspectiva latinoamericana.

Revista científica Tzhoecoen, 5, 23-43.

Recuperado de

http://sgpwe.izt.uam.mx/files/users/ua $\mathrm{mi} / \mathrm{sabi} /$ Aprendizaje_y_servicio/pdfs/La _propuesta_pedagogica_delAprendizaje_servicio_una_perspectiva_latinoamericana.pdf

Martínez, A. (2020). El aprendizaje-servicio: una forma para impulsar la participación en los jóvenes. RIDAS, Revista Iberoamericana de Aprendizaje Servicio, 9, 22-42. DOI10.1344/RIDAS2020.9.2 
Proyectos de aprendizaje-servicio en el marco de la Responsabilidad Social Universitaria en las Instituciones Educativas rurales del distrito de Independencia, Huaraz, Perú

\author{
Liszeth Cerna Ruiz \\ César Brito Mallqui \\ Laura Nivin Vargas \\ Universidad Nacional Santiago Antúnez de Mayolo, Perú \\ Luis Taramona Ruiz \\ Universidad Le Cordon Bleu, Perú
}

\title{
Resumen
}

La presente investigación tuvo como objetivo demostrar la incidencia de la aplicación de proyectos de aprendizaje-servicio en el marco de la responsabilidad social universitaria en instituciones educativas rurales del distrito de Independencia, Huaraz. Se caracteriza como una investigación aplicada. La verificación del desempeño de la muestra se recoge por una ficha de inscripción y el nivel de incidencia ha sido medido cuantitativamente a través del nivel de satisfacción de los beneficiarios en base a encuestas. Los datos han sido analizados desde el nivel explicativo y el diseño de la investigación fue cuasi experimental a fin de verificar la validez de la hipótesis. Los resultados reportan que cuando se aplican de manera eficaz los proyectos de aprendizaje-servicio en las instituciones educativas rurales con estudiantes del nivel primario se logra fortalecer la vinculación entre universidad y comunidad educativa.

\section{Palabras clave}

Proyectos de aprendizaje-servicio, responsabilidad social universitaria, instituciones educativas rurales. 


\title{
Service-learning projects within the framework of University Social Responsibility in rural educational institutions in the district of Independencia (Huaraz, Peru)
}

\begin{abstract}
The main objective of the research was to demonstrate the impact of the implementation of service-learning projects within the framework of university social responsibility in rural educational institutions in the district of Independencia (Huaraz, Peru). The data were analyzed from an explanatory level and the research design was quasi-experimental. The results of this research indicate that when service-learning is applied, the link between the university and the educational community is strengthened. In addition, there is an urgent need to design service-learning projects to strengthen the links between the university and the educational community, recognizing that service-learning contributes to solving problems that require the strengthening of rural educational institutions. This implies that institutions need to coexist, get involved with each other, work together and form networks to solve problems, to actively manage community activity.
\end{abstract}

\section{Keywords}

Service-learning projects, university social responsibility, rural educational institutions. 


\section{Introducción}

La Universidad sin duda constituye una de las instituciones más importantes de las sociedades contemporáneas. Los servicios que presta se consideran valiosos para el desarrollo del país. La responsabilidad social es una de las funciones más recientes de la universidad, y hace referencia a aquellas actividades usualmente conducidas por la universidad través de sus miembros fuera del campus y relacionados con sus programas regulares de enseñanza e investigación. Cabe indicar que estos programas deben estar relacionados con el currículo regular de la universidad y ser requeridos o deseados por la comunidad.

La responsabilidad social unida al aprendizaje-servicio provoca efectos en el desarrollo personal, cambios en las instituciones educativas y sociales que lo impulsan y mejoras en el entorno comunitario que recibe el servicio. El aprendizaje-servicio es una práctica educativa que incide en el aprendizaje de contenidos y en la educación en valores, así como en la transformación del entorno social y de la propia institución educativa que lo impulsa y práctica.

Cabe indicar que el aprendizaje-servicio requiere una red de alianzas entre las instituciones educativas y las entidades sociales que facilitan servicios a la comunidad. Por un lado, el aprendizajeservicio depende de una imagen de la escuela que rompa con la tendencia a encerrarse en sí misma y, por el otro, requiere por naturaleza un trabajo en red que coordine las instituciones educativas -escolares y no escolares- y las entidades sociales que facilitan la intervención en la realidad.

En este contexto, la Universidad Nacional Santiago Antúnez de Mayolo promueve un eje estratégico denominado Responsabilidad Social Universitaria, considerando como uno de sus objetivos el desarrollo e implementación de modelos de vinculación y acciones estratégicas hacia la comunidad con énfasis en las áreas salud y educación; generando iniciativas y propuestas que permitan relacionar el campo profesional de los docentes y estudiantes universitarios con el trabajo comunitario. Como docentes universitarios nos toca asumir un rol importante en la gestión de acciones comunitarias que alcancen impacto en el aprendizaje y en los beneficiarios de las instituciones educativas para esta investigación.

Por tanto, la presente investigación se plantea como objetivo general demostrar el nivel de incidencia de la aplicación de proyectos de aprendizajeservicio en el marco de la responsabilidad social universitaria en las instituciones educativas rurales del distrito de Independencia de la ciudad de Huaraz, en el año 2016. Asimismo, como objetivos específicos se propuso formular proyectos de aprendizajeservicio en el ámbito educativo para mejorar las prácticas de responsabilidad social universitaria en beneficio de las instituciones educativas rurales y aplicar la metodología de proyectos de aprendizaje-servicio para contribuir en las áreas de la responsabilidad social

Cerna, L., Brito, C., Nivin, L. y Taramona, L. (2020). Proyectos de aprendizaje-servicio en el marco de la Responsabilidad Social Universitaria en las Instituciones Educativas rurales del distrito de Independencia, Huaraz, Perú. RIDAS, Revista Iberoamericana de Aprendizaje Servicio, 9, 43-61. DOI10.1344/RIDAS2020.9.3 
universitaria en las instituciones educativas rurales.

Es de suma importancia reconocer que esta investigación ha promovido la participación de los miembros de la comunidad universitaria como parte de la responsabilidad social universitaria que toda institución superior debería realizar en atención a problemáticas educativas que contribuyan con los estudiantes de educación primaria de las instituciones educativas rurales seleccionadas, dado que estas poblaciones se encuentran en zonas vulnerables y de limitada atención por parte de instituciones públicas y privadas, desarrollando actividades para fortalecer las competencias matemáticas, comunicativas y artísticas del alumnado de educación primaria, a partir de la ejecución de proyectos de aprendizaje-servicio que involucren a la comunidad educativa y del ámbito rural.

\section{Marco teórico}

\subsection{Responsabilidad Social Universitaria}

Dentro del marco de la responsabilidad social universitaria, las universidades se involucran con su entorno a partir de sus funciones primordiales como la investigación, la formación académica y la proyección social.

Por tanto la responsabilidad social universitaria tiene dos estadios de acción claramente diferenciables. Vallaeys (2009) indica:

- El primero, hacia el interior de la institución, que debe ser sistemático y desde el primer hasta el último día que el estudiante permanezca en sus instalaciones, básicamente formando valores humanos, solidaridad, tolerancia y principios de convivencia, para crear conciencia sobre su obligación individual y colectiva de ayudar a los más necesitados y mejorar su entorno. En este proceso deben estar directamente vinculados los directivos, estudiantes, docentes, y administradores de la institución.

- El segundo, hacia el exterior de la institución, es decir hacia la sociedad en general, liderando procesos que cumplan finalmente con el objetivo de lograr una sociedad más justa, con acceso al conocimiento, la información y el trabajo, en un marco de respeto por las diferentes culturas y costumbres, el uso adecuado de los recursos y la preservación del medio ambiente.

La importantísima labor académica que desarrollan las universidades, tiene hoy que complementarse con acciones directas de intervención sobre el medio que las rodea. Tendremos una universidad socialmente responsable cuando las iniciativas sociales perduren y se multipliquen por la misma dinámica de la formación académica sostenida desde la administración central y estimulada desde la investigación. Cuando el personal académico investigue y mejore permanentemente los procesos de

Cerna, L., Brito, C., Nivin, L. y Taramona, L. (2020). Proyectos de aprendizaje-servicio en el marco de la Responsabilidad Social Universitaria en las Instituciones Educativas rurales del distrito de Independencia, Huaraz, Perú. RIDAS, Revista Iberoamericana de Aprendizaje Servicio, 9, 43-61. DOI10.1344/RIDAS2020.9.3 
aprendizaje basado en proyectos sociales, pero sobre todo cuando seamos responsables de nuestra propia convivencia en el mundo.

Del Castillo y Yamada (2008) afirman que los dos principales propósitos de la universidad son, ante todo 1)la formación humana y profesional (propósito académico); y 2)la construcción de nuevos conocimientos (propósito de investigación), sabiendo que estos dos fines se relacionan estrechamente. Es a partir de las investigaciones de sus profesores que la universidad construye los contenidos académicos que se transmiten a los estudiantes para su formación. Notemos que la Universidad no está naturalmente destinada a jugar un papel de Organización no gubernamental (ONG) de Desarrollo, ni de substituto del Estado en el alivio de la pobreza, por lo que su responsabilidad social no puede ser confundida con la de dotarse de una oficina de ayuda social.

Castillo y Yamada (2008) manifiestan que los impactos que genera la Universidad en su actuar cotidiano, pueden ser agrupados en cuatro rubros:

\section{Impactos de funcionamiento} organizacional: como cualquier organización laboral, la universidad genera impactos en la vida de su personal administrativo, docente y estudiantil (que su política de bienestar social debe de gestionar) y también contaminación en su medioambiente (desechos, deforestación, polución atmosférica por transporte vehicular, etc.). La universidad deja huellas en las personas que viven en ella y tiene también su huella ecológica.

2. Impactos educativos: La universidad tiene un impacto directo sobre la formación de los jóvenes y profesionales, su manera de entender e interpretar el mundo, comportarse en él y valorar ciertas cosas en su vida. Influye, asimismo, sobre la deontología profesional, orienta (de modo consciente o no) la definición de la ética profesional de cada disciplina y su rol social.

3. Impactos cognitivos y epistemológicos: la universidad orienta la producción del saber y las tecnologías, influye en la definición de lo que se llama socialmente verdad, ciencia, racionalidad, legitimidad, utilidad, enseñanza, etc. Incentiva (o no) la fragmentación y separación de los saberes al participar en la delimitación de los ámbitos de cada especialidad. Articula la relación entre tecnociencia y sociedad, posibilitando (o no) el control social de la ciencia. Genera actitudes como el elitismo científico, la expertocracia o al contrario, promueve la democratización de la ciencia. Influye, finalmente, sobre la definición y selección de los problemas de la agenda científica. 
4. Impactos sociales: la universidad tiene un impacto sobre la sociedad y su desarrollo económico, social y político. No sólo tiene un impacto directo sobre el futuro del mundo, en cuanto forma a sus profesionales y líderes, sino que ella es también un referente y un actor social, que puede promover (o no) el progreso, que puede crear (o no) capital social, vincular (o no) la educación de los estudiantes con la realidad social exterior, hacer accesible (o no) el conocimiento a todos. Así el entorno social de la universidad se hace una cierta idea de su papel y su capacidad (o no) de ser un interlocutor válido en la solución de sus problemas.

\section{Estos parámetros son considerados} dentro de la normatividad vigente en las universidades, generando directrices para el trabajo comunitario, atendiendo cada vez problemáticas más reales, que respondan a las necesidades académicas de los estudiantes, docentes y comunidad universitaria.

El enfoque de la responsabilidad social universitaria pretende aportar a la discusión y reflexión sobre los modelos de enseñanza-aprendizaje vigentes y despertar el interés para iniciar la transformación hacia una gestión comprometida con el capital social y el desarrollo humano sostenible; de manera que se logre crear un vínculo estrecho entre la enseñanza y la investigación con la participación social.

\subsection{Proyectos de aprendizaje-servicio}

El trabajo por proyectos no es nuevo en la práctica educativa. En rigor, educadores en todo el país lo vienen incorporando a sus prácticas de enseñanza desde hace muchos años. Esta forma de estructurar las propuestas curriculares se ha vuelto muy común en las aulas, tanto en el nivel de primaria como en el de secundaria y en la enseñanza técnico profesional.

Un proyecto es, fundamentalmente, una herramienta de cambio, un instrumento que posibilita producir cambios en la realidad que a partir de un análisis se considera primariamente insatisfactoria o que puede ser pasible de mejoras o adelantos. Un proyecto es, esencialmente, un conjunto de acciones y actividades que coadyuvarán a la consecución de los objetivos que tiendan a cambiar esa realidad (AnderEgg y Aguilar, 1996).

El ciclo de un proyecto reconoce, en primer lugar, la identificación del problema a partir de un diagnóstico riguroso de la situación que se intenta cambiar. Un conocimiento exhaustivo de la realidad en la que el proyecto realizará sus intervenciones y de un conjunto de informaciones fieles, recientes y relevantes de los problemas, son elementos imprescindibles sin los que será muy difícil o imposible la correcta visualización y elaboración del proyecto.

Respecto a los proyectos de aprendizaje-servicio, en su definición nos permite entender que representa una metodología pedagógica orientada al aprender haciendo, a partir de la generación de proyectos o actividades

\footnotetext{
Cerna, L., Brito, C., Nivin, L. y Taramona, L. (2020). Proyectos de aprendizaje-servicio en el marco de la Responsabilidad Social Universitaria en las Instituciones Educativas rurales del distrito de Independencia, Huaraz, Perú. RIDAS, Revista Iberoamericana de Aprendizaje Servicio, 9, 43-61. DOI10.1344/RIDAS2020.9.3
} 
que responden a una necesidad en un contexto determinado y en una comunidad determinada, practicando la solidaridad y fortaleciendo el compromiso social.

Esta metodología permite sistematizar actividades en proyectos concretos que respondan a un diagnóstico y establezcan conexiones curriculares entre los conocimientos vertidos en la aulas universitarias y el trabajo en las comunidades, fortaleciendo los aprendizajes propios de la carrera de educación. Para tal finalidad, el aprendizaje-servicio solidario provoca efectos en el desarrollo personal, cambios en las instituciones educativas y sociales que lo impulsan, y mejoras en el entorno comunitario que recibe el servicio (Puig y Palos, 2006).

En este sentido, el aprendizaje-servicio se conceptualiza como una metodología que combina en una sola actividad el aprendizaje de contenidos, competencias y valores con la realización de tareas de servicio a la comunidad (Tapia, 2006). El aprendizaje-servicio parte de la idea que la ayuda mutua, es un mecanismo de progreso personal, económico y social mejor que la persecución obsesiva del provecho individual (Puig, 2009).

Para Cecchi (2006) "el aprendizajeservicio, parte de una premisa: la solidaridad puede ser no sólo un contenido de enseñanza; sino que las actividades solidarias desarrolladas por los estudiantes pueden ser en sí mismas, una fuente de aprendizaje, si se planifican adecuadamente" (p.4). En este sentido, la pedagogía del aprendizaje-servicio podría definirse, en primera instancia, según Tapia (Cecchi, 2006) como una metodología de enseñanza y aprendizaje mediante la cual los jóvenes desarrollan sus conocimientos y competencias a través de una práctica de servicio a la comunidad.

Hablamos de aprendizaje-servicio cuando se da la intersección de estos dos tipos de actividades, es decir cuando en el desarrollo de un proyecto están presentes simultáneamente la intencionalidad pedagógica y la intencionalidad solidaria.

Teniendo en cuenta los criterios con mayor consenso a nivel internacional, podemos decir que un servicio a la comunidad es aprendizaje-servicio cuando es planificado (Tapia, 2006):

- en función del proyecto educativo institucional, y no sólo de las demandas de la comunidad;

- con la participación de toda la comunidad educativa: incluyendo el liderazgo de la conducción institucional, la participación directa o indirecta del cuerpo docente, y la activa participación de los estudiantes desde las etapas de diagnóstico y planificación hasta las de gestión y evaluación;

- al servicio de una demanda efectivamente sentida por la comunidad, y a la cual pueden atender los estudiantes en forma eficaz y valorada;

- atendiendo con igual énfasis a un alto nivel de respuesta a la demanda

Cerna, L., Brito, C., Nivin, L. y Taramona, L. (2020). Proyectos de aprendizaje-servicio en el marco de la Responsabilidad Social Universitaria en las Instituciones Educativas rurales del distrito de Independencia, Huaraz, Perú. RIDAS, Revista Iberoamericana de Aprendizaje Servicio, 9, 43-61. DOI10.1344/RIDAS2020.9.3 
de la comunidad y a un aprendizaje de calidad para los estudiantes.

Los proyectos de aprendizaje-servicio buscan a la vez que los conocimientos que los estudiantes deben incorporar o desarrollar, se articulen con la vida cotidiana y, sobre todo, con la vida comunitaria. La metodología de los proyectos puede facilitar una interacción armónica de la institución educativa con la comunidad y sus organizaciones. Al mismo tiempo, es posible vincular progresivamente la experiencia de servicio con los contenidos curriculares y planes de estudio de forma que se fortalecen los contenidos académicos con el aprendizaje que se produce en el desarrollo del servicio.

Por lo tanto, la ejecución de proyectos de aprendizaje-servicio permite a las universidades fortalecer sus prácticas de responsabilidad social universitaria, generar espacios de participación y compromiso, a la vez que brinda una serie de beneficios a sus estudiantes en el ámbito académico como en su desarrollo personal e interpersonal, de igual forma a sus docentes, contribuye con las organizaciones y ofrece beneficios para la universidad, como por ejemplo integrar a sus instituciones cercanas, sin desviarse de su misión principal, la de educar a sus estudiantes; establecer y fortalecer relaciones con otras instituciones de la comunidad; lograr una mayor identificación y sentido de pertenencia por parte de los estudiantes con la universidad (Furco, 2005).

Una institución es parte de la estructura social y la reproduce, es concreta, histórica y compleja. Son las instituciones espacios en las que desarrollamos gran parte de nuestra existencia. La universidad no se excluye de esta tarea.

\section{Metodología}

El tipo de estudio corresponde a una investigación explicativa. El diseño de investigación aplicado es cuasi experimental, de dos grupos no equivalentes conocido con preprueba, posprueba y grupo control. La población corresponde a 888 estudiantes de 22 instituciones educativas rurales del distrito de Independencia y la muestra es estratificada determinándose 181 estudiantes de 8 instituciones educativas rurales del distrito de Independencia. En el grupo experimental se ha considerado a 101 estudiantes de 4 instituciones de zona rural y para el grupo control a 80 estudiantes de 4 instituciones de zona rural, la diferencia numérica de los grupos se debe a la ubicación y zonificación de cada institución educativa.

Respecto a los instrumentos de recolección de datos, se procedió al registro en una ficha de inscripción, donde se considera los datos personales de estudiantes y docentes del grupo control y experimental, las propuestas del área de trabajo y los grupos poblacionales a atender. Asimismo, se utilizó un cuestionario tipo escala de Likert donde se ha priorizado dimensiones e indicadores de la investigación centrada en las dos variables: responsabilidad social universitaria y aprendizaje-servicio. Se ha elaborado un instrumento con 16

\footnotetext{
Cerna, L., Brito, C., Nivin, L. y Taramona, L. (2020). Proyectos de aprendizaje-servicio en el marco de la Responsabilidad Social Universitaria en las Instituciones Educativas rurales del distrito de Independencia, Huaraz, Perú. RIDAS, Revista Iberoamericana de Aprendizaje Servicio, 9, 43-61. DOI10.1344/RIDAS2020.9.3
} 
ítems que abarca las dimensiones de ambas variables, como los indicadores a considerar y las interrogantes planteadas. Dicho instrumento ha sido validado con una prueba piloto.

Por la naturaleza de la información que buscamos, se utilizaron métodos cuantitativos para procesar la información, a través del programa SPSS (versión 18), con el cual se evaluó la prueba de hipótesis. La técnica estadística adecuada es la prueba de los rangos con signo de wilcoxon, una prueba no paramétrica para comparar el rango medio de dos muestras relacionadas y determinar si existen diferencias entre ellas. Se utiliza como alternativa a la prueba t de Student cuando no se puede suponer la normalidad de dichas muestras.

\section{Resultados}

\subsubsection{Variable dependiente: 01}

Tabla 1. Sesiones del diagnóstico participativo. Instrumento de medición de estudiantes de las instituciones educativas rurales del distrito de Independencia - Huaraz, 2016

\begin{tabular}{|c|c|c|c|c|}
\hline \multirow[t]{2}{*}{ Indicador } & \multicolumn{2}{|c|}{$\begin{array}{l}\text { Grupo control } \\
\quad(n=80)\end{array}$} & \multicolumn{2}{|c|}{$\begin{array}{c}\text { Grupo } \\
\text { experimental } \\
(n=101)\end{array}$} \\
\hline & $\mathbf{N}$ & $\%$ & $\mathbf{n}$ & $\%$ \\
\hline & \multicolumn{4}{|c|}{ Pretest } \\
\hline $\begin{array}{l}\text { Nada } \\
\text { Eficiente }\end{array}$ & 61 & 0,76 & 75 & 0,75 \\
\hline $\begin{array}{l}\text { Poco } \\
\text { Eficiente }\end{array}$ & 19 & 0,24 & 20 & 0,20 \\
\hline Eficiente & 0 & 0 & 5 & 0,05 \\
\hline Total & 80 & 1 & 101 & 1 \\
\hline Media & \multicolumn{2}{|c|}{50.8} & \multicolumn{2}{|c|}{60.5} \\
\hline $\begin{array}{l}\text { Desviación } \\
\text { estándar }\end{array}$ & \multicolumn{2}{|c|}{17.8} & \multicolumn{2}{|c|}{25.3} \\
\hline & \multicolumn{4}{|c|}{ Postest } \\
\hline
\end{tabular}

\begin{tabular}{lcccc}
$\begin{array}{l}\text { Nada } \\
\text { Eficiente }\end{array}$ & 39 & 0,49 & 20 & 0,20 \\
$\begin{array}{l}\text { Poco } \\
\text { Eficiente }\end{array}$ & 34 & 0,43 & 36 & 0,36 \\
$\begin{array}{l}\text { Eficiente } \\
\quad \text { Total }\end{array}$ & 6 & 0,08 & 45 & 0,44 \\
\hline $\begin{array}{l}\text { Media } \\
\text { Desviación } \\
\text { estándar }\end{array}$ & & 1 & 101 & 1 \\
\hline \hline
\end{tabular}

Nota: Test aplicado a los estudiantes Fuente: elaboración propia

En la tabla 1 se han codificado en tres categorías la percepción sobre responsabilidad universitaria: nada eficiente, poco eficiente y eficiente; debido a que el tipo de estudio de la investigación es explicativo, del modo que los 5 ítems considerados en las encuestas nos reflejan cómo son percibidos las actividades que realiza la UNASAM, a través de sus miembros, como el caso de sus docentes y estudiantes universitarios.

Los resultados del Pretest muestran que los estudiantes del grupo de control el $76 \%$ se encuentra Nada eficiente, el $24 \%$ Poco eficiente, y el $0.0 \%$ se encuentran eficiente. Mientras que los estudiantes del grupo experimental, el $75 \%$ se encuentra nada eficiente, el $20 \%$ poco eficiente y el $5 \%$ se encuentra eficiente.

En cuanto a los resultados del Postest, muestran que los estudiantes del grupo de control el $49 \%$ se encuentra nada eficiente, el $43 \%$ Poco eficiente, y el $8 \%$ se encuentraeficiente. En cuanto a los estudiantes del grupo experimental el $20 \%$ se encuentra nada eficiente, el $36 \%$ en poco eficiente, y el $44 \%$ se encuentra eficiente.

Cerna, L., Brito, C., Nivin, L. y Taramona, L. (2020). Proyectos de aprendizaje-servicio en el marco de la Responsabilidad Social Universitaria en las Instituciones Educativas rurales del distrito de Independencia, Huaraz, Perú. RIDAS, Revista Iberoamericana de Aprendizaje Servicio, 9, 43-61. 
Figura 1. Responsabilidad Social Universitaria

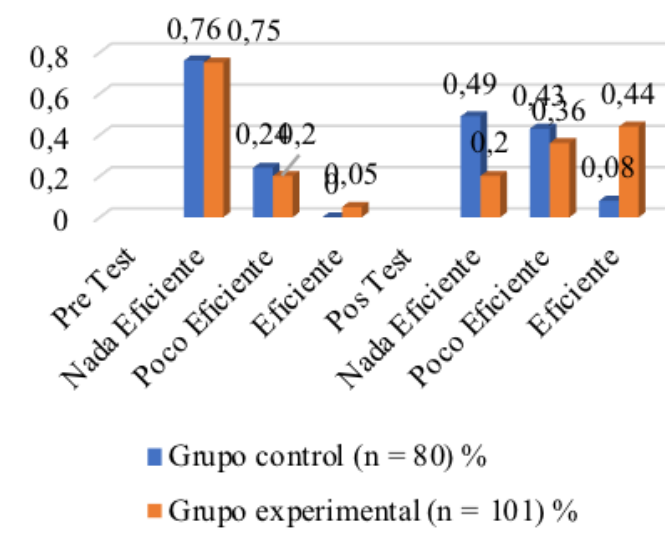

Nota: Instrumento de medición de los estudiantes

Fuente: elaboración propia

Estos resultados nos reflejan el grado de intervención que debe tener la UNASAM en su ámbito social, para el caso de la investigación se refleja que un $44 \%$ de los encuestados del grupo experimental en el post test manifiesta que los proyectos ejecutados son muestra de la labor que debería realizar las Instituciones de nivel universitario con las comunidades de su entorno, entonces solo así hablaríamos del vínculo Universidad-Sociedad, del mismo modo sería importante considerar proyectos interdisciplinarios y a largo plazo que nos refleje el impacto de los mismos en las comunidades atendidas.

\subsubsection{Variable Independiente: 02}

Tabla 2. Proyectos de aprendizaje-servicio. Instrumento de medición de estudiantes de las instituciones educativas rurales del distrito de Independencia - Huaraz, 2016

\begin{tabular}{|c|c|c|c|c|}
\hline \multirow[t]{2}{*}{ Indicador } & \multicolumn{2}{|c|}{$\begin{array}{c}\text { Grupo } \\
\text { control } \\
(\mathbf{n}=\mathbf{8 0})\end{array}$} & \multicolumn{2}{|c|}{$\begin{array}{c}\text { Grupo } \\
\text { experimental } \\
(n=101)\end{array}$} \\
\hline & $\mathbf{n}$ & $\%$ & $\mathbf{N}$ & $\%$ \\
\hline & \multicolumn{4}{|c|}{ Pretest } \\
\hline Negativa & 48 & 0.6 & 73 & 0.72 \\
\hline Positiva & 24 & 0.3 & 19 & 0.19 \\
\hline Muy Positiva & 8 & 0.1 & 9 & 0.09 \\
\hline Total & 80 & 1 & 101 & 1 \\
\hline Media & \multicolumn{2}{|c|}{36.8} & \multicolumn{2}{|c|}{56.8} \\
\hline \multirow[t]{2}{*}{$\begin{array}{l}\text { Desviación } \\
\text { estándar }\end{array}$} & \multicolumn{2}{|c|}{14.4} & \multicolumn{2}{|c|}{25.7} \\
\hline & \multicolumn{4}{|c|}{ Postest } \\
\hline Negativa & 38 & 0.47 & 25 & 0.25 \\
\hline Positiva & 23 & 0.29 & 49 & 0.49 \\
\hline Muy Positiva & 19 & 0.24 & 27 & 0.26 \\
\hline Total & 80 & 100 & 010 & 1 \\
\hline Media & \multicolumn{2}{|c|}{29} & \multicolumn{2}{|c|}{37.3} \\
\hline $\begin{array}{l}\text { Desviación } \\
\text { estándar }\end{array}$ & \multicolumn{2}{|c|}{8.2} & \multicolumn{2}{|c|}{11.2} \\
\hline
\end{tabular}

Los ítems relacionados a esta variable nos reflejan cómo la aplicación de proyectos de aprendizaje-servicio han sido determinantes en el fortalecimiento de los aprendizajes de los estudiantes participes y beneficiarios del proyecto. Esta situación nos permite determinar las necesidades educativas a atender para intervenir con acciones que contribuyan a la calidad educativa.

Los resultados del Pretest, muestran que de los estudiantes del grupo de control, el $60 \%$ se encuentra en negativo, el $30 \%$ en positivo y el $8 \%$ en muy positivo. Respecto a los estudiantes del grupo experimental, el $72 \%$ se encuentra en negativo, el $19 \%$

Cerna, L., Brito, C., Nivin, L. y Taramona, L. (2020). Proyectos de aprendizaje-servicio en el marco de la Responsabilidad Social Universitaria en las Instituciones Educativas rurales del distrito de Independencia, Huaraz, Perú. RIDAS, Revista Iberoamericana de Aprendizaje Servicio, 9, 43-61. DOI10.1344/RIDAS2020.9.3 
en positivo, y el $9 \%$ en muy positivo.

Por otra parte, los resultados del

Postest muestran que, de los

estudiantes del grupo de control, el

$47 \%$ se encuentran en negativo, el

$29 \%$ en positivo y el $24 \%$ en muy

positivo; mientras que de los

estudiantes del grupo experimental el

$25 \%$ se encuentra en negativo, el $49 \%$

en positivo, y el $26 \%$ en muy positivo.

Figura 2. Ejecución de Proyectos de Aprendizaje

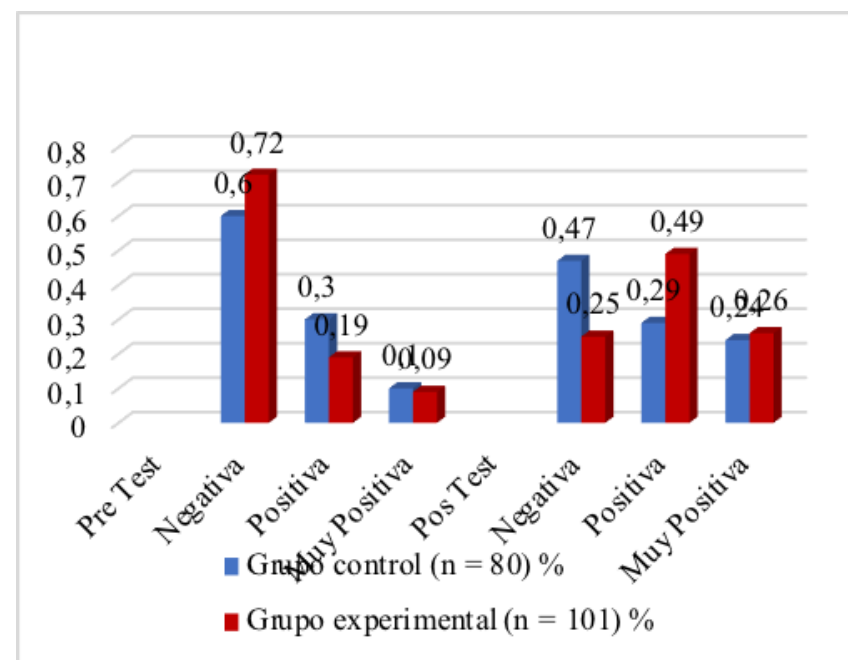

Nota: Instrumento de medición de los estudiantes

Fuente: elaboración propia

Los resultados para esta variable se presentan sobre la calificación de Negativa, Positiva y muy Positiva hacia la ejecución de proyectos que atiendan y respondan a las necesidades de aprendizaje. Es aquí que, en el postest, el $49 \%$ y $26 \%$ de los estudiantes encuestados del grupo experimental manifiestan una aceptación positiva y muy positiva ante la realización conjunta de los proyectos de aprendizaje-servicio en sus
Instituciones Educativas.

\subsubsection{Dimensión: 01}

Tabla 3. Aprendizaje-servicio en el ámbito educativo. Instrumento de medición de estudiantes de las instituciones educativas rurales del distrito de Independencia - Huaraz, 2016

\begin{tabular}{|c|c|c|c|c|}
\hline \multirow[t]{2}{*}{ Indicador } & \multicolumn{2}{|c|}{$\begin{array}{c}\text { Grupo } \\
\text { control } \\
(n=80)\end{array}$} & \multicolumn{2}{|c|}{$\begin{array}{c}\text { Grupo } \\
\text { experimental (n } \\
=101)\end{array}$} \\
\hline & $\mathbf{n}$ & $\%$ & $\mathbf{n}$ & $\%$ \\
\hline & \multicolumn{4}{|c|}{ Pretest } \\
\hline Negativo & 54 & 0,68 & 66 & 0,65 \\
\hline Positivo & 23 & 0,29 & 24 & 0,25 \\
\hline Muy Positivo & 2 & 0,03 & 10 & 0,1 \\
\hline Total & 80 & 1 & 101 & 1 \\
\hline Media & \multicolumn{2}{|c|}{43,8} & \multicolumn{2}{|c|}{49,7} \\
\hline \multirow[t]{2}{*}{$\begin{array}{l}\text { Desviación } \\
\text { estándar }\end{array}$} & \multicolumn{2}{|c|}{15,8} & \multicolumn{2}{|c|}{22} \\
\hline & \multicolumn{4}{|c|}{ Postest } \\
\hline Negativo & 41,6 & 0,52 & 20 & 0,20 \\
\hline Positivo & 23,2 & 0,29 & 20 & 0,20 \\
\hline Muy Positivo & 15,2 & 0,19 & 61 & 0,60 \\
\hline Total & 80 & 1 & 101 & 1 \\
\hline Media & \multicolumn{2}{|c|}{31,2} & \multicolumn{2}{|c|}{44,4} \\
\hline $\begin{array}{c}\text { Desviación } \\
\text { estándar }\end{array}$ & \multicolumn{2}{|c|}{11,2} & \multicolumn{2}{|c|}{19,9} \\
\hline
\end{tabular}

Nota: Test aplicado a los estudiantes Fuente: elaboración propia

Respecto a los resultados de la tabla 3, esta manifiesta que los 6 ítems relacionados a la dimensión sobre el aprendizaje-servicio en el ámbito educativo muestra que las actividades programadas en el proyecto se vincularon a los aprendizajes que debería desarrollar los estudiantes en función a su nivel y grado de estudios considerando a su vez el uso de los materiales educativos adecuados. 
Los resultados del Pretest muestran que, del grupo de control, el $68 \%$ de los estudiantes se encuentra en negativo, el $29 \%$ en positivo y el $3 \%$ en muy positivo. Mientras que, de los estudiantes del grupo experimental, el $65 \%$ se encuentra en negativo, el $25 \%$ en positivo y el $1 \%$ en muy positivo.

Asimismo, los resultados del Postest muestran que, de los estudiantes del grupo de control, el $52 \%$ se encuentra en negativo, el $29 \%$ en positivo, y el $19 \%$ en muy positivo. Mientras que, de los estudiantes del grupo experimental, el $20 \%$ se encuentra en negativo, el $20 \%$ en positivo, y el $60 \%$ en muy positivo.

Figura 3. Aprendizaje-servicio en el ámbito educativo

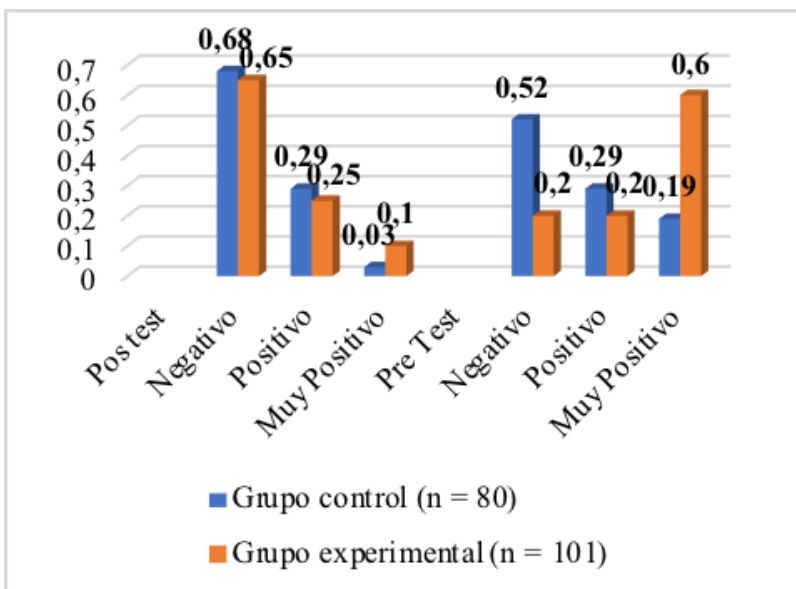

Nota: Instrumento de medición de los estudiantes

Fuente: elaboración propia a la participación de todos miembros involucrados en el proyecto, han sido muy positiva, reconociendo que han contribuido a fortalecer los aprendizajes y se ha respondido a la atención de la necesidades educativas encontradas.

\subsubsection{Dimensión: 02}

Tabla 4. Metodología de proyectos de aprendizaje-servicio. Instrumento de medición de estudiantes de las instituciones educativas rurales del distrito de Independencia - Huaraz, 2016

\begin{tabular}{|c|c|c|c|c|}
\hline \multirow[t]{2}{*}{ Indicador } & \multicolumn{2}{|c|}{$\begin{array}{c}\text { Grupo } \\
\text { control } \\
(\mathbf{n}=\mathbf{8 0})\end{array}$} & \multicolumn{2}{|c|}{$\begin{array}{c}\text { Grupo } \\
\text { experimental } \\
(n=101)\end{array}$} \\
\hline & $\mathbf{n}$ & $\%$ & $\mathbf{N}$ & $\%$ \\
\hline & \multicolumn{4}{|c|}{ Pretest } \\
\hline Negativo & 46 & 0,57 & 66 & 0,65 \\
\hline Positivo & 30 & 0,38 & 30 & 0,30 \\
\hline Muy Positivo & 4 & 0,05 & 5 & 0,05 \\
\hline Total & 80 & 1 & 101 & 1 \\
\hline Media & \multicolumn{2}{|c|}{37,7} & \multicolumn{2}{|c|}{52} \\
\hline \multirow[t]{2}{*}{$\begin{array}{l}\text { Desviación } \\
\text { estándar }\end{array}$} & \multicolumn{2}{|c|}{2.5} & \multicolumn{2}{|c|}{2.8} \\
\hline & \multicolumn{4}{|c|}{ Postest } \\
\hline Negativo & 39 & 0,48 & 25 & 0,25 \\
\hline Positivo & 26 & 0,33 & 15 & 0,15 \\
\hline Muy Positivo & 15 & 0,19 & 61 & 0,6 \\
\hline Total & 80 & 1 & 101 & 1 \\
\hline Media & \multicolumn{2}{|c|}{30,3} & \multicolumn{2}{|c|}{44,9} \\
\hline $\begin{array}{c}\text { Desviación } \\
\text { estándar }\end{array}$ & \multicolumn{2}{|c|}{9,3} & \multicolumn{2}{|c|}{19,5} \\
\hline
\end{tabular}

Nota: Test aplicado a los estudiantes Fuente: elaboración propia

Para conocer los resultados de esta dimensión ha sido necesario determinar qué áreas de la educación básica regular deberían ser atendidas en las Instituciones Educativas del grupo
En la figura 3 se muestra que el $60 \%$ de los estudiantes del grupo experimental indican que las actividades vinculadas a desarrollar habilidades sociales, a la relación entre los aprendizajes y servicio comunitario,
Cerna, L., Brito, C., Nivin, L. y Taramona, L. (2020). Proyectos de aprendizaje-servicio en el marco de la Responsabilidad Social Universitaria en las Instituciones Educativas rurales del distrito de Independencia, Huaraz, Perú. RIDAS, Revista Iberoamericana de Aprendizaje Servicio, 9, 43-61. DOI10.1344/RIDAS2020.9.3 


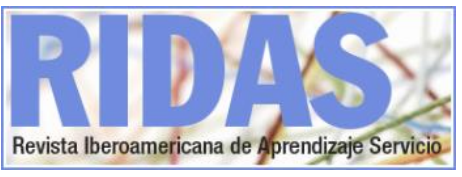

experimental, a través de la ejecución de proyectos de aprendizaje-servicio que respondan a las necesidades educativas existentes. Así, se trabajó con el apoyo de estudiantes universitarios y con el trabajo directo de los docentes universitarios en las aulas de nivel primario. Asimismo, es necesario recalcar que esta metodología convierte en protagonistas a los miembros de la comunidad universitaria como a los estudiantes de educación primaria.

Los resultados del pretest muestran que, de los estudiantes del grupo de control, el $57 \%$ se encuentra en negativo, el $38 \%$ en positivo y el $5 \%$ se encuentra en muy positivo. En cuanto a los estudiantes del grupo experimental, el $65 \%$ se encuentra en negativo, el $30 \%$ en positivo, y el $5 \%$ en muy positivo.

Por otro lado, los resultados del postest, muestran que de los estudiantes del grupo de control, el $48 \%$ se encuentran en negativo, el $33 \%$ se encuentran en positivo, y el $19 \%$ se encuentran en muy positivo; mientras que, de los estudiantes del grupo experimental, el $25 \%$ se encuentra en negativo, el $15 \%$ en positivo, y el $60 \%$ se encuentra en muy positivo.
Figura 4. Metodología de proyectos de aprendizaje-servicio

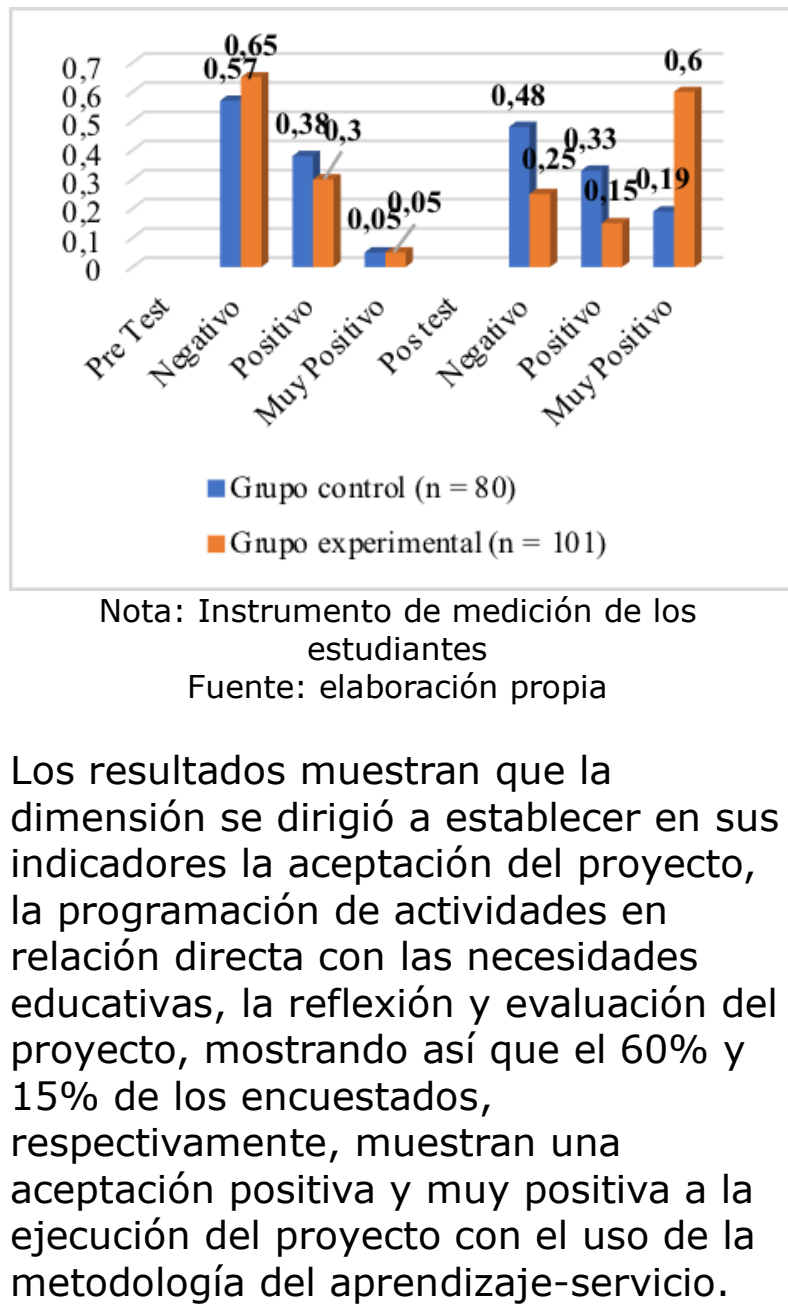

\subsubsection{Prueba de hipótesis}

La contrastación de algunas hipótesis se probó mediante la prueba de comparación de medias para muestras relacionadas. Para ello, se utilizó la prueba t-Student si. En ambos grupos se cumple el supuesto de normalidad, caso contrario se utilizó la prueba Wilcoxon si no se cumple el supuesto de normalidad en uno o ambos grupos. 
Tabla 5. Prueba de normalidad de los datos

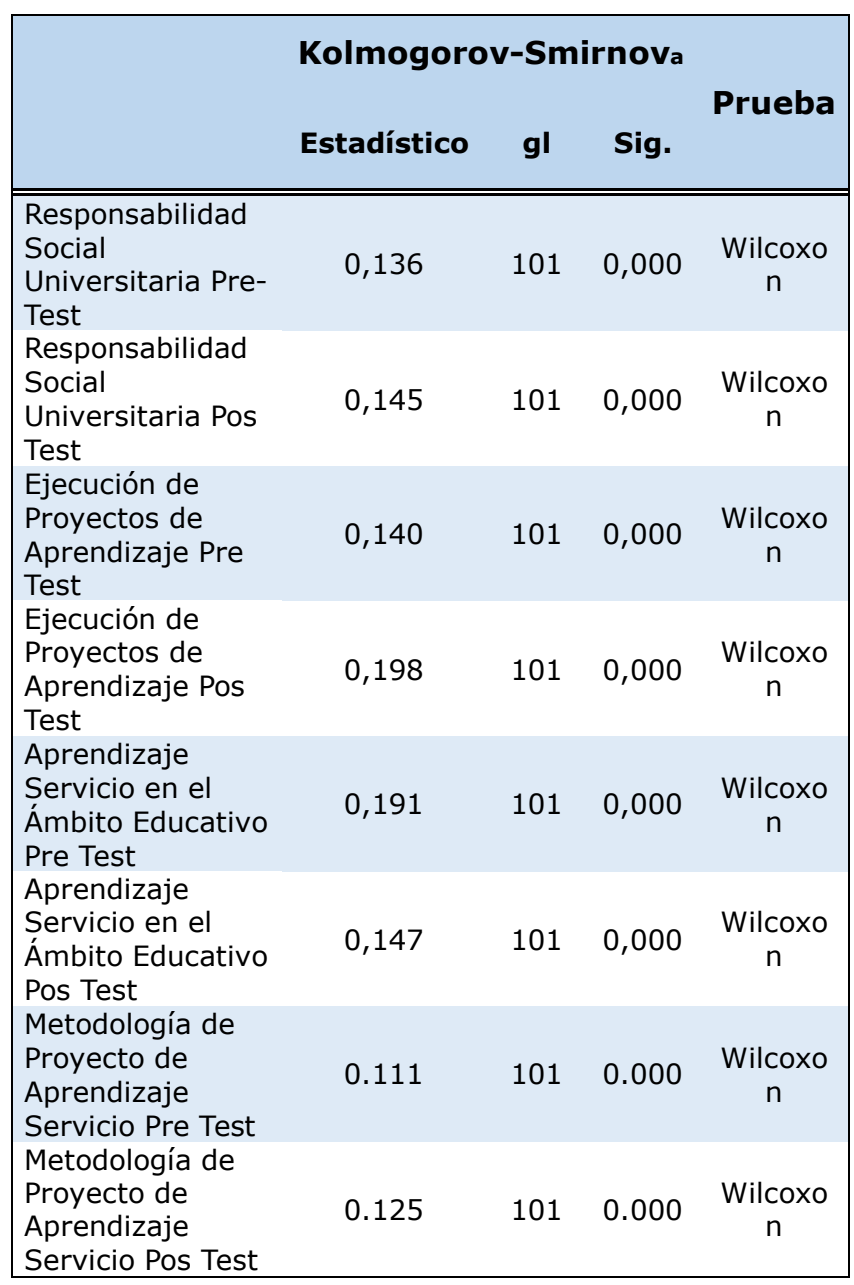

Nota: Base de datos

Fuente: elaboración propia

\subsubsection{Hipótesis general}

I. Hipótesis de Investigación

Demostrar el nivel de incidencia de la aplicación de proyectos de aprendizajeservicio en el marco de la responsabilidad social universitaria en las instituciones educativas rurales del distrito de Independencia de la ciudad de Huaraz en el año 2016.
II. Hipótesis Estadística

- Ho: La no incidencia de la aplicación de proyectos de aprendizaje servicio en el marco de la responsabilidad social universitaria en las instituciones educativas rurales del distrito de Independencia - Huaraz, 2016.

- H1: La incidencia de la aplicación de proyectos de aprendizajeservicio en el marco de la responsabilidad social universitaria en las instituciones educativas rurales del distrito de Independencia - Huaraz, 2016

- Nivel de Significación: El nivel de significación teórica es $\alpha=0.05$, que corresponde a un nivel de confiabilidad del 95\%.

\section{Función de Prueba}

Se realizó por medio de la prueba no paramétrica Wilcoxon para el pretest y la prueba no paramétrica Wilcoxon para el postest (ver tabla 5).

\section{Regla de decisión}

- Rechazar Ho cuando la significación observada " $p$ " de los coeficientes del modelo logístico es menor que $\alpha$.

- No rechazar Ho cuando la significación observada " $p$ " de los coeficientes del modelo logístico es mayor que $\alpha$. 


\section{Cálculos}

Tabla 6. Prueba de comparación de medias para muestras dependientes

\begin{tabular}{ccc}
\hline Test & Indicador & Resultado \\
\hline \multirow{3}{*}{ Pretest } & Wilcoxon & 8.235 \\
& Z & 2.54 \\
& Sig. asintótica (bilateral) & .979 \\
\hline \multirow{3}{*}{ Postest } & Wilcoxon & 7.000 \\
& Z & 5.314 \\
& Sig. asintótica (bilateral) & .000 \\
\hline \multicolumn{3}{c}{ Nota: Base de datos } \\
& Fuente: elaboración propia
\end{tabular}

En la tabla 6 se observa la no incidencia de la aplicación de proyectos de aprendizaje-servicio en el marco de la responsabilidad social universitaria en las instituciones educativas rurales del distrito de Independencia - Huaraz 2016, entre el grupo de control y experimental en el pretest, mientras que si existen diferencias significativas en la Incidencia de la aplicación de proyectos de aprendizaje-servicio en el marco de la responsabilidad social universitaria en las instituciones educativas rurales del distrito de Independencia - Huaraz, 2016, entre el grupo de control y experimental en el postest teniendo mayor ventaja los estudiantes del grupo experimental.

\section{Conclusión}

Como el valor de significación observada en el postest $\mathbf{p}=0.000$ es menor al valor de significación teórica $\alpha=0.05$, se rechaza la hipótesis nula. Ello significa que si hay incidencia de la aplicación de proyectos de aprendizajeservicio en el marco de la responsabilidad social universitaria en las instituciones educativas rurales del distrito de Independencia - Huaraz,
2016. Por lo tanto, se acepta la hipótesis general de investigación.

\section{Discusión}

El objetivo principal de nuestra investigación se dirige a establecer la incidencia de la aplicación de proyectos de aprendizaje-servicio en el marco de la responsabilidad social universitaria en las instituciones educativas rurales del distrito de Independencia. En este contexto, entendemos este marco como las dimensiones que impactan en la gestión de una institución y la normatividad existente, en función a resaltar que, la gestión de la responsabilidad social universitaria, está dirigida a fomentar acciones comunitarias que involucre a la investigación y la formación académica, generando espacios de participación activa de los miembros de la comunidad universitaria y atendiendo necesidades más reales y existentes en nuestro entorno social.

Los resultados muestran que el $44 \%$ de los encuestados y beneficiarios indica que la responsabilidad social universitaria es eficiente, debido a que se pudo realizar un previo diagnóstico de las necesidades educativas reales a atender relacionado con el fortalecimiento de aprendizajes en matemática, comunicación, ciudadanía y arte, se evidenció trabajos de otras carreras profesionales en estas zonas rurales, la coordinación entre Instituciones y sobre todo el involucramiento directo de docentes universitarios, cómo el apoyo de los estudiantes universitarios; aspectos que abren el camino a garantizar la preocupación de la universidad por 
sectores con necesidades educativas que no son circunstanciales o que solo se promueven por iniciativas académicas o exigencias institucionales.

Respecto a nuestros problemas y objetivos específicos, se considera como el primero, que la formulación de proyectos de aprendizaje-servicio en el ámbito educativo mejora las prácticas de responsabilidad social universitaria en beneficio de las instituciones educativas rurales del distrito de Independencia, si bien los resultados nos muestran un $15 \%$ y $60 \%$ de aceptación de los encuestados como positivo y muy positivo, la pregunta va hacia cómo estamos realizando el trabajo comunitario y que debería ser considerado responsabilidad social, proyección social o extensión universitaria. En tal caso, el adoptar una metodología que se acerce más a establecer un mejor vínculo entre los aprendizajes generados en la UNASAM y su aplicación en comunidades, nos lleva a confluir que este trabajo muestra un aporte en las Instituciones Educativas de nivel primario atendidas, responde más a los requerimientos hoy exigidos en la universidad peruana bajo el enfoque de la responsabilidad social universitaria. Asimismo nos permitió reconocer que la continuidad de la intervención consolidará el impacto que exige este tipo de prácticas.

En relación a nuestro segundo problema y objetivo específico sobre si la aplicación de la metodología de proyectos de aprendizaje-servicio contribuyo en las dimensiones de la responsabilidad social universitaria en las instituciones educativas rurales del distrito de Independencia. Cabe mencionar que las dimensiones de la responsabilidad social universitaria nacen de los impactos de una gestión socialmente responsable de la Universidad, generando cambios en la organización, formación académica, la producción y difusión del saber y la participación social (Del Castillo y Yamada, 2008). A partir de estas dimensiones se generaron indicadores e ítems que permitan conocer la percepción de los beneficiarios, considerando que no se trata de únicamente de los actores ejecutores de actividades y proyectos (miembro de comunidad universitaria) sino también de quienes perciben el servicio que ofrecemos, con un trabajo conjunto e interinstitucional.

En este aspecto, muestran los resultados que el $60 \%$ de los beneficiarios manifiesta un rango muy positivo hacia que la UNASAM muestra su presencia con la atención y preocupación a los problemas educativos, que podrían existir en las instituciones educativas, consideremos así el antecedente que otros proyectos y actividades se han generado en la zona atendida, dato que permite que nuestras actividades plasmadas en proyectos de aprendizaje-servicio hayan sido viables y bien recibidas, a esto se debe considerar que han existido condiciones y espacios que surgen en todo proyecto; cómo los mutuos acuerdos, la integración a las actividades de aprendizaje, los recursos utilizados, los tiempos, ambientes requeridos y sobre todo la generación de convenios interinstitucionales para la atención de nuevas problemáticas y el seguimiento de la atención de las

\footnotetext{
Cerna, L., Brito, C., Nivin, L. y Taramona, L. (2020). Proyectos de aprendizaje-servicio en el marco de la Responsabilidad Social Universitaria en las Instituciones Educativas rurales del distrito de Independencia, Huaraz, Perú. RIDAS, Revista Iberoamericana de Aprendizaje Servicio, 9, 43-61. DOI10.1344/RIDAS2020.9.3
} 
problemáticas existentes.

Los resultados contribuyen a mostrar que la aplicación de proyectos que involucren los contenidos académicos y el servicio a la comunidad pueden contribuir a conseguir el involucramiento y atención de problemas, necesidades y requerimientos acordes a los servicios académicos que puede prestar la UNASAM, por tanto los resultados de aprendizaje son importantes porque suponen concebir la universidad como un espacio de aprendizaje ético, lo cual implica la necesidad de definir estrategias y propuestas formativas que lo hagan posible más allá de las declaraciones de intenciones en documentos institucionales (Martínez, 2010).

En este sentido, reconocidos especialistas en responsabilidad social universitaria señalan el aprendizaje basado en proyectos sociales o aprendizaje servicio como propuesta formativa que expresa y materializa su dimensión docente (Vallaeys, De La Cruz y Sasia, 2009), tal alcance fomenta que sea el docente quien tome la iniciativa para desarrollar prácticas educativas en comunidades, dónde pueda aportar desde su ejercicio profesional y formar a estudiantes universitarios que tomen iniciativas para generar proyectos acordes a necesidades más reales y evidentes de su propio entorno.

\section{Conclusiones}

La aplicación de proyectos de aprendizaje servicio, con la participación de estudiantes y docentes universitarios en la orientación y ejecución de actividades garantizan los aprendizajes académicos relacionados con el servicio comunitario, respondiendo a las necesidades educativas reales en las instituciones educativas rurales del distrito de Independencia, dentro del marco de la responsabilidad social universitaria, generando nexos interinstitucionales.

La formulación de proyectos de aprendizaje-servicio en el ámbito educativo, según el diagnóstico realizado en las instituciones educativas permitió fomentar las habilidades sociales, fortaleciendo la autoestima, el trabajo en equipo y utilizando materiales acorde al área y al grado de estudios lo que contribuyó a mejorar las prácticas de responsabilidad social universitaria.

La aplicación de la metodología de proyectos de aprendizaje-servicio permitió desarrollar actividades en las áreas de comunicación, matemática, ciudadanía y arte aportando a las dimensiones de la responsabilidad social universitaria en las instituciones educativas rurales del distrito de Independencia.

\section{Referencias bibliográficas}

Ander-Egg, E. y Aguilar, M. (1996.) Cómo elaborar un proyecto. Guía para diseñar proyectos sociales y culturales. Buenos Aires, Argentina: Lumen/Humanitas.

Cecchi, N. (Abril de 2006). Aprendizaje Servicio en Educación Superior. La experiencia latinoamericana.

Presentación llevada a cabo en el

Cerna, L., Brito, C., Nivin, L. y Taramona, L. (2020). Proyectos de aprendizaje-servicio en el marco de la Responsabilidad Social Universitaria en las Instituciones Educativas rurales del distrito de Independencia, Huaraz, Perú. RIDAS, Revista Iberoamericana de Aprendizaje Servicio, 9, 43-61. DOI10.1344/RIDAS2020.9.3 
Seminario Internacional

Responsabilidad Social Universitaria:

Aprendizaje Servicio. Caracas,

Venezuela. Recuperado de

http://www.ucv.ve/uploads/media/AS_e

n_ES_Nestor_Horacio_Cecchi.pdf

Del Castillo, E. y Yamada, G. (2008).

Responsabilidad social y buen clima

laboral: Una fórmula ganadora.

Recuperado de

https://www.researchgate.net/publicati

on/242693173_Responsabilidad_social_

y_buen_clima_laboral_Una_formula_ga nadora

Furco, A. (2005). Impacto de los proyectos de aprendizaje servicio. Aprendizaje y servicio solidario en la Educación Superior y en los sistemes educativos latinoamericanos. Actas del 70 Seminario Internacional Aprendizaje y Servicio Solidario, Buenos Aires (Argentina), 19-26. Recuperado de http://www.ucv.ve/fileadmin/user_uplo ad/facultad_ciencias_juridicas/cservicio cominitario/AprendizajeyservicioenlaEd ucacionSuperior_y_en_sistemaseducati voslatinoamericanos.pdf

Martínez, M. (Ed.). (2010). Aprendizaje Servicio y Responsabilidad Social de las Universidades. Barcelona, España:

Octaedro.

Puig, J. M. (2009). Aprendizaje servicio (ApS): educación y compromiso cívico. Barcelona, España: Graó.

Puig, J. y Palos, J. (2006). Rasgos pedagógicos del aprendizaje-servicio. Cuadernos de Pedagogía, 357, 60-63. Recuperado de https://roserbatlle.files.wordpress.com/ 2009/03/rasgos-pedagogicos.pdf
Tapia, M. N. (2006). Aprendizaje y servicio solidario en el sistema educativo y las organizaciones juveniles. Buenos Aires, Argentina: Ciudad Nueva.

Vallaeys, F. (2009). La Responsabilidad Social Universitaria: ¿Cómo entenderla para querer practicarla? . Recuperado de https://www.academia.edu/21125213/L A_RESPONSABILIDAD_SOCIAL_UNIVER SITARIA_C\%C3\%93MO_ENTENDERLA_ PARA_QUERERLA_Y_PRACTICARLA

Vallaeys, F., De La Cruz, C. y Sasia, P. (2009). La responsabilidad Social Universitaria. Manual de primeros pasos. Ciudad de México, México: McGraw Hill. Recuperado de https://publications.iadb.org/es/publica cion/14191/responsabilidad-socialuniversitaria-manual-de-primerospasos

\footnotetext{
Cerna, L., Brito, C., Nivin, L. y Taramona, L. (2020). Proyectos de aprendizaje-servicio en el marco de la Responsabilidad Social Universitaria en las Instituciones Educativas rurales del distrito de Independencia, Huaraz, Perú. RIDAS, Revista Iberoamericana de Aprendizaje Servicio, 9, 43-61. DOI10.1344/RIDAS2020.9.3
} 


\title{
Innovación y aprendizaje-servicio virtual: elementos para una reflexión basada en la experiencia
}

\author{
Juan García-Gutiérrez \\ Marta Ruiz-Corbella \\ Universidad Nacional de Educación a Distancia - UNED, España \\ Araceli del Pozo \\ Universidad Complutense de Madrid, España
}

\section{Resumen}

La innovación constituye una de las claves desde donde leer los desarrollos pedagógicos contemporáneos. En esta dirección, nuestro trabajo se aproxima a la noción de aprendizaje-servicio virtual como una modalidad innovadora que posibilita, justamente, la inclusión y el desarrollo de esta metodología en contextos educativos a distancia o virtuales. Concretamente, buscamos una definición basada en la experiencia. Por tanto, trataremos de reflexionar a partir del caso de un proyecto concreto de aprendizaje-servicio virtual sobre qué elementos y qué prácticas conexas ayudan a definir el recorrido de este tipo de proyectos. Consideramos que este tipo de aproximación y reflexión basada en la experiencia podría servir, además, para identificar aspectos que permitan y hagan posible su replicabilidad en otros contextos.

\section{Palabras clave}

Innovación, aprendizaje-servicio virtual, tecnologías digitales, ciudadanía global. 


\title{
Innovation and virtual service-learning: key elements for experience-based reflection
}

\begin{abstract}
Innovation is undoubtedly one of the key factors in assessing the best contemporary pedagogical outcomes. Our paper approaches the notion of virtual learning-service as an innovative modality that allows the inclusion and development of this methodology in distance or virtual educational environments. Specifically, we seek to provide a definition based on experience that also serves to identify elements and practices that allow others to start in this particular modality of service-learning. Therefore, we try to reflect on what elements and related practices help to define the development of this type of project. We believe that this reflexive approach would allow us to conceptualize the experience in a specific project of virtual learning-service and identify the key elements that would allow for replication in other contexts.
\end{abstract}

\section{Keywords}

Innovation, virtual service-learning, digital technologies, global citizenship. 


\section{El aprendizaje-servicio (en)clave de innovación en Europa}

La innovación educativa en la enseñanza superior es una de las líneas de investigación que, de forma interdisciplinar, más ha crecido y diversificado en las últimas fechas. La proliferación de congresos, jornadas así como los proyectos de investigación e innovación dedicados a esta intervención en las universidades reflejan este interés. Durante los últimos años, la investigación en innovación se ha convertido en una de las señas de identidad de las mejores instituciones de educación superior del mundo, lo que muestra un cambio en la mentalidad pedagógica institucional, producto de los ajustes y transformaciones que ha introducido en nuestro contexto europeo, especialmente a partir de la puesta en marcha del Espacio Europeo de Educación Superior.

En efecto, el proceso de Bolonia inaugura una etapa pedagógica nueva en la educación superior europea y también española. Cierto que no faltan críticas a sus planteamientos y que, para algunos, ha supuesto una cierta decadencia o universitaria (Llovet, 2011). Sin embargo, incluso aquellos más críticos, reconocerán que uno de los aspectos positivos de Bolonia pasa por haber situado la educación superior en el centro de la preocupación pedagógica y política. Si bien esta preocupación ha sido una constante en el tiempo, con Bolonia se renuevan las expectativas $y$, con ello, también la reflexión sobre su carácter educativo y

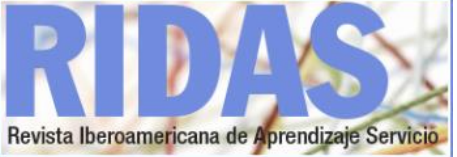

su necesaria implicación en la sociedad, su responsabilidad, lo que deriva en el conocimiento de la particular misión de aquellas instituciones donde se imparte (Esteban y Román, 2016).

Que la educación superior atienda a un complejo conjunto de competencias, reflejando así la globalidad del fenómeno educativo, lleva parejo la reflexión sobre el sentido y alcance de los elementos éticos y cívicos en los aprendizajes. Aunque para algunos este hecho significa cierta infantilización ${ }_{1}$ de las instituciones de educación superior (Furedi, 2018), desde nuestro punto de vista consideramos que la preocupación por esos elementos éticos y cívicos, que forman parte misma del fenómeno educativo, no quedan resueltos definitivamente o limitados a los niveles educativos inferiores al universitario. La educación sigue siendo tal, con independencia de la modalidad y del nivel educativo de que se trate.

Aunque, precisamente será la modalidad y el nivel educativo lo que permita ajustar y modular sus finalidades, contenidos, metodologías, etc.

Los políticos también han sabido ver en nuestras universidades como centros de innovación y creación de conocimiento, claves para una economía del conocimiento. Esta idea quedaba fijada en la Estrategia de Lisboa del 2000 y que posteriormente ha ido actualizándose de acuerdo al contexto cambiante en la política de esta región. Como es sabido, la estrategia de Lisboa

1 Tal y como reflejan también algunos titulares en prensa: "Universitarios poco adultos" (La Vanguardia, 2015).

García-Gutiérrez, J.; Ruiz-Corbella, M. y del Pozo, A. (2020). Innovación y aprendizaje-servicio virtual: elementos para una reflexión basada en la experiencia. RIDAS, Revista Iberoamericana de Aprendizaje Servicio, 9, 62-80. DOI10.1344/RIDAS2020.9.4 
apuntaba a hacer de la UE la economía basada en el conocimiento más competitiva y dinámica del mundo, capaz de crecer económicamente de manera sostenible con más y mejores empleos y con mayor cohesión social (Consejo Europeo, 2000). Ahora bien, tras la crisis económica de 2008, y con vistas a salir de ella de la mejor forma posible, la Unión Europea lanzaría en 2010 una visión renovada pero con una formulación muy similar. El objetivo se dirigió a que una Europa 2020 supondría una estrategia que ayude a salir fortalecidos de la crisis y convierta a la UE en una economía inteligente, sostenible e integradora que disfrute de altos niveles de empleo, de productividad y de cohesión social (Comisión Europea, 2010).

Esta visión de la economía del conocimiento ha puesto a los centros universitarios en el punto de mira de la estrategia político-económica de la UE y de los países miembros. Por ejemplo, la estrategia para la internacionalización de las Universidades españolas, del Ministerio de Educación, Cultura y Deporte (2015), abundaba en este planteamiento:

El conocimiento, es decir, la educación, la investigación y la innovación, se ha convertido en un importante motor de crecimiento y prosperidad, dada su capacidad para crear valor económico en el marco de un nuevo modelo de desarrollo socioeconómico basado en la inversión en capital humano y bienes intangibles [...] en este nuevo contexto la universidad está llamada a jugar un papel fundamental en cuanto que proveedora de capital humano cualificado, generadora de nuevo conocimiento y transmisora del existente, al ámbito productivo (p.14).

En cierta forma, con el Proceso de Bolonia se ha revitalizado y actualizado el debate entre los partidarios de una educación liberal y aquellos defensores de una educación vocacional; entre los defensores del papel que las humanidades pueden jugar en la construcción de la propia personalidad y la sociedad democrática y la necesidad de que los centros universitarios impulsen la innovación y la empleabilidad de los estudiantes. Ahora bien, actualmente no cabe considerar de forma antagónica estas posiciones sino que es preciso encontrar vías de conciliación y sinergia. Tan importante es formar a los estudiantes para saber conducirse en su vida personal, como para desarrollar con éxito una trayectoria profesional. Por tanto, no cabe decantarse a favor de una u otra posición sin poner en riesgo a la propia persona, en su identidad y proyecto vital. La búsqueda de una vida más plena conforme a las propias convicciones y un desarrollo profesional exitoso no deberían ser excluyentes.

Desde esta perspectiva, consideramos que el aprendizaje-servicio constituye no sólo una metodología innovadora sino una filosofía educativa que junto a otras modalidades como la investigación basada en la comunidad (Munck, McIlrath, Budd y Tandon, 2014) nos ayuda a comprender mejor la complejidad y riqueza del fenómeno educativo desde una posición 
integradora. Si tuviéramos que preguntamos el porqué del éxito del aprendizaje-servicio en las instituciones universitarias del contexto europeo, identificaríamos tres tipos de razones que, a la vez, nos ayudan a desmenuzar la complejidad actual por la que atraviesa la educación superior.

- En primer lugar, el aprendizajeservicio responde a la necesidad de encontrar y poner en marcha metodologías innovadoras que respondan a las demandas y postulados del Espacio Europeo de Educación Superior. La centralidad del estudiante, la promoción de aprendizajes activos y prácticos frente a clases magistrales, etc. constituyen buenas razones para indagar qué metodologías pueden adaptarse mejor a estos postulados.

- En segundo lugar, nos encontramos con la necesidad de profundizar y reforzar los aprendizajes éticos y cívicos en la educación superior (Bergan y Damian, 2010). En efecto, se constata desde hace décadas la solidez del movimiento por el compromiso cívico en la educación superior (Hartley, Saltmarsh y Clayton, 2010; McIlrath, 2015; Watson, Hollister, Stroud y Babcock, 2011), algo que también ha calado institucionalmente en el contexto europeo, como podemos comprobar por las recientes propuestas de la propia Comisión Europea. Así en la Comunicación de la Comisión titulada Sobre una agenda renovada de la UE para la educación superior de 2017 ( Comisión Europea, 2017) se dice que la Unión analiza:
"[...] la educación superior desempeña un papel único [...] para contrarrestar la creciente polarización de nuestra sociedad y la desconfianza hacia las instituciones democráticas, cada uno de nosotros, incluidos el personal y los estudiantes de educación superior, debemos comprometernos más activamente con las comunidades que nos rodean y promover la inclusión social y la movilidad (...) y que las instituciones de educación superior no sean torres de marfil, sino comunidades de aprendizaje con conciencia cívica conectadas a sus comunidades (párr.2).

- En tercer lugar, y fruto de las dos anteriores, encontramos la necesidad de las propias instituciones de educación superior por comunicarse y relacionarse con su entorno, desde un enfoque de responsabilidad social (Martínez, 2008). Preocupación constante por desarrollar ese carácter formativo, cívico y ético, y no únicamente profesionalizante, lo que exige "[...] una formación de todas las capacidades humanas, la promoción cultural, el desarrollo económico, técnico- 
científico, la consolidación de una ciudadanía democrática, con la misión de alcanzar, en definitiva, una sociedad con rostro humano" (Naval y Ruiz-Corbella, 2012, p.112).

Desde este horizonte, el aprendizajeservicio conduce a una valoración compleja del hecho educativo universitario sin reduccionismos y con una voluntad integradora. Una respuesta excelente a las demandas académicas, sociales y políticas que hoy vive la universidad y que lo han conducido a una importante expansión a lo largo de la geografía europea pero también en países y entornos culturales muy diversos. Expansión ya muy consolidada en Estados Unidos, Canadá y Latinoamérica, que han influido en la rápida extensión de esta metodología en universidades europeas, africanas y asiáticas. Prueba de ello fue la celebración del primer Congreso Europeo de Aprendizaje-Servicio en la Educación Superior (Madrid, 2018) donde se puso de manifiesto la gran apertura y recepción de esta metodología en nuestra región europea (de hecho, esta expansión europea del aprendizaje-servicio ya había comenzado con la celebración en 2016 y en 2017 del Congreso de la IARSLCE en Bolonia y en Galway, respectivamente).

A la extensión geográfica y cultural se suma también la puesta en marcha de modalidades novedosas en el desarrollo de los proyectos de aprendizajeservicio, atendiendo una característica de la educación de nuestro tiempo, que no cabe entenderla sin las tecnologías de la información y la comunicación, que abren escenarios digitales, cada vez más interconectados, en los que debemos disponer de los conocimientos y competencias necesarias para encontrar maneras de conectar redes, intereses y habilidades tanto en contextos online como offline, de tal modo que todo individuo pueda actuar e interaccionar en ellos como contextos de oportunidad.

\section{Modalidades innovadoras para el desarrollo del aprendizaje-servicio}

Para facilitar un acercamiento más completo al aprendizaje-servicio virtual es preciso detenernos, brevemente, en observar algunos elementos facilitadores y prácticas conexas de la educación digital. Aquellos elementos que favorecen el surgimiento de esta modalidad virtual son las tecnologías de la información y la comunicación y los dispositivos portátiles e inteligentes, precisamente, los mismos que están vinculados al crecimiento de esta educación virtual. Mientras que entre las prácticas conexas al aprendizajeservicio virtual cabría incluir, por ejemplo, el aprendizaje-servicio internacional o los proyectos de aprendizaje-servicio global.

\subsection{Aprendizaje-servicio internacional y aprendizaje-servicio global}

Desde la óptica del aprendizajeservicio, los proyectos pueden adoptar diversas modalidades según el énfasis o las características que se acentúen en cada uno de ellos. Tanto en la modalidad internacional como global, el aprendizaje-servicio articula y presta atención a la dimensión internacional 
de los aprendizajes, ya sea en clave transnacional o desarrollando las nociones de ciudadanía mundial y responsabilidad global. Sin embargo, la opción por una u otra modalidad no supone merma alguna en los elementos o rasgos esenciales que identifican los proyectos aprendizaje-servicio. Estamos ante la misma metodología ofrecida y desarrollada en contextos y con intencionalidades educativas diferentes.

Concretamente, a partir de estas modalidades podemos afirmar dos cosas. La primera, que la existencia de modalidades no supone algo distinto del aprendizaje-servicio tradicional, pero sí suponen un algo más, ya que acentúan una determinada característica, bien en el aprendizaje o bien en el servicio. Paradójicamente, la segunda cosa que puede decirse es que estas modalidades también ayudan a cuestionar pedagógicamente algunas nociones básicas del aprendizajeservicio tradicional. Por ejemplo, en estos casos, la noción de cercanía en la relación con la comunidad.

Como sucede con el aprendizajeservicio tradicional, estas modalidades también podría confundirse con acciones similares en las que la prestación de un servicio o el aprendizaje cuentan con ese componente internacional. Así, si ponemos el acento en la idea de servicio internacional podemos encontrar múltiples acciones que podrían asemejarse al aprendizajeservicio internacional. Entre otras, podemos encontrar las siguientes: la cooperación internacional, la cooperación universitaria para el desarrollo; el voluntariado internacional o el más reciente turismo solidario y sostenible. Si nos detenemos en analizar este tipo de acciones solidarias, que subrayan la dimensión internacional de la ayuda podemos encontrar algunas características comunes con el aprendizaje-servicio internacional. Por ejemplo, la cooperación internacional constituye un canal ya institucionalizado por el que los Estados ayudan a otros países, integrándose en la política exterior de los países que comprende todo un conjunto de acciones orientadas a la lucha contra la pobreza, el progreso humano sostenible y el mantenimiento de la paz. La cooperación universitaria al desarrollo, por su parte, constituye "una actividad diferenciada de otras orientadas de modo general a la internacionalización de la Universidad o a la cooperación internacional entre Universidades" (CRUE, 2006, p.4) que puede definirse, según el Código de conducta de las universidades en materia de cooperación internacional, como:
"el conjunto de actividades llevadas a cabo por la comunidad universitaria y orientadas a la transformación social en los países más desfavorecidos, en pro de la paz, la equidad, el desarrollo humano y la sostenibilidad medioambiental en el mundo, transformación en la que el fortalecimiento institucional y académico tienen un importante papel" (p.4).

Y, además, en la que la cooperación "enriquece humana y académicamente a las personas que participan en ella" (CRUE, 2006,p.4). 
Otra acción similar a las anteriores es el voluntariado internacional que, atendiendo a la cooperación al desarrollo, se distingue por no estar en manos del Estado, sino de organizaciones de la sociedad civil y de las organizaciones no gubernamentales. Esto ha interesado especialmente al ámbito universitario, que ha desarrollado este tipo de propuestas. Se trata de un voluntariado que se realiza fuera del país, colaborando y ayudando a organizaciones en muchos casos vinculadas a los sectores donde se realizan los estudios (educación, medicina, ingeniería, etc.).

Un movimiento novedoso que trata de establecer una sinergia entra las acciones de cooperación y voluntariado con el turismo es el turismo solidario. Esta actuación es recogida, por ejemplo, por la Agencia de Naciones Unidas para los refugiados (ACNUR), quien lo define en su propia web2 como una modalidad que conjuga el placer y la diversión del viaje, asociándolo a proyectos de cooperación. Se pretende que los turistas no sean meros espectadores de la realidad del lugar sino que se involucren de alguna manera que resulte beneficiosa para la población local. Esas características pueden ser compartidas tanto por las acciones anteriores como por el propio aprendizaje-servicio internacional:

- Sostenibilidad económica y ambiental. Este tipo de acciones, realizadas principalmente en

\footnotetext{
2 "Turismo solidario y sostenible: ¿qué ventajas tiene?" Disponible en:

https://eacnur.org/blog/turismo-solidariosostenible-ventajas/
}

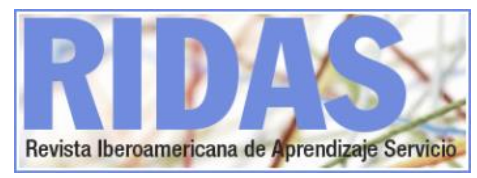

países en vías de desarrollo, tratan de tener un mínimo impacto ambiental, cuidando los entornos autóctonos.

- Promueve valores como el respeto, el cuidado y la justicia social. Quienes participan de estas acciones solidarias y sostenibles desarrollan conciencia mayor de las necesidades y dificultades que atraviesan las comunidades y los habitantes de otros países, ya que han convivido de cerca con sus necesidades. Se adquiere una mirada socialmente más sensible y responsable también al retornar al lugar de procedencia.

Tras lo dicho hasta ahora, podemos entender el aprendizaje-servicio internacional como una modalidad de aprendizaje-servicio donde la prestación del servicio se realiza en un país diferente al país donde se cursan los estudios, tratando de dar respuesta solidaria a las necesidades de una comunidad en un país distinto al que se cursan estudios. Lo relevante es cómo se establece la integración del servicio internacional dentro del plan de estudios. En esta modalidad es importante tener en cuenta el tiempo que durará la experiencia internacional, ya que es necesario contar con un tiempo razonable para que una experiencia de este tipo tenga sentido. $A$ la vez que exige una continuidad sostenible en el tiempo, mientras se alcanza el objetivo propuesto de cada proyecto.

Por tanto, una de las intenciones del 
aprendizaje-servicio internacional es abrir la mente al desarrollo de una responsabilidad global y hacer propios los problemas que tienen lugar más allá de las propias fronteras. Se busca es reforzar un sentido de ciudadanía global, responsabilidad y dialogo intercultural al conocer y permanecer inmerso durante un tiempo en una cultura distinta a la propia.

El límite más importante para este tipo de modalidad reside en la inseguridad de algunos países y en la financiación. Un ejemplo de este tipo de modalidad suele ser la salida de estudiantes de medicina, enfermería, educación, arquitectura o ingenierías a países en vías de desarrollo, donde pueden poner en práctica sus conocimientos desde el enfoque del aprendizaje-servicio o la investigación basada en la comunidad.

Por su parte, el aprendizaje-servicio global constituye, según Hastman y Kiely (como se citó en Morrinson, 2015):

"una experiencia de servicio impulsada por la comunidad que emplea prácticas estructuradas, críticas y reflexivas para comprender mejor la dignidad humana común; a uno mismo; la cultura; el posicionamiento; los problemas socioeconómicos, políticos y ambientales; las relaciones de poder y la responsabilidad social y todo en contextos globales [...] algo que ayuda a los estudiantes a aumentar la competencia intercultural, analizar suposiciones estructurales, comprender y reflexionar sobre la globalización y comprometer su imaginación cívica y moral ( $p$. 53).

Por tanto, el aprendizaje-servicio global apunta a la noción de ciudadanía global sin que esta intencionalidad suponga, necesariamente, un desplazamiento a otro país. El estudio de los fenómenos globales y la interdependencia socioambiental hacen de la Universidad un espacio pedagógico idóneo para desarrollar en los estudiantes un compromiso cívico que vaya más allá de visiones localistas y poder formar ciudadanos críticos globales (Larsen, 2014). Esto es, hacer posible a los estudiantes alargar los lazos del compromiso cívico a comunidades geográficamente distantes a la propia, desde la convicción de que aquello que ocurra allá apela también a la responsabilidad propia.

Para la Organización de las Naciones Unidas para la Educación, la Ciencia y la Cultura (UNESCO), tomar conciencia de esta común pertenencia es el elemento fundamental de una ciudadanía global. Esta idea de ciudadanía es la que trata de desarrollar esta perspectiva metodológica, sensibilizando sobre las problemáticas globales (por ejemplo la inmigración y los refugiados o el impacto del plástico en los océanos) y las posibilidades de actuación personal, cada vez más impulsados por los múltiples canales que nos facilitan las tecnologías.

2.2 Tecnologías digitales y aprendizajeservicio

La progresiva aplicación de las

García-Gutiérrez, J.; Ruiz-Corbella, M. y del Pozo, A. (2020). Innovación y aprendizaje-servicio virtual: elementos para una reflexión basada en la experiencia. RIDAS, Revista Iberoamericana de Aprendizaje Servicio, 9, 62-80. DOI10.1344/RIDAS2020.9.4 
tecnologías digitales a los procesos educativos es una constante que favorece tanto la innovación en las instituciones presenciales como la expansión sin precedentes de la educación a distancia y virtual (García Aretio y Ruiz Corbella, 2015). Por tanto, atender a los factores tecnológicos que posibilitan el desarrollo de una modalidad virtual del aprendizajeservicio implica preguntarnos, de alguna manera, por la forma en que las tecnologías digitales pueden intervenir o ser usadas en los proyectos de aprendizaje-servicio.

En efecto, las tecnologías digitales facilitan el desarrollo de los proyectos de aprendizaje-servicio, a la vez que propician el desarrollo de proyectos novedosos que abren paso a nuevas modalidades de aprendizaje-servicio. Esto es, las tecnologías digitales se pueden incluir en los proyectos de manera instrumental porque facilitan y optimizan el desarrollo de los proyectos, pero también pueden ser el objeto central del aprendizaje o del servicio.

Por ejemplo, si creamos una página web para que los estudiantes encuentren información sobre los proyectos y puedan registrarse online en ellos, estamos usando los recursos que nos ofrece la web 2.0 para impulsar proyectos de diversa índole. Ahora bien, si un proyecto se propone la reparación de dispositivos por parte de estudiantes de electrónica en la formación profesional para ofrecerlos a colectivos que los necesitan o cuando un grupo de estudiantes acompañan a personas mayores o personas inmigrantes para capacitarlos en el uso de las tecnologías digitales, como sucede con el programa Conectajoven, comprobamos que las tecnologías no sólo se están usando sino que tienen sentido, y se sitúan en el centro del proyecto al convertirse en canales de comunicación para interactuar entre dos colectivos con un objetivo común.

Como sucede en muchos ámbitos educativos puede resulta difícil diferenciar entre las tecnologías digitales como medios y como objetos de aprendizaje. Sin embargo, los proyectos basados en tecnologías digitales se distinguen por acentuar aquellos tipos de habilidades $y$ competencias que reclama la sociedad del conocimiento $y$, por tanto, prestan especial atención al desarrollo de la competencia digital y a las acciones que sólo pueden tener lugar en el ciberespacio. Los ejemplos anteriores nos muestran de manera sencilla de qué forma las tecnologías pueden enriquecer los proyectos de aprendizaje-servicio.

La inclusión de las tecnologías digitales en los proyectos de aprendizaje-servicio nos permite observar un rango amplio de interacciones, que llegan a identificar tres niveles o modos de interacción entres tecnologías digitales y el aprendizaje-servicio, recogidos en el siguiente cuadro.

3 "Proyecto Conecta joven". Disponible en: https://fundacionesplai.org/socioeducativa/cone cta-joven/

García-Gutiérrez, J.; Ruiz-Corbella, M. y del Pozo, A. (2020). Innovación y aprendizaje-servicio virtual: elementos para una reflexión basada en la experiencia. RIDAS, Revista Iberoamericana de Aprendizaje Servicio, 9, 62-80. DOI10.1344/RIDAS2020.9.4 
Cuadro 1. Niveles de integración tecnológica en los proyectos de aprendizaje-servicio

\begin{tabular}{|c|c|}
\hline $\begin{array}{c}\text { Nivel de } \\
\text { integración de } \\
\text { las tecnologías }\end{array}$ & Contenido \\
\hline $\begin{array}{l}\text { Integración } \\
\text { básica }\end{array}$ & $\begin{array}{l}\text { Las tecnologías digitales se } \\
\text { integran en los proyectos de } \\
\text { aprendizaje-servicio de } \\
\text { manera natural, ya que las } \\
\text { tecnologías facilitan la gestión } \\
\text { del proyecto. La introducción } \\
\text { no se establece con una } \\
\text { intencionalidad educativa sino } \\
\text { puramente instrumental o } \\
\text { facilitadora. }\end{array}$ \\
\hline $\begin{array}{l}\text { Inclusión } \\
\text { intencional }\end{array}$ & $\begin{array}{l}\text { Las tecnologías no sólo se } \\
\text { incluyen porque facilitan el } \\
\text { trabajo o mejoran la } \\
\text { visibilidad de los proyectos, } \\
\text { sino que existe una reflexión } \\
\text { pedagógica particular } \\
\text { tomándolas como objeto } \\
\text { educativo, bien desde la } \\
\text { perspectiva del aprendizaje o } \\
\text { del servicio. }\end{array}$ \\
\hline $\begin{array}{l}\text { Inmersión } \\
\text { tecnológica }\end{array}$ & $\begin{array}{l}\text { Las tecnologías digitales no } \\
\text { sólo están integradas en los } \\
\text { proyectos con una } \\
\text { intencionalidad educativa, } \\
\text { sino que el mismo proyecto se } \\
\text { desarrolla íntegramente en el } \\
\text { ciberespacio, apoyado en } \\
\text { recursos exclusivamente } \\
\text { digitales. Esto es, tanto el } \\
\text { aprendizaje como el servicio } \\
\text { es desarrollado de forma } \\
\text { online. }\end{array}$ \\
\hline
\end{tabular}

Fuente: elaboración propia

Podemos decir que la mayoría de los proyectos se sitúan en los dos primeros niveles. En cuanto facilitadoras, las tecnologías se incluyen en los proyectos de aprendizaje-servicio en tareas de comunicación, búsqueda de información o de creación de contenidos, por ejemplo. Algo que redunda en la mejora de los propios proyectos, la calidad de los aprendizajes y su difusión. Por tanto, las tecnologías se incluyen como parte de la gestión del proyecto pero también puede existir una intencionalidad educativa particular, como se comentaba en los ejemplos iniciales. En este sentido, para que dicha integración sea realmente pedagógica conviene realizar algunas preguntas: ¿de qué modo la incorporación de las tecnologías de la información y la comunicación potencia el aprendizaje curricular?, ¿de qué modo la incorporación de estas tecnologías promueve el protagonismo de los estudiantes para atender a los problemas de su comunidad?, ¿se podrían haber alcanzado los mismos resultados sin la incorporación de estas?, ¿cuál es el valor añadido que aportan las tecnologías de la información y la comunicación a los proyectos de aprendizaje-servicio? (Tapia Sasot, 2012).

En este sentido, cuando la inclusión de las tecnologías digitales cuenta además una intencionalidad educativa emergen diferentes relaciones. Por ejemplo, desde la organización pantallas amigas se ha desarrollado un programa denominado Cibermanagers 4 donde tras un proceso de capacitación los propios estudiantes se convierten en agentes de sensibilización para otros estudiantes y sus familias en materia

4 "Proyectocibermanagers". Disponible en: http://cibermanagers.com 
riesgos y uso seguro y responsable de internet. Como recoge Escofet (2017), los recursos tecnológicos pueden orientarse de diferentes formas: a la comunicación y la colaboración, a la búsqueda de información, hacia la creación de contenidos y para propiciar la reflexión. Para estos fines nos encontramos con recursos diferentes: videoconferencias, chats, foros virtuales, correo electrónico, Facebook, Twitter, wikis, blog, grupos de whatsapp, Drive, Dropbox, mapas conceptuales, infografías, etc.

Desde esta perspectiva, los proyectos de aprendizaje-servicio basados en tecnologías digitales nos permiten, además del desarrollo de las competencias digitales, ofrecer una apropiación ética y cívica de las mismas. En consecuencia, este tipo de proyectos nos permiten impulsar una visión humanista y humanizadora de las tecnologías digitales.

\section{Una noción de aprendizaje- servicio virtual basada en la experiencia}

Desde el horizonte de convergencia que hemos trazado anteriormente entre innovación pedagógica, tecnologías digitales y compromiso cívico se desarrollan los proyectos de aprendizaje-servicio puestos en marcha por el Grupo COETIC5 . A lo largo de los últimos años, han puesto en marcha diferentes proyectos de aprendizajeservicio virtual, entre los que destaca el

\section{Grupo de Innovación Docente para el} Desarrollo de la Competencia Ética y Cívica y las metodologías basadas en la comunidad en la educación superior de la UNED. proyecto Español en vivo6. Además de impulsar un programa específico para los Trabajos Fin de Grado y de Máster desde la investigación basada en la comunidad. Si en otras publicaciones hemos recogido el desarrollo de la experiencia del proyecto Español en vivo y sus resultados de aprendizaje, en este artículo pretendemos iniciar un proceso de reflexión y construcción, desde la experiencia, de la noción de aprendizaje-servicio virtual. Pero para ello es necesaria una breve descripción de nuestro proyecto.

Español en vivo promueve una serie de encuentros virtuales entre estudiantes universitarios españoles y africanos con el objetivo de hablar en castellano. El proyecto arranca con el viaje de una profesora española que se traslada a Benín, donde comienza a dar clases de español en la Escuela Normal Superior de Porto Novo (Benín). Tras compartir su experiencia sobre la situación educativa que se encontró; la falta de recursos pedagógicos de calidad, y la necesidad que manifiestan muchos de sus estudiantes de mejorar su español hablado, surge la idea de desarrollar un proyecto de aprendizaje-servicio que articule esa necesidad de los estudiantes africanos con el desarrollo de las competencias genéricas de los estudiantes españoles. Tras el primer curso, el proyecto se ha ampliado a otras Universidades como son la Universidad de Abomey-Calaví (Benín); Strathmore University (Nairobi, Kenia), y la Universidad de Dschang (Camerún).

6 Sitio web Grupo Coetic: https://www.uned.es/coetic/ 
Los estudiantes españoles están matriculados, en su mayoría, en la Universidad Nacional de Educación a Distancia (UNED) por lo que, desde el principio, el proyecto de aprendizajeservicio contaba con dos limitaciones, en relación con otros proyectos desarrollados en nuestro entorno. De un lado, los estudiantes no estaban todos juntos agrupados en un aula física, sino dispersos por todo el territorio español; de otro, la necesidad del colectivo al que se prestaba el servicio no estaba vinculada a una comunidad cercana. Ahora bien, estas limitaciones constituyen el punto de partida para el desarrollo de los proyectos de aprendizaje-servicio virtual, ya que la distancia (tanto en la agrupación de los estudiantes españoles, como en la relación con la comunidad) es salvada por la introducción de las tecnologías de la información y la comunicación.

Concretamente, el proyecto pretende incidir en el desarrollo de competencias éticas y cívicas de los estudiantes en un contexto educativo a distancia. Pero también, indirectamente, se trata de familiarizar a los estudiantes con la puesta en práctica de metodologías innovadoras, apoyados por las tecnologías digitales. Mostrar cómo aprovechar los entornos virtuales de enseñanza, característicos de la metodología a distancia para favorecer acciones solidarias. Lo que nos lleva a comprender la propuesta de los objetivos vinculados al aprendizaje:

- familiarizar a los estudiantes con el diálogo y la diversidad cultural;
- fomentar el compromiso con la ciudadanía global;

- tomar conciencia del compromiso ético en el desarrollo de la profesión;

- desarrollar la competencia digital y comunicativa.

Por un lado, los estudiantes de la UNED que cursan asignaturas que permiten participar en el proyecto, se encuentran distribuidos por diferentes regiones españolas. Estos cuentan con diferentes tipos de recursos para comunicarse online, lo que facilita una interacción digital que constituye uno de los elementos más relevantes del diseño de un entorno virtual de aprendizaje, que responde, según Mercado Borja, Guarnieri y Rodríguez (2019):

[...] a las diversas y cambiantes demandas de los participantes, a construir y democratizar el conocimiento, impulsar la innovación tecnológica, tributar al desarrollo integral del estudiante y a plantear alternativas de solución a problemáticas concretas desde espacios de discusión que permitan el flujo de conocimientos, ideas o información (p.73).

Se logra un aprendizaje mediado por la tecnología, vinculado a diferentes asignaturas de grado y postgrado, mediante la participación del estudiante y su interacción con los compañeros y los recursos disponibles en la plataforma aLF. Entre estos destacamos la Guía breve del proyecto que ofrece a

García-Gutiérrez, J.; Ruiz-Corbella, M. y del Pozo, A. (2020). Innovación y aprendizaje-servicio virtual: elementos para una reflexión basada en la experiencia. RIDAS, Revista Iberoamericana de Aprendizaje Servicio, 9, 62-80. DOI10.1344/RIDAS2020.9.4 
los participantes información básica para su participación en el proyecto (en qué consiste el aprendizaje-servicio y en qué consiste el propio proyecto, la descripción del servicio y de qué se habla en las entrevistas, plan de trabajo, etc.). Además de la Guía y otros recursos es importante mencionar el papel del foro, pues articula el trabajo colaborativo y las interacciones de los estudiantes a la hora de preparar las entrevistas, resolver dudas, plantear problemas, intercambiar experiencias sobre el proyecto y sus actuaciones. Desde el horizonte virtual que plantea el proyecto estos elementos son fundamentales para generar un clima de confianza y seguridad en las interacciones y en los aprendizajes y su relación con las asignaturas.

Por otra parte, el servicio también se desarrolla íntegramente en el ciberespacio. Esta vez, no es a través de una plataforma de e-learning específica sino mediante los diferentes programas que soportan comunicación online con video y voz (Whatsapp, Skype, etc.). El primer contacto se establece mediante correo electrónico con los coordinadores en las universidades africanas quienes indican al estudiante español el grupo de su universidad que le corresponde. La presencia de un coordinador en cada institución participante ayuda también a generar un ambiente de seguridad y confianza en el ciberespacio, además de facilitar el seguimiento, la reflexión y la evaluación del proyecto.

En suma, los proyectos de aprendizajeservicio virtual ponen en cuestión dos de los rasgos centrales de los proyectos de aprendizaje-servicio tradicionales, como son la cercanía y la presencialidad. Cercanía porque permite expandir la noción de comunidad (en línea con las propuestas del aprendizaje-servicio global o internacional) y presencialidad porque posibilita un contacto personal, pero no necesariamente síncrono y físico. Así, una vez visto que tanto el aprendizaje como el servicio se pueden conducirse íntegramente en el ciberespacio, podemos desarrollar brevemente aquellas características más relevantes que se inducen de la experiencia realizada con el proyecto:

- Creación de espacios de encuentro y confianza. En efecto, en primer lugar es fundamental apuntar a la creación de confianza entre todos los participantes. Los elementos que conforman el proyecto, así como aquellos otros que pudieran incluirse, deben estar orientados desde la perspectiva de los estudiantes, al encuentro y a la creación de espacios de seguridad y confianza online.

- La mediación tecnológica libera a los proyectos de aprendizajeservicio de los condicionamientos temporales y las limitaciones geográficas. Además, con la utilización de internet y dispositivos móviles se introduce la noción de aprendizaje ubicuo en el aprendizaje-servicio. De esta manera se facilita la interacción entre los participantes, dando lugar a formas de comunicación síncrona y asíncrona, diluyendo los espacios y acercando 
comunidades diferentes, incluso alejadas del lugar donde se desarrolla el aprendizaje. En este sentido, cabría la posibilidad de calificar también el aprendizajeservicio virtual como ubicuo, dado que tanto el servicio como el aprendizaje se pueden realizar desde cualquier lugar ya que en ambos casos se pueden desarrollar en el ciberespacio.

- Una tercera característica que observamos en el desarrollo del proyecto desde la modalidad virtual es el carácter solidario y humanizador que adquieren las tecnologías digitales, dado que propician la realización de una experiencia solidaria y humanizadora en el ciberespacio. De un lado, los fines del proyecto atienden al desarrollo de la competencia ética, el compromiso cívico y la ciudadanía global; de otro, la experiencia de la cooperación ya que esta no se limita a la ayuda material, sino que se abre a la solidaridad que se teje también de forma inmaterial.

- Por último, los proyectos de aprendizaje-servicio virtual permiten la inclusión ya que facilitan el acceso este tipo de proyectos innovadores a estudiantes y personas que por alguna razón (personales, familiares, profesionales) no pueden acceder a propuestas que se desarrollan presencialmente. A la vez que la accesibilidad que facilita la educación online permite también a los estudiantes con alguna discapacidad participar en esta modalidad.

Desde esta perspectiva, los proyectos de aprendizaje-servicio pueden adoptar una gran variedad de formatos atendiendo a la variable online, tal y como se recoge en el cuadro siguiente. Denominación que es calificada también por otros autores como aprendizajeservicio extremo (Waldner, McGorry y Widener, 2010).

Cuadro 2. Modalidades de aprendizaje-servicio online

\begin{tabular}{ll}
\hline \multicolumn{1}{c}{$\begin{array}{c}\text { Tipo de } \\
\text { aprendizaje- } \\
\text { servicio }\end{array}$} & \multicolumn{1}{c}{ Características } \\
\hline $\begin{array}{l}\text { Aprendizaje- } \\
\text { servicio } \\
\text { tradicional }\end{array}$ & $\begin{array}{l}\text { En este caso, tanto el } \\
\text { aprendizaje como el } \\
\text { servicio se desarrollan } \\
\text { presencialmente, en un } \\
\text { lugar determinado. }\end{array}$ \\
$\begin{array}{ll}\text { Aprendizaje } \\
\text { online - } \\
\text { servicio } \\
\text { presencial }\end{array}$ & $\begin{array}{l}\text { El aprendizaje se desarrolla } \\
\text { online, a través de un } \\
\text { curso en un espacio virtual } \\
\text { de aprendizaje, mientras } \\
\text { que el servicio se } \\
\text { desarrolla de forma } \\
\text { presencial. }\end{array}$ \\
& \\
$\begin{array}{l}\text { Aprendizaje } \\
\text { presencial - } \\
\text { servicio online }\end{array}$ & $\begin{array}{l}\text { El aprendizaje se desarrolla } \\
\text { de forma tradicional en un } \\
\text { aula mientras que el } \\
\text { servicio se desarrolla de } \\
\text { forma online. }\end{array}$ \\
\hline
\end{tabular}

García-Gutiérrez, J.; Ruiz-Corbella, M. y del Pozo, A. (2020). Innovación y aprendizaje-servicio virtual: elementos para una reflexión basada en la experiencia. RIDAS, Revista Iberoamericana de Aprendizaje Servicio, 9, 62-80. DOI10.1344/RIDAS2020.9.4 
Aprendizaje y servicio se desarrollan digitalmente. El aprendizaje se desarrolla de forma online, a través

Aprendizajeservicio virtual de un curso en un espacio virtual de aprendizaje, mientras que el servicio también se desarrolla de forma online, en el ciberespacio

Fuente: elaboración propia

Por otra parte, si donde ponemos el acento no es tanto en el ciberespacio sino en la noción de lugar (donde se producen los aprendizajes, y donde se realiza el servicio), si problematizamos este elemento de los proyectos de aprendizaje-servicio tradicionales podemos encontrar aun más posibilidades para el desarrollo de los proyectos. En efecto, al problematizar o extender la noción de lugar y cercanía, bien como aprendizaje-servico internacional, global o virtual nos encontramos con un enriquecimiento mayor de las experiencias realizadas por los estudiantes en los proyectos de aprendizaje-servicio (Snider, 2017). Idea que resumimos en la siguiente figura y que muestra las inmensas oportunidades que facilitan las tecnologías digitales a esta metodología.
Figura 1. Coordenadas que orientan la innovación en los proyectos de aprendizajeservicio

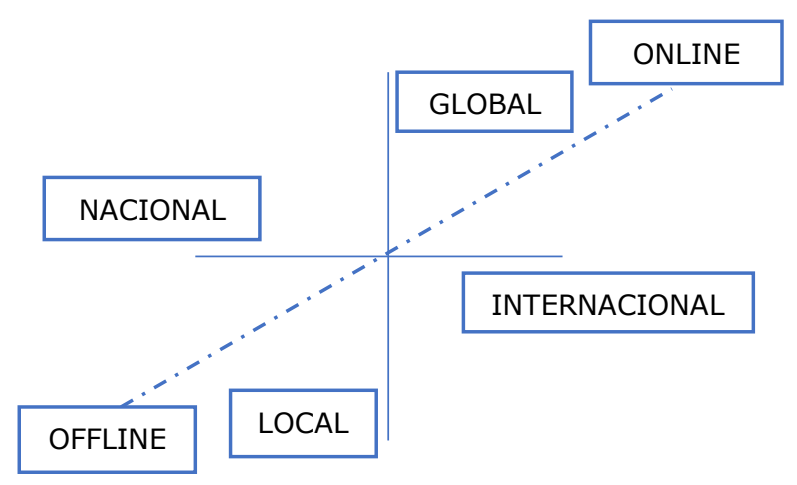

Fuente: elaboración propia

Tal como indicamos al inicio de este artículo, el objetivo de este trabajo era comenzar una reflexión sobre la conceptualización del aprendizajeservicio virtual y sobre el aprendizajeservicio basado en tecnologías digitales. En este punto, avanzamos ya una definición de aprendizaje-servicio virtual como una modalidad para el desarrollo de los proyectos de aprendizaje-servicio basada en internet y las tecnologías digitales, donde el aprendizaje y el servicio se realizan íntegramente en el ciberespacio.

En suma, como destacan diferentes instituciones internacionales, como la UNESCO o los últimos Informes del relator especial de Naciones Unidas sobre el derecho a la educación, es preciso afirmar el derecho a la educación y su sentido humanista frente a la comercialización y su función instrumental (o utilitarista) al servicio del desarrollo económico pero también frente a la creciente digitalización educativa. En efecto, en los citados 
informes, uno sobre la comercialización y otro sobre tecnologías digitales, el Relator recuerda que no debemos perder el carácter humanista de la educación ya sea en los escenarios digitales por presencia de las tecnologías digitales ni por la comercialización, lo que nos obliga a buscar, a hacer visible, esa dimensión humanizadora que deben mostrar las tecnologías digitales, ya que, en definitiva, son las personas las que humanizan todas sus acciones y actuaciones, mientras que "la tecnología es una herramienta, pero todas las herramientas están diseñadas con un propósito en la mente" (Breyfogle, 2018, 59).

\section{Referencias bibliográficas}

Agencia de Naciones Unidas para los refugiados. (Octubre de 2016). Turismo solidario y sostenible. ¿Qué ventajas tiene? [Mensaje en un blog].

Recuperado de https://eacnur.org/blog/turismosolidario-sostenible-ventajas/

Bergan, S. y Damian, R. (2010). Higher education for modern societies: competences and values. Strasbourg, France: Council of Europe Publishing.

Breyfogle, T. (2018). La tecnología como un medio para el progreso. En Aspen Institute España, Tech \& Society Un foro para pensar sobre el futuro de la sociedad tecnológica (pp.55-62). Madrid, España: Fundación Telefónica.

Comisión Europea. (2010). Comunicación de la Comisión. EUROPA 2020:Una estrategia para un crecimiento inteligente, sostenible e integrador. Bruselas: Comisión Europea. Recuperado de https://eurlex.europa.eu/legalcontent/ES/TXT/?uri=celex:52010DC20 20

Comisión Europea. (2017). Comunicación de la Comisión al Parlamento Europeo, al Consejo, al Comité Económico y Social Europeo y al Comité de las Regiones sobre una agenda renovada de la UE para la educación superior. Bruselas: Comisión Europea. Recuperado de https://eurlex.europa.eu/legalcontent/ES/TXT/HTML/?uri=CELEX:520 17DC0247\&from $=\mathrm{EN}$

Consejo Europeo. (2000). Sesión especial para acordar un nuevo objetivo estratégico de la Unión a fin de reforzar el empleo, la reforma económica y la cohesión social como parte de una economía basada en el conocimiento. Conclusiones de la Presidencia. Lisboa: Consejo Europeo de Lisboa.

Ministerio de Educación, Cultura y Deporte. (2015). Estrategia para la Internacionalización de las Universidades Españolas 2015-2020. Recuperado de: https://sede.educacion.gob.es/publiven $\mathrm{ta} / \mathrm{d} / 21475 / 19 / 1$

CRUE. (2006). Código de conducta de las Universidades en materia de cooperación al desarrollo. Recuperado de

http://ocud.es/es/files/doc512/codigoco nducta.pdf

Escofet, A. (2017). Aprenentatge servei i tecnologies digitals. Disponible en: https://www.fbofill.cat/publicacions/apr

García-Gutiérrez, J.; Ruiz-Corbella, M. y del Pozo, A. (2020). Innovación y aprendizaje-servicio virtual: elementos para una reflexión basada en la experiencia. RIDAS, Revista Iberoamericana de Aprendizaje Servicio, 9, 62-80. DOI10.1344/RIDAS2020.9.4 
enentatge-servei-i-tecnologies-digitals

Esteban, F. y Román, B. (2016). ¿Quo vadis, Universidad?. Barcelona, España: Universitad Oberta Cataluña (UOC).

Furedi, F. (2018). Qué le está pasando a la universidad. Un análisis sociológico de su infantilización. Madrid, España: Narcea.

García Aretio, L. y Ruiz Corbella, M. (2015). Educación a distancia, la perspectiva de la universidad en una sociedad en red: Una perspectiva desde las regiones de América Latina, El Caribe y América del Norte. Revista Española de Educación Comparada, 26, 11-14. Recuperado de http://revistas.uned.es/index.php/REEC /article/view/15819/13771

Hartley, M., Saltmarsh, J., y Clayton, P. (2010). Is The Civic Engagement Movement Changing Higher Education?. British Journal of Educational Studies, 58(4), 391-406. Doi:

$10.1080 / 00071005.2010 .527660$

Larsen, M. A. (2014). Critical Global Citizenship and International Service Learning: A case Studiy of the intensification Effect. Journal of Global Citizenship \& Equity Education, 4(1), 143. Recuperado de http://journals.sfu.ca/jgcee/index.php/j gcee/article/view/112/151

Llovet, J. (2011). Adiós a la universidad. El eclipse de las humanidades. Madrid, España: Galaxia Gutenberg.

Martínez, M. (Ed.). (2008). Aprendizaje Servicio y Responsabilidad Social de las
Universidades. Barcelona, España: Octaedro.

McIlrath, L. (2015). La Universidad cívica ¿un vacío legal y político?. Profesorado. Revista de currículum y formación del profesorado, 19(1), 2640. Recuperado de https://recyt.fecyt.es/index.php/profes orado/article/view/41020/23310

Mercado Borja, W., Guarnieri, G. y Rodríguez, G. (2019). Análisis y evaluación de procesos de interactividad en entornos virtuales de aprendizaje. Trilogía Ciencia, Tecnología y Sociedad, 11(20), 63-99.

doi: $10.22430 / 21457778.1213$

Morrison, E. (2015). How the I Shapes the Eye:The Imperative of Reflexivity in Global Service-Learning Qualitative Research. Michigan Journal of Community Service Learning, 22, 5266. Recuperado de https://quod.lib.umich.edu/cgi/p/pod/d od-idx/how-the-i-shapes-the-eye-theimperative-ofreflexivity.pdf?c $=$ mjcsl;idno $=3239521.0$ 022.105; format $=$ pdf

Naval, C. y Ruiz-Corbella, M. (2012). Aproximación a la responsabilidad social universitaria: la respuesta de la universidad a la sociedad. Bordón.

Revista de Pedagogía, 64(3), 103-115. Recuperado de https://recyt.fecyt.es/index.php/BORD ON/article/view/22053

Snider, M. (2017). Why 'where' Matters: Exploring the Role of Space in Servicelearning. Michigan Journal of Community Service Learning, 24, 3848. Recuperado de 
https://quod.lib.umich.edu/cgi/p/pod/d od-idx/why-where-matters-exploringthe-role-of-space-inservice.pdf?c $=$ mjcsloa; $i d n o=3239521.0$ 024.104; format $=$ pdf

Tapia Sasot, M. R. (2012). Las TIC en el desarrollo de los proyectos de aprendizaje-servicio. Recuperado de http://www.clayss.org/06_investigacion /jornadas/Libro_II-Jornada-

Investigadores-Aprendizaje-Servicio/CI09_TapiaSasot.pdf

Universitarios poco adultos. (15 de diciembre de 2015). La Vanguardia. Recuperado de https://www.lavanguardia.com/vida/20 151215/30811172390/universitariospoco-adultos.html

Waldner, L., McGorry, S. y Widener, M. (2010). Extreme E-Service Learning (XE-SL): E-Service Learning in the $100 \%$ Online Course. MERLOT Journal of Online Learning and Teaching, 6(4), 839-851. Recuperado de http://jolt.merlot.org/vol6no4/waldner 1210.pdf

Watson, D., Hollister, R., Stroud, S. y Babcock, E. (2011). The engaged University. International Perspectives on Civic Engagement. NY: Routledge. 


\title{
Percepciones del alumnado universitario sobre el aprendizaje-servicio como herramienta para su desarrollo personal y profesional
}

\author{
Virginia Martínez Lozano \\ Rosa Ma Rodríguez Izquierdo \\ María Marco Macarro \\ Beatriz Macías Gómez-Estern \\ Universidad Pablo de Olavide, España
}

\section{Resumen}

El artículo presenta una experiencia de innovación docente desarrollada con metodología de aprendizaje-servicio en el primer curso del Grado de Educación Social de una universidad pública española. La experiencia implica a dos asignaturas llevando a cabo un servicio comunitario en un C.E.I.P. constituido como Comunidad de Aprendizaje en una zona con necesidades de transformación social, con población mayoritaria de etnia gitana. Mostramos los resultados sobre las percepciones de los estudiantes sobre los aprendizajes adquiridos durante la experiencia. Los resultados se han organizado clasificando los aprendizajes percibidos en curricularesprofesionales; sobre la realidad social; y sobre sí mismos. Se analizaron también las valoraciones sobre la metodología empleada. Los datos muestran que el estudiantado destaca especialmente los aprendizajes personales. Concluimos que la metodología empleada es una buena herramienta docente generadora de motivación por el aprendizaje y de futuros profesionales comprometidos.

\section{Palabras clave}

Aprendizaje-servicio, aprendizaje auténtico, identidad profesional, identidad personal, educación superior. 


\title{
University students' perceptions on service-learning as a tool for personal and professional development
}

\begin{abstract}
This article presents a teaching innovation experience developed in the first year of a Social Education Degree at a public university in Spain, using a service-learning methodology. The experience involves two disciplines from this degree program working collaboratively and the results show students' perceptions on the personal and professional skills they acquired. The proposal is based not only on the notion of SL as a tool for the construction of committed and active citizenship, but from the consideration of SL as a methodology able to produce authentic learning, which involves transformations that go much further than cognitive changes and affect students' own personal construction. We have used two sets of students' narratives: a questionnaire about their learning perceptions and another on their reflections throughout the experience. The data shows that students more emphatically refer to personal learning, followed by curricular-professional learning and finally learning about the reality. We also found that evaluation of the experience was mainly positive, pointing especially to the idea of learning by doing. We conclude that the methodology used generates in the students personal and social conceptions that go beyond what is achieved with traditional methodologies, showing that SL can be considered as an optimal teaching methodology to generate motivation for learning and commitment in future professionals.
\end{abstract}

\section{Keywords}

Service-learning, authentic learning, professional identity, personal identity, higher education. 


\section{Aprendizaje-servicio y educación superior, una apuesta para formar profesionales comprometidos}

El programa para la sostenibilidad de la educación superior elaborado por la Unión Europea en 2013 plantea como una de las funciones de la Universidad la de "agente de cambio, catalizador de la acción social y política, así como centro de aprendizaje" (European Union, 2013, p.4). Esta premisa supone uno de los pilares en los que se apoya la experiencia que aquí presentamos donde resaltamos el papel de la universidad como motor social de cambio y transformación, así como formadora de agentes con conocimientos y sensibilidad social.

Sin embargo, entender la universidad en estos términos requiere una reconceptualización de la cultura docente y necesita de la incorporación de nuevos métodos de enseñanza y aprendizaje que se ajusten de una manera más real a las demandas del entorno. Supone provocar un cambio en los diseños y propuestas metodológicas que favorezcan el desarrollo de aprendizajes que vayan más allá del currículum teórico, fomentando competencias específicas y transversales relacionadas con posicionamientos vitales, conocimiento del otro y herramientas de transformación social.

En esta línea la aproximación el proceso de enseñanza-aprendizaje que se trabaja desde la metodología del aprendizaje-servicio se presenta como una opción altamente válida para cumplir de manera global con los objetivos anteriormente expuestos. Esta metodología se entiende como herramienta de formación que integra el servicio a la comunidad con el estudio académico, con el objeto de enriquecer el aprendizaje desde la práctica (McMillan, 2011; MittonKükner, Nelson y Desrochers, 2010; Kolb, 1984). Esta práctica debe generar responsabilidades cívicas en los estudiantes, así como conectar a la universidad con comunidades con necesidades reales, generando cooperación con la sociedad que dará sentido a la responsabilidad social que tiene la universidad como uno de sus principales cometidos (Blázquez y Martínez-Lozano, 2012; Puig, Gijón, Martín y Rubio, 2011). La sociedad, como contraparte, debe servir de herramienta para permitir y obligar a los estudiantes universitarios a la realización de análisis complejos y reales desde sus aprendizajes, a la vez que implicarlos en procesos de transformación y de participación ciudadana.

El aprendizaje-servicio permite romper con el distanciamiento que se interpone entre los estudios universitarios y los problemas reales y cotidianos de las aulas (Korthagen, 2007; Korthagen y Kessels, 2009), contribuyendo a que los y las estudiantes aprendan y crezcan "moralmente mediante la participación activa en experiencias de servicio organizadas inteligentemente de manera que implican conocimientos" (Naval, 2008, p.64).

En esta línea se encuentran también las recomendaciones que propone la Comisión Europea para la

Martínez-Lozano, V., Rodríguez, R., Marco, M., y Macías, B. (2020). Percepciones del alumnado universitario sobre el aprendizaje-servicio como herramienta para su desarrollo personal y profesional. RIDAS, Revista Iberoamericana de Aprendizaje Servicio, 9, 81-101. DOI10.1344/RIDAS2020.9.5 
modernización de la educación superior, en las que expresa que:

[...] hay que confrontar a los estudiantes con problemas que ellos consideren importantes. Tienen que comprometerse con nuevas preguntas que son más amplias que las asignaturas en sí, que tienen relevancia para sus propias vidas y que provocarán una viva participación que va mucho más allá de la simple presentación a evaluaciones o exámenes (European Union, 2013, p.18).

\section{Aprendizaje-servicio como aprendizaje auténtico}

Trabajar con metodologías docentes de aprendizaje-servicio supone introducir en la docencia nuevas formas de aprendizaje donde la práctica comunitaria se convierte en una piedra angular para la formación del estudiante. Podemos decir así que el aprendizaje adquirido en el ejercicio del aprendizaje-servicio es un aprendizaje situado (Lave y Wenger, 1991; Rogoff, 1990) que tiene relación con el contexto en el que se aprende y que puede llevar a la adquisición de aprendizajes auténticos (Meijers y Wardeker, 2003; Simons, 2000; Van Oers, 2005 y 2007). Hablamos de este tipo de aprendizaje cuando es posible implicar en el proceso formativo no sólo aspectos cognitivos relacionados con contenidos, sino también aspectos emocionales que van más allá e implican a la persona como un todo, afectando a su propia construcción identitaria. Esto se consigue introduciendo al alumnado en problemáticas reales a las que debe enfrentarse, con las que debe comprometerse, y sobre las que debe buscar herramientas que le permitan aprehenderla y entenderla, para así poder transformarla desde su propio ámbito profesional. En este sentido, y siguiendo a Wenger (1998), pensamos que el compromiso con el aprendizaje que se está adquiriendo se convierte en pieza clave para la formación de las y los estudiantes universitarios, fomentando su motivación y su aprender a aprender (Van Dijk y Jochems, 2002), todo ello en el proceso de sentir y tomar conciencia de la utilidad de los mismos.

\section{Antecedentes y contextualización de la investigación}

Los antecedentes de esta experiencia provienen de ámbitos diferentes, aunque complementarios. Por una parte, experiencias nacidas en el seno del enfoque teórico-metodológico de la Psicología Socio-Cultural nos aportan una perspectiva que combina actividades de intervención social con docencia universitaria e investigación. Esta propuesta está sostenida sobre unos pilares teóricos que hacen comprender el desarrollo y el aprendizaje desde una visión social y enlazada con la práctica (Vygotski, 1979). Algunas de estas experiencias son La Quinta Dimensión (Cole, 1996; Cole y the Distributed Literacy Consortium, 2006), La Clase Mágica (Macías y Vásquez, 2014 y 2015; Vásquez, 2003), o La Casa de Shere Rom (Lalueza, Crespo, Pallí y Luque, 1999 y 2001; Lalueza, Crespo, Sánchez, Camps y Cazorla, 2004).

Martínez-Lozano, V., Rodríguez, R., Marco, M., y Macías, B. (2020). Percepciones del alumnado universitario sobre el aprendizaje-servicio como herramienta para su desarrollo personal y profesional. RIDAS, Revista Iberoamericana de Aprendizaje Servicio, 9, 81-101. DOI10.1344/RIDAS2020.9.5 
Por otra parte, encontramos también antecedentes en las experiencias universitarias con metodología aprendizaje-servicio. La existencia de una Red Universitaria de AprendizajeServicio, junto con los encuentros anuales que vienen realizándose desde hace ya casi una década, ha posibilitado el contacto con otras experiencias (Rubio, Prats y Gómez, 2013) que nos han inspirado y animado en el diseño de la práctica que aquí se presenta.

Partiendo de estas aportaciones, en el curso 2012-2013 comenzamos en el Grado de Educación Social una experiencia piloto en la que de manera optativa podía cursarse la asignatura de Procesos de Aprendizaje en Contextos no Formales desde la metodología del aprendizaje-servicio. La evaluación de este curso y el análisis de las notas de campo del alumnado nos reveló importantes aportaciones del aprendizaje-servicio en la formación y aprendizaje del alumnado (Macías, Martínez-Lozano y Mateos, 2014; Macías y Vásquez, 2014) que nos llevó a plantearnos la posibilidad de avanzar en el proyecto con nuevas ambiciones e incorporaciones. Continuamos pues con la experiencia de aprendizaje-servicio implantándola ya como metodología única en un proyecto interdisciplinar entre diferentes asignaturas.

Para el desarrollo y seguimiento del proyecto formamos un grupo de estudios de innovación educativa formado por profesorado de diferentes disciplinas. El proyecto se vio respaldado por su inclusión como acción de innovación docente de la universidad. A continuación describimos los detalles del desarrollo del proyecto docente.

\section{Descripción de la experiencia1}

La experiencia que presentamos se ha llevado a cabo con estudiantes del primer semestre de $1^{\circ}$ del Grado de Educación Social de una universidad pública española, durante los cursos 2014-2015 y 2015-2016. Se trata de un proyecto docente interdisciplinar de aprendizaje-servicio en el que se introduce la acción real, en forma de servicio a la comunidad, como estructura articuladora de dos asignaturas: Bases del Funcionamiento Psicológico Humano y Didáctica en Educación Social. Se contaba además con el apoyo de otra asignatura del semestre, Fundamentos de la Antropología, que introducía en sus prácticas herramientas de análisis de la realidad necesarias para la reflexión y el aprendizaje, como son la etnografía $y$, más concretamente, el cuaderno de campo.

En las dos asignaturas matrices, la parte práctica, que habitualmente se cursa en clases diferentes a las de contenido teórico, se sustituyeron por la asistencia y colaboración con un Centro de Educación Infantil y Primaria constituido como Comunidad de

\footnotetext{
1 Esta experiencia es parte del Proyecto $\mathrm{I}+\mathrm{D}+\mathrm{i}$ Ref. EDU2014-55354-R, 2015/2018 titulado Formación Universitaria: Análisis del proceso de aprendizaje y cambio identitario a través del Aprendizaje-Servicio en comunidades de prácticas en contextos de exclusión, subvencionado por el Programa Estatal de Investigación, Desarrollo e Innovación Orientada a los Retos de la Sociedad, Convocatoria 2014. Así mismo forma parte de los Proyectos de Innovación Docente del Plan de Formación de la Universidad Pablo de Olavide, Acción 2.
} 
Aprendizaje y ubicado en una de las zonas con mayores necesidades de transformación social de la provincia de Sevilla. Su población es

mayoritariamente de etnia gitana.

Los objetivos principales de esta experiencia han sido formulados a varios niveles. Por una parte, con respecto a los aprendizajes del alumnado universitario, tratamos de combinar teoría con práctica, buscando aprendizajes auténticos que permitan al alumnado aplicar conceptos teóricos a sus experiencias y, por tanto, que los estudiantes adquieran no sólo destrezas conceptuales sino conocimientos sobre sí mismos y sobre su papel como futuros profesionales de la educación social. Además, perseguimos el aprendizaje de comportamientos y actitudes orientadas al compromiso ético y a la asunción de responsabilidades sociales como ciudadanos que son. Por otra parte, nos planteamos objetivos de investigación, desde los que pretendemos avanzar en el conocimiento y desarrollo teórico sobre los procesos de aprendizaje que tienen lugar a través del uso de la metodología aprendizaje-servicio. En la línea de estos objetivos, desarrollamos actualmente un $\mathrm{I}+\mathrm{D}+\mathrm{i}$ con la Universidad Autónoma de Barcelona. Un tercer bloque de objetivos se refiere al compromiso social institucional de la universidad para con la sociedad, desde el que entendemos fundamental la colaboración con diferentes entidades sociales y educativas, visibilizando el papel de la universidad como institución a la búsqueda de modelos responsables del sostenimiento de una sociedad igualitaria y justa con todos.
En cuanto a la realización de la experiencia, se ha llevado acabo de la siguiente manera: la docencia presencial de enseñanzas básicas (teóricas) son cursadas en el aula en cada asignatura con la salvedad de la primera semana y la última donde en las que a las clases de ambas asignaturas asiste todo el profesorado implicado (en nuestro caso, tres profesoras) con el objeto de abordar aspectos genéricos e introductorios. En la primera se presenta la asignatura, la metodología a seguir, así como algunas estrategias relevantes para la formación universitaria en general como es el trabajo en grupo, el uso del aula virtual, la elaboración de informes, los trabajos científicos o la búsqueda de bibliografía; la última semana se dedica a la organización de uno de los productos del curso (una jornada de presentación de cortometrajes sobre educación y transformación social en los que han estado trabajando durante el semestre). El resto de las clases teóricas corresponden a cada disciplina y en ellas se discute sobre el temario partiendo de lecturas que los estudiantes deben trabajar, y que deben relacionar con ejemplos de su experiencia en el colegio. Las enseñanzas prácticas dirigidas (clases prácticas) se invierten, en parte, en actividades de servicio a la comunidad. Las horas que corresponden a estas enseñanzas (14 por cada asignatura) se computan en conjunto en las dos asignaturas y se liberan 20 horas para la colaboración del estudiante en el colegio. Estas horas se reparten de la siguiente manera: de la semana tercera a la doceava del semestre los estudiantes realizan el servicio 
comunitario asistiendo dos horas por semana al colegio (un total de 10 semanas). En el colegio, los estudiantes se integran en clases interactivas donde el alumnado está dividido en grupos con actividades distintas. En esas clases hay entre tres y cuatro personas adultas (incluyendo al profesorado) de manera que cada una se encargue de llevar a cabo una actividad. Su objetivo es trabajar el aprendizaje colaborativo entre el alumnado al tiempo que ofrecer una enseñanza individualizada, necesidad que surge por la enorme heterogeneidad que existe en la misma clase, debido a la situación de marginalidad que existe en la zona en la que se ubica el colegio. Las 8 horas restantes se dedican a actividades en el aula, en grupos pequeños, donde se abordan aspectos relacionados directamente con su participación en el colegio y con la evaluación de la experiencia y de sus aprendizajes. Para la primera sesión de trabajo sobre el barrio y el colegio contamos con el apoyo de la Residencia Universitaria Flora Tristán, que se constituye como proyecto social de la universidad ubicada en ese barrio y que cuenta con un conocimiento y una experiencia amplia sobre esta realidad (Blanco, Almirón, Blázquez, Fernández y Maguilla, 2015).

Para la evaluación de los estudiantes planteamos la entrega de varios productos, siempre de manera coordinada entre las asignaturas. Los productos son los diarios de campo, el informe final, la elaboración de un cortometraje y un comentario crítico de varios libros. Además, los estudiantes van realizando informes de seguimiento a través de cuestionarios, debates y microrrelatos. El diario consiste en una nota de campo por cada uno de los días que van al colegio donde registran lo que ha pasado en su jornada de dos horas siguiendo un modelo que les facilitamos y que se divide en tres partes: descripción general del escenario físico y social del aula, descripción detallada de las actividades, interacciones y conductas registradas en la misma, y reflexión personal y teórica sobre la sesión. Hemos de señalar en este punto que una de las piezas fundamentales de esta metodología es la reflexión continua sobre y desde la práctica, mediante el empleo de herramientas teóricas, pues, siguiendo a Dewey (1938), entendemos que para un aprendizaje auténtico y significativo es fundamental la reelaboración del material aprendido, especialmente si está vinculado a la actividad real. En el informe teórico se trabajan conjuntamente conceptos relacionados con ambas asignaturas en especial conexión con las prácticas concretas vividas y reflejadas en las notas de campo.

\section{Evaluación de la experiencia de aprendizaje-servicio}

Tras mostrar el desarrollo de la experiencia, pasamos a mostrar los resultados que estamos obteniendo y que arrojan luz sobre la potencialidad del aprendizaje-servicio como estrategia pedagógica docente. Para ello vamos a guiarnos por los objetivos que planteamos al inicio del texto, y que organizados quedan como sigue:

- Analizar las percepciones de los estudiantes sobre el impacto de

Martínez-Lozano, V., Rodríguez, R., Marco, M., y Macías, B. (2020). Percepciones del alumnado universitario sobre el aprendizaje-servicio como herramienta para su desarrollo personal y profesional. RIDAS, Revista Iberoamericana de Aprendizaje Servicio, 9, 81-101. DOI10.1344/RIDAS2020.9.5 
la experiencia docente en la construcción de su rol profesional, los aprendizajes que realizan a nivel social, sobre la realidad cercana y el otro, y especialmente en su desarrollo como personas.

- Explorar la percepción que tienen sobre la transferibilidad de los aprendizajes adquiridos para su futuro profesional.

- Analizar las valoraciones que realizan sobre la metodología del aprendizaje-servicio.

\subsection{Método}

Para responder a los objetivos planteados se han analizado las narraciones que los estudiantes universitarios han ido realizando a lo largo del semestre. Hemos optado por tanto por una metodología de carácter cualitativo en la que se realizaron análisis del discurso mediante la herramienta EnVivo11.

\subsection{Participantes}

Los estudiantes objeto de estudio fueron todos los que cursaron las asignaturas implicadas en el proyecto de innovación descrito durante los cursos 2014-2015 y 2015-2016.

Participaron un total de 124 estudiantes de la titulación de Educación Social de una universidad pública. El $9,7 \%$ son hombres y el $90,3 \%$ mujeres, oscilando sus edades entre los 18 y los 45 años, siendo la media de 20 años.

\subsection{Instrumentos}

Los datos provienen de narraciones generadas por el alumnado en dos momentos diferentes a lo largo del semestre. El primer momento a mitad de curso donde se plantearon preguntas relacionadas con el desarrollo de mismo. Fueron las siguientes:

1. ¿Qué impacto está teniendo la experiencia de aprendizaje-servicio en ti?

\section{2. ¿Qué aprendizajes estás percibiendo?}

3. ¿Ves la conexión de la experiencia con el contenido curricular de las asignaturas que están implicadas en la experiencia? ¿Te está ayudando la experiencia con otras asignaturas que no están implicadas directamente en ella? Explica tus respuestas

4. ¿Para qué crees que está sirviendo tu colaboración en el colegio? ¿Qué crees que estás aportando al colegio a lo largo del semestre?

5. ¿Qué objetivos te planteas más a largo plazo en cuanto a tu aprendizaje?

6. Describe una experiencia que te haya hecho sentir bien. ¿Por qué crees que te hizo sentir bien?

7. Describe una experiencia que te haya hecho sentir mal. ¿Por qué crees que te hizo sentir mal?

8. ¿Qué tres aspectos destacarías de la experiencia de aprendizaje-servicio?

9. ¿Qué tres aspectos mejorarías de esta experiencia de aprendizajeservicio?

10. ¿Qué no te hemos preguntado y

Martínez-Lozano, V., Rodríguez, R., Marco, M., y Macías, B. (2020). Percepciones del alumnado universitario sobre el aprendizaje-servicio como herramienta para su desarrollo personal y profesional. RIDAS, Revista Iberoamericana de Aprendizaje Servicio, 9, 81-101. DOI10.1344/RIDAS2020.9.5 
crees importante incluir en esta valoración?

El segundo momento de recogida fue a fin de curso, en forma de micro-relatos donde se les pedía que describieran su experiencia durante el semestre. Concretamente se solicitaba una reflexión en base a las siguientes cuestiones:

1. Cómo llegué a la universidad.

2. Qué esperaba encontrarme.

3- Cómo he avanzado en este tiempo.

4. Hacia dónde voy y dónde quiero llegar.

\section{Análisis de los datos}

Los datos han sido analizados desde una aproximación interpretativa basada en el análisis de contenido (Flick, 2004; Krippendorff, 2002), apoyándonos en la Teoría Fundamentada de Strauss y Corbin (1990). Para la codificación, en una primera fase, el profesorado implicado en la experiencia hizo una lectura en paralelo de las narraciones, extrayendo categorías de manera intuitiva. Posteriormente se realizó una puesta en común de las categorías extraídas que fueron agrupadas en torno a los objetivos específicos. Así surgieron las primeras etiquetas:

- Percepciones sobre aspectos relacionados con el aprendizaje de competencias profesionales y sobre cómo van adquiriendo y construyendo su identidad profesional.

- Percepción sobre la realidad social, referido a cómo el alumnado percibe el entorno en el que se está relacionando, sus prejuicios o cambios en sus perspectivas. En este caso es especialmente interesante observar las percepciones sobre las desigualdades sociales, los entornos marginales y sobre la población gitana con la que están trabajando.

- Percepciones sobre aspectos relacionados con su identidad personal, cambios referidos a sí mismos y a la manera de definirse.

- Percepciones sobre el modelo formativo basado en aprendizajeservicio frente a modelos más tradicionales de enseñanza. Valoraciones positivas y negativas.

En una siguiente fase codificamos las narraciones del alumnado en cada una de las categorías anteriores recurriendo al software Nvivo11. En este proceso agrupamos además las respuestas de cada categoría en subcategorías, generando etiquetas que nos permitían describir con más precisión las percepciones de los estudiantes. A continuación presentamos la descripción de las respuestas organizada por categorías y subcategorías.

\section{Resultados}

Los resultados se presentan mostrando frecuencias y porcentajes de respuestas arrojadas en cada categoría. Se analizan estos datos mostrando citas

Martínez-Lozano, V., Rodríguez, R., Marco, M., y Macías, B. (2020). Percepciones del alumnado universitario sobre el aprendizaje-servicio como herramienta para su desarrollo personal y profesional. RIDAS, Revista Iberoamericana de Aprendizaje Servicio, 9, 81-101. DOI10.1344/RIDAS2020.9.5 
textuales que los ilustran, utilizando la inicial A para referirnos a los estudiantes, y añadiendo a continuación un número para identificarlos, ej. $A .1$. Empleamos así mismo el número 14 para referirnos al curso 2014-2015 y el número 15 para el 2015-2016. Mostramos a continuación un resumen general de los resultados, para pasar posteriormente a analizarlos desglosados por categorías y subcategorías.

Tabla 1. Frecuencias y porcentajes de las respuestas del alumnado sobre sus percepciones en diferentes aspectos relacionados con la experiencia de aprendizaje-servicio

\begin{tabular}{ccc}
\hline Categorías & Frecuencias & Porcentajes \\
\hline $\begin{array}{c}\text { Adquisición de } \\
\text { competencias } \\
\text { profesionales y del rol } \\
\text { profesional }\end{array}$ & 210 & $33 \%$ \\
$\begin{array}{c}\text { Aprendizajes sobre la } \\
\text { realidad social }\end{array}$ & 155 & $24,30 \%$ \\
$\begin{array}{c}\text { Aprendizajes y } \\
\text { cambios personales } \\
\quad \text { Total }\end{array}$ & 272 & $42,70 \%$ \\
$\begin{array}{c}\text { Valoraciones positivas } \\
\text { del modelo formativo } \\
\text { basado en }\end{array}$ & $\mathbf{6 3 7}$ & $\mathbf{1 0 0 \%}$ \\
$\begin{array}{c}\text { aprendizaje-servicio } \\
\text { Valoraciones }\end{array}$ & 243 & $68,10 \%$ \\
$\begin{array}{c}\text { negativas del modelo } \\
\text { formativo basado en } \\
\text { aprendizaje-servicio }\end{array}$ & 114 & $31,90 \%$ \\
$\quad$\begin{tabular}{l} 
Total \\
\hline
\end{tabular} & $\mathbf{3 5 7}$ & $\mathbf{1 0 0 \%}$ \\
\hline
\end{tabular}

Fuente: elaboración propia

Observando los totales contabilizados se puede apreciar que aparecen 637 afirmaciones relacionadas con adquisiciones de competencias profesionales, aprendizajes sobre la realidad o percepción de cambios personales. Aparecen así mismo 357 valoraciones sobre la metodología empleada, de las cuales la mayor parte corresponde a aspectos positivos sobre esta. Pasamos a continuación a describir en detalle cada una de las categorías, mostrando ejemplos que ilustren cada una de ellas.

\subsection{Percepciones sobre la adquisición} de competencias profesionales y sobre construcción del rol profesional

En la tabla 2 se muestran las frecuencias y los porcentajes de los resultados del aprendizaje en relación con la adquisición de competencias elementales para el desempeño de su profesión, así como en la identificación de aspectos relevantes para la construcción de su identidad profesional.

Tabla 2. Frecuencias y porcentajes de resultados sobre percepciones sobre su identidad profesional declarados por los estudiantes

\begin{tabular}{ccc}
\hline Subcategorías & Frecuencias & Porcentajes \\
\hline $\begin{array}{c}\text { Adquisición de } \\
\text { metodologías, recursos } \\
\text { y estrategias }\end{array}$ & 88 & $41.9 \%$ \\
$\begin{array}{c}\text { Capacidad para } \\
\text { trabajar en equipo }\end{array}$ & 41 & $19.5 \%$ \\
$\begin{array}{c}\text { Descubrimiento del rol } \\
\text { de mediación en } \\
\text { contextos educativos. }\end{array}$ & 21 & $10 \%$ \\
$\begin{array}{c}\text { Conocimiento de } \\
\text { nuevos ámbitos y } \\
\text { nichos profesionales }\end{array}$ & 15 & $7.1 \%$ \\
$\begin{array}{c}\text { Compromiso con la } \\
\text { justicia social }\end{array}$ & 45 & $\mathbf{2 1 . 4 \%}$ \\
\hline Total & $\mathbf{2 1 0}$ & $\mathbf{1 0 0} \%$ \\
\hline
\end{tabular}

Fuente: elaboración propia

Las percepciones sobre los aprendizajes en relación con la dimensión profesional 
aparecen principalmente alrededor de adquisiciones de estrategias

relacionadas con la profesión (41.9\%) y en concreto con el trabajo en grupo $(19.5 \%)$ que hemos destacado por ser la estrategia más destacada. Entre ambos aspectos suman más del $60 \%$ por lo que vemos que dentro de esta categoría es el aspecto que más se destaca. Lo siguiente que aparecen son narraciones en las que aluden a su compromiso con la justicia y la transformación social (21.4\%). Podemos observar además como la experiencia de aprendizaje-servicio también aporta una mejor comprensión del rol mediador del aprendizaje de los profesionales de la educación (10\%), permitiéndoles además el descubrimiento de ámbitos y nichos profesionales para la Educación social (7.1\%). A continuación aportamos algunos ejemplos de los discursos producidos por los estudiantes en este sentido:

- A29.14. "Me he dado cuenta de lo importante que es trabajar en grupo. Es algo que ha estado presente en estas asignaturas, en las profesoras, y que hemos aprendido también en el colegio trabajando con el maestro y otros voluntarios en las comunidades de aprendizaje. Gracias al aprendizajeservicio estoy aprendiendo a trabajar en grupo, a cooperar, a no disgustarme si alguien hace algo distinto a lo que yo pienso que tiene que ser, a coordinarme en el trabajo...".

- A22.14. "He tenido la oportunidad de comprobar las estrategias que funcionan y las que no... No solo haciéndolo, sino observando al maestro. La idea de unir la teoría a la práctica mediante un servicio me entusiasmó porque me hizo darme cuenta de que es así como yo tengo que trabajar desde la educación social".

- A18.14. "La experiencia en el colegio con lo del aprendizajeservicio nos ha completado a todos y nos ha dado una visión amplia de la función imprescindible que tenemos hoy y que tendremos en el futuro como educadores sociales en la sociedad. Somos mediadores de aprendizajes. Ahora entiendo mejor lo que he leído de Freire, eso de la concienciación y la liberación... Antes no me lo hubiera creído, lo vería muy utópico pero he visto que si se puede y es lo que tenemos que hacer los educadores sociales".

- A82.15. "Aún es pronto para saber en qué ámbito me gustaría trabajar pero he descubierto el mundo de la infancia... Ahora no estoy cerrada a trabajar en centros de menores, colegios, y otros lugares donde haya niños o menores".

- A59.14. "No conocía el trabajo con comunidades de aprendizaje... Pensaba que la educación social se dedicaba más a ámbitos no formales. Me ha abierto un mundo de posibilidades nuevas a nivel profesional. Quiero trabajar en desarrollo comunitario pero desde dentro de la escuela...".

- A94.15. "No sabía que existían tantas diferencias y desigualdades... lo que he visto gracias al aprendizaje-servicio no lo conocía. Y ahora sé que mi profesión es para intentar cambiar justo eso. Me siento motivada y comprometida". 
Con estos enunciados mostramos cómo el alumnado implicado en el proyecto adquiere, desde los primeros momentos de su participación, tanto destrezas relacionadas con su futura profesión (trabajo en grupo, metodologías activas, capacidad de mediación), como un acercamiento a ámbitos de trabajo de la misma (menores, desarrollo comunitario), y al tiempo desarrolla actitudes necesarias para su labor profesional, como es en este caso la conciencia de la desigualdad social y la voluntad de minimizar sus efectos, así como un compromiso con la transformación y la justicia social.

\subsection{Percepciones sobre la realidad social}

En esta categoría el alumnado hace referencia a sus aprendizajes y cambios de visión con respecto a la comunidad gitana y al entorno del Polígono Sur, ya que esta zona está enormemente estigmatizada y es considerada como muy peligrosa por gran parte de la población. Son múltiples las expresiones en este sentido (155 menciones de 994).

Tabla 3. Frecuencias y porcentajes de resultados sobre percepciones sobre la realidad social.

\begin{tabular}{ccc}
\hline Subcategorías & Frecuencias & Porcentajes \\
\hline $\begin{array}{c}\text { Estereotipos sobre } \\
\text { la etnia gitana }\end{array}$ & 86 & $55.4 \%$ \\
\hline $\begin{array}{c}\text { Estereotipos sobre } \\
\text { el barrio }\end{array}$ & 69 & $44.5 \%$ \\
\hline Total & $\mathbf{1 5 5}$ & $\mathbf{1 0 0 \%}$ \\
\hline
\end{tabular}

Fuente: elaboración propia
Algunos fragmentos interesantes y elocuentes para ilustrar esta categoría son los que presentamos a continuación:

- A12.14. "He conocido el barrio y he cambiado mucho de los estereotipos negativos que tenía, no todo es malo en el Polígono Sur... hay muchos padres y madres interesados en la educación de sus hijos y eso te llena de alegría y esperanza".

- A84.15. "He aprendido a diferenciar entre las personas de etnia gitana $y$ la marginación... Son dos cosas diferentes. Muchas veces los confundimos pero no es por ser gitanos, es por estar en un barrio de mucha exclusión".

- A59.14. "Personalmente se me han caído muchas ideas preconcebidas que tenía sobre la comunidad gitana, muchos estereotipos... Al principio me dio mucho miedo pensar que tenía que ir allí... Ahora veo que son personas como nosotros y sé distinguir entre la etnia gitana y la exclusión social que son dos cosas distintas..."

Tal y como se puede observar en los tres enunciados presentados, la experiencia de aprendizaje-servicio representa un impacto importante en el cuestionamiento de las ideas previas y los estereotipos sobre el barrio en el que realizan la actividad, sobre la comunidad gitana $y$, en general, sobre los contextos relacionados con la marginación y la exclusión social. Las consideraciones que realizan sobre la separación de cultura gitana y cultura de la marginación constituyen un aspecto enormemente importante

Martínez-Lozano, V., Rodríguez, R., Marco, M., y Macías, B. (2020). Percepciones del alumnado universitario sobre el aprendizaje-servicio como herramienta para su desarrollo personal y profesional. RIDAS, Revista Iberoamericana de Aprendizaje Servicio, 9, 81-101. DOI10.1344/RIDAS2020.9.5 
desde nuestro punto de vista, ya que es la base para entender la sociedad y la desigualdad. Consideramos que estos cambios sobre el conocimiento del otro son imprescindibles para que estos y estas estudiantes se conviertan en futuros profesionales comprometidos socialmente.

\subsection{Percepciones sobre cambios personales}

En la tabla 4 se muestran los datos relacionados con narraciones que hacen referencia a ellos mismas, ofreciendo muestras de cómo la experiencia les está afectando emocional y personalmente y por tanto cómo estos aprendizajes inciden también en sus procesos de construcción personal e identitaria.

Tabla 4. Frecuencias y porcentajes de resultados de aprendizajes personales.

\begin{tabular}{ccc}
\hline Subcategorías & Frecuencias & Porcentajes \\
\hline Empatía & 47 & $17.3 \%$ \\
\hline Paciencia & 80 & $29.4 \%$ \\
\hline $\begin{array}{c}\text { Empoderamiento/ } \\
\text { autoconfianza }\end{array}$ & 76 & $27.9 \%$ \\
\hline $\begin{array}{c}\text { Flexibilidad } \\
\text { Confirmación en } \\
\text { la elección } \\
\text { vocacional }\end{array}$ & 22 & $8.1 \%$ \\
\hline Total & $\mathbf{1 5 5}$ & $\mathbf{1 0 0} \%$ \\
\hline
\end{tabular}

Fuente: elaboración propia

Tal como se muestra en la tabla, los resultados relacionados con aspectos personales revelan que mayoritariamente el estudiantado hace referencia al desarrollo de la paciencia (29.4\%) como aspecto más reseñable, seguido por el empoderamiento y la autoconfianza que muestran tras unos meses de colaboración en el colegio (27.9\%). Destacan igualmente la empatía $(17.3 \%)$ como un aspecto que consideran de relevancia en sus aprendizajes y hacen referencia también a la flexibilidad que están observando en el desarrollo de sus acciones $(8.1 \%)$. Finalmente hemos encontrado un aspecto relacionado con su formación identitaria como es la confirmación de su vocación profesional $(17.3 \%)$, aspecto enormemente relevante en los procesos motivacionales de aprendizaje. Algunos ejemplos de los discursos producidos por los estudiantes en este sentido son:

- A12.14. "Me he tenido que situar en el lugar del otro para evitar hacer juicios... Me he tenido que poner muchas veces en la situación de estos niños...".

- A92.15. "Lo que más me ha ayudado en el contacto con estos niños es a desarrollar mi paciencia... Como educadora no puedes perder los nervios y ellos intentan ponerte a prueba. Los primeros días en el colegio me di cuenta de que no tenía paciencia y que la necesitaba. Ahora me doy cuenta de que he ido creciendo en ella y me siento muy satisfecha..."

- A32.14. "Creo que en estos tres primeros meses ha cambiado mi vida totalmente: mayor autonomía, más confianza en mí misma, libertad total para ir creando mi propio camino, nuevos objetivos que cumplir y metas que alcanzar. Me considero una persona muy rígida,

Martínez-Lozano, V., Rodríguez, R., Marco, M., y Macías, B. (2020). Percepciones del alumnado universitario sobre el aprendizaje-servicio como herramienta para su desarrollo personal y profesional. RIDAS, Revista Iberoamericana de Aprendizaje Servicio, 9, 81-101. DOI10.1344/RIDAS2020.9.5 
me gusta tenerlo todo claro y controlar pero ahora veo que esto no es así y que tengo que adecuarme a cada circunstancia y trabajar con lo que me encuentro".

- A12.14. "Ahora sé que esto es lo que quiero hacer y lo que me gusta. Al principio no estaba segura. Esta experiencia me ha transmitido la esencia que tiene para mí la Educación Social: luchar juntos por una vida mejor".

En estos fragmentos los estudiantes muestran sus percepciones con relación a sí mismos, mostrando el peso que la experiencia de aprendizaje-servicio está teniendo en su autoconcepto y en propia identidad personal. Encontramos alguna afirmación que expone cómo está cambiando su vida su vida por la forma en la que ahora se autopercibe, como parte de una comunidad diferente en la que debe asumir roles y posicionamientos diferentes (A.32.14).

\subsection{Valoraciones sobre el modelo} formativo docente basado en aprendizaje-servicio

Para esta categoría se hizo un recuento de valoraciones positivas y negativas, agrupando qué aspectos se señalan en cada una de ellas. Las frecuencias positivas se refieren a aprendizajes que explícitamente señalan como derivadas de la metodología empleada. Las negativas indican aspectos problemáticos o con los que se han sentido a disgusto. Las tablas 5 y 6 reflejan los resultados de cada una de las subcategorías que hemos utilizado para analizar los diferentes aspectos valorados.
Tabla 5. Frecuencias y porcentajes de los fragmentos textuales declarados por el alumnado sobre aspectos positivos relacionados con la experiencia con aprendizaje-servicio.

\begin{tabular}{ccc}
\hline Subcategorías & Frecuencia & Porcentajes \\
\hline $\begin{array}{c}\text { Enseñanza más } \\
\text { activa (aprender } \\
\text { haciendo) }\end{array}$ & 59 & $24,30 \%$ \\
\hline $\begin{array}{c}\text { Conexión teórico- } \\
\text { práctica }\end{array}$ & 63 & $25,90 \%$ \\
$\begin{array}{c}\text { Satisfacción } \\
\text { general con la } \\
\text { experiencia }\end{array}$ & 48 & $19,80 \%$ \\
$\begin{array}{c}\text { Pertinencia de la } \\
\text { evaluación } \\
\text { continua }\end{array}$ & 37 & $15,20 \%$ \\
$\begin{array}{c}\text { Permite conocer la } \\
\text { profesión desde } \\
\text { dentro }\end{array}$ & 36 & $14,80 \%$ \\
\hline Total & $\mathbf{2 4 3}$ & $\mathbf{1 0 0} \%$ \\
\hline
\end{tabular}

Fuente: elaboración propia

Tabla 6. Frecuencias y porcentajes de los fragmentos textuales declarados por el alumnado sobre aspectos negativos relacionados con la experiencia con aprendizaje-servicio.

\begin{tabular}{ccc}
\hline Subcategorías & Frecuencia & Porcentajes \\
\hline $\begin{array}{c}\text { Genera } \\
\text { inseguridad al } \\
\text { inicio }\end{array}$ & 29 & $25,40 \%$ \\
$\begin{array}{c}\text { Diferencias } \\
\text { metodológicas } \\
\text { entre asignaturas } \\
\text { Gran carga de } \\
\text { trabajo }\end{array}$ & 33 & $28,90 \%$ \\
$\begin{array}{c}\text { Dudas acerca de } \\
\text { los aprendizajes } \\
\text { académicos }\end{array}$ & 28 & $21,10 \%$ \\
\hline Total & $\mathbf{1 1 4}$ & $\mathbf{1 0 0} \%$ \\
\hline
\end{tabular}

Fuente: elaboración propia

De un total de 357 unidades de texto en esta categoría, 243 son narraciones

Martínez-Lozano, V., Rodríguez, R., Marco, M., y Macías, B. (2020). Percepciones del alumnado universitario sobre el aprendizaje-servicio como herramienta para su desarrollo personal y profesional. RIDAS, Revista Iberoamericana de Aprendizaje Servicio, 9, 81-101. DOI10.1344/RIDAS2020.9.5 
que destacan aspectos positivos y 114 negativos. Un análisis pormenorizado de estas afirmaciones muestra que el alumnado valora especialmente la posibilidad de aprender desde la práctica $(24,3 \%)$, así como la conexión que se establece entre la teoría y la práctica $(25,9 \%)$ que les ayuda a entender mejor los conceptos. Uniendo estas dos primeras subcategorías encontramos que como método de aprendizaje de conocimientos teóricos esta metodología es enormemente valorada, y destacada como la mayor ventaja de esta metodología $(50,2 \%)$. Es importante destacar también la satisfacción general que despierta la experiencia, de manera que, tal y como afirman algunos/as estudiantes, compensa la carga de trabajo $(19,8 \%)$. La preferencia por la evaluación continua y no mediante pruebas objetivas es también valorado como positivo $(15,2 \%)$, así como la posibilidad que les ofrece esta experiencia de conocer la profesión desde dentro $(14,8 \%)$.

En la parte negativa el estudiantado destaca su preocupación por no poder conectar esta experiencia con todas las asignaturas del semestre $(28,9 \%)$, lo que entienden como deseable y muestra un mayor deseo de interdisciplinariedad en sus estudios. Hacen referencia también al miedo inicial ante una población y un barrio desconocidos y con marcadores muy negativos, cargados de prejuicios. Le sigue su preocupación por el aprendizaje conceptual que están realizando $(24,6 \%)$, lo cual debería preocuparnos, aunque anteriormente se han manifestado en sentido contrario.
Nuestras intuiciones nos indican que la falta de exámenes puede estar generando en ellos y ellas la sensación de poco aprendizaje, aunque en los textos que generan hemos apreciado un manejo muy diestro de los conceptos trabajados en clase. Este aspecto merecería la pena ser analizado en posteriores estudios. Por último señalan que esta metodología les requiere gran carga de trabajo ya que deben leer y producir textos semanalmente, además de asistir al colegio.

A continuación se presentan algunos fragmentos ilustrativos de esta categoría:

- A63.14. "Lo que he aprendido con el aprendizaje-servicio no lo podría haber aprendido en la universidad solamente. He aprendido haciendo y he puesto en práctica habilidades que solo las desarrollas en el contacto real con la gente. Especialmente en una profesión como la nuestra. Creo que de no haber llevado las clases con aprendizaje-servicio me hubiera encasillado y, tal vez, incluso lo hubiera dejado... pero esto me ha cautivado y quiero seguir".

- A101.15. "Pensaba que todo iba a ser mucho más teórico, sobre todo en los primeros cursos pero ahora veo que gracias al aprendizajeservicio no es así y que no tengo que esperar a que lleguen las prácticas. No veo otro modo mejor para aprender la profesión que acercándonos a ella y reflexionando en las clases".

- A74. 15. "Pensaba que los profesores iban a ser distantes y que nosotros íbamos a ser unos meros receptores, pero la verdad es que ha

Martínez-Lozano, V., Rodríguez, R., Marco, M., y Macías, B. (2020). Percepciones del alumnado universitario sobre el aprendizaje-servicio como herramienta para su desarrollo personal y profesional. RIDAS, Revista Iberoamericana de Aprendizaje Servicio, 9, 81-101. DOI10.1344/RIDAS2020.9.5 
sido lo contrario, tanto profesores como alumnos nos hemos implicado y juntos hemos hecho algo útil... Ha sido una experiencia única... me ha hecho crecer como persona".

\section{Conclusiones}

Este trabajo muestra la experiencia con metodología de aprendizaje-servicio que venimos realizando desde hace dos años en la universidad. Desde la perspectiva del alumnado sobre los principales aprendizajes que señalan haber adquirido, así como sobre sus valoraciones sobre esta forma de trabajo en la formación universitaria. Los resultados muestran la potencialidad que en diferentes aspectos tienen el aprendizaje-servicio: permite conocer de primera mano un campo profesional en el que trabajar así como adquirir competencias adecuadas para ello; fomenta la motivación y la iniciativa para la acción social, confrontando con realidades y grupos socio-culturales diferentes sobre los que, como el estudiantado indica, tenían escaso conocimiento e incluso podían albergar prejuicios negativos; y posibilita reconocer y activar destrezas personales útiles de las que hasta entonces no habían sido conscientes o no habían prestado atención.

Destacamos que los aprendizajes alcanzados por el estudiantado no se circunscriben a contenidos disciplinares de carácter conceptual. Por el contrario, dado que el aprendizaje-servicio conjuga la dimensión académica con un planteamiento experiencial -en el que el plano emocional del aprendizaje tiene un valor esencial-, los aprendizajes conceptuales se entretejen con otros procedimentales y con cambios actitudinales y valores que les dan sentido personal. En el caso que analizamos, junto al cuestionamiento de las propias creencias y actitudes previas y al compromiso con la búsqueda de una mayor justicia social, el alumnado refiere como resultado directo de la experiencia de aprendizaje-servicio la adquisición o mejora de, entre otras, las siguientes competencias: habilidades de relación interpersonal, habilidad para adaptarse y trabajar en un contexto intercultural complejo, capacidad para gestionar la diversidad cultural y la mejora de competencias del trabajo en equipo. Estas habilidades son de indudable valor en la formación integral de personas $y$, especialmente, en la de profesionales de la intervención social.

En definitiva, estos resultados muestran la gran utilidad formativa de la metodología aprendizaje-servicio, especialmente con relación al desarrollo personal y a los aprendizajes profesionales, destacando cuatro aspectos fundamentales: en primer lugar, facilita una percepción más realista de la profesión, tanto por la complejidad del campo de trabajo como por las destrezas implicadas en el desempeño; en segundo lugar, contribuye a que el alumnado reflexione sobre su implicación en las labores profesionales y adquieran confianza en sí mismos en el ejercicio de esa práctica profesional; en tercer lugar, ayuda a participar y a sentirse agentes en una comunidad de práctica profesional, lo cual despierta una mayor motivación en su formación como educadores sociales; en cuarto y último lugar, pero

Martínez-Lozano, V., Rodríguez, R., Marco, M., y Macías, B. (2020). Percepciones del alumnado universitario sobre el aprendizaje-servicio como herramienta para su desarrollo personal y profesional. RIDAS, Revista Iberoamericana de Aprendizaje Servicio, 9, 81-101. DOI10.1344/RIDAS2020.9.5 
no menos importante, favorece el acercamiento a la diversidad social, el conocimiento de las desigualdades y la reivindicación de la equidad y la justicia social. Estos resultados se ven reforzados por la positiva valoración que el alumnado realiza de la metodología seguida, especialmente por la conexión teoría-práctica que facilita, lo que, a su juicio, compensa la mayor carga de trabajo y les hace desear la vinculación de la experiencia a otras materias.

Estos resultados concuerdan en gran parte con los obtenidos por Folgueiras, Luna y Puig (2013), donde analizan la satisfacción del estudiantado tras pasar por una experiencia aprendizajeservicio, concluyendo que la dimensión más destacada fue la valoración atribuida a la experiencia, es decir, sus percepciones sobre la adquisición de aprendizajes conceptuales, personales y ciudadanos.

Por todo ello consideramos que el aprendizaje-servicio es una herramienta docente que puede conducir a las y los estudiantes a un aprendizaje auténtico (Meijers y Wardeker, 2003; Simons, 2000; Van Oers, 2005 y 2007), que no sólo suponga cambios a nivel cognitivo, sino que lleve a aprendizajes que van más allá del currículum e incluyan cambios en los posicionamientos personales. Es decir, lo que aprenden, lo aprenden desde la práctica, conectando con ella y replanteándose a sí mismos como agentes, lo que implica un compromiso personal y profesional con la realidad social y con las personas con las que se trabaja, aspecto que Wenger (1998) considera esencial en todo aprendizaje.
Finalmente, y no menos importante, este estudio muestra el aprendizajeservicio como herramienta que permite que las universidades cumplan con su responsabilidad social como institución transformadora de la sociedad. $Y$ esto en un doble sentido: de un lado, facilitando la original misión de las instituciones universitarias como ámbito para la formación integral de futuros profesionales como personas comprometidas y responsables que articularán la sociedad en un futuro cercano; y de otro, yendo más allá y promoviendo un espacio base para la articulación y la colaboración con instituciones públicas y entidades sociales que presentan demandas reales en una sociedad compleja y en crisis como en la que ahora nos movemos.

\section{Perspectivas de futuro}

Dada la potencialidad del aprendizajeservicio para propiciar aprendizajes auténticos parecen obvios los beneficios que traería su transferencia a otros cursos superiores, y a otras disciplinas. Encontramos esta metodología especialmente interesante para grados en el marco de las Ciencias Sociales y Humanas, en los que la implicación de los estudiantes en las problemáticas sociales ha de constituir gran parte de su repertorio formativo. Pero no solo en Ciencias Sociales, las Ilamadas carreras experimentales y técnicas se nos antojan un campo en el que el aprendizaje de servicio podría cobrar especial sentido.

En nuestra experiencia hemos planteado el servicio comunitario y el aprendizaje-servicio en el marco de la

Martínez-Lozano, V., Rodríguez, R., Marco, M., y Macías, B. (2020). Percepciones del alumnado universitario sobre el aprendizaje-servicio como herramienta para su desarrollo personal y profesional. RIDAS, Revista Iberoamericana de Aprendizaje Servicio, 9, 81-101. DOI10.1344/RIDAS2020.9.5 
colaboración entre diferentes asignaturas del mismo curso, implicando altas dosis de cooperación docente y planificación conjunta. Para el futuro, consideramos que la colaboración y coordinación docente constituyen una piedra angular de este tipo de proyectos. Idealmente, un escenario a alcanzar sería el trabajo en torno al aprendizaje-servicio a lo largo de un curso completo, en el que todas las asignaturas del mismo estuvieran de alguna manera implicadas en el proyecto. Para esto sería necesaria la implicación de la institución universitaria, generando un eje prioritario del programa formativo en las memorias verifica de los grados y reorganizando, si fuera necesario, la planificación docente para adaptarla a esta metodología. A la vez se deben establecer relaciones intensas de trabajo con instituciones y entidades educativas y de atención social que permitan, de un lado, configurar ese escenario idóneo para el aprendizaje y, de otro, que el servicio comunitario sobre el que se establece responda a necesidades reales de la población con la que se trabaja.

Entendemos asimismo que conocer el know-how del trabajo, a través de la triangulación con las instituciones públicas y las entidades colaboradoras, es claramente necesario para valorar las potencialidades y las limitaciones de este tipo de experiencias, además de hacerlas claramente exportables a otras titulaciones y niveles de enseñanza, universitarias (posgrados), o no (secundaria).

En consecuencia, se espera que esta experiencia sirva como palanca para impulsar nuevos desarrollos en el aprendizaje-servicio y futuras investigaciones, no sólo para promover aprendizajes en el alumnado universitario y evaluar su impacto, sino también para valorar la incidencia de este modo de trabajar en el desarrollo de alineamientos entre universidades y comunidad, así como de redes interuniversitarias.

\section{Referencias bibliográficas}

Blanco, J., Almirón, M. A., Blázquez, A., Fernández, A., y Maguilla, M. (febrero de 2015). La Residencia Universitaria Flora Tristán un experiencia de intervención/acción en el territorio desde la universidad. En M. León (Presidencia), Desigualdad y democracia: políticas públicas e innovación social. Ponencia llevada a cabo en el V Congreso de la Red Española de Política Social (REPS), Barcelona, España. Recuperado de https://cendocps.carm.es/documentaci on/2016_Actas_finales_Red_Espa\%c3 \%b1ola_Politica_Social2015.pdf

Blázquez, A. y Martínez-Lozano, V. (2012). La residencia universitaria Flora Tristán: Un ejemplo de formación humana y de compromiso con la sociedad. Revista de Educación, 358, 618-630.

Cole, M. (1996). Cultural Psychology. A Once and Future Discipline. Cambridge, United States of America: Harvard University Press.

Cole, M. y The Distributed Literacy Consortium. (2006). The Fifth Dimension: An after-school program built on diversity. New York, United 
States of America: Russell Sage Foundation.

Dewey, J. (1938). Education and experience. New York, United States of America: Simon \& Schuster.

European Union. (2013). Improving the quality of teaching and learning in Europe's higher education institutions. Report of the European Commission. Luxembourg: Publications Office of the European Union.

Flick, U. (2004). Introducción a la investigación cualitativa. Madrid, España: Morata.

Folgueiras, P., Luna, E., y Puig, G. (2013). Aprendizaje y servicio: estudio del grado de satisfacción de estudiantes universitarios. Revista de Educación, 362, 159-185.

Kolb, D. (1984). Experiential learning: Experience as the source of learning and development. New Jersey, United States of America: Prentice-Hall.

Korthagen, F. (2007). The gap between research and practice revisited.

Educational Research and Evaluation, 13(3), 303-310.

Korthagen, F. y Kessels, J. (2009). Linking theory and practice: Changing the pedagogy of teacher education. Educational Researcher, 28(4), 4-17.

Krippendorff, K. (2002). Metodología de análisis de contenido. Teoría y práctica. Barcelona, España: Paidós.

Lalueza, J.L., Crespo, I., Pallí, C. y Luque, M.J. (1999). Intervención educativa, comunidad y cultura gitana. Una experiencia con nuevas tecnologías: la Casa de Shere Rom. En M.A. Essombra (Ed.), Construir la escuela intercultural. Reflexiones y propuestas para trabajar la diversidad étnica y cultural (pp. 185-194). Barcelona, España: Graó.

Lalueza, J.L., Crespo, I., Pallí, C. y Luque, M.J. (2001). Socialización y cambio cultural en una comunidad étnica minoritaria. El nicho evolutivo gitano. Cultura y Educación, 13(1), 115-130.

Lalueza, J. L., Crespo, I., Sánchez, S., Camps, S. y Cazorla, A. (2004). Intervención psicopedagógica en comunidades minoritarias. En C. Monero (Ed.) La práctica psicopedagógica en educación no formal. Barcelona, España: EDIUOC.

Lave, J. y Wenger, E. (1991). Situated Learning: Legitimate Peripheral Participation. Cambridge, UK: Cambridge University Press.

Macías, B., Martínez-Lozano, V. y Mateos, C. (2014). Usos de la etnografía en un proyecto de Aprendizaje-Servicio en el contexto universitario. En P. Mata, B. Balleteres e I. Gil-Jaurena (Eds.), Aprendizaje de la ciudadanía y la participación (pp. 115121).

Macías, B., Martínez-Lozano, V., y Vásquez, O. A. (2015). "Real Learning" in Service Learning: Lessons from La Clase Mágica in the US and Spain. International Journal for Research on Extended Education, 2(2), 63-68. 
Macías, B. y Vásquez, O.A. (2014). La Clase Mágica goes international: adapting to new sociocultural contexts. En B. Bustos, O. Vasquez \& E. Clark (Eds.). Generating transworld pedagogy (pp.193-208). Maryland, United States of America: Lexington Books.

Macías, B. y Vásquez, O.A. (2015). Identity construction in narratives of migration. En T. Hansen \& K. Jensen (Eds). Self in Culture in Mind. Connectional and applied perspectives (pp.177-200). Aalborg, Denmark: Aalborg University Press.

McMillan, J. (2011). What happens when the university meets the community? Service learning, boundary work and boundary workers. Teaching in Higher Education, 16(5), 553-564.

Meijers, F. y Wardekker, W. (2003). Cateer learning in a changing world: The role of emotions. International Journal for the Advancement of Counseling, 24, 149-167.

Mitton-Kükner, J., Nelson, C. y Desrochers, C. (2010). Narrative inquiry in service-learning contexts: Possibilities for learning about diversity in teacher education. Teaching and Teacher Education, 26, 1162-1169.

Naval, C. (2008). Universidad y conciencia cívica. Algunas experiencias fructíferas: service learning y campus compact. En M. Martínez (Ed.). Aprendizaje servicio y responsabilidad social de las Universidades (pp. 57-80). Madrid, España: Octaedro.

Rogoff, B. (1990). Apprenticeship in thinking: Cognitive development in social context. Oxford, UK: Oxford University Press.

Puig, J., Gijón, M., Martín, X. y Rubio, L. (2011). Aprendizaje-servicio y educación para la ciudadanía. Revista de Educación, número extraordinario, 45-67. Recuperado de

http://www.revistaeducacion.educacion .es/re2011/re2011_03.pdf

Rubio, L., Prats, E. y Gómez, L. (Coord.). (2013). Universidad y Sociedad. Experiencias de Aprendizaje Servicio en la Universidad. Barcelona: Universitat de Barcelona (Institut de Ciències de I'Educació). Recuperado de https://www.uv.es/aps/doc/Biblioteca\% 20Blog/Univerdidad\%20y\%20sociedad. pdf

Simons, J. (2000). Towards a constructivist theory of self-directed learning. En G. Straka (Ed.), Selflearning (pp. 155-169). Münster, Germany: Waxmann.

Strauss, A. L. y Corbin, J. (1990). Basics of qualitative research. Newbury Park, United States of America: Sage publications.

Van Dijk, L. A. y Jochems, W.M.G. (2002). Changing a traditional lecturing approach into an interactive approach: Effects of interrupting the monologue in lectures. International Journal of Engineering Education, 18(3), 275-284. Recuperado de https://www.ijee.ie/articles/Vol183/IJEE1300.pdf

Van Oers, B. (2005). The potentials of imagination. Inquiry, 24(4), 5-18. 
Van Oers, B. (2007). Helping young

children to become literate: The relevance of narrative competence for developmental education. European Early Childhood Education Research Journal, 15(3), 299-312.

Vásquez, O. (2003). La Clase Mágica: Imagining optimal possibilities in a bilingual community of learners. New Jersey: Laurence Erlbaum.

Vygotski, L.S. (1979). El desarrollo de los procesos psicológicos superiores. Barcelona, España: Crítica.

Wenger, E. (1998). Communities of practice: learning, meaning, and identity. Cambridge, UK: Cambridge University Press. 


\title{
Formación del profesorado a distancia sobre aprendizaje- servicio: aspectos a considerar
}

\author{
Beatriz Ortega-Ruipérez \\ Universidad Internacional de La Rioja, España
}

\section{Resumen}

La formación de docentes debe ser práctica y aplicada, de modo que aprendan cómo implementar diferentes técnicas educativas en sus clases, como ocurre con el aprendizaje-servicio. Si, además, la formación es online, pueden surgir inconvenientes para su correcta difusión, como que los docentes no valoren el aprendizaje-servicio o no sepan cómo aplicarla. Por esta razón, resulta importante estudiar y planificar las experiencias formativas en línea para docentes. Por tanto, el objetivo de este estudio es mejorar la difusión del aprendizaje-servicio entre los futuros docentes para conseguir que se aplique en más aulas. Para ello, se va a evaluar la opinión de profesores en formación, tras impartir una breve experiencia que permita conocer los aspectos más prioritarios en una formación de este tipo. Se va a utilizar un cuestionario para valorar el conocimiento sobre aprendizaje-servicio y la percepción de estos docentes sobre los beneficios e inconvenientes de esta práctica educativa. Los resultados muestran que los docentes valoran la parte práctica de la formación como lo más positivo para comprender los beneficios de esta técnica, pero valoran por debajo el desarrollo de algunas habilidades y los materiales disponibles para aplicar el aprendizaje-servicio. Estos resultados sirven para reflexionar sobre los aspectos en los que debe centrarse en el futuro una formación online sobre aprendizaje-servicio.

\section{Palabras clave}

Aprendizaje social, enseñanza a distancia, método de proyectos, formación de profesores, aprendizaje-servicio.

Fecha de recepción: 30/VII/2019

Fecha de aceptación: 28/VIII/2019 


\title{
Online teacher training in service-learning: aspects to consider
}

\begin{abstract}
Teacher training should be practical and applied, so that teachers learn how they should apply different educational techniques in their classes, as is the case with service-learning. If, however, training takes place online, some difficulties may arise in the promotion of service-learning, such as, for example, teachers not valuing servicelearning enough or not knowing how to implement it in their teaching. For this reason, it is important to study and properly plan online training experiences for teachers. Therefore, the objective of this study is to improve the promotion of service-learning among future teachers in order to extend its use to more classrooms. For this purpose, the opinion of teachers in training was evaluated, after they took part in a brief experience that showed them the most important aspects in a training of this type, with a view to its subsequent improvement. The results show that teachers value the practical part of the training as the most positive aspect for understanding the benefits of this technique; however, they give a low rating to the development of certain skills and the materials available to apply service-learning. These results will help us reflect on the aspects that an online training in service-learning should focus on in the future.
\end{abstract}

\section{Keywords}

Social learning, distance study, project method, teacher education, service-learning. 


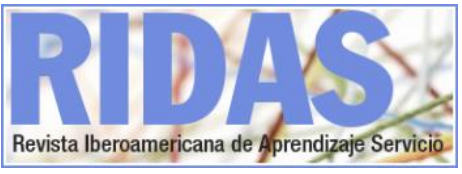

grado de educación primaria.

\section{Introducción}

En los últimos años están proliferando las iniciativas y proyectos sobre aprendizaje-servicio. Este enfoque educativo, que vincula servicios sociales con aprendizaje, permite que los alumnos realicen proyectos reales con impacto social (Martín et al., 2018). Como señalan Puig, Gijón, Martín y Rubio (2011) esto permite una educación más inclusiva y sirve para un aprendizaje por competencias, ya que se realiza un aprendizaje reflexivo de conocimientos, habilidades y valores.

Desde la universidad debemos promover proyectos que vayan más allá del aprendizaje, debemos formar a una sociedad concienciada para la justicia social, por lo que resulta necesario utilizar enfoques educativos como el aprendizaje-servicio. Si, además, las personas a las que formamos van a encargarse de la enseñanza de las generaciones futuras, debemos plantearnos dos objetivos. Por una parte, que entiendan por qué este enfoque educativo debe ser un eje central en el proyecto educativo de cualquier centro $y$, por otra parte, que conozcan cómo aplicar el aprendizajeservicio en su aula de manera efectiva con sus alumnos.

\section{Existen bastantes propuestas para} incluir el aprendizaje-servicio en la formación de docentes, como la de Fuertes (2013) en el prácticum del profesorado, la de Rodríguez (2014) sobre la importancia de incluirla en el grado de pedagogía, o las de Martínez (2018), y López y Benítez (2018) en el
Sin embargo, la formación online sobre aprendizaje-servicio conlleva unas pautas propias, por lo que, si la instrucción se realiza online, se deben tener en cuenta una serie de aspectos que garanticen que la formación cumple con los dos objetivos antes

mencionados. Los docentes en este caso únicamente reciben una formación a distancia. Sin embargo, tendrán que ponerla en práctica de forma presencial con sus alumnos.

Con este estudio se va a valorar la calidad percibida de una formación online sobre aprendizaje-servicio, por parte de los docentes en formación en línea, que permita reducir las limitaciones respecto a cualquier formación presencial, y que cualquier formador de formadores de educación superior a distancia pueda aplicar en su aula virtual. En concreto, esta experiencia se ha diseñado para llevar a cabo dos sesiones sobre el aprendizajeservicio, partiendo de la limitación de que este contenido suele ser una pequeña parte de los contenidos de una asignatura.

La primera sesión, de explicación sobre esta práctica educativa, pretende una difusión adecuada de la misma, haciendo hincapié sobre los beneficios que puede aportar y sobre cómo se pueden superar algunos inconvenientes que puedan surgir al aplicarla. La segunda sesión consiste en una sesión práctica, de simulación de un proyecto de aprendizaje-servicio, en la que experimentan las diferentes fases a partir de analizar su propio entorno, el de los docentes en formación, durante 
una semana.

Además, como destaca Puig (2018), para una correcta difusión del aprendizaje-servicio es importante, entre otras cuestiones, poder crear las condiciones necesarias para que las entidades sociales ofrezcan espacios de servicio adecuados, y para promover sinergias entre la sociedad y las administraciones. Sin embargo, los alumnos de la formación en línea pueden residir en diferentes partes del mundo, con lo que sería imposible crear una red en un entorno social concreto.

En este caso, se nos presenta un desafío, que es el de crear conciencia sin poder aplicar un proyecto real de aprendizaje-servicio, por lo que se apuesta por mostrar la iniciativa de Design for Change a través de las páginas web de cada país, en las que se pueden visualizar proyectos ya realizados y aparece el contacto de los coordinadores de cada región.

\section{Marco teórico}

El aprendizaje-servicio es una práctica educativa, basada en proyectos, que permite aplicar los contenidos curriculares en situaciones reales de compromiso social. Como afirman Pérez y Ochoa (2017) a los alumnos que llevan a cabo este tipo de práctica educativa les permite "ser protagonistas activos al implicarse en las necesidades de su entorno con la finalidad de mejorarlo" (p.175).

Esto implica que son los propios alumnos quienes deben decidir cuál va a ser el propósito de su proyecto de aprendizaje-servicio, ya que la implicación en un proyecto impuesto será menor que en un proyecto elegido. Por tanto, aspectos como la elección del proyecto por parte de los alumnos, son fundamentales para que la aplicación de esta técnica sea adecuada.

2.1 Design for Change: la iniciativa de aprendizaje-servicio a nivel mundial

Para facilitar la aplicación del aprendizaje-servicio existe una iniciativa internacional que establece diferentes fases en el proyecto. Estas fases se pueden utilizar en la propia formación a distancia, y aunque no todas se podrán poner en práctica debido a las características de esta formación, se debe buscar un equilibrio entre la práctica real y la simulación.

Design for Change es una iniciativa de aprendizaje-servicio a nivel mundial que se inició en India, en 2009.

Actualmente, 10 años después, cuenta con la participación de más de 65 países y regiones (DFC World, s.f.). Esta iniciativa ha creado un marco de aplicación que cuenta principalmente con 4 fases: siente, imagina, haz y comparte. Esta iniciativa se propone a través de estas cuatro fases para facilitar la aplicación del aprendizajeservicio en cualquier aula de cualquier parte del mundo.

Cada una de las fases propuestas en Design for Change cuenta con unas acciones determinadas que permiten a los alumnos avanzar a través del problema hasta la realización de un proyecto. Para que los profesores puedan llevar a cabo esta experiencia sin problemas, la web dispone unas guías y vídeos para docentes que 
faciliten el trabajo y desarrollo de habilidades través de este tipo de proyectos (Fisch, McLeod y Bronman, 2013).

\subsection{La formación a distancia}

La formación del aprendizaje-servicio en línea es conocida como eAprendizaje-servicio. El eAprendizajeservicio corresponde a una experiencia de aprendizaje-servicio con algún componente online, pudiendo ser la instrucción o el servicio (Waldner, McGorry y Widener, 2012), en este caso la instrucción.

La mayoría de literatura sobre eAprendizaje-servicio no trabaja la enseñanza online del aprendizajeservicio como técnica educativa, es decir, no hay estudios sobre cómo enseñar en línea a futuros docentes sobre cómo aplicar el aprendizajeservicio con sus alumnos. Las propuestas que se recogen en la investigación aplican esta técnica a disciplinas diferentes, como Bellas Artes, Biblioteconomía, Biología, Derecho, Economía o Enfermería (Esparza, Morín y Rubio, 2018).

Las investigaciones revisadas no coinciden sobre si el aprendizajeservicio online ofrece la experiencia necesaria para el aprendizaje de aprendizaje-servicio o, por el contrario, los alumnos a distancia pueden obtener concepciones erróneas a través de las experiencias online (McWhorter, Delello y Roberts, 2016).

Por una parte, existen resultados a favor de la factibilidad de las experiencias $100 \%$ online, como los de
Waldner, McGorry y Widener, (2010). Por otra parte, estudios como los realizados por Malvey, Hamby y Fottler (2006) sugieren que la pérdida de experiencias in situ afecta, o el realizado por Lehman y Conceição (2010) sobre la falta de autorreflexión en situaciones de aprendizaje online, clave en el aprendizaje-servicio (Páez y Puig, 2013).

La falta de acuerdo perjudica el rápido desarrollo de una formación online de calidad sobre el aprendizaje-servicio, aunque en este estudio se va a optar por una visión positiva sobre la factibilidad de las experiencias online, pero teniendo en cuenta que es muy fácil caer en la pérdida de la efectividad si no se realiza correctamente. Para ello, se lleva a cabo un apoyo continuo que guía la experiencia a los alumnos, ayudándoles a reflexionar sobre qué conlleva esta práctica educativa en cada una de las fases propuestas en Design for Change.

2.3 Valoración docente sobre el empleo del aprendizaje-servicio

El enfoque del aprendizaje-servicio resulta idóneo para desarrollar habilidades de trabajo en equipo y competencias cívicas, como recogen entre otros muchos Hébert y Hauf (2015) o Miyazaki, Anderson y Jones (2017). Los docentes en formación tienen que conocer las posibilidades de esta técnica y ser capaces de aprovecharla para el desarrollo de habilidades en sus alumnos.

Tras realizar un proyecto de aprendizaje-servicio, la valoración que hacen los propios estudiantes sobre la

Ortega-Ruipérez, B. (2020). Formación del profesorado a distancia sobre aprendizaje-servicio: aspectos a considerar. RIDAS, Revista Iberoamericana de Aprendizaje Servicio, 9, 102-122. 
formación personal y sobre el desarrollo de habilidades profesionales suele ser alto, aunque la valoración puede variar dependiendo de las características de cada proyecto: de su diseño, planificación y ejecución (Caire, 2019).

Estudios como el de Duque (2018) muestran la mayor sensibilidad social de los alumnos después de realizar prácticas de aprendizaje-servicio. Por su parte, Sotelino, Santos y García (2019) estudian el desarrollo de competencias interculturales, detectando mayores expectativas de los alumnos sobre sus competencias cívicosociales.

En cualquier caso, de acuerdo con Strait, Turk y Nordyke (2015), para su enseñanza se necesita reflexionar sobre cómo va a ser la experiencia, una reflexión que permita definir la situación de partida de los estudiantes respecto a estas habilidades y a través de qué actividades lograrán desarrollar las habilidades a un nivel adecuado para su edad y desarrollo. Sólo de esta forma conseguiremos desarrollar competencias, con esta o con cualquier técnica educativa.

Por otra parte, no se han encontrado valoraciones previas en estudios de formación de docentes sobre dificultades para la aplicación de esta técnica docente. Se va a incluir como dimensión del estudio para abrir una nueva línea de investigación.

\section{Metodología}

\subsection{Diseño de la investigación}

Este estudio pretende ser el inicio de una investigación más amplia sobre cómo enseñar a docentes en activo técnicas instruccionales con impacto social, como es el aprendizaje-servicio, en contextos online donde la aplicación de estos proyectos resulta mucho más complicada. Por tanto, este artículo consiste en un estudio exploratorio que nos permitirá construir una base para mejorar la enseñanza del aprendizajeservicio online, en contextos educativos en los que los alumnos dispongan de sesiones presenciales síncronas, pero no sea obligatorio asistir a dichas sesiones presenciales.

Para construir esta base, se han delimitado unas dimensiones que nos permitirán analizar de forma más objetiva cómo perciben y valoran el aprendizaje-servicio los docentes que reciben una formación online. Estas dimensiones son conocimiento general sobre aprendizaje-servicio, valoración de los beneficios del aprendizajeservicio y valoración de los inconvenientes del aprendizaje-servicio.

El estudio se basa en una experiencia educativa que comprende dos sesiones síncronas en las que cada alumno se conecta a la clase desde su domicilio. La primera sesión se dedica a explicar las características del aprendizajeservicio, insistiendo en los beneficios que tiene para los alumnos cada una de las fases, y en cómo se pueden superar algunas dificultades que puede conllevar esta técnica educativa. La segunda sesión es una sesión práctica para que ellos mismos lleven a cabo la realización de un proyecto aprendizajeservicio en clase.

Se adopta un enfoque cuantitativo

Ortega-Ruipérez, B. (2020). Formación del profesorado a distancia sobre aprendizaje-servicio: aspectos a considerar. RIDAS, Revista Iberoamericana de Aprendizaje Servicio, 9, 102-122. 
basado en estadística descriptiva, que pretende servir para generar una idea general sobre la percepción que tienen los docentes en formación online sobre el aprendizaje-servicio, de manera que nos permita mejorar la formación de futuros docentes.

\subsection{Participantes}

Los participantes de esta investigación son cinco grupos del Máster de Tecnología Educativa y Competencias Digitales, de la Universidad Internacional de La Rioja con sede principal en España y varias sedes en diferentes países de Latinoamérica. En total, en estos cinco grupos de alumnos hay matriculados 185 alumnos. Todos los alumnos que acceden al máster deben tener un título en educación superior (grado, diplomatura, licenciatura, ingeniería técnica, etc.), siendo la mayoría de ellos docentes en distintas etapas educativas, desde educación infantil hasta educación superior.

La experiencia práctica de aprendizajeservicio se realizó en dos asignaturas diferentes. Dos de los grupos realizaron la experiencia en la asignatura de Programación y Robótica para Docentes, siendo un total de 97 alumnos matriculados. Los alumnos de la asignatura de Programación y Robótica están en su totalidad matriculados en España. Los tres grupos restantes realizaron la experiencia de aprendizaje-servicio en la asignatura de Emprendimiento, Innovación y Creatividad Digital, siendo un total de 88 alumnos matriculados en la asignatura. La totalidad de estos alumnos están matriculados en

\section{Ecuador.}

La respuesta al cuestionario fue voluntaria para todos aquellos alumnos que quisieran participar. La participación se premió con una recompensa en la calificación final de $+0,1$. La participación finalmente alcanzó un $35 \%$ del total de los alumnos matriculados en ambas asignaturas, esto es 65 alumnos.

\subsection{Instrumentos y materiales}

El instrumento que se ha utilizado para recoger la información necesaria para lograr los objetivos es un cuestionario realizado específicamente para el estudio. Se ha elegido la creación de un cuestionario propio con un total de 38 preguntas, dado que los cuestionarios revisados durante la investigación (De Castro, Martínez y Guerra, 2017; Toncar, Reid, Burns, Anderson y Nguyen, 2006) no respondían adecuadamente a todas las dimensiones del estudio.

Para responder al propósito de la investigación se necesitaba un cuestionario sencillo, rápido y fácil de contestar, en el que los alumnos pudieran responder a preguntas que abarcasen toda la investigación, ya que se trata de una investigación exploratoria y se consideró que elegir un cuestionario estandarizado podría desmotivar a los participantes, ya que son más extensos, y esto afectaría a la fiabilidad de sus respuestas.

Para diseñar el cuestionario se han elegido las preguntas en base a los cuestionarios revisados, de forma que se garantice un mínimo de fiabilidad.

Ortega-Ruipérez, B. (2020). Formación del profesorado a distancia sobre aprendizaje-servicio: aspectos a considerar. RIDAS, Revista Iberoamericana de Aprendizaje Servicio, 9, 102-122. 
Las respuestas se recogen con una escala tipo Likert con diferente número de opciones según la sección concreta del cuestionario, debido al carácter multidimensional del cuestionario, que ha sido realizado a partir de diferentes fuentes. El cuestionario tiene en total cinco secciones:

- Sección 1. Aspectos importantes para mi aprendizaje. Preguntas sobre cómo de importante es para el docente unas afirmaciones sobre el aprendizaje significativo y desarrollo de habilidades (tabla 1). Escala de respuesta de 1 a 7 , siendo 1 la respuesta más baja posible y 7 la más alta.

- Sección 2. Mi experiencia con EL aprendizaje-servicio. Preguntas sobre la experiencia de aprendizaje-servicio realizada en clase (tabla 2). Escala de 1 a 5.

- Sección 3. Enseñanza desde la perspectiva de aprendizajeservicio. Preguntas sobre la percepción de utilidad de la enseñanza aprendizaje-servicio (tabla 3). Escala de 1 a 5.

- Sección 4. Situación laboral actual: trabajo en educación / no trabajo en educación. Preguntas sobre las posibilidades reales de aplicación según su situación (tabla 4). Escala de 1 a 5.

- Sección 5. Para terminar. Pregunta final de valoración global de la experiencia y de la técnica aprendizaje-servicio (tabla 5). Escala de 1 a 10.
Estas secciones contienen preguntas de todas las dimensiones que se quieren estudiar y que se pueden ver en la figura 1.

Figura 1. Dimensiones y subdimensiones de estudio

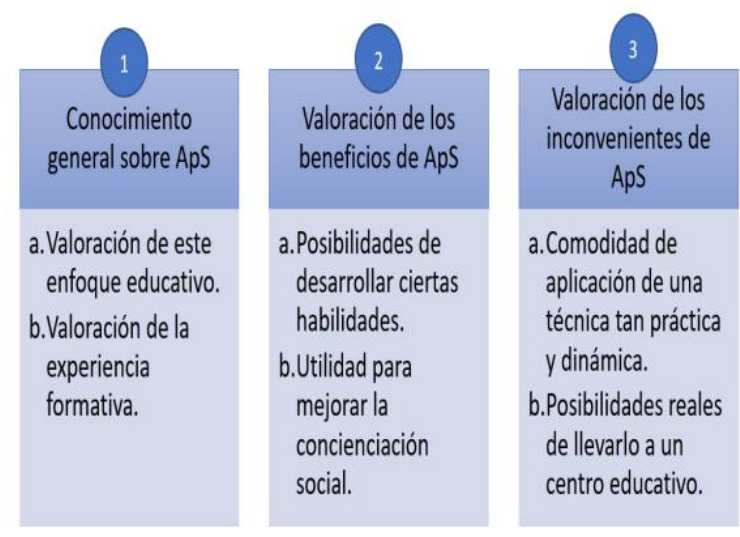

Fuente: elaboración propia

En las tablas $1-5$ se pueden consultar todas las preguntas incluidas en las diferentes secciones del cuestionario y la dimensión de estudio a la que pertenece cada una de las preguntas.

Por último, a modo de resumen, en la tabla 6 se muestran los números de las preguntas incluidas en cada dimensión del estudio.

Tabla 1. Preguntas de la Sección 1 del cuestionario de investigación

\begin{tabular}{ccc}
\hline No & Preguntas & $\begin{array}{c}\text { Dimensión } \\
\text { de estudio }\end{array}$ \\
\hline $\mathbf{1}$ & $\begin{array}{l}\text { Aplicar el conocimiento al } \\
\text { mundo real }\end{array}$ & $1 \mathrm{a}$ \\
$\mathbf{2}$ & $\begin{array}{l}\text { Desarrollar habilidades de } \\
\text { trabajo }\end{array}$ & $2 \mathrm{2a}$ \\
\hline
\end{tabular}

Ortega-Ruipérez, B. (2020). Formación del profesorado a distancia sobre aprendizaje-servicio: aspectos a considerar. RIDAS, Revista Iberoamericana de Aprendizaje Servicio, 9, 102-122. 


\begin{tabular}{|c|c|c|}
\hline 3 & $\begin{array}{l}\text { Desarrollar habilidades de } \\
\text { organización }\end{array}$ & $2 a$ \\
\hline 4 & $\begin{array}{l}\text { Entender las diferencias } \\
\text { culturales y raciales }\end{array}$ & $2 b$ \\
\hline 5 & $\begin{array}{l}\text { Desarrollar habilidades de } \\
\text { responsabilidad social y } \\
\text { ciudadana }\end{array}$ & $2 b$ \\
\hline 6 & $\begin{array}{l}\text { Desarrollar habilidades para } \\
\text { marcar una diferencia en la } \\
\text { comunidad }\end{array}$ & $2 b$ \\
\hline 7 & $\begin{array}{l}\text { Desarrollar una confianza } \\
\text { social }\end{array}$ & $2 b$ \\
\hline 8 & $\begin{array}{l}\text { Desarrollar habilidades para } \\
\text { asumir la responsabilidad } \\
\text { individual }\end{array}$ & $2 b$ \\
\hline 9 & $\begin{array}{l}\text { Desarrollar habilidades para } \\
\text { ganarse la confianza de los } \\
\text { demás }\end{array}$ & $2 b$ \\
\hline 10 & $\begin{array}{l}\text { Desarrollar habilidades de } \\
\text { liderazgo }\end{array}$ & $2 a$ \\
\hline 11 & $\begin{array}{l}\text { Desarrollar habilidades de } \\
\text { comunicación }\end{array}$ & $2 a$ \\
\hline
\end{tabular}

Nota: Sección 1. Aspectos importantes para mi aprendizaje. Indica cómo de importante es para ti lo siguiente según tu experiencia educativa con el Máster, para que tu aprendizaje sea más significativo.

Fuente: elaboración propia

Tabla 2. Preguntas de la Sección 2 del cuestionario de investigación

\begin{tabular}{|c|c|c|}
\hline No & Preguntas & $\begin{array}{l}\text { Dimensión } \\
\text { de estudio }\end{array}$ \\
\hline 12 & $\begin{array}{l}\text { Con la experiencia } \\
\text { aprendizaje-servicio he } \\
\text { trabajado los aspectos que he } \\
\text { marcado como importantes } \\
\text { en la sección anterior }\end{array}$ & $1 b$ \\
\hline 13 & $\begin{array}{l}\text { Con la introducción teórica de } \\
\text { la sesión anterior ya supe lo } \\
\text { valioso que es el enfoque } \\
\text { aprendizaje-servicio }\end{array}$ & $1 b$ \\
\hline
\end{tabular}

La actividad práctica me ha servido para darle aún más valor al enfoqueaprendizajeservicio

El haber llevado a cabo una experiencia de aprendizajeservicio me ha servido para conocer la sensación que se tiene cuando se trabaja desde esta perspectiva

El haber llevado a cabo una experiencia de aprendizaje-

16 servicio ha sido positivo para mi desde un punto de vista de impacto social

El hecho de poner en práctica las fases de sentir e imaginar

17 me ha motivado más a llevarlo a la práctica en mis clases

Nota: Sección 2. Mi experiencia con aprendizajeservicio. Valora tu grado de acuerdo con las siguientes afirmaciones sobre tu experiencia en la sesión práctica de aprendizaje-servicio Fuente: elaboración propia

Tabla 3. Preguntas de la Sección 3 del cuestionario de investigación

\begin{tabular}{|c|c|c|}
\hline No & Preguntas & $\begin{array}{l}\text { Dimensión } \\
\text { de estudio }\end{array}$ \\
\hline 18 & $\begin{array}{l}\text { Antes del máster tenía una } \\
\text { idea clara sobre qué es } \\
\text { aprendizaje-servicio }\end{array}$ & $1 a$ \\
\hline 19 & $\begin{array}{l}\text { Actualmente tengo una idea } \\
\text { clara sobre qué es } \\
\text { aprendizaje-servicio }\end{array}$ & $1 a$ \\
\hline 20 & $\begin{array}{l}\text { Conozco las cuatro fases } \\
\text { principales del aprendizaje- } \\
\text { servicio y sé qué se hace en } \\
\text { cada una de ellas. }\end{array}$ & $1 a$ \\
\hline 21 & $\begin{array}{l}\text { Con los materiales y vídeos } \\
\text { de la web me siento } \\
\text { preparado para poner en } \\
\text { práctica una experiencia de } \\
\text { aprendizaje-servicio }\end{array}$ & $1 b$ \\
\hline 22 & $\begin{array}{l}\text { Con la formación recibida, } \\
\text { me siento a gusto para } \\
\text { poner en práctica una } \\
\text { experiencia de aprendizaje- } \\
\text { servicio }\end{array}$ & $1 b$ \\
\hline
\end{tabular}

Ortega-Ruipérez, B. (2020). Formación del profesorado a distancia sobre aprendizaje-servicio: aspectos a considerar. RIDAS, Revista Iberoamericana de Aprendizaje Servicio, 9, 102-122. 


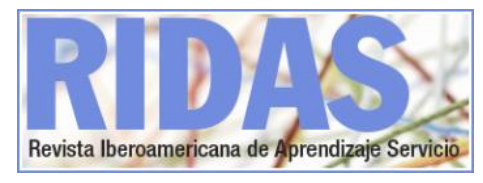

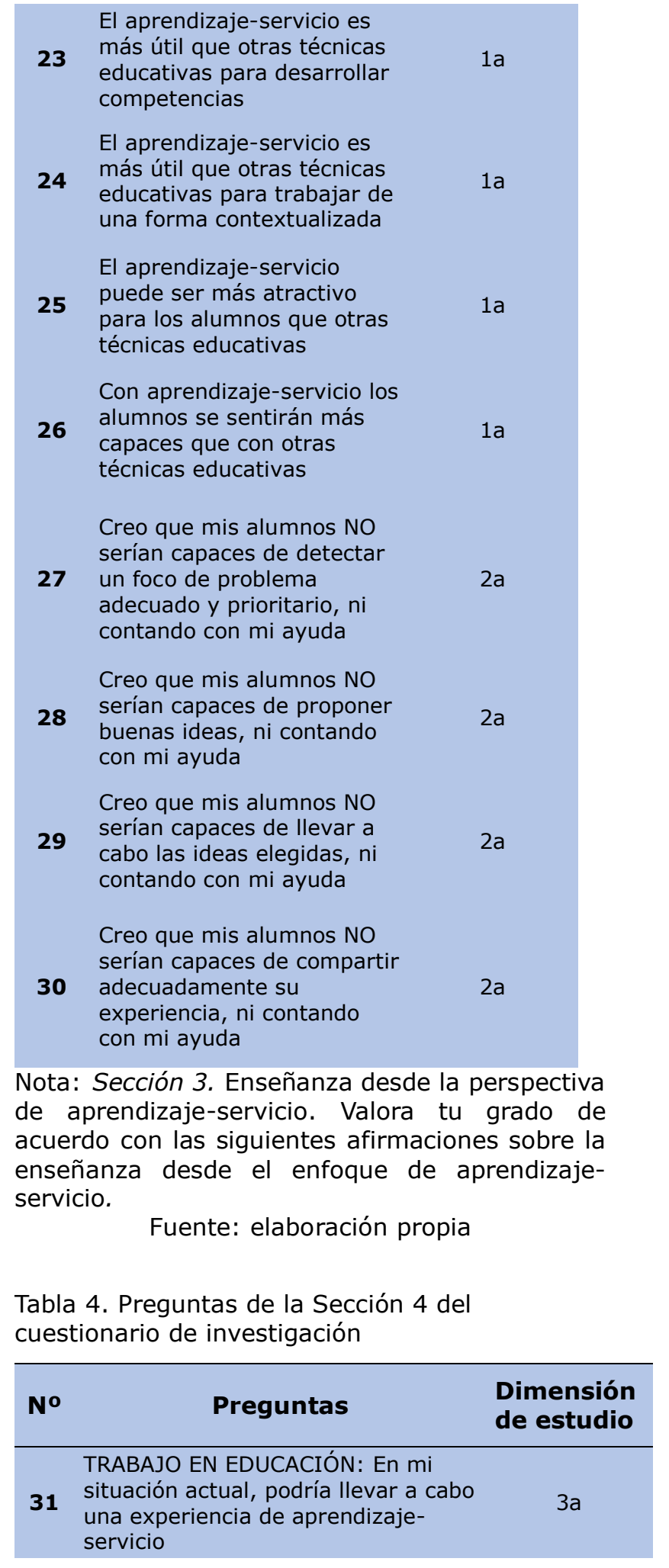

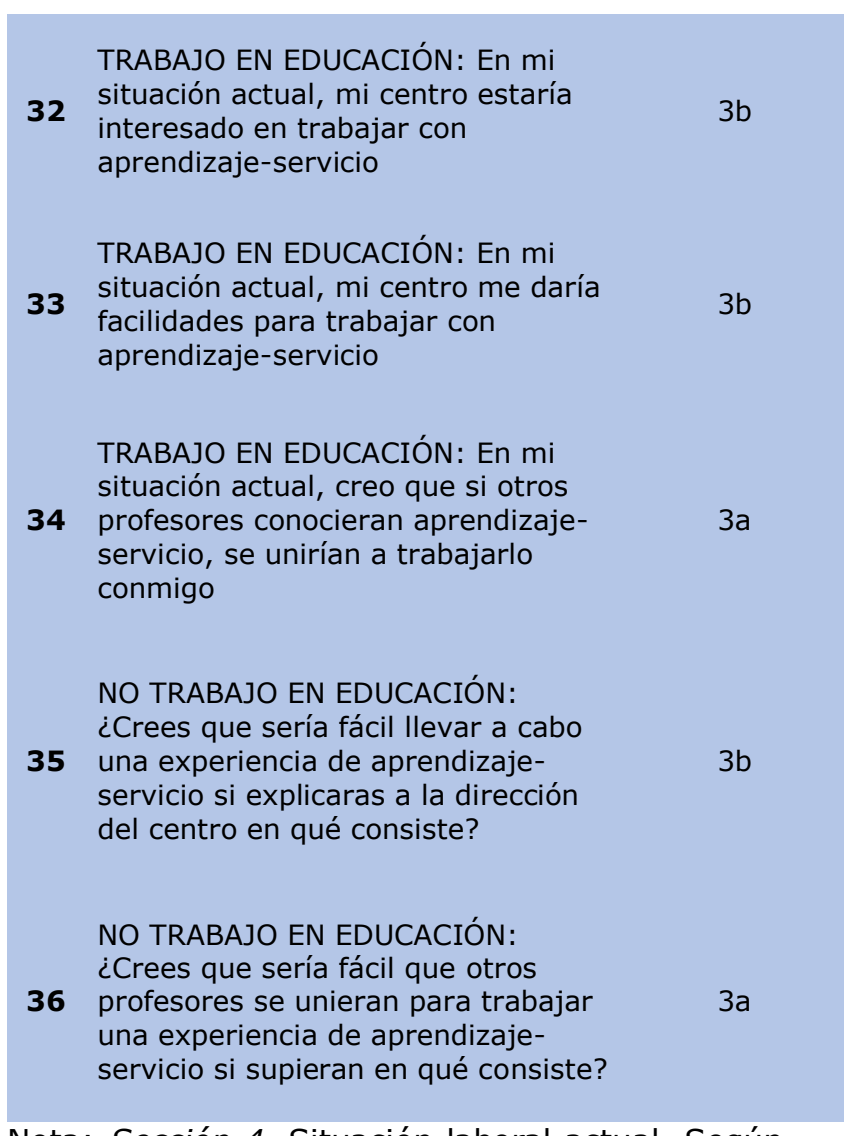

Nota: Sección 4. Situación laboral actual. Según tu respuesta a esta pregunta, el formulario te llevará a una sección que se ajuste a tu situación actual.

\section{Fuente: elaboración propia}

Tabla 5. Preguntas de la Sección 5 del cuestionario de investigación

\begin{tabular}{clc}
\hline No & \multicolumn{1}{c}{ Preguntas } & $\begin{array}{c}\text { Dimensión } \\
\text { de estudio }\end{array}$ \\
\hline 37 & $\begin{array}{l}\text { Valora tu satisfacción } \\
\text { respecto a la experiencia } \\
\text { llevada a cabo en clase }\end{array}$ & 1b \\
& $\begin{array}{l}\text { Valora tu satisfacción } \\
\text { respecto a esta forma de } \\
\text { enseñar con impacto social }\end{array}$ & $1 \mathrm{a}$ \\
\end{tabular}

Nota: Sección 5. Para terminar.

Fuente: elaboración propia

Ortega-Ruipérez, B. (2020). Formación del profesorado a distancia sobre aprendizaje-servicio: aspectos a considerar. RIDAS, Revista Iberoamericana de Aprendizaje Servicio, 9, 102-122. 
Tabla 6. Resumen de las preguntas incluidas por dimensión de estudio.

\begin{tabular}{|c|c|c|}
\hline No & Dimensión & $\begin{array}{l}\text { Número de } \\
\text { preguntas }\end{array}$ \\
\hline 1.a & $\begin{array}{l}\text { Valoración de este enfoque } \\
\text { educativo. }\end{array}$ & $\begin{array}{c}1,18,19,20,23 \\
24,25,26,38\end{array}$ \\
\hline 1.b & $\begin{array}{l}\text { Valoración de la } \\
\text { experiencia educativa } \\
\text { llevada en el aula. }\end{array}$ & $\begin{array}{c}12,13,14,15,16 \\
17,21,22,37\end{array}$ \\
\hline 2.a & $\begin{array}{l}\text { Posibilidades de desarrollar } \\
\text { ciertas habilidades en los } \\
\text { alumnos. }\end{array}$ & $\begin{array}{l}2,3,10,11,27 \\
28,29,30\end{array}$ \\
\hline 2.b & $\begin{array}{l}\text { Utilidad para mejorar la } \\
\text { concienciación social. }\end{array}$ & $4,5,6,7,8,9$ \\
\hline 3.a & $\begin{array}{l}\text { Comodidad de aplicación } \\
\text { de una técnica tan práctica } \\
\text { y dinámica. }\end{array}$ & $31,34,36$ \\
\hline 3.b & $\begin{array}{l}\text { Posibilidades reales de } \\
\text { llevar el aprendizaje- } \\
\text { servicio a la práctica en un } \\
\text { centro educativo. }\end{array}$ & $32,33,35$ \\
\hline
\end{tabular}

Fuente: elaboración propia

\section{Procedimiento}

En esta universidad de educación a distancia, la asistencia a las sesiones en directo es optativa, aunque se recompensa con una subida de $+0,1$ puntos en la calificación final por cada sesión a la que se asista en directo, con un máximo de 0,3 puntos.

Para esta experiencia práctica sobre aprendizaje-servicio llevada a cabo se emplearon dos sesiones presenciales completas, de una hora de duración cada una, ya que la cantidad de contenidos a impartir en cada

asignatura no permitía dedicar más tiempo a esta experiencia. Para todos aquellos alumnos que no pueden asistir en directo, la sesión queda grabada en el aula virtual.

En la primera sesión presencial se explicó de forma teórica en qué consisten las experiencias de aprendizaje-servicio y se compartió la web del proyecto Design for Change para que los alumnos pudieran entender mejor este enfoque educativo. En la web del proyecto aparecen 4 vídeos, uno por cada una de las fases propuestas en este proyecto. En esta sesión se visualizó el primero de los vídeos, correspondiente a la fase uno, Siente. En el vídeo se anima a explorar el ambiente y detectar focos de mejora o necesidades concretas. Se comunicó a los alumnos el objetivo de la siguiente sesión, la sesión práctica, llamando a la máxima asistencia posible a los alumnos. Se les pidió que pensaran necesidades y focos de mejora de su entorno escolar de cara a la siguiente sesión, la sesión en la que se llevaría a cabo la experiencia educativa.

Durante la sesión práctica, se llevó el esquema de Design for Change. A la primera fase se dedicaron los 15 primeros minutos de la sesión, los primeros 5 minutos se pusieron en común los focos detectados por los alumnos en sus respectivos centros educativos, en los siguientes 5 minutos se realizó una votación para seleccionar los focos de mejora que requerían una mayor urgencia de resolución, y los últimos 5 minutos de esta fase se utilizaron para hacer grupos que trabajasen los diferentes focos de 
mejora seleccionados. Los alumnos que asistían en ese momento a la sesión fueron repartidos aleatoriamente a los diferentes grupos en un número proporcional.

A la segunda fase, Imagina, se dedicaron los siguiente 20 minutos, en los primeros minutos se vio el vídeo correspondiente a esa fase, para que cada grupo empezara a proponer diferentes ideas para solucionar el foco a mejorar, en los minutos finales de esa fase (la docente dio un aviso cuando quedaban 5 minutos) debían elegir la o las mejores ideas (dependiendo del esfuerzo que lleve cada una de las ideas elegidas) para realizar.

La tercera fase, Haz, duró 5 minutos ya que no era posible llevarla a cabo. Por tanto, se visionó el vídeo de esta tercera fase y se dijo a los alumnos que imaginasen que habían llevado a cabo sus propuestas.

Por último, a la cuarta y última fase se dedicaron los 20 minutos restantes. En este tiempo se visualizó el vídeo de esta fase, y acto seguido empezaron a pensar qué imágenes o vídeos querrían compartir con el resto del mundo para mostrar el proyecto que habían Ilevado a cabo. Además, tenían que decidir entre los integrantes de cada grupo un mensaje para dar a conocer su aportación. Todas las ideas sobre cómo compartir el proyecto se compartieron en un documento común a toda la clase y se comentaron en los minutos finales de clase.

Cuando terminó la sesión práctica se explicó a los alumnos el estudio que se está llevando a cabo y se pidió amablemente la colaboración voluntaria de todos ellos, lo que ha dado lugar a los resultados obtenidos que se comentan a continuación.

\section{Resultados}

\subsection{Conocimiento general sobre aprendizaje-servicio}

Este primer análisis se ha realizado para obtener un mayor conocimiento de base que nos sirva de partida para entender las valoraciones que realizan los docentes sobre el aprendizajeservicio. Para ello, se han analizado los ítems de la tabla 6 .

Antes del máster, más de la mitad de los docentes apenas conocía el enfoque de aprendizaje-servicio. Según la pregunta 18 , el $26,2 \%$ no tenían conocimiento, respondiendo 1 sobre 5; y el $29,2 \%$ tenía un conocimiento básico sobre la técnica ( 2 sobre 5 ). Esto hace un total de $55,4 \%$ de los docentes, es decir, más de la mitad apenas tenía conocimiento sobre aprendizaje-servicio. Sin embargo, después de la experiencia llevada a cabo, el 43,1\% tiene una idea clara sobre qué es, marcando un 5 sobre 5 en la pregunta 19 , si a esto sumamos el $44,6 \%$ de los que marcaron un 4 sobre 5 , obtenemos que actualmente el $87,7 \%$ tiene una idea bastante clara sobre qué es el aprendizaje-servicio. Respecto al conocimiento sobre las 4 fases que se proponen en Design for Change, sumando las respuestas de $4 \mathrm{y}$ 5 sobre 5 , el $86,2 \%$ manifiesta saber qué acciones llevar a cabo en cada una de ellas.

En cuanto a la valoración de esta

Ortega-Ruipérez, B. (2020). Formación del profesorado a distancia sobre aprendizaje-servicio: aspectos a considerar. RIDAS, Revista Iberoamericana de Aprendizaje Servicio, 9, 102-122. 
técnica sobre su utilidad para desarrollar competencias, trabajar de forma contextualizada, motivar a los alumnos y mejorar la percepción de los alumnos sobre sus capacidades reales, los docentes han valorado más positivamente los beneficios de utilizar esta técnica por ser atractiva para los alumnos, con una media de 4,26 sobre 5 ; seguido de mejorar la percepción sobre las capacidades de los alumnos (4,08 sobre 5$)$ y de trabajar de forma contextualizada (4,06 sobre 5$)$. En último lugar, los docentes valoran la capacidad del aprendizaje-servicio para desarrollar competencias en los alumnos, con una media de 3,8 sobre 5 puntos.

Además, los docentes consideran fundamental aplicar el conocimiento al mundo real, con una puntuación media de 6,69 sobre 7 (el 76,9\% puntúo esta pregunta con la máxima puntuación). Un aspecto clave de esta técnica educativa.

En general, la valoración final que los docentes le dan al aprendizaje-servicio es de 8,78 sobre 10 , habiéndose distribuido las valoraciones como se muestra en la figura 2.

Por otra parte, se ha querido conocer la valoración de la experiencia educativa llevada en el aula, lo que permitirá mejorar la acción formativa para que los alumnos vean la importancia de utilizar técnicas educativas con impacto social. Las puntuaciones medias de todas las preguntas correspondientes a esta dimensión se pueden observar en la tabla 7.
Figura 2. Distribución de resultados con porcentajes de la pregunta 38

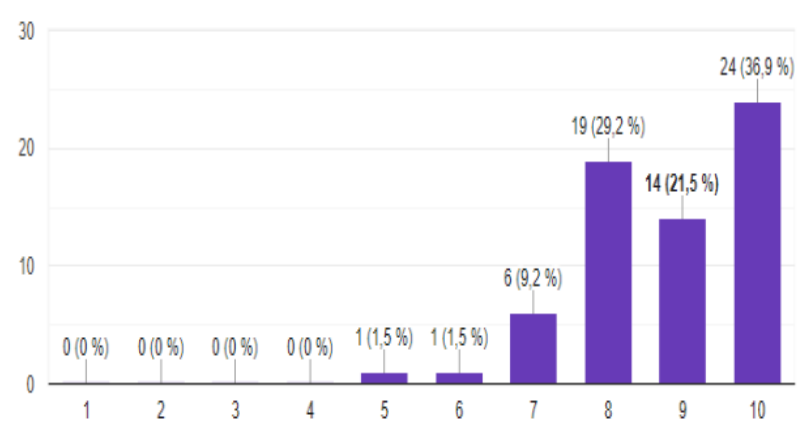

Fuente: elaboración propia

Tabla 7. Puntuaciones medias de las preguntas correspondientes a la dimensión $1 \mathrm{~b}$

\begin{tabular}{|c|c|c|}
\hline No & Preguntas & $\begin{array}{c}\text { Puntuación } \\
\text { media }\end{array}$ \\
\hline 12 & $\begin{array}{l}\text { Con la experiencia aprendizaje- } \\
\text { servicio he trabajado los aspectos } \\
\text { que he marcado como importantes } \\
\text { en la sección anterior }\end{array}$ & $4,138 / 5$ \\
\hline 13 & $\begin{array}{l}\text { Con la introducción teórica de la } \\
\text { sesión anterior ya supe lo valioso } \\
\text { que es el enfoque aprendizaje- } \\
\text { servicio }\end{array}$ & $4,246 / 5$ \\
\hline 14 & $\begin{array}{l}\text { La actividad práctica me ha servido } \\
\text { para darle aún más valor al } \\
\text { enfoque aprendizaje-servicio }\end{array}$ & $4,476 / 5$ \\
\hline 15 & $\begin{array}{l}\text { El haber llevado a cabo una } \\
\text { experiencia de aprendizaje-servicio } \\
\text { me ha servido para conocer la } \\
\text { sensación que se tiene cuando se } \\
\text { trabaja desde esta perspectiva }\end{array}$ & $4,261 / 5$ \\
\hline 16 & $\begin{array}{l}\text { El haber llevado a cabo una } \\
\text { experiencia de aprendizaje-servicio } \\
\text { ha sido positivo para mi desde un } \\
\text { punto de vista de impacto social }\end{array}$ & $4,369 / 5$ \\
\hline 17 & $\begin{array}{l}\text { El hecho de poner en práctica las } \\
\text { fases de sentir e imaginar me ha } \\
\text { motivado más a llevarlo a la } \\
\text { práctica en mis clases }\end{array}$ & $4,492 / 5$ \\
\hline
\end{tabular}




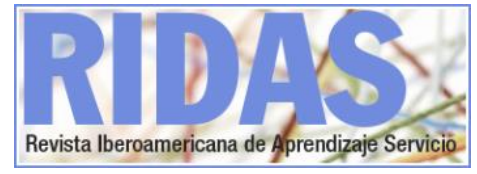

Con los materiales y vídeos de la

21 web me siento preparado para poner en práctica una experiencia de aprendizaje-servicio

Con la formación recibida, me siento a gusto para poner en práctica una experiencia de aprendizaje-servicio

Valora tu satisfacción respecto a la experiencia llevada a cabo en clase

$8,492 / 10$ que arroje esta investigación, mejorando la distribución de puntuaciones (figura 3).

Figura 3. Distribución de resultados con porcentajes de la pregunta 37

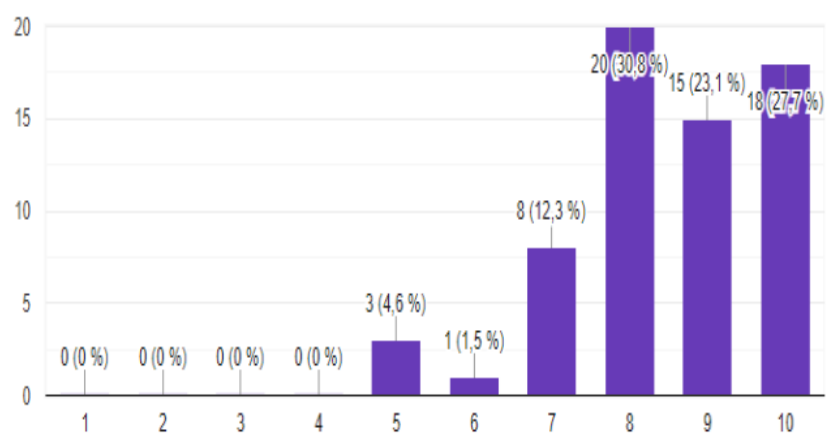

Fuente: elaboración propia

5.2 Valoración de los beneficios del aprendizaje-servicio

En segundo lugar, se ha querido conocer la valoración docente sobre algunos de los beneficios que más se estudian en la literatura relativa al aprendizaje-servicio.

Se ha estudiado, por una parte, las posibilidades de desarrollar ciertas habilidades en los alumnos. Las puntuaciones medias se encuentran en la tabla 8. Entre las habilidades que los docentes creen que más desarrollar trabajar desde un enfoque de aprendizaje-servicio son las habilidades de comunicación y las de trabajo, la primera con una media de 6,7 y la segunda de 6,63 sobre 7 . Les sigue el desarrollo de habilidades organizativas, $y$, por último, creen que las habilidades que menos se desarrollan son las relativas al liderazgo. 
El resto de las preguntas de esta dimensión están planteadas de forma negativa, esto quiere decir que la valoración positiva implica una menor puntuación. En este caso, todas las preguntas tienen una escala de respuesta sobre 5 puntos. Se ha planteado de esta forma para comprobar la confianza que tienen los docentes en sus alumnos en las 4 fases de DFC.

Los docentes creen que sus alumnos serían más capaces de proponer buenas ideas (fase 2. Imagina) y serían capaces de compartir los resultados en redes sociales (fase 4 . Comparte). Creen que serían ligeramente menos capaces para llevar a cabo las ideas elegidas (fase 3. Haz) y aún menos capaces para detectar los focos de problemas adecuados y prioritarios en su entorno (fase 1 . Siente).

Aún con estos resultados, las diferencias son mínimas $(0,3$ puntos de diferentes entre las medias de las preguntas mejor puntuadas y la pregunta peor puntuada), y todas ellas se sitúan por debajo de la puntuación media de la escala, es decir, por debajo de 2,5 sobre 5 .

Por otra parte, se ha estudiado la utilidad de esta técnica para mejorar la concienciación social en los alumnos (tabla 9). En este caso, los docentes valoran de forma más positiva la capacidad del aprendizaje-servicio para desarrollar habilidades para asumir la responsabilidad individual, con una media de 6,43 sobre 7; seguido del desarrollo de habilidades de responsabilidad social y ciudadana, con un 6,36 sobre 7 . El resto de preguntas se ha valorado desde los 0,3 puntos por debajo hasta los 0,6 puntos por debajo.

Tabla 8. Puntuaciones medias de las preguntas correspondientes a la dimensión $2^{a}$

\begin{tabular}{|c|c|c|}
\hline No & Preguntas & $\begin{array}{c}\text { Puntuación } \\
\text { media }\end{array}$ \\
\hline 2 & $\begin{array}{l}\text { Desarrollar habilidades de } \\
\text { trabajo }\end{array}$ & $6,630 / 7$ \\
\hline 3 & $\begin{array}{l}\text { Desarrollar habilidades de } \\
\text { organización }\end{array}$ & $6,492 / 7$ \\
\hline 10 & $\begin{array}{l}\text { Desarrollar habilidades de } \\
\text { liderazgo }\end{array}$ & $6,015 / 7$ \\
\hline 11 & $\begin{array}{l}\text { Desarrollar habilidades de } \\
\text { comunicación }\end{array}$ & $6,707 / 7$ \\
\hline 27 & $\begin{array}{l}\text { Creo que mis alumnos NO serían } \\
\text { capaces de detectar un foco de } \\
\text { problema adecuado y prioritario, } \\
\text { ni contando con mi ayuda }\end{array}$ & $2,369 / 5$ \\
\hline 28 & $\begin{array}{l}\text { Creo que mis alumnos NO serían } \\
\text { capaces de proponer buenas } \\
\text { ideas, ni contando con mi ayuda }\end{array}$ & $2,061 / 5$ \\
\hline 29 & $\begin{array}{l}\text { Creo que mis alumnos NO serían } \\
\text { capaces de llevar a cabo las } \\
\text { ideas elegidas, ni contando con } \\
\text { mi ayuda }\end{array}$ & $2,107 / 5$ \\
\hline 30 & $\begin{array}{l}\text { Creo que mis alumnos NO serían } \\
\text { capaces de compartir } \\
\text { adecuadamente su experiencia, } \\
\text { ni contando con mi ayuda }\end{array}$ & $2,061 / 5$ \\
\hline
\end{tabular}

Fuente: elaboración propia

Tabla 9. Puntuaciones medias de las preguntas correspondientes a la dimensión $2 \mathrm{~b}$

\begin{tabular}{clc}
\hline No & Preguntas & $\begin{array}{c}\text { Puntuación } \\
\text { media }\end{array}$ \\
\hline $\mathbf{4}$ & $\begin{array}{l}\text { Entender las diferencias } \\
\text { culturales y raciales }\end{array}$ & $6,061 / 7$ \\
$\mathbf{5}$ & $\begin{array}{l}\text { Desarrollar habilidades de } \\
\text { responsabilidad social y } \\
\text { ciudadana }\end{array}$ & $6,369 / 7$ \\
\hline
\end{tabular}


Desarrollar habilidades para

6 marcar una diferencia en la comunidad

7 Desarrollar una confianza social $6,076 / 7$ Desarrollar habilidades para

8 asumir la responsabilidad individual

Desarrollar habilidades para

9 ganarse la confianza de los demás

Fuente: elaboración propia

5.3 Valoración de los inconvenientes del aprendizaje-servicio

Por último, se ha realizado una valoración de los docentes sobre los inconvenientes más repetidos en la literatura sobre aprendizaje-servicio. Las preguntas de esta dimensión han sido diferentes para los docentes que se encuentran trabajando en educación y para los docentes que actualmente no trabajan en educación. De los 65 participantes, 61 de ellos están trabajando y sólo 4 de ellos no trabajan en educación.

Por una parte, en el caso de los docentes que están trabajando actualmente, se ha preguntado por la comodidad de aplicación de una técnica tan práctica y dinámica, por si podrían llevar a cabo una experiencia de este tipo y si creen que otros profesores se unirían a trabajar este tipo de experiencias si conocieran el aprendizaje-servicio. En estas dos preguntas, las puntuaciones medias han sido 3,85 y 3,73 sobre 5 , respectivamente. También, si creen que el centro estaría interesado en trabajarlo y si, en ese caso, les daría facilidades. En estos casos, las puntuaciones medias han descendido hasta 3,6 y 3,31 respectivamente. Aquí vemos cómo los docentes estarían más dispuestos, pero serían los centros quienes no estarían tan dispuestos y menos aún si tienen que dar facilidades.

En el caso de los docentes que no están trabajando actualmente, se pregunta si cree que sería fácil introducir aprendizaje-servicio en un centro si se explica a la dirección en qué consiste y si creen que otros profesores se animarían a realizar esta técnica si supieran qué es. En este caso, las respuestas han sido mucho más positivas, obteniendo puntuaciones medias de 4,25 y 4,5 sobre 5 , respectivamente.

\subsection{Discusión de resultados}

Respecto a la primera dimensión de estudio, en general, la valoración sobre esta técnica educativa es positiva. Lo que más valoran los docentes es el atractivo que supone para los alumnos esta técnica, también valoran en menor medida que los alumnos se sienten más capaces de hacer cosas y que trabajan de forma contextualizada. Sin embargo, no se valora como se esperaba el desarrollo de competencias en los alumnos. Esto nos hace reflexionar sobre la formación, para incorporar información sobre cómo podemos desarrollar determinadas competencias en nuestros alumnos con esta técnica.

Por otra parte, lo más relevante para esta investigación es poder aplicar los conocimientos aquí obtenidos en la 
mejora de la experiencia formativa. En general, la formación ha sido bien valorada, aunque se esperan obtener mejores resultados en formaciones futuras. Los docentes consideran que la parte práctica ha sido la más valiosa y valoran por encima de todo el haber puesto en práctica las fases de sentir e imaginar. Lo peor valorado ha sido el material subido a la plataforma, lo que será relativamente fácil de solucionar de cara a la siguiente formación a través de la búsqueda y confección de nuevos materiales. Otro resultado que llama la atención es que, aún con la formación recibida no se sienten del todo capaces de aplicarla en sus clases, esto puede mejorar proponiendo una actividad en la evaluación continua en la que tengan que plantear un proyecto fase a fase.

En cuanto a la segunda dimensión de estudio, la valoración que hacen los docentes sobre los beneficios del aprendizaje-servicio es, en general, positiva en el desarrollo de habilidades. Respecto a los dos grandes grupos de habilidades estudiados: habilidades de trabajo, comunicación, organización y liderazgo, por una parte, y habilidades relacionadas con la concienciación social en los alumnos por otra parte; los docentes valoran el aprendizaje-servicio como una técnica más adecuada para desarrollar habilidades de comunicación y trabajo, seguidas por las habilidades sociales relacionadas con la responsabilidad individual, social y ciudadana. Si obtenemos la media de valoración de las competencias de trabajo y relacionadas frente a la valoración de las competencias con carácter más social, las competencias de trabajo obtienen una media mayor $(6,45$ frente a 6,2 sobre 7$)$. La media de las competencias de trabajo y relacionadas supera incluso a las mayores puntuaciones de las preguntas de competencia social: responsabilidad individual y responsabilidad social y ciudadana.

Esto hace reflexionar de nuevo sobre cómo enfocar la formación. Se debe resaltar más el carácter social de esta técnica, a pesar de que la fase de siente nos ayuda a pensar en necesidades de nuestro entorno, quizá las soluciones que se proponen en la fase 2, Imagina, no son las que más impacto social pueden conseguir. Hay que estudiar más a fondo sobre esta cuestión, sobre la orientación que debemos ofrecer a los alumnos en la segunda fase, imagina.

Por último, la tercera dimensión de estudio, la valoración que hacen los docentes sobre los inconvenientes del aprendizaje-servicio, principalmente sobre la comodidad para llevarlo a la práctica y las posibilidades reales de aplicarlo. Se aprecia en general que los docentes que no están trabajando actualmente en ningún centro educativo son más optimistas que sus colegas que sí están trabajando actualmente, respecto a ambas cuestiones. Bastantes docentes que están en activo actualmente creen que podrían llevar a cabo una experiencia de aprendizajeservicio, y algunos de ellos contando incluso con otros profesores. Sin embargo, al preguntar sobre si el centro facilitaría la realización de la experiencia, el grado de acuerdo baja considerablemente. En este sentido, quizá la creación de material de 
información para la dirección de los centros podría ser un buen comienzo para poder realizar más experiencias de este tipo.

\section{Conclusiones}

Como conclusión se hace evidente la necesidad de aplicar de forma práctica una experiencia de formación de aprendizaje-servicio para mejorar la difusión online de esta técnica, aunque sea de forma simulada. Los resultados han coincido en líneas generales con los obtenidos por Caire (2019) sobre las altas valoraciones de la experiencia.

Sin embargo, se requiere la elaboración de materiales formativos que faciliten la aplicación del aprendizaje-servicio, ya que lo que encontramos actualmente son presentaciones con información básica o artículos de experiencias concretas. Entre ellos se deben encontrar materiales para informar a la dirección de los centros, de forma que faciliten la realización de estas experiencias, incluyéndolas en sus proyectos educativos de centro. Además, se debe profundizar más en cómo podemos desarrollar determinadas habilidades en los alumnos a través de esta técnica, de acuerdo con Strait, Turk y Nordyke (2015).

Por último, se debe considerar incluir en la evaluación continua la realización de una actividad práctica en la que simulen las diferentes fases, para asegurar que los alumnos de formación en línea aplican el aprendizaje-servicio y les permite comprenderlo mejor. Esta iniciativa podría mejorar la autoreflexión que echan en falta
Lehman y Conceição (2010) en su estudio sobre experiencias en línea.

Una de las principales limitaciones de este estudio ha sido la baja participación en la sesión presencial en la que se llevó a cabo la experiencia educativa. Al ser una universidad cuyas sesiones se graban para que los alumnos puedan visualizarlas en el momento que deseen, la asistencia a las sesiones es relativamente baja, no llegando al $50 \%$ en muchas ocasiones.

Una futura línea de investigación, además de la investigación principal que se lleva a cabo sobre formación online, será realizar la misma experiencia práctica de aprendizajeservicio en la educación superior presencial, con el fin de comprobar si existen diferencias en cuanto a las percepciones y la valoración de los docentes en formación sobre la utilidad $y$, en general, los beneficios e inconvenientes de este enfoque educativo con impacto social. Para ello se impartirá una formación similar, con la simulación de la fase 3, Haz, en la que imaginarán las acciones que llevarían a cabo, debido al ajustado tiempo de clase del que se dispone en una asignatura de máster que no se destina exclusivamente a tratar el aprendizaje-servicio.

\section{Referencias bibliográficas}

Caire, M. (2019). Contribuciones de las experiencias de aprendizaje-servicio desde la perspectiva de estudiantes de la Universidad Alberto Hurtado. RIDAS, Revista Iberoamericana de Aprendizaje Servicio, 7 89-111.

Ortega-Ruipérez, B. (2020). Formación del profesorado a distancia sobre aprendizaje-servicio: aspectos a considerar. RIDAS, Revista Iberoamericana de Aprendizaje Servicio, 9, 102-122. 
De Castro, A., Martínez, A., y Guerra, D. (2017). Aprendizaje Servicio, investigación de aula y desarrollo docente. En A. De Castro, y Domínguez Merlano, E. (Comps.) Transformar para educar 4. Aprendizaje Servicio (pp. 4166). Colombia: Universidad del Norte. Recuperado de https://dialnet.unirioja.es/servlet/libro? codigo $=705350$

DFC World. (sf.). Design for Change, Our Story: Timeline. Boston, United States of America .Recuperado de https://dfcworld.com/SITE/dfcstory

Duque, E. (2018). Evaluando una experiencia de aprendizaje servicio en torno al aprendizaje de conceptos de la ciudadanía digital. RIDAS, Revista Iberoamericana de Aprendizaje Servicio, 5, 12-23.

Esparza, M., Morín, V. y Rubio, L. (2018). La incorporación del aprendizaje-servicio en la universidad: la experiencia de la Universidad de Barcelona. RIDAS, Revista Iberoamericana de Aprendizaje Servicio, 6, 97-114.

Fisch, K., McLeod, S., y Bronman, J. (2013). Why Design Thinking in Education. Consider the Current Scenario. En DFC Toolbox of Change (Ed.) Design for Change. Teacher's Manual: Teaching \& Assessing the 21st century skills. India: Riverside.

Fuertes, M. (2013). El ApS en el prácticum de la formación inicial del profesorado. Propuesta de una estrategia de docencia y aprendizaje para la adquisición de competencias genéricas claves para la formación y el desempeño profesional (Tesis doctoral). Universitat Internacional de Catalunya, Barcelona, España.

Hébert, A., y Hauf, P. (2015). Student learning through service learning: Effects on academic development, civic responsibility, interpersonal skills and practical skills. Active Learning in Higher Education, 16 (1), 37-49. Recuperado de https://journals.sagepub.com/doi/abs/1 $0.1177 / 1469787415573357$

Lehman, R., \& Conceição, S. (2010). Creating a sense of presence in online teaching: How to "be there" for distance learners. San Francisco, United States of America: John Wiley \& Sons.

López, I. y Benítez, J. (2018). El Aprendizaje Servicio en la Universidad: una experiencia en el marco de una asignatura del Grado en Educación Primaria. REDU, Revista de docencia Universitaria, 16(2), 195-210.

Recuperado de https://dialnet.unirioja.es/servlet/articu lo? codigo $=6726715$

Malvey, D., Hamby, E., \& Fottler, M. (2006). E-service learning: A pedagogic innovation for healthcare management education. Journal of Health Administration Education, 33(2), 181198. Recuperado de https://europepmc.org/abstract/med/1 6700443

Martín, E., Solari, M., De Vicente, J., Luque, M.J., Nieto, M., y Coll, C. (2018). La potencialidad del aprendizaje servicio para la personalización del aprendizaje escolar. RIDAS, Revista Iberoamericana de 
Aprendizaje Servicio, (5), 37-61.

Martínez, A. (2018). El aprendizaje servicio como experiencia en el Grado de Educación Primaria. RIDAS, Revista Iberoamericana de Aprendizaje Servicio, (5), 142-149.

McWhorter, R., Delello, J., y Roberts, P. (2016). Giving back: exploring serviceLearning in an online learning environment. Journal of Interactive Online Learning, 14 (2), 80-99.

Recuperado de http://hdl.handle.net/10950/494

Miyazaki, T., Anderson, J. B., \& Jones, S. (2017). The Influence of ServiceLearning on the Civic Attitudes and Skills of Japanese Teacher Education Candidates. International Journal of Research on Service-Learning in Teacher Education, 5(1), 1-10. Recuperado de https://ijrslte.journal.library.uta.edu/in dex.php/IJRSLTE/article/view/54

Páez, M. y Puig, J., (2013) La reflexión en el Aprendizaje-Servicio. Revista internacional de educación para la justifica social, 2(2), 13-32. Recuperado de

https://repositorio.uam.es/handle/1048 6/660355

Pérez, L. y Ochoa, A. (2017). El aprendizaje-Servicio (APS) como estrategia para educar en la ciudadanía. Alteridad. Revista de educación, 12 (2), 175-187.

Puig, J., Gijón, M., Martín, X. y Rubio, L. (2011). Aprendizaje-servicio y educación para la ciudadanía. Revista de Educación, número extraordinario,
45-67. Recuperado de

http://www.revistaeducacion.educacion .es/re2011/re2011_03.pdf

Rodríguez, M. (2014). El AprendizajeServicio como estrategia metodológica en la Universidad. Revista Complutense de Educación, 25(1), 95-113.

Recuperado de

https://idus.us.es/xmlui/handle/11441/ 43001

Sotelino, A., Santos, M. y García, J. (2019). El aprendizaje-servicio como vía para el desarrollo de competencias interculturales en la Universidad. Educatio Siglo XXI, 37(1), 73-90.

Strait, J., Turk, J. y Nordyke, K. (2015). Pedagogy of civic engagement, highimpact practices, and eServiceLearning. En J. Strait y K. Nordyke (Eds.) eService-Learning. Creating experiential learning and civic engagement through online and hybrid courses (pp. 7-19). Virginia, United States of America: Stylus Publishing, LLC.

Toncar, M., Reid, J., Burns, D., Anderson, C. y Nguyen, H. (2006). Uniform assessment of the benefits of service learning: The development, evaluation, and implementation of the SELEB scale. Journal of Marketing Theory and Practice, 14(3), 223-238. Recuperado de https://www.tandfonline.com/doi/abs/1 0.2753/MTP1069-6679140304

Waldner, L., McGorry, S. y Widener, M. (2010). Extreme E-Service Learning (XE-SL): E-Service Learning in the $100 \%$ Online Course. MERLOT Journal of Online Learning and Teaching, 6(4), 
839-851. Recuperado de

http://jolt.merlot.org/vol6no4/waldner

1210.pdf

Waldner, L., McGorry, S. \& Widener, M.

(2012). E-Service Learning: the

evolution of Service-Learning to engage

a growing online student population.

Journal of Higher Education Outreach

and Engagement, 16(2), 123-150.

Recuperado de

http://openjournals.libs.uga.edu/index.

php/jheoe/article/view/792 


\title{
Solidaridad en la travesía: como el aprendizaje solidario puede cruzar el ferry
}

\author{
Isabella Alchorne \\ Sofia Carvalho \\ ONG Movimiento Futuro, Brasil
}

\section{Resumen}

Este escrito presenta la experiencia del proyecto Caminho del Futuro, un juego de seis pasos llevado a cabo por la ONG brasileña Movimento Futuro, que tuvo como propósito unir las realidades de dos escuelas de Brasil, posibilitando que alumnos que "nunca podrían llegar a conocerse" hicieran proyectos de aprendizaje solidario juntos.

\section{Palabras clave}

Protagonismo, sueños, jóvenes, habilidades socioemocionales, solidaridad, escuela, aprendizaje solidario, proyectos. 


\title{
Solidarity on the crossing: how solidary education can be a ferry
}

\author{
Abstract \\ This paper presents the Way of the Future project, a six-step game carried out by the \\ Brazilian NGO Movimento Futuro which aimed to bring together the realities of two \\ schools in Brazil, making it possible for students who would otherwise never be able to \\ meet to do solidarity learning projects together.
}

\section{Keywords}

Protagonism, dreams, youth, social-emotional skills, solidarity, school, solidary education, projects. 


\section{Introducción}

La escuela es uno de los principales espacios en que las personas se conocen e interactúan con otras de diferentes edades y personalidades. Pero en ellas también se perciben situaciones de conflicto, tanto en los estudiantes, como en los directivos. En el caso de los alumnos, podemos mencionar el bullying, los cambios en el cuerpo y en el propio espacio escolar. En cuanto a los directivos, tienen muchísimo trabajo, muchas responsabilidades y conflictos diarios para solucionar.

Frente a esta realidad, y con el fin de contribuir a mejorar las situaciones mencionadas, en junio de 2015 nació Movimento Futuro1, constituida como una Organización No Gubernamental (ONG) en Brasil. Su principal propósito es desarrollar habilidades socioemocionales en los jóvenes a través de sus sueños. En el año 2018 se convirtió en una asociación socioeducativa y comenzó a formar parte de la Red Brasileña de Aprendizaje Solidario.

El proyecto principal de la organización se llama Caminho do Futuro, que consiste en un juego de seis pasos. En el mismo, los jóvenes realizan acciones de aprendizaje-servicio, valorizando la escuela y disminuyendo los conflictos.

1 https://www.movimentofuturo.com.br/

\section{RIDIS}

Los 6 pasos del proyecto "Caminho do Futuro" son:

- Inter-agir: Es el momento en que el grupo se conoce de otra manera, experimenta una organización diferente del aula, comienza a contactar con la metodología del juego. En este paso se trabaja la conciencia colectiva.

- Com-fiar: el momento de descubrir historias de personas en la escuela y lo que más les gusta allí. Además, para movilizar los recursos que tienen en el espacio, ejercen el Look de Abundancia. Esto se debe a que el objetivo es realizar el show de talentos. La habilidad socioemocional que se trabaja en este paso es la colaboración.

- Sonhar: soñar es el paso en que los estudiantes miran su vecindario y se dan cuenta de las fortalezas y debilidades que pueden transformarse. La pregunta guía es: Si tuviera un mes para transformar el mundo, ¿qué haría?. En este paso se la habilidad socioemocional que se aborda es la empatía.

- Planejar: la planificación es el paso más desafiante, ya que implica la autonomía de muchos estudiantes. Con una propuesta gamificada para un modelo de negocio, los jóvenes aprenden a hacer realidad sus ideas. Todos los jóvenes tienen un personaje importante en el juego para que el sueño se haga realidad. El 
trabajo se centra en la autonomía.

- Realizar: el momento más esperado, cuando ponemos nuestras manos en la masa para hacer realidad el sueño. Por supuesto, pedimos a todos que ayuden y trabajen juntos. Las habilidades socioemocionales que se trabajan en este paso son la autoestima y la confianza.

- Contagiar: está marcado por la celebración en Sonhatura, una gran fiesta de reunión para todos los que participaron en el Movimiento Futuro, para que puedan intercambiar experiencias. La celebración es esencial para involucrar a los jóvenes en un mayor cambio social. En el último paso se trabaja la capacidad de logro.

A través del juego, los jóvenes, de manera rápida, fácil y divertida, se descubren y llevan a cabo acciones transformadoras. Cada paso del juego tiene una caja misteriosa asociada y el grupo realiza varias actividades para avanzar y descubrir qué hay dentro de la caja. En el proceso de los 6 pasos, se trabajan habilidades socioemocionales; se aprende a interactuar con los demás, a confiar en ellos y en el otro; a soñar sin límites; y a realizarse con y entre todos.

Una de las experiencias que se encuendran en este proyecto, es la llevada a cabo desde el año 2016, en dos escuelas que se encuentran en el Brooklin (barrio de la ciudad de San Pablo) y en el Riacho Grande (barrio de la ciudad de San Bernardo del Campo) y son asociadas a la ONG. La escuela del Brooklin es privada y pertenece a un público de clase media alta de la capital paulista. Está muy influenciada por las nuevas tecnologías, incluyendo un laboratorio maker para que los alumnos hagan sus proyectos.

En contrapartida, la escuela del Riacho es pública y para llegar a ella, se tiene que tomar un ferry. Además, no hay señal de teléfono móvil ni estructuras básicas para la organización de una escuela. Está localizada en una naturaleza increíble. Las dos están a solamente $50 \mathrm{~km}$ de distancia una de la otra, pero muy lejos en calidad y funcionamiento.

Con el tiempo, los estudiantes de los dos lugares comenzaron a preguntarse por los de la otra escuela.

Posteriormente, quisieron conocerse. Por ello, en el año 2018, las dos escuelas, en conjunto, jugaron el Caminho del Futuro para planear cómo podrían hacer los proyectos de aprendizaje-servicio juntos.

\section{Los proyectos +Amor, -Guerra y de Skate}

El proyecto +Amor, -Guerra fue basado en un deseo de una estudiante que quería disminuir, con el amor, los prejuicios entre las personas. Entonces, se formó un grupo de diez alumnos para trabajar con ella. Después de mucha investigación sobre los tipos de prejuicios, percibieron que a ellos les incomodaba muchísimo el racismo y que este era muy fuerte en Brasil. Entonces, comenzó el próximo desafío: ¿cómo ellos, que son tan diferentes y 
viven en lugares tan diferentes, podrían hacer un mismo proyecto?

La idea vino en un brainstorming. En Brasil existe una muñeca llamada Abayomi" que es negra y es muy simple de hacer. Es toda rellena de nudos y de tejidos baratos. En dos días, los dos grupos se organizaron para contar estas historias en jardines de infantes públicos de sus regiones. Ellos enseñaron a los chicos todo lo que descubrieron juntos en este proceso $y$, para finalizar, hicieron una oficina de creación de Abayomis para que ellos pudieran jugar y luego, las muñecas, se queden en los espacios escolares para los infantes.

Se puede decir que el proyecto +Amor, -Guerra está relacionado con el aprendizaje-servicio, según el concepto de Mori (2013) "aprendizagem-serviço solidário é o nome de atividades pedagógicas de intervenção social onde o aluno aprende a pensar e a utilizar os saberes escolares para resolver problemas sociais reais" (p.149)2.

Sobre el proyecto del campeonato de Skate en el Riacho Grande, este se inició cuando dos estudiantes percibieron que tenían el mismo sueño de transformar el mundo con su deporte preferido. Después de mucho trabajo, 20 jóvenes, entre ellos niños y niñas participaban del primer campeonato de skate de la comunidad. Al final del día, jóvenes que nunca

2 Traducción libre: el aprendizaje-servicio solidario es el nombre de actividades pedagógicas de intervención social en que el alumno aprende a pensar y a utilizar los saberes escolares para resolver problemas sociales reales. siquiera pensaron que podrían compartir las mismas pistas de skate lo hacían, gracias a que dos alumnos de realidades tan diferentes se unieron para pensar en cómo podrían impactar la región saliendo de la lógica de la caridad.

La Base Nacional Común Curricular de Brasil, ley establecida en 2018 sobre cómo las escuelas deben elaborar el currículo, determina que es necesario que se tenga como objetivo "consolidar, profundizar y ampliar la formación integral de los alumnos, de modo que ellos puedan construir y realizar sus proyectos de vida, teniendo en cuenta la justicia, la ética y la ciudadanía" (Ministério da Educação, 2018, p.471).

En este sentido, según De Almeida y Mori (2016) "a aprendizagem solidária acontece quando os alunos aplicam na vida o que estudam nas aulas e assim transformam a realidade, aprendendo questões que não se encontram necessariamente nos livros, nos laboratórios ou nas lições das escolas" (p.104)3.

Al respecto, concluimos que en este proyecto también se pudo percibir el aprendizaje-servicio desarrollado entre los dos estudiantes.
3 Traducción libre: el aprendizaje sollidario ocurre cuando los alumnos aplican en la vida lo que estudian en las clases y así transforman la realidad, aprendiendo cuestiones que no se encuentran necesariamente en los libros, en los laboratorios o en las tareas de casa. Ello ocurre cuando el sujeto del aprendizaje se siente preparado a tener la responsabilidad de no solamente constatar las desgracias del mundo, pero de interferir en ellas, pensando y organizando soluciones concretas. 


\section{Conclusiones}

Es posible decir que la ONG brasileña Movimento Futuro llevo a cabo una experiencia de aprendizaje-servicio con los estudiantes, ya que les proporcionó la posibilidad de intervenir y asumir la responsabilidad sobre su realidad, pensando en soluciones concretas, organizando y realizando su intervención.

Durante los proyectos presentados fue utilizada la fuerza del estudiante para transformar el currículo de la escuela y desarrollar en los alumnos la importancia de pensar y crear soluciones completas para una sociedad digna para todas las personas.

\section{Referencias bibliográficas}

De Almeida, F. y Mori, K. (2017). Aprendizagem solidária: construção de um currículo significativo e eficaz. Revista Trama Interdisciplinar, 8(1), 92-108. Recuperado de http://editorarevistas.mackenzie.br/ind ex.php/tint/article/view/9376

Ministério da Educação.(2018). Base Nacional Común Curricular. Recuperado de http://basenacionalcomum.mec.gov.br/i mages/BNCC_EI_EF_110518_versaofin al_site.pdf

Mori, K. (2013). A solidariedade como prática curricular educativa (Tesis doctoral). Recuperado de https://tede2.pucsp.br/bitstream/handl e/9728/1/Katia\%20Regina\%20Goncalv es\%20Mori.pdf 


\title{
Del Instituto a Tinduf. El proyecto El Sáhara Occidental
}

\author{
Sergi Sanchiz \\ Noelia Box \\ IES La Foia d'Elx, España
}

\section{Resumen}

El alumnado de secundaria no es ajeno al avance de ideologías discriminatorias que promueven la violencia contra el otro sobre la base de un nacionalismo excluyente y agresivo. La escuela debe promover actitudes basadas en la justicia y solidaridad, sin eludir la crítica a la realidad existente. Los proyectos de aprendizaje-servicio permiten conocer otras situaciones distintas a las vividas y, a la vez, educar en el compromiso y experimentar la satisfacción de trabajar por el bien colectivo. Sobre estas premisas, durante los tres últimos cursos el IES La Foia d'Elx ha desarrollado el proyecto El Sáhara Occidental. A través de actividades de enseñanza y aprendizaje, charlas, propuestas culturales e iniciativas solidarias hemos promovido actitudes críticas y el compromiso con el pueblo saharaui en el conjunto de la comunidad educativa.

\section{Palabras clave}

Aprendizaje-servicio, cooperación, solidaridad, conflicto, Sáhara Occidental. 


\title{
From High School to Tindouf. The Western Sahara project
}

\begin{abstract}
Secondary school students are not immune to the proliferation of discriminatory ideologies that promote violence against others on the basis of exclusionary and aggressive nationalism. Schools must promote attitudes based on justice and solidarity, without avoiding criticism of the existing reality. Service-learning projects make it possible for students to learn about situations other than those they have experienced and, at the same time, increase commitment and experience the satisfaction of working for the collective good. Based on these premises, over the past three years La Foia d'Elx High School has developed the project Western Sahara, which through teaching and learning activities, talks, cultural activities and solidarity initiatives, has sought to promote critical attitudes and increased commitment to the Saharan people among the whole educational community.
\end{abstract}

\section{Keywords}

Service-learning, cooperation, solidarity, conflict, Western Sahara. 


\section{Introducción}

Nuestros estudiantes se enfrentan a un mundo en el que, contrariamente a la imagen que se les muestra en redes sociales, anuncios publicitarios y videoclips, el conflicto es la norma; y todo parece apuntar a que así seguirá siendo, probablemente con mayor intensidad, durante su vida adulta. Si bien los jóvenes no son ajenos a esta realidad, no es menos cierto que la adopción de actitudes y sobre todo prácticas solidarias no es lo común entre nuestros adolescentes (como tampoco en el resto de nuestra sociedad), aunque esta es una etapa tradicionalmente conceptuada como de tendencia al altruismo, en relación con la construcción de la subjetividad y de una visión del mundo propia.

Si partimos de la idea de que la educación pública debe aportar no solo conocimientos científicos, sino también experiencias relevantes, podemos concluir que la escuela debe procurar proporcionar a los estudiantes vivencias que les ayuden a construir una subjetividad en la que la solidaridad activa y el compromiso con la transformación del mundo que les rodea tengan al menos un peso importante, de manera que puedan enfrentarse a los cambios con los mejores asideros posibles.

El proyecto El Sáhara Occidental surge a partir del recuerdo y la experiencia dejados por un proyecto anterior del centro, Escuela solidaria, desarrollado hace una década. Por aquel entonces, como colofón de todo un curso de organización y formación en nuestro instituto, un grupo de estudiantes de Bachillerato desarrollaba actividades de docencia y cooperación en los campamentos de refugiados saharauis durante dos semanas. Recuperar esta experiencia fue el objetivo al que, durante algún tiempo, diversos docentes estuvimos dedicando reflexiones y tanteos.

\section{Marco teórico}

Aunque los recursos curriculares relativos al conflicto del Sáhara Occidental no abundan, lo cierto es que nuestro proyecto no es del todo único ni pionero. En primer lugar, hay disponibles materiales destinados a la educación preuniversitaria que, al proceder por lo general del mundo de la solidaridad y la cooperación, están cerca del espíritu y la práctica del aprendizaje-servicio, normalmente con objetivos de concienciación social ${ }_{1}$.

También hay alguna experiencia de inclusión del problema en las programaciones curriculares, dada la conexión que se puede establecer, en particular, con la materia de Historia; es el caso de Fernández Álvarez (2014), centrado en un objetivo disciplinar,

\footnotetext{
1 Ejemplos de ello son la unidad didáctica Sáhara en el corazón, del grupo Jaima, para el Bachillerato; la unidad Voces del Sahara, de la Asociación de Amistad con el Pueblo Saharaui de Sevilla (AAPSS), para Primaria; y el número 2 de la interesante serie del Centro de Investigación para la Paz dedicada a Las raíces de los conflictos, elaborado por J.M. Baraibar con el título El Sahara Occidental. La AAPSS también ha editado STOPMINAS junto a la Agencia Andaluza de Cooperación Internacional para el Desarrollo.
} 
como es el desarrollo de las habilidades de investigación histórica. En sentido contrario, podemos encontrar iniciativas destinadas a recabar ayuda a los refugiados saharauis en las aulas a partir de actividades y contenidos académicos no relacionados con el conflicto, como Al cor de la memòria (Fernández Pou, 2002).

Finalmente, diversos centros educativos se han animado a implicar a su alumnado en acciones sobre el terreno, a través de estancias de distinta naturaleza en los campamentos de Tinduf: es el caso del proyecto Lleida amb el Sàharaz y de la experiencia descrita por Campillo y Para (2003) en Santa Coloma de Gramenet.

En puridad, aún siendo de gran interés, parece que ninguno de estos proyectos encajaría en lo que supone la metodología del aprendizaje-servicio, de acuerdo con los cuadrantes desarrollados por la Universidad de Standford (Tapia y Montes, 2017) que contemplan los diferentes manuales. Por otro lado, tenemos iniciativas que sí han sido planteadas como proyectos de este tipo (Valero, 2020) y que abordan parte de lo que nosotros hemos querido hacer en el centro (las recogidas de alimentos), pero con otros objetivos curriculares y de servicio.

Tal y como señalan Del Campo, Gimelli y Tapia (2017), al esbozar este proyecto pretendíamos propiciar en nuestro alumnado la comprensión de

2 Se puede consultar diversa información relativa al proyecto, así como reportajes y testimonios, en la web www.saharaponent.com/lleida-ambel-sahara

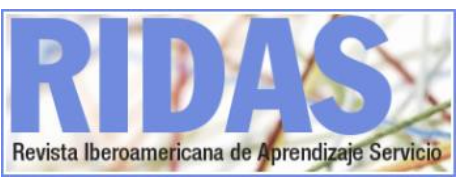

una problemática que va más allá de lo inmediato y conocido, abordándola desde diferentes perspectivas disciplinarias con el fin de asumir su complejidad y la de las posibles estrategias para afrontarla. En esta línea, no hemos obviado la relación que hay entre el sufrimiento de una comunidad humana concreta, las decisiones políticas y los problemas estructurales.

De ahí que un elemento importante en nuestro proyecto sea la consideración del medio y largo plazo, que implica: a) un compromiso sostenido del instituto, sin fecha de finalización; b) el conocimiento y acción del alumnado, en función de su propio compromiso, a lo largo de todo un curso o de varios; y c) animar a los estudiantes a proseguir sus tareas solidarias fuera del espacio y tiempo en que transcurre su vida escolar, y poner las bases para ello.

Entendemos que este proyecto debe durar, al menos, tanto como el conflicto y las necesidades de la población afectada, y por ello lo concebimos como una construcción que debe mejorarse, crecer, adaptarse y reinventarse en función de cómo evolucione el contexto global, pero también el local en el que actuamos.

Siguiendo a los mismos autores, consideramos de gran importancia la toma de contacto con realidades culturales muy distintas, pero también con el mundo adulto (asociaciones de solidaridad y de inmigrantes, instituciones locales, empresas, entre otros), del que la escuela ha tendido tradicionalmente a separar a los jóvenes. Con la asunción de 
responsabilidades y la adopción de roles distintos a los que, como adolescentes, se ven sometidos en su vida cotidiana, facilitamos su maduración y su formación como ciudadanos autónomos y responsables de sus actos, lo cual resulta de trascendental importancia en el momento actual. Pese a lo costosa que ha resultado la tarea de involucrar a cierto número de estudiantes a un determinado nivel, somos optimistas respecto a la forma en que este proyecto podrá contribuir a mejorar una diversidad de competencias que les será de utilidad en su vida adulta, tal y como se ha demostrado en otros casos (Torregrosa, 2017).

Como destacan Martín et al. (2017), para el éxito de un proyecto de aprendizaje-servicio es fundamental que el alumnado perciba la utilidad y la relación del proyecto con su vida cotidiana. En el caso que nos ocupa, además del papel que cumple la presencia frecuente de las asociaciones solidarias, mantenemos la hipótesis de que la perspectiva de vivir el problema al finalizar su escolarización otorga sentido a los aprendizajes relacionados, haciéndolos más significativos: esto debería servir de impulso a la identificación de los estudiantes con el proyecto y a su implicación en el mismo a lo largo de su permanencia en el instituto (Batlle, s.f.; Mendía, 2012).

\section{El marco institucional}

El IES La Foia d'Elx se ha venido caracterizando por un ambiente favorable a la cooperación, que ha facilitado retomar nuestra relación con el pueblo saharaui desde una perspectiva que fuera más allá de lo escolar, pero integrándola de forma sólida con nuestra identidad institucional, tal y como recomiendan Tapia y Montes (2017). Así, durante el curso 2016/2017 introdujimos una serie de actividades de aprendizaje, en diferentes áreas, relativas a la problemática de las personas refugiadas"(o, más exactamente, en busca de refugio). Estas iniciativas, además, se incluyeron en el proyecto de innovación (PIIE) Hamelin, que ya llevaba algunos cursos en marcha y con el que hemos ido entretejiendo algunas de las acciones. Esta relación, así como las colaboraciones establecidas durante el curso 2018/2019, aparecen resumidas en la figura 1 .

Por fin, con el inicio del curso 2017/2018, el conocimiento de la convocatoria de los Premios aprendizaje-servicio nos sirvió como pretexto para estructurar, desarrollar y ampliar las ideas que veníamos barajando, en sintonía con la idea compartida de utilizar pedagógicamente las tareas de carácter solidario y darles un alcance que abarcara nuestro entorno social, más allá de los muros del instituto3.

Así pues, a lo largo de ese curso desarrollamos diversas propuestas curriculares que se entretejieron con numerosas iniciativas de contacto con la cultura saharaui y ayuda a los campamentos de refugiados en Tinduf (Argelia)4.

3 La evaluación posterior nos ha mostrado que de hecho, más o menos instintivamente, contemplamos desde el comienzo varios de los puntos señalados por Puig (2010) para iniciar un proyecto de aprendizaje-servicio.

4 Nuestro canal de Youtube 
Con la experiencia acumulada, hemos ido desarrollando el proyecto en una triple dirección: en primer lugar, hacia afuera, ampliando el entorno al que se dirige El Sáhara Occidental fuera del instituto; por otro lado, dentro de este, acotando el grupo que debía vertebrar el desarrollo del aprendizaje-servicio (la Asociación de Alumn@s), desplegando una sensibilización más concienzuda para el conjunto del alumnado y desarrollando más exhaustivamente las propuestas de o para determinados grupos de estudiantes. Por último, y en lo que se refiere a los objetivos, hemos querido concretar más el destino del servicio en el territorio $y$, al mismo tiempo, diversificar su carácter (ayuda material, concienciación y estancias del alumnado), a partir de las observaciones y contactos realizados en sendas visitas de docentes a los campos de refugiados saharauis durante los cursos 2018/2019 y $2019 / 2020$.

\section{Objetivos y metodología}

Las necesidades que detectamos son básicamente tres. Por un lado, se trata de atender problemas específicos de los refugiados saharauis en Tinduf, y en concreto del Centro de Discapacitados de la wilaya de Auserd, a través de la difusión del problema y la ayuda material. Para el presente curso, esta parte del servicio se ha ampliado, de acuerdo con las autoridades educativas

(http://bit.ly/YoutubeSahara) recoge tanto algunas de las actividades llevadas a cabo como los resúmenes en vídeo de los dos últimos cursos. La cuenta de Twitter @ProjecteSahara nos sirve tanto para dar a conocer la marcha del proyecto como para difundir noticias y artículos relativos al conflicto. saharauis, a la colaboración en tareas docentes en centros de Primaria de la misma wilaya y la realización de actividades de animación cultural.

Además, el proyecto se plantea como contribución del instituto a las tareas de asociaciones de solidaridad con el Sáhara Occidental que trabajan en nuestro territorio próximo, facilitándoles espacios y audiencia para sus labores de concienciación y otras actividades.

En tercer lugar, y como tarea más propiamente vinculada a un centro educativo, abordamos la concienciación acerca de la cuestión saharaui, y de los derechos humanos en general, entre la población de nuestro entorno, en conexión con la problemática general referida a la inmigración y la islamofobia. Son dos motivos, relativos al impacto de las acciones educativas, que de hecho recoge Rubio (2008) para justificar la puesta en marcha de proyectos de aprendizaje-servicio solidario.

Por lo que se refiere al alumnado, vimos necesario ampliar su horizonte de intereses $y$, sobre todo, estimular la empatía, la solidaridad y la cooperación hacia otros grupos y sociedades, así como la preocupación por problemas generales, tales como los derechos humanos, las personas en busca de refugio y las causas de la inmigración. Se trata de competencias sociales y cívicas imprescindibles para construir una sociedad democrática, y por ello hemos procurado atender especialmente a los niveles más bajos, con el fin de ir recogiendo los frutos en los próximos años. 
Por otra parte, el proyecto se ha enfocado como elemento de refuerzo para la cohesión y el estímulo del activismo de la Asociación de Alumn@s, constituida tan solo hace dos cursos. Se trata de fomentar el debate y la toma de decisiones, el trabajo en equipo y la valoración de sus propias actividades, y su implicación en el proyecto ha servido como experiencia importante en la que desarrollar esas competencias.

De acuerdo con estos objetivos, las primeras acciones se dirigieron a buscar ayuda fuera del centro. Con las entidades dedicadas a la solidaridad hemos emprendido diversas actividades de sensibilización, servicio (recogidas de alimentos y otros productos, Jornada Solidaria del instituto, charlas, debates y otros eventos públicos de difusión) y celebración.

Además, hemos ido ampliando el alcance de nuestro trabajo al ámbito institucional para, así, ayudar a extender el impacto del proyecto en el municipio, a través de los acuerdos alcanzados con el Ayuntamiento de Elche, del que hemos recabado diversos medios materiales (espacios, equipamientos y subvenciones) con los que desarrollar actos de celebración, así como reforzar y ampliar el servicio en sus aspectos de difusión del problema y de colaboración de los estudiantes en los campamentos de refugiados. Esta diversidad de alianzas se recoge en la figura 1.

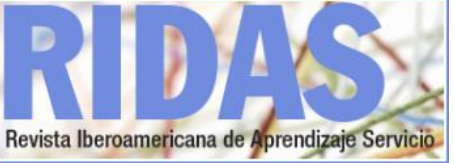

Figura 1. Entidades involucradas y vinculación al proyecto El Sáhara Occidental

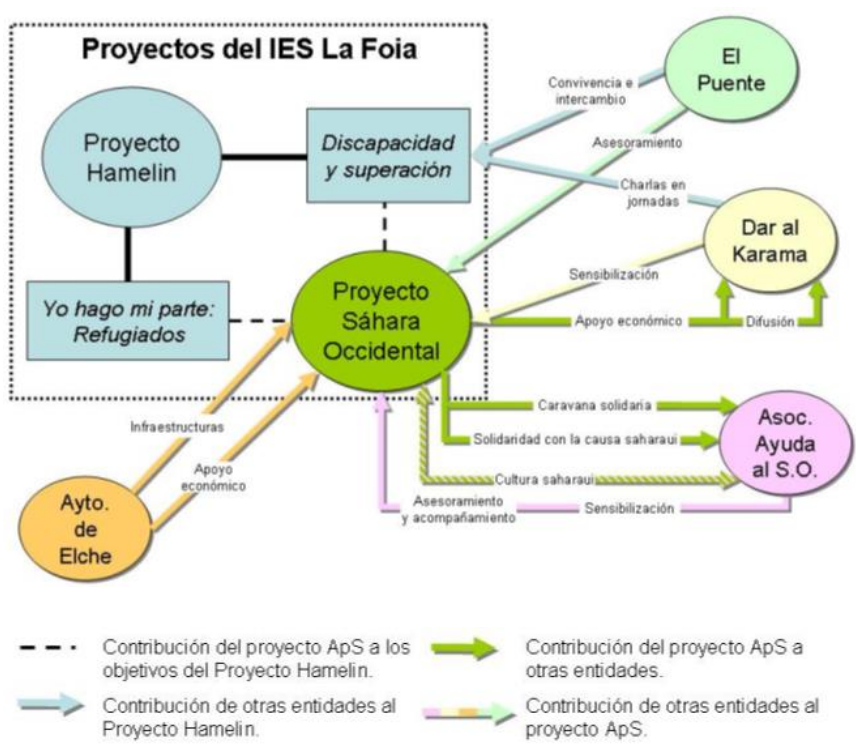

Fuente: elaboración propia

Cada curso se inicia con reuniones del profesorado interesado en las que se evalúa la edición anterior y se analiza las necesidades de adaptación del proyecto, su posible imbricación con el PIIE Hamelin, la incorporación de docentes y nuevas actividades en las diferentes áreas, las posibilidades de ampliar las alianzas institucionales, la envergadura o modificación del servicio a realizar y los materiales con los que iniciar la sensibilización del alumnado. Esta tiene lugar en octubre, a partir de vídeos para la reflexión colectiva en todos los niveles, gracias a la implicación de las tutorías y el departamento de Orientación, encargado de coordinarlas. Con estas sesiones, que se pueden completar con otras actividades en los meses siguientes, se da a conocer la cuestión 
saharaui y sus coordenadas históricas, así como la realidad de los campamentos y la vida de los refugiados, además de facilitar la implicación del alumnado en actividades de servicio.

Por lo que respecta a las actividades de aprendizaje, aunque no es posible detallar aquí, por razones de espacio, todas las que hemos llevado a cabo desde las distintas áreas de conocimiento, sí debemos dejar constancia de la implicación entusiasta con la que muchos compañeros y compañeras se han sumergido en el proyecto, desde la voluntariedad y el respeto a los tiempos, intereses y posibilidades de cada docente.

En la figura 2 hemos incluido las áreas participantes con algunos de los contenidos que trabajaron durante el curso 2018/2019, aunque faltaría detallar la diversidad de niveles y añadir otros departamentos que se involucraron en la primera edición, como Música, Religión y Dibujo.

Queremos destacar también el protagonismo que han adquirido, en particular, los estudiantes de $2^{\circ}$ y $4^{\circ}$ de ESO que han conformado la Asociación de Alumn@s. Por la propia naturaleza de esta forma de agrupación, los aprendizajes adquiridos han sido eminentemente competenciales y no vinculados a disciplinas concretas, sino que se han producido en el mismo proceso de puesta en práctica del servicio.

Junto a las tareas de carácter más formal, otras actividades han acercado al alumnado los aspectos de la cultura saharaui desde una perspectiva lúdica, gracias a la implicación de las asociaciones y docentes vinculados al proyecto. Esta faceta se concentra en la Jornada Solidaria que celebramos al final del segundo trimestre. En esa misma Jornada, llevamos la cultura saharaui a la Escuela Infantil de La Foia, donde alumnado de ESO relata a los pequeños algunos cuentos del Sáhara. Esta actividad ha acabado consolidándose, hasta el punto de dar lugar a un Taller de cuentacuentos que, inserto en las actividades propias del PIIE Hamelin (los patios lúdicos), cuenta en la actualidad con diez estudiantes y tres profesores participantes y contribuye a animar diversas celebraciones del centro.

De acuerdo con los objetivos descritos, el servicio ha incluido actividades para recabar ayuda material dirigida a los campamentos saharauis $y$, en particular, para el Centro de discapacitados de la wilaya de Auserd5: participación en las caravanas solidarias, recogidas de juegos de desarrollo psicomotriz, coorganización del Festival Solidari pel Sàhara Occidental (mayo de 2019), recogida de mochilas usadas, compra de cuentos para la red de bibliotecas Bubisher.

Otra vertiente han sido las acciones para la difusión del conflicto del Sáhara Occidental, la más destacada de las cuales ha sido, además de las apariciones en la prensa local y la intervención en distintos foros, la

5 Una introducción al trabajo que realiza este centro se puede ver en el vídeo que preparamos para el festival del 17 de mayo:

(http://bit.ly/VideoAuserd). 
Jornada de debate y concienciación del 12 de abril de 2019 en el Centre de Congressos de la ciudad. Para todo ello, los chicos y chicas de la Asociación de Alumn@s han tenido que planificar su intervención en la clasificación y empaquetado de los materiales aportados por sus compañeros en las distintas caravanas, la recaudación de dinero para el transporte, las tareas de apoyo en la jornada de abril y su participación en el Festival.

\section{Otros grupos han contribuido} elaborando materiales de difusión y exposición, recaudando dinero para comprar libros infantiles, redactando un comunicado de apoyo al pueblo saharaui para la jornada de debate, planificando la Carrera solidaria, elaborando artesanía, llevando los cuentos saharauis al centro de Educación Infantil cercano, elaborando cometas para actividades de celebración del proyecto, organizando un recital musical o publicitando y organizando la elaboración y recogida de juguetes, según los casos.

Así pues, algunas actividades de aprendizaje han desembocado en servicios muy concretos emprendidos por grupos-clase o por la Asociación, mientras que otras han promovido la implicación del alumnado en las actividades solidarias propias de todo el instituto (recogidas para las caravanas a los campamentos y Carrera solidaria), como queda resumido en la figura 2.
Figura 2. Vinculación curricular del servicio

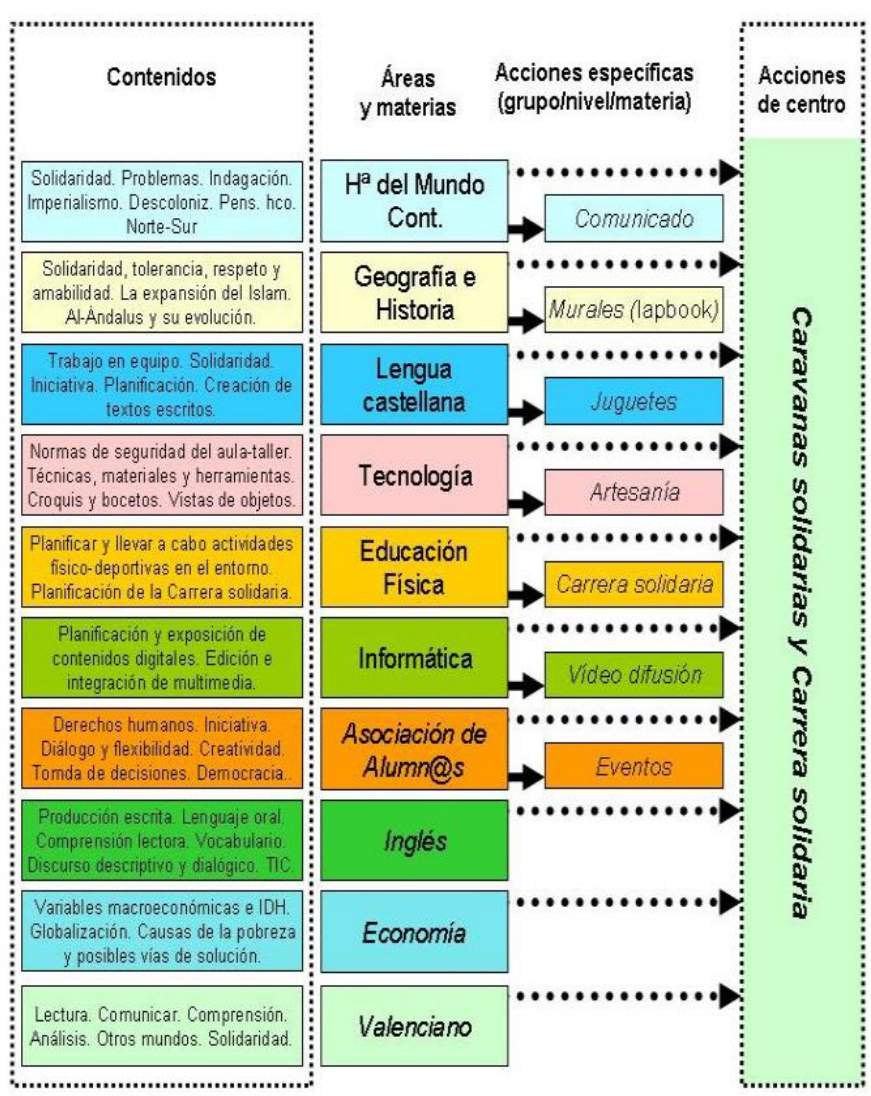

Fuente: elaboración propia

Como ya se ha señalado, el nuevo servicio previsto para este curso es la estancia de algunas estudiantes en la wilaya de Auserd durante las vacaciones de Semana Santa, acompañadas de cinco docentes, para colaborar en la enseñanza del castellano a alumnado de Primaria y desarrollar otras actividades lúdicas y culturales. Con ese objetivo, profesorado y alumnas estamos organizando y elaborando de forma conjunta los recursos que necesitaremos, mientras planificamos 
las campañas que nos permitirán recabar la ayuda material que llevaremos a los campamentos.

En lo que respecta a las tareas de concienciación social, además de proseguir con nuevas actuaciones fuera del centro en forma de conciertos solidarios y charlas, una ayuda de la Concejalía de Cooperación del Ayuntamiento de Elche nos ha permitido convertir las fotografías tomadas por nuestras compañeras en los campamentos de Tinduf en la exposición Mirades del Sàhara, que está siendo demandada por entidades de todo el territorio valenciano, incrementando así el impacto del proyecto.

Por último, cabe recordar que, finalizado el curso 2018/2019, pusimos nuestro instituto a disposición de la Asociación Ayuda al Sáhara Occidental para que pudiera celebrar en las mejores condiciones la Fiesta del Cordero (11 de agosto de 2019), junto a los niños participantes en el programa Vacaciones en Paz y sus familias de acogida. No es menos reseñable el hecho de que allí hubiera una familia de acogida de nuestro centro gracias al proyecto de aprendizaje-servicio.

Así pues, con todas estas acciones cubrimos de una u otra forma las tres metas o pilares sobre los que inicialmente surgió el proyecto: ayuda a los campamentos de refugiados, apoyo a entidades y concienciación en el entorno social del centro

\section{Resultados y conclusión}

Señala Battle (s.f.) que nuestros adolescentes "son ya ciudadanos capaces de provocar cambios en su entorno (...), desplegando sus competencias a través de un amplio abanico de tareas posibles", tales como "sensibilizar a la población", "conseguir recursos para una causa" o "denunciar, defender y reivindicar" (pp.5-6). Así lo advertimos también nosotros a la hora de definir el impacto social que deseábamos conseguir con el proyecto El Sáhara Occidental.

Desde el inicio de cada curso, todo el alumnado es convocado a participar de este proyecto con sus reflexiones, propuestas y colaboración, con diversos niveles, grados de compromiso y duración. A todos los grupos se les da a conocer, en sus rasgos generales, el conflicto saharaui y las difíciles condiciones de vida de los refugiados, y se promueve la participación de todos en las recogidas de ayuda material para las caravanas a Tinduf y en la tradicional Carrera solidaria anual.

En un escalón intermedio, la Asociación deAlumn@s, con la coordinación de Vicedirección, constituye el núcleo dinamizador del trabajo a escala de todo el instituto, en el que ha destacado la Comisión de Solidaridad de la Asociación, creada a partir de las tareas vinculadas al aprendizajeservicio. En sus reuniones propias, los chicos y chicas de la Asociación han evaluado muy positivamente el trabajo llevado a cabo, sin desatender los errores cometidos, que han ido corrigiendo con el apoyo de Vicedirección.

En el nivel más reducido, el grupoclase, se ha promovido la participación 
en las campañas de recogida de artículos para las caravanas solidarias, a través de las tutorías, con la colaboración de la junta de delegados y delegadas y con la coordinación y el impulso de Vicedirección. A ese nivel también se propicia la reflexión colectiva en las tutorías, favoreciendo la disposición del alumnado a asumir sus propios servicios y a conseguir los aprendizajes necesarios para ello dentro de diferentes asignaturas: los estudiantes eligen temas de investigación, formas de expresión o productos que deben resultar de los aprendizajes conseguidos, según los casos, para hacer realidad el servicio que deben prestar (ayuda material, difusión, etc.).

Creemos asimismo que cala entre una parte del alumnado la necesidad de implicarse en la resolución de los problemas sociales; y que, si bien la lejanía de los destinatarios últimos de nuestro trabajo hace más difícil visualizar el conflicto del Sáhara Occidental y las necesidades de los refugiados, el pueblo saharaui va ganando una presencia y cotidianeidad crecientes en el instituto, lo cual debe contribuir a rechazar las ideas xenófobas y racistas.

Ha sido visible el avance de la Asociación de Alumn@s en compromiso, organización, autonomía y cohesión, lo cual indica que es posible ejercitar mucho más la competencia del resto de nuestro alumnado para analizar problemas reales, proponer y desarrollar respuestas y evaluar los resultados de su acción.

No han quedado al margen de esta evolución los propios docentes, entre los cuales se ha ido conformando un núcleo que ha consolidado su compromiso hasta llegar a trabajar como una pequeña asociación de solidaridad: actualmente, no solo desarrollamos las actividades curriculares vinculadas al proyecto, sino que desempeñamos también diversidad de tareas de difusión, ayuda material y asistencia a las asociaciones, tanto de forma colectiva como a nivel particular.

En el apartado del servicio, docentes y Asociación de Alumn@s hemos valorado muy positivamente los resultados: en primer lugar, hemos contribuido a difundir los fines y actividades de las asociaciones participantes, y hemos atendido algunas necesidades que nos han planteado. Por otro lado, hemos llevado el conflicto del Sáhara Occidental a todas nuestras actividades y allí donde nos han invitado a explicar nuestro proyecto. $Y$, en lo que se refiere a la ayuda material a la población saharaui refugiada, hemos logrado incrementarla y diversificarla.

Por último, hemos cubierto otros dos objetivos. En primer lugar, el que nuestro proyecto se haya dado a conocer a la opinión pública ha ido abriendo nuevas perspectivas de mejora y extensión del proyecto. Por otra parte, hemos logrado implicar a instituciones del ámbito local, y en particular a los poderes públicos, lo cual fortalece la capacidad de intervención del proyecto $y$, al mismo tiempo, puede facilitar su arraigo en el territorio circundante. De acuerdo con Rubio y Lucchetti (2016), el hecho de contar con unas condiciones favorables para el trabajo coordinado con las entidades, 
manteniendo la autonomía del centro educativo y la capacidad de adaptación del proyecto, así como fortalecer la relación con aquellas, son factores capitales para consolidar los proyectos de aprendizaje-servicio y darles continuidad.

Tal y como destacan señaladas especialistas en el aprendizaje-servicio, con este tipo de proyectos se produce un "círculo virtuoso", por el cual "los aprendizajes académicos mejoran la calidad del servicio ofrecido", mientras que el servicio "estimula la adquisición o producción de nuevos conocimientos" a la vez que "otorga sentido al aprendizaje", fomentando el compromiso de los estudiantes con la mejora de la sociedad (Tapia y Montes, 2017, 20; Batlle, s.f., 4). Creemos que en el IES La Foia d'Elx, aunque queda mucho por hacer todavía, el lejano Sáhara está ayudando a nuestro alumnado a forjar ese círculo.

\section{Referencias bibliográficas}

Batlle, R. (s.f.). Proyecto Social. Guía práctica de aprendizaje-servicio. Madrid, España: Santillana. Recuperado de https://roserbatlle.net/wpcontent/uploads/2018/09/Guiapractica-ApS.pdf

Campillo, J. y Para, M.A. (2003). El viaje solidario al Sahara: un nuevo tipo de campo de aprendizaje. Íber. Didáctica de las Ciencias Sociales, Geografía e Historia, 36, 47-54. Recuperado de https://www.grao.com/es/producto/elviaje-solidario-al-sahara-un-nuevo-tipode-campo-de-aprendizaje
Del Campo, G., Gimelli, A., Tapia, M.N. (2017). Escuelas para el encuentro. Cómo desarrollar proyectos de aprendizaje-servicio solidario. Buenos Aires, Argentina: Centro Latinoamericano de Aprendizaje y Servicio Solidario (CLAYSS).

Recuperado de www.clayss.org/04_publicaciones/Manu al_CLAYSS_Scholas.pdf

Fernández Álvarez, J.M. (2014). De la investigación al aula: la explotación de los fosfatos del Sahara Occidental español (1945-1975). Íber. Didáctica de las Ciencias Sociales, Geografía e Historia, 76, 18-24.

Fernández Pou, M. (2002). Al cor de la memòria. Les vivències de la Guerra Civil. Articles. Didàctica de la Llengua $i$ de la Literatura, 28, 45-52. Recuperado de

https://www.grao.com/es/producto/alcor-de-la-memoria-les-vivencies-de-laguerra-civil-ar0289109

Martín, E., Solari, M., Luque, M.J., De Vicente, J., Nieto, M., Coll, C. (2017). La potencialidad del aprendizajeservicio para la personalización del aprendizaje escolar. En M.A. Herrero (Presidencia), IV Jornada de investigadores sobre aprendizajeservicio. Buenos Aires, Argentina. Recuperado de www.clayss.org.ar/JIAS/IV_jias/Libro_I VJIA-S.pdf

Mendía, R. (2012). Guías Zerbikas 5: Aprendizaje y servicio Solidario: un proyecto integrado de aprendizaje. Bilbao, España: Zerbikas Fundazioa. Recuperado de www.zerbikas.es/wpcontent/uploads/2015/07/5.pdf 
Puig, J. (2010). Com fer APS en els centres educatius? Barcelona: Fundació Jaume Bofill. Recuperado de https://aprenentatgeservei.cat/wpcontent/uploads/guies/aps_centres_edu catius_3.pdf

Rubio, L. (Coord.). (2008). Guías Zerbikas 0: Aprendizaje y servicio solidario. Guía de bolsillo. Bilbao, España: Zerbikas Fundazioa.

Recuperado de http://www.zerbikas.es/wpcontent/uploads/2015/07/0.pdf

Rubio, L. y Lucchetti, L. (2016). ApS: pau, drets humans i solidaritat. Noves propostes d'educació per a la justícia global. Barcelona, España: Fundació Jaume Bofill. Recuperado de https://aprenentatgeservei.cat/wpcontent/uploads/guies/guia_pau-dretshumans-i-solidaritat_web.pdf.

Tapia, M.N. y Montes, R. (Eds.). (2017). Herramientas prácticas para desarrollar un proyecto de aprendizaje-servicio solidario. Buenos Aires, Argentina: Centro Latinoamericano de Aprendizaje y Servicio Solidario (CLAYSS).

Recuperado de http://www.clayss.org.ar/uruguay/3_He rramientas.pdf

Torregrosa, A. (Agosto de 2017). Impacto del aprendizaje servicio en el alumnado 5 años después: un estudio longitudinal. En M.A. Herrero (Presidencia), IV Jornada de investigadores sobre aprendizajeservicio. Buenos Aires, Argentina. Recuperado de www.clayss.org.ar/JIAS/IV_jias/Libro_I VJIA-S.pdf
Valero, A. (2020). Las campañas de recogida de alimentos desde el aprendizaje-servicio. Íber. Didáctica de las Ciencias Sociales, Geografía e Historia, 98, 55-60. 


\title{
Intérpretes de las necesidades de la comunidad
}

\author{
Verónica Yépez-Reyes \\ Juan Carlos González Ortiz \\ Elizabeth García Alarcón \\ Pontificia Universidad Católica del Ecuador
}

\section{Resumen}

En el Ecuador existe una relación especial entre instituciones de educación superior y organizaciones de la sociedad civil, especialmente con comunidades urbanomarginales y rurales, que busca promover un futuro transformador. Las instituciones de educación superior, además de generar conocimiento, son responsables de transferirlo hacia la sociedad. Este artículo, a partir de un método exploratorio de investigación de los proyectos, propuestas y modelos de vinculación, busca responder a la pregunta ¿Cómo articular las funciones sustantivas de la educación superior para ser verdaderos intérpretes de las necesidades de la comunidad? Los resultados se resumen en un diseño de articulación de la investigación, docencia y vinculación; un sistema de gestión de la vinculación entre instituciones de educación superior y organizaciones de la sociedad civil; y una plataforma de encuentro entre ambas. Esto abre la posibilidad de continuar la investigación y la validación empírica de estos instrumentos.

\section{Palabras clave}

Vinculación, instituciones de educación superior, organizaciones de la sociedad civil, sistema de gestión. 


\title{
Interpreting the needs of the community. A proposal for a management system of the links between higher education institutions and civil society organizations in Ecuador.
}

\begin{abstract}
The relationship between higher education institutions (HEIs) and civil society organizations (CSOs), and their specific focus on urban-marginal and rural communities, seeks to promote a transformational future for the society in Ecuador. Besides generating knowledge, HEIs are responsible for transferring such knowledge to society. For this reason, this article seeks to offer a proposal for the management of community outreach work based on an exploratory research method used in the projects, proposals and community outreach models of HEIs in Ecuador and internationally. We seek to answer the question of how to articulate the substantive functions of higher education in order to acknowledge the significant weight that community outreach has in academic work. The outcomes of this research are: a) a design of articulation of research, teaching and community outreach; b) a management system to connect HEIs-CSOs; and c) a meeting platform between IES and CSOs. This will open the way for continuing to research and empirically validate the instruments.
\end{abstract}

\section{Keywords}

Community outreach, higher education institutions, civil society organizations, community outreach management system. 


\section{Introducción}

La misión de las Instituciones de Educación Superior (IES) en el Ecuador -universidades, escuelas politécnicas, institutos superiores técnicos, tecnológicos, pedagógicos, de artes y conservatorios- se cumple a través de tres procesos fundamentales: formación de profesionales e investigadores generación y difusión de conocimiento, y vinculación con la colectividad (Rueda, Acosta y Cueva, 2018).

La educación superior enfrenta múltiples y diversos cambios. Ahora, los principios que rigen la educación superior colocan al estudiante como eje fundamental del proceso de enseñanzaaprendizaje. Por otra parte, ha tomado gran impulso la relación entre las IES y las organizaciones de la sociedad civil (OSC) propiciando relaciones más fuertes y duraderas, encaminadas a una transformación positiva de la sociedad.

El estudio de Ramírez, Gutiérrez y López (2018) sobre participación de la sociedad civil en el Ecuador señala que "la sociedad civil, en su heterogeneidad de actores, recursos e intereses, puede conectarse a través de los nuevos espacios participativos con los procesos de toma de decisiones y abrir ejercicios de rendición de cuentas al sistema político" (p.11).

Es importante notar que actualmente las IES se fundamentan en lo humano, en la adquisición de conocimientos profesionales al servicio de otras personas y grupos sociales, creando sinergias entre las IES y las OSC. Esto da cuenta del carácter dinámico de las IES, ya que hace apenas diez años se hablaba de universidad de élites y universidad de masas:

Hoy en el contexto de la universidad moderna de masas, de la universidad moderna de investigación y de la universidad moderna de élites, la formación profesional se ha transformado en un proceso permanente, continuo y para toda la vida. La investigación ha pasado de ser una práctica para alimentar la academia a una práctica para la producción, socialización y comercialización del conocimiento; y la extensión ha pasado de ser un servicio social asistencial a un conjunto de acciones, patrones y modelos que involucran las dos funciones anteriores y favorecen la intervención y proyección social de la universidad (Malangón 2009, p.1).

Si bien hoy en día los modelos, propuestas y proyectos pedagógicos de las IES son personalizados y centrados en las y los estudiantes -alejándose de la idea de las masas estudiantiles- la relación que plantea Malagón (2009) entre IES y OSC es muy actual. Esta relación ha de tomar en cuenta factores multi-actorales y de sostenibilidad de los procesos que determinan necesidades y quehaceres conjuntos.

La investigación que se realiza en las IES se entiende como una herramienta que articula los saberes sociales y los de la academia. Se procura entonces la participación responsable de las IES y

Yépez-Reyes, V., González, J.C., y García, E. (2020). Intérpretes de las necesidades de la comunidad. RIDAS, Revista Iberoamericana de Aprendizaje Servicio, 9, 142-154. DOI10.1344/RIDAS2020.9.9 
las OSC en el desarrollo de iniciativas, proyectos y programas de vinculación que se nutran del perfil de los y las estudiantes, de las líneas de investigación de las IES y de las necesidades reales y sentidas de la comunidad.

La vinculación se construye participativamente entre todos los actores involucrados, las IES no imponen criterios sin opción a réplica, al contrario, se constituyen en intérpretes de la realidad y constructoras de consensos para generar un trabajo conjunto, activo y participativo. Tampoco las comunidades son únicamente beneficiarias pasivas de la intervención, al contrario, la relación IES-OSC es activa y requiere de compromisos compartidos. El principio del trabajo interdisciplinario está en el centro de la atención, y requiere de la participación conjunta y complementaria de varias carreras y campos del saber para enfrentar sistémicamente las necesidades sentidas.

\section{Responsabilidad Social Universitaria}

Ser socialmente responsable es una de las demandas de la sociedad actual que considera a la responsabilidad de todo tipo de organizaciones como un deber a cumplir, sobre todo, como plantean Rueda, Acosta, Cueva e Idrobo (2019, p. 62), la responsabilidad social "ofrece un nuevo enfoque al insistir en la importancia de la concienciación de los valores e intereses sociales y los efectos que tienen éstos en el entorno en que las organizaciones se desenvuelven". Así, en el ámbito de la educación superior se ha insertado con mucha fuerza el enfoque de la responsabilidad social universitaria (RSU).

La propuesta de políticas y gestión de la RSU de la Asociación de Universidades confiadas a la Compañía de Jesús en América Latina (AUSJAL) promueve "impulsar una vinculación directa de estudiantes universitarios en proyectos de intervención social", con el fin de "poner el conocimiento generado y difundido en la universidad al servicio de la comunidad, en especial de quienes tienen menos oportunidades de acceso, propiciando el diálogo de saberes" (AUSJAL, 2014, p.19).

La AUSJAL plantea gestionar la RSU (Fig. 1) a través de cuatro criterios fundamentales: experiencia vivencial, conocimiento y análisis crítico de la historia y realidad contemporánea del país y región, alta capacidad técnica y profesional y sentido de lo público. La experiencia vivencial promueve el contacto directo con comunidades, particularmente con aquellas marginales y vulnerables en donde se evidencian y buscan causas para "la poca generación de oportunidades y bienestar para las grandes mayorías" (AUSJAL, 2014 p. 16). 
Figura 1. Responsabilidad Social Universitaria AUSJAL

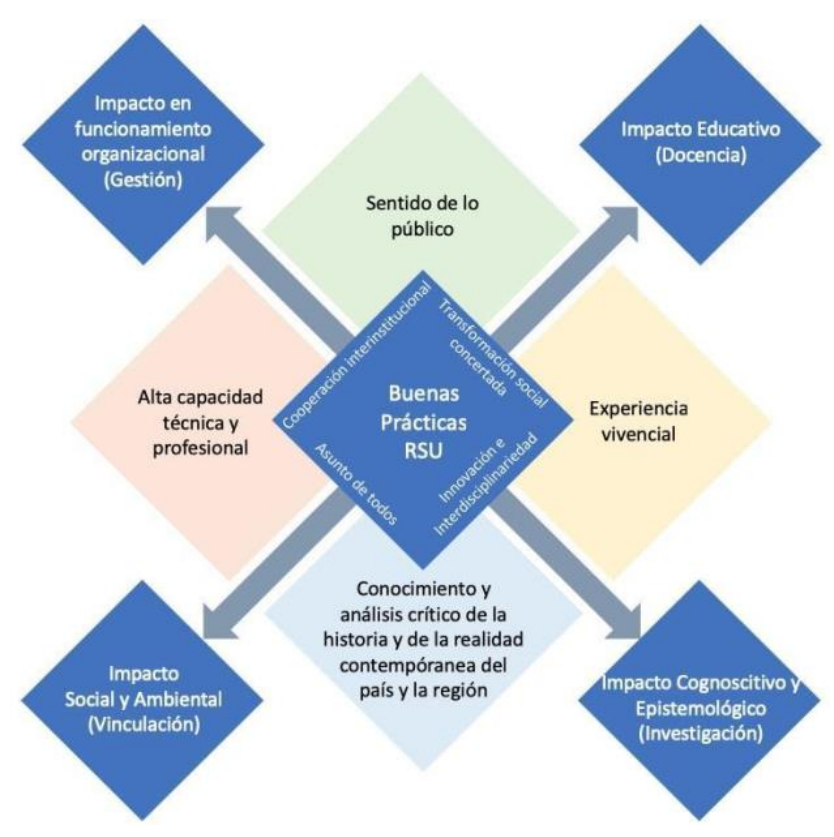

Fuente: elaboración propia

De esta manera, la práctica de RSU implica apertura a la innovación pedagógica y científica, interdisciplinariedad, cooperación interinstitucional y trabajo en red, compromiso de todos los actores implicados y, sobre todo, apunta a una transformación social concertada. Como resultado busca impactar en cinco aspectos: educativo, cognoscitivo y epistemológico, social, organizacional y ambiental.

Así se busca favorecer la formación universitaria con conciencia crítica, generando espacios de reflexión y participación, proponiendo respuestas efectivas para el desarrollo y la inclusión social, y, fomentando el diálogo de saberes a través de diversas estrategias comunicacionales.

\section{Articulación de las funciones sustantivas de las IES}

En América Latina, muchas IES involucran a estudiantes en proyectos de vinculación comunitaria (Tapia, 2016). Autores como Álvarez y Villareal (2019) plantean la adopción de esta metodología con un enfoque interdisciplinario en dos niveles, uno sistemico curricular y otro instrumental de aprendizaje-servicio. En el caso de Ecuador, la participación de estudiantes y docentes en estos proyectos es parte del currículo, según la Ley Orgánica de Educación Superior (LOES).

La articulación tripartita de las funciones sustantivas de la educación superior permite la suma de vinculación (V)+investigación(I)+docencia(D), dando como resultado la adquisición de una experiencia significativa para todos los participantes del proceso, pero de manera particular para estudiantes de las IES.

La Figura 2 muestra cómo la articulación $\mathrm{V}+\mathrm{I}+\mathrm{D}$ permite alcanzar la formación integral centrada en la persona capaz de responder a los problemas y necesidades de la sociedad (Estado, empresa y comunidad) y proveer respuestas transformadoras. 
Figura 2. Formación integral centrada en la persona

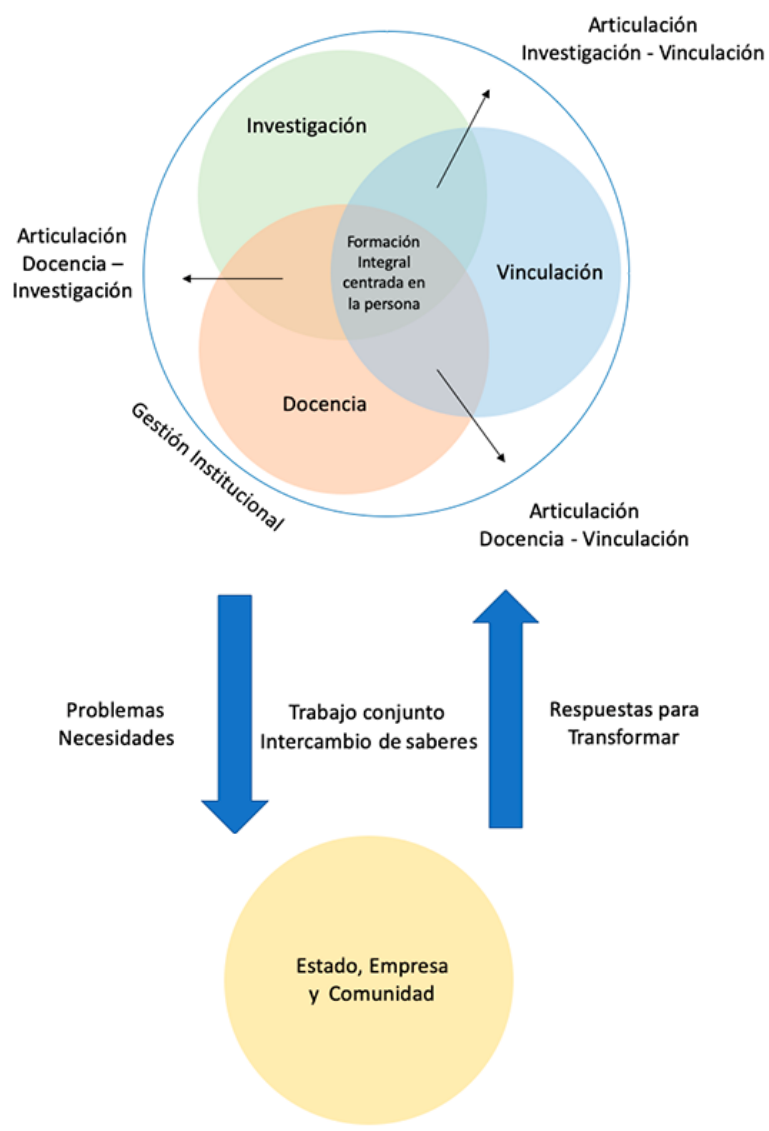

Fuente: elaboración propia

La docencia es entendida como la formación académica de estudiantes y tiene como finalidad desarrollar una alta capacidad técnica y profesional para asegurar el conocimiento y el análisis de la realidad de manera crítica con el fin de proponer soluciones coherentes y viables a las distintas problemáticas sociales.

La investigación se considera como el espacio para la exploración de tecnologías innovadoras, la producción y la democratización del saber. Las metodologías de investigación aplicada suponen la búsqueda de una articulación entre tecnociencia y saberes sociales para evitar la fragmentación y favorecer el intercambio del conocimiento con la comunidad.

La vinculación responde a la participación responsable de las IES en el desarrollo humano sostenible de la comunidad, ejecutando programas y proyectos que articulen el perfil profesional de los estudiantes, las líneas de investigación de la universidad, la agenda política vigente y las necesidades de la comunidad en un diálogo continuo de coparticipación. Todo esto tiene la finalidad de transformar la realidad mejorando la calidad de vida de la sociedad (González, 2018).

El impacto social que tiene la sinergia $\mathrm{V}+\mathrm{I}+\mathrm{D}$, encamina tres resultados clave: la adaptación curricular, el establecimiento de nuevas líneas de investigación y la transformación social. Su fin último es una mejora de la calidad de vida de las comunidades.

\section{Sistema de vinculación}

El estudio de Tapia (2016) da cuenta de la inserción del aprendizaje-servicio, como una estrategia de la vinculación dentro del currículo en Hispanoamérica. Según la autora, para que una actividad de vinculación sea considerada de aprendizaje-servicio ha de cumplir con tres condiciones fundamentales: atender necesidades reales y sentidas por la comunidad, estar protagonizadas activamente por estudiantes y articularse intencionadamente con los contenidos de aprendizaje curriculares. 
La propuesta de articulación de las funciones sustantivas de la educación superior supone incluir la activa participación de todos los involucrados, es decir el protagonismo por igual de todos los actores sociales o stakeholders.

En Ecuador, en abril de 2018 para intercambiar experiencias entre proyectos de vinculación se llevó a cabo, un evento nacional sobre Buenas Prácticas de Vinculación 1 en la Pontificia Universidad Católica del Ecuador (PUCE). A través de los proyectos seleccionados se dieron a conocer visiones diferentes de la gestión de la vinculación que resaltan por su creatividad, articulación con diversos actores sociales, impacto y sostenibilidad.

Es a partir del análisis de las prácticas de vinculación de las diferentes IES, se propone el siguiente sistema de gestión de vinculación (ver Figura 3). El sistema está compuesto por una primera zona de base horizontal donde se encuentran los fundamentos teóricos y conceptuales de la vinculación, la normativa aplicable y la organización funcional y administrativa para los procesos.

Una segunda zona señala la ruta de respuesta que comienza con el establecimiento de un problema a enfrentar y, a continuación, cuatro fases consecutivas para su gestión: (1) Diagnóstico; (2) Planificación; (3)

1 La revista digital Ruta hacia una Vinculación Responsable (UnOS, 2018) recoge todas estas experiencias: http://www.unos.ec/ruta-haciauna-vinculacion-responsable/
Implementación; (4) Difusión y termina con el resultado esperado: la respuesta efectiva al problema, es decir la realidad transformada. Finalmente, la tercera zona (en la parte superior) muestra los impactos de la vinculación.

Figura 2. Sistema de Gestión de la Vinculación de las IES

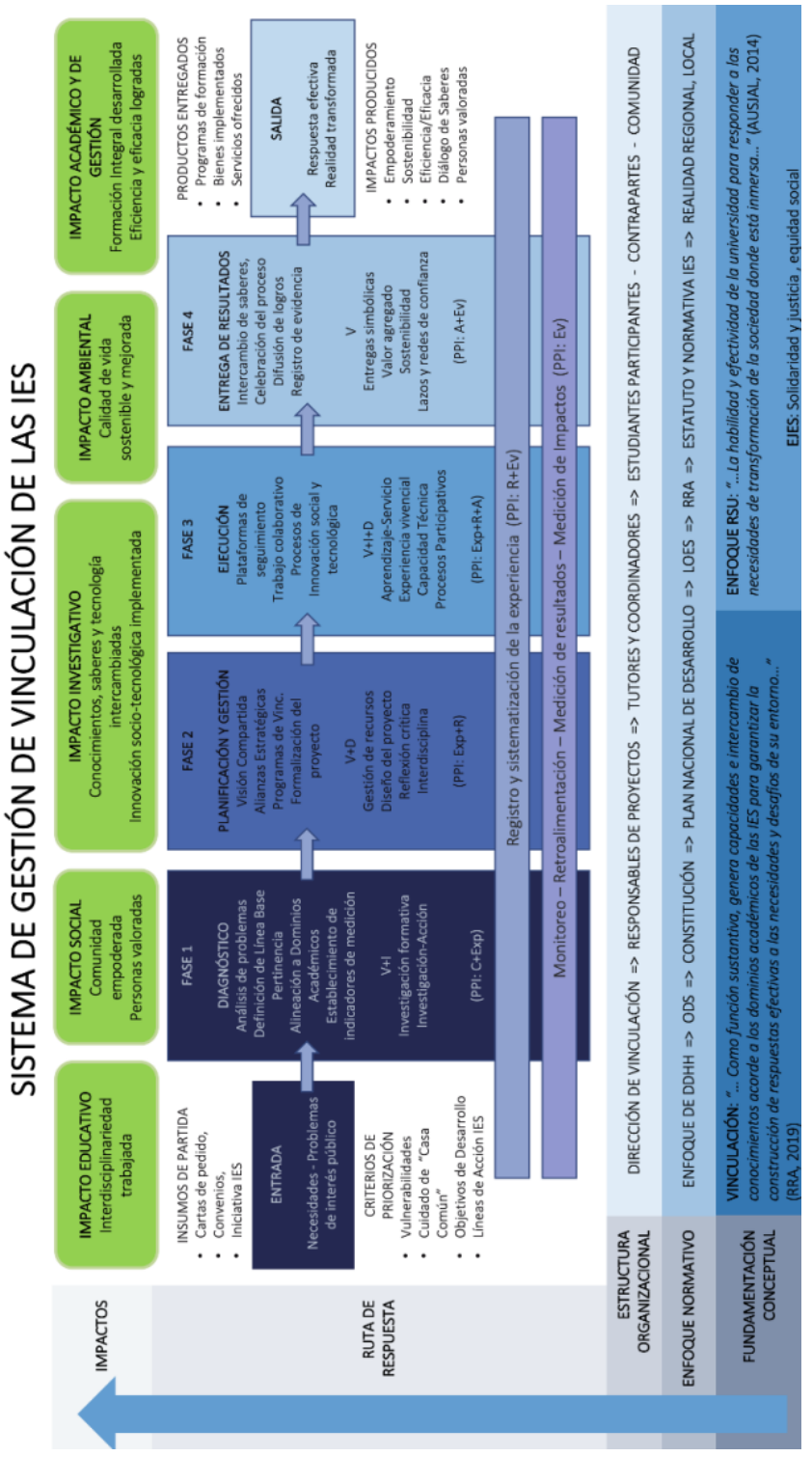

Fuente: elaboración propia 
Es importante recalcar la particular conexión de este sistema propuesto con el proyecto académico que promueve la PUCE: formar personas CON los demás, en donde es importante notar que la propuesta no es la de formar personas PARA los demás, sino que trabajen con los otros; personas conscientes de su contexto histórico y contemporáneo; compasivas, capaces de asumir la realidad del otro como la propia; competentes, con una alta capacitad técnica para ofrecer respuestas efectivas y personas comprometidas con el cambio y la transformación social.

Las fases de la ruta se orientan a intercambiar conocimientos y a generar un trabajo interdisciplinario que aborde integralmente las problemáticas planteadas con el fin de transformar la realidad. Ahora bien, estas cuatro fases tienen una profunda inspiración en el enfoque del paradigma pedagógico ignaciano (PPI) el cual busca una formación integral de la persona humana mediante el desarrollo de la mente, el corazón y la acción como una forma de transformar la realidad (REI, 2014).

Los cinco componentes fundamentales del PPI son: a) análisis crítico de la realidad y de la historia; b) experiencia vivencial en el contexto que marque el sentir de los actores, c) reflexión crítica y profunda sobre la experiencia, d) accionar eficaz y de alta capacidad técnica para la transformación social y e) proceso de evaluación y sistematización constante para intercambiar el conocimiento, difundir los aprendizajes y medir el impacto social.
A continuación, se amplía la información sobre algunas de las actividades sugeridas dentro del sistema de gestión de la vinculación de las IES, no obstante, el abordaje metodológico de cada una de ellas puede variar sustancialmente de un proyecto a otro. La razón es que su implementación depende del contexto social y la perspectiva teóricometodológica de las disciplinas involucradas, por lo que las aclaraciones siguientes solo son orientadoras y responden a los distintos modelos de vinculación implementados por las IES en el Ecuador.

- Diagnóstico: todo proyecto de vinculación inicia con un detallado y profundo análisis de las necesidades reales, concretas y dimensionadas de intervención. Una vez determinadas, se establece la plataforma para el proceso participativo de trasformación social, se construye la visión compartida del proyecto, la línea base, los objetivos, metas e impactos a alcanzar; la ruta de intervención y las estrategias para la participación, innovación social, valor agregado de las respuestas y sostenibilidad a mediano y largo plazo del proyecto.

- Participación con los diferentes actores: por trabajarse con comunidades y grupos sociales vulnerables, los proyectos dependen de la participación plena de los diferentes actores: estudiantes, docentes, comunidades, empresas pública y privada y organizaciones de la 
sociedad civil. Esta participación orientada al empoderamiento comunitario tiene especial importancia ya que permite respetar y aceptar las capacidades "del otro" con un profundo estímulo al diálogo horizontal mediante una constante retroalimentación y monitoreo de procesos y atenta a la posibilidad de impartir y recibir diferentes tipos de conocimiento, en diferentes momentos y niveles (Ríos et al., 2016).

- Reflexión crítica: los proyectos deben promover el aprendizaje, permitiendo a estudiantes cumplir con los requerimientos académicos, asegurando el conocimiento adquirido a través de la investigación y la experiencia de vinculación que conducen a una efectiva reflexión crítica. A través de ella, los estudiantes desarrollan competencias genéricas como trabajo en equipo, comunicación asertiva, gestión de la tecnología, autonomía, creatividad y sensibilidad, investigación, aprendizaje de habilidades específicas de su campo profesional, responsabilidad socio-ambiental, valores éticos y humanísticos. La reflexión crítica también alienta al estudiante a ser asertivo y compasivo, asumiendo la realidad de la comunidad como propia. De esta manera, son capaces de proponer soluciones más contextualizadas (Ríos, González, Armijos, Borja y Montaño, 2016).
Adicionalmente, los resultados de los proyectos deben superar la fragmentación curricular, en busca de soluciones interdisciplinarias y holísticas que conecten diferentes campos de conocimiento con el propósito de alcanzar los objetivos macro de un desarrollo sostenible.

- Plan de acción: El plan de acción prioriza las iniciativas más importantes para cumplir con los objetivos propuestos, constituyéndose en una guía que establece un marco estructural para llevar a cabo los proyectos. Aquí se determina el diseño de la propuesta, los compromisos adquiridos, modalidades de trabajo, asignación de responsables, recursos necesarios y cronograma de actividades. La base de la planeación es priorizar los problemas que tengan más impacto y la manera cómo se llega a posibles soluciones basadas en el contexto y los actores sociales. Aquí se determinan las estrategias y acciones establecidas después del análisis del diagnóstico. Además, cada estudiante da valor agregado aportando con conocimiento específico, de acuerdo a su carrera, y proponiendo soluciones integrales para los problemas encontrados.

- Sostenibilidad: La sostenibilidad de los proyectos en el tiempo permite una constante renovación del trabajo en equipo 
y apertura de nuevos campos profesionales que abordan otras necesidades detectadas a nivel comunitario. Estos nuevos elementos generan una mayor participación social que garantiza el empoderamiento de las partes interesadas, así como un mayor impacto y cooperación (Ríos et al., 2016). La sostenibilidad de un proyecto de vinculación depende de una correcta administración interna de las IES, de una visión transformadora compartida, de un buen diagnóstico, una constante participación con los diferentes actores y una meticulosa reflexión crítica de los resultados.

- Sistematización/evaluación: la sistematización de la experiencia es un proceso de vital importancia en el ciclo del proyecto ya que permite mantener un registro ordenado de la evolución de las acciones y la evidencia levantada, lo cual, provee de insumos para el monitoreo de la intervención, la elaboración de productos comunicativos de difusión y, el procesamiento de datos cualitativos y cuantitativos de verificación de resultados y medición de impactos, a partir de indicadores previamente establecidos en las fases de diagnóstico y diseño del proyecto.

\section{Plataforma tecnológica de vinculación}

Para el trabajo mancomunado y en red en una determinada comunidad, no es fácil juntar en un solo espacio a las IES y OSC. El desafío actual es hacerlo para no detener la gestión propuesta o iniciada o para dar una respuesta emergente ante una coyuntura determinada. No todas las IES cubren todos los campos del saber ni todas las OSC tienen necesidades similares, por ende, la vinculación implica una fuerte dosis de colaboración y adaptabilidad entre una multiplicidad de actores.

Por esto, es indispensable la generación de una plataforma de encuentro, y así se diseñó la Plataforma de Vinculación UnOS, como espacio para la gestión de información y proyectos de vinculación que aprovecha las facilidades de las tecnologías digitales para promover la colaboración entre OSC e IES, y genera conocimiento compartido y desarrolla capacidades que permitan redefinir y fortalecer las relaciones entre el Estado y la sociedad civil.

La plataforma de Vinculación UnOS es un espacio virtual de encuentro entre las instituciones de educación superior y las organizaciones de la sociedad civil, refuerza lazos de colaboración y cooperación en proyectos conjuntos. Ésta se encuentra actualmente alojada dentro del portal www.unos.ec pero es lo suficientemente dinámica para poder alojarse en redes más sólidas de OSC o de IES dispuestas a fortalecer estos lazos y aprovechar la sinergia del trabajo conjunto y en red.

Además de los datos informativos de las OSC e IES, la plataforma permite el ingreso y despliega proyectos que se desarrollan en territorio, gracias a la georreferenciación de los datos. La 
plataforma permite conocer, publicar información, colaborar, entrar en contacto, crear alianzas estratégicas y enlaces de negocios entre instituciones de educación superior y organizaciones de la sociedad civil. También provee un repositorio con información documental de interés con normativas y manuales, entre otros.

El uso de plataformas tecnológicas para fortalecer el trabajo en red no es una novedad, ya las empresas e industrias público-privadas desarrollan estas herramientas para identificar y priorizar las necesidades de investigación e innovación en distintos campos y así impulsar el trabajo multidisciplinario para el desarrollo de proyectos con sentido social (Mena, 2008). Sin embargo, suelen ser plataformas impulsadas por una sola organización que pretende articularse a otras. El principal aporte de esta plataforma de vinculación es gestionarla desde una red de educación superior, para que pueda ser de utilidad a varias IES de entrada y varias OSC de salida y viceversa. De esta forma, la información aportada por cada uno de los registros y que fluye a través de redes de información estará disponible para la libre asociación, la investigación y el desarrollo de respuestas a las problemáticas sociales priorizadas.

\section{Conclusiones}

La relación entre las IES y las OSC genera cambios y promueve transformaciones en el contexto del cual forman parte. Las IES, además de generar conocimiento, deben diseminarlo, intercambiarlo y aplicarlo en la sociedad por lo que actúan como intérpretes de las necesidades comunitarias. La propuesta de gestión de la vinculación presentada se construyó con base en las buenas prácticas y articula las funciones sustantivas de la universidad en favor de la formación integral y significativa de todos los actores involucrados en estos procesos de transformación.

La vinculación se construye participativamente con todos los actores involucrados, sin imposición desde la academia ni recepción pasiva en la comunidad. Cuando las IES son intérpretes de las necesidades de la comunidad se involucran en los procesos de diálogo e intercambio de saberes para fomentar el desarrollo.

La propuesta de articulación de las tres funciones sustantivas se sustenta en el trabajo interdisciplinario, la reflexión crítica, la oportunidad de relacionar la academia con la realidad concreta de la comunidad, la necesidad de intercambiar conocimiento para apoyar el desarrollo local, el esfuerzo por lograr el empoderamiento de la comunidad de sus propios procesos y la evaluación constante como una buena práctica de desarrollo social sostenible.

Finalmente, la respuesta adecuada ante situaciones de crisis como la que vivimos actualmente en el 2020, es la utilización de plataformas tecnológicas, que gestionan información y permiten la colaboración entre OSC e IES. De esta manera, el conocimiento es compartido y desarrolla capacidades que redefinen y fortalecen las relaciones entre el Estado y la sociedad civil, en donde la IES ocuparían el lugar de mediadoras en esta compleja 
relación.

Los resultados constituyen solamente instrumentos útiles para fortalecer proyectos de vinculación en donde tanto IES como OSC son actores fundamentales y motores del cambio. Su puesta en práctica abre la posibilidad de futuras investigaciones que den cuenta de su empleo en propuestas diversas.

\section{Referencias bibliográficas}

Álvarez, A. y Villareal, M. (2019). Integración interdisciplinaria en el aprendizaje-servicio. RIDAS. Revista Iberoamericana de Aprendizaje Servicio, (8), 96-105. doi: 10.1344/RIDAS2019.8.5

AUSJAL. (2014). Políticas y sistema de autoevaluación y gestión del a responsabilidad social universitaria en AUSJAL. Córdoba, Argentina: EDUCC Universidad Católica de Córdoba.

Recuperado de https://www.ausjal.org/wpcontent/uploads/Pol\%C3\%ADticas-ySistemas-de-Autoevaluaci\%C3\%B3n-yGesti\%C3\%B3n-de-la-RSU-en-AUSJAL2014.pdf

González, J. (2018). Buenas prácticas para las Experiencias Significativas en la proyección social de la PUCE. Buenas Prácticas de Vinculación con la Colectividad de la PUCE 2017, 1, 2-7. Recuperado de http://edipuce.edu.ec/buenaspracticas-de-vinculacion-con-lacolectividad-no-1/
Malagón, L. (2009). La relación universidad-sociedad: una visión crítica. Revista Perspectivas Educativas, 2, 1750. Recuperado de http://revistas.ut.edu.co/index.php/per spectivasedu/article/view/787

Mena, N. (2008). Plataforma informática para la gestión en red de información multimedia y geoespacial orientada a grupos sociales que trabajan en entornos virtuales distribuidos. Acimed, 18(6), 1-15. Recuperado de: http://scielo.sld.cu/pdf/aci/v18n6/aci06 1208.pdf

Ramírez, F. (Coord.). (2018). Participación de la Sociedad Civil en Ecuador 2008-2018: Diseños Institucionales, Conflicto y Participación Popular en la Política Pública. Quito, Ecuador: UnOS. Recuperado de http://www.unos.ec/wpcontent/uploads/2019/03/ESTUDIOPARTICIPACI\%C3\%93N-DE-LASOCIEDAD-CIVIL-EN-ECUADOR.pdf

REI. (2014). Proyecto Educativo Institucional de la Red Educativa Ignaciana del Ecuador. Quito, Ecuador: Secretaria de Educación de la Provincia Ecuatoriana de la Compañía de Jesús.

Ríos, R., González, J., Armijos, E., Borja, K. y Montaño, M. (2016). Estrategias para el Arquitecto intérprete: El Consultorio en el Laboratorio de los Paisajes Vivos. 
Arquitecturas del Sur, 34(49), 22-31.

Recuperado de

http://revistas.ubiobio.cl/index.php/AS/

article/view/2264

Rueda, I., Acosta, B. y Cueva, F. (Junio de 2018). Las universidades y su

entorno: la vinculación con la sociedad y el rol de la transferencia de tecnología. Ponencia presentada en el XII Congreso Iberoamericano de Contabilidad de Gestión y IV Congreso de Gestión Empresarial Ilevado a cabo en la Facultad de Ciencias

Administrativas y Contables de la Pontificia Universidad Católica del Ecuador, Quito.

Rueda, I., Acosta, B., Cueva, F. e Idrobo, P. (2019). Modelos de Responsabilidad Social Universitaria. En J. C. González, V. Yépez Reyes, y E. García (Eds.), Vinculación con la Colectividad: una propuesta de gestión (pp. 59-84). Quito, Ecuador: Centro de Publicaciones PUCE. Recuperado de http://edipuce.edu.ec/wpcontent/uploads/2019/08/Vinculacion_c on_la_colectividad.pdf

Tapia, M. N. (2016). Inserción curricular del aprendizaje- servicio en la

Educación Superior. Buenos Aires, Argentina: Ediciones CLAYSS.

Recuperado de http://www.clayss.org/04_publicacione s/Insercion_curricular_EdSup.pdf 


\title{
La institucionalización del aprendizaje-servicio solidario en la Orquesta-Escuela de Chascomús
}

\author{
Geronimo Daguerre \\ Universidad Nacional de La Plata, Argentina
}

\section{Resumen}

El aprendizaje-servicio solidario es una propuesta de innovación educativa para los procesos de enseñanza-aprendizaje, con amplia difusión en el panorama internacional. Sin embargo todavía no abundan desarrollos que se enfoquen en el campo musical y en especial en sistemas educativos no formales. A partir de la revisión de documentos institucionales, la observación de diferentes proyectos y entrevistas grupales a diversos actores, se intenta establecer una línea de base tanto para favorecer la institucionalización de estas prácticas, como para implementar un futuro modelo evaluativo sobre el impacto socioeducativo que tiene este proyecto para la comunidad, sus alumnos y la escuela.

\section{Palabras clave}

Rúbrica, desarrollo organizacional, aprendizaje-servicio solidario, orquesta escuela. 


\title{
The institutionalization of Solidarity Service Learning in the practices of the Orchestra School of Chascomús
}

\begin{abstract}
Solidarity Service Learning is an educational innovation proposal that optimizes teaching-learning processes, which has acquired great academic relevance and wide dissemination in the international scene. However, these practices are not yet common in the area of developments that focus on the musical field and especially on non-formal educational processes. Based on a review of the institutional documents of the Orchestra School of Chascomús, a visit to its different projects and interviews with various agents involved in the establishment and development of this school, this paper attempts to establish a baseline in order to both promote the institutionalization of their practices and to implement a model for the future evaluation of the socioeducational impact that this project has for the community, its students and the school.
\end{abstract}

\section{Keywords}

Rubric, organizational development, solidarity service learning, school orchestra. 


\section{Introducción}

La Orquesta-Escuela de Chascomús (OECh) promueve iniciativas conjuntas en diferentes localidades de la Argentina con la finalidad de potenciar las acciones territoriales destinadas a revertir situaciones de desigualdad educativa, social y cultural.

De esta manera los alumnos aprenden y se desarrollan a través de la participación en programas $\mathrm{y} / \mathrm{o}$ proyectos, que se realizan en la comunidad y se dirigen a satisfacer las necesidades de la misma. Algunas actividades surgen como propuestas de articulación con instituciones educativas y comunitarias locales, en las que se ofrecen espacios didácticos-musicales de acuerdo al perfil que se aspira impactar. Dichas actividades se coordinan con escuelas primarias, secundarias u organizaciones barriales, y programas de servicio comunitario; esto promueve ciudadanía al mismo tiempo que invita a formar parte de las actividades dentro de la Orquesta

\section{Experiencia desarrollada}

La rúbrica de Furco (2005) sirvió para establecer una serie de criterios sobre los cuales fuera posible medir la institucionalización del aprendizajeservicio en la Orquesta-Escuela de Chascomús, en el año 2019.

Los objetivos planteados fueron los siguientes:

- Operacionalizar la rúbrica de Furco al desarrollo organizacional de la Orquesta-Escuela;

- Problematizar el grado de institucionalización de las prácticas de aprendizaje-servicio;

- Establecer un panorama previo para realizar una evaluación de impacto del proyecto en la comunidad a través del método de control sintético.

Dicha rubrica facilitó los grupos focales de discusión entre actores y permitió medir ciertos logros alcanzados para determinar el estatus de la institucionalización y asegurar la futura realización de un esfuerzo sistemático y comprensible en el impulso de estas prácticas hacia la comunidad. A continuación se explica la concreción de cada una de las dimensiones.

\subsection{Dimensión 1. Misión del aprendizaje-servicio solidario}

El desarrollo de una definición a nivel de toda la organización sobre el aprendizaje-servicio permite entregar significado, focalización, y énfasis a los esfuerzos de la misma. Lo anterior involucra a los actores de la institución que participan y define el grado en el que el aprendizaje-servicio es parte constitutiva de la organización. La Orquesta-Escuela de Chascomús se encuentra en una etapa de construcción, ya que todavía hay ciertas inconsistencias en la aplicación de una definición concreta.

Se entiende que la definición de este concepto es una dimensión fundamental y previa para el logro de su institucionalización. Si bien se han

Daguerre, G. (2020). La institucionalización del aprendizaje-servicio solidario en la Orquesta-Escuela de Chascomús. RIDAS, Revista Iberoamericana de Aprendizaje Servicio, 9, 155-161. 
definido algunas metas de corto y largo plazo, no han sido formalizadas dentro de un planeamiento estratégico que guíe la implementación de dichas metas. La organización aún no cuenta con un planeamiento estratégico, lo que de alguna manera imposibilita también que el aprendizaje-servicio sea parte constitutiva de la misma.

Por otra parte, si bien ciertos rasgos y características del aprendizaje-servicio han sido comúnmente mencionados como parte importante de la misión institucional, todavía esto no se encuentra incluido en la misión oficial.

Finalmente el nivel más débil de esta dimensión es el que refiere a la alineación con las reformas educativas, ya que si bien se desarrollan esfuerzos para generar alianzas entre la Orquesta, la escuela y la comunidad, la particularidad de esta organización reside en que interactúa con diversos actores del sistema educativo formal estando al mismo tiempo fuera del mismo.

En definitiva si bien la definición del aprendizaje-servicio tiene un significado implícito para algunos actores dentro de la organización, existen quienes ponen énfasis para extender esto al nivel de toda la organización. Por el momento no es posible focalizar estos esfuerzos en una dirección concreta que permita hacer del aprendizaje-servicio parte constitutiva de la Orquesta-Escuela de Chascomús.

\subsection{Dimensión 2. Apoyo e} involucramiento de los docentes en el aprendizaje-servicio solidario
Se observa que un número de miembros conocen que es aprendizajeservicio o comprenden de modo implícito en qué medida el aprendizajeservicio es diferente al servicio comunitario, voluntariado u otras actividades de aprendizaje experiencial.

La Orquesta-Escuela de Chascomús se encuentra en una etapa de creación, debido a que muy pocos docentes son defensores del aprendizaje-servicio en su trabajo dentro de la organización. Estas actividades son respaldadas por un reducido número de docentes. Existe una polarización entre el perfil técnicomusical frente a otro mayormente ligado a la defensa de la educación integral mediante el compromiso social. Estos perfiles coexisten de manera notable en el equipo, sin embargo en cuanto al liderazgo, el perfil vinculado con la educación integral se configura hacia el interior de la organización como un grupo de docentes respetado e influyentes que sirven como líderes o defensores de las prácticas del aprendizaje-servicio. Este componente podría servir como una iniciativa futura fundamental en el camino hacia la institucionalización sustentable del aprendizaje-servicio.

Finalmente el aspecto más débil de esta dimensión es el incentivo y reconocimiento a los docentes, ya que si bien existen motivos personales para que estos se involucren en actividades relacionadas con el aprendizajeservicio, igualmente expresan cierta falta de reconocimiento en la evaluación de su participación en estos procesos.

2.3 Dimensión 3. Apoyo e involucramiento de los alumnos en el

Daguerre, G. (2020). La institucionalización del aprendizaje-servicio solidario en la Orquesta-Escuela de Chascomús. RIDAS, Revista Iberoamericana de Aprendizaje Servicio, 9, 155-161. 
aprendizaje-servicio solidario

Un elemento importante para la institucionalización del aprendizajeservicio es el grado en que los alumnos son conscientes de las oportunidades que poseen para desempeñar roles de liderazgo en el desarrollo del aprendizaje-servicio. Si bien existen algunos mecanismos para informar a los alumnos acerca de las actividades relacionadas con el aprendizajeservicio, muchas veces estos desconocen los recursos y oportunidades que la institución brinda, dado que estas se concentran en algunos programas o actividades.

Si bien este aspecto se ubica en una etapa de construcción, debido a la falta de ciertos recursos y mecanismos de información institucionales, por otro lado se observa que las oportunidades para los alumnos gozan de una institucionalización sustentable, dado que las opciones y oportunidades en donde el aprendizaje-servicio se integra a la esencia de las actividades, se presentan disponibles para los alumnos sin consideraciones de edad, años en la organización e intereses.

En cuanto al liderazgo de los alumnos, se ve reflejado en su participación y desempeño al interior de cada formación orquestal, existiendo todavía un limitado número de oportunidades para que estos tomen roles de liderazgo en el fomento del aprendizaje-servicio hacia la organización en su conjunto. Lo anterior surge como un aspecto que institucionalmente está relacionado mayormente con el rol docente.

Finalmente, el incentivo y reconocimiento a los alumnos, al igual que lo ocurrido con los docentes, se presenta también como un aspecto a mejorar o en construcción, ya que si bien la organización ofrece algunos incentivos y reconocimiento informales, igualmente estos todavía resultan insuficientes en comparación a las oportunidades que la organización ofrece a sus alumnos.

\subsection{Dimensión 4. Participación y asociación con socios comunitarios}

Un elemento importante para la institucionalización del aprendizajeservicio es el grado en que la organización fomenta relaciones colaborativas con los socios comunitarios (organizaciones comunitarias, públicas o privadas), y la medida en que fomenta a los representantes de estas organizaciones a desempeñar roles en la implementación e impulso del aprendizaje-servicio.

La Orquesta-Escuela de Chascomús se encuentra en una etapa de construcción, debido a que solo algunos de los socios comunitarios, pero no la mayoría, están conscientes de las metas que la organización tiene con respecto al aprendizaje-servicio y el rango completo de oportunidades de aprendizaje-servicio que los alumnos poseen.

En cuanto al entendimiento mutuo que existe entre la Orquesta-Escuela de Chascomús y sus socios comunitarios, solo algunos son conscientes de las necesidades del otro, los tiempos, objetivos, recursos y las capacidades que cada uno se ha planteado o posee

Daguerre, G. (2020). La institucionalización del aprendizaje-servicio solidario en la Orquesta-Escuela de Chascomús. RIDAS, Revista Iberoamericana de Aprendizaje Servicio, 9, 155-161. 
para desarrollar e implementar actividades de aprendizaje-servicio. Debido a esto es que en ocasiones se manifiestan discrepancias entre los objetivos de cada socio.

En este sentido existen pocas oportunidades para que las personas representantes de los socios comunitarios lideren el fomento del aprendizaje-servicio, ya que estos no son comúnmente incentivados a expresar las necesidades específicas de sus organizaciones, sino que más bien se adecuan a los tiempos, objetivos, recursos y capacidades de la OECh. Esto permite observar para la Orquesta un alto grado de asociación con la comunidad, en referencia a las diferentes actividades de aprendizajeservicio, pero al mismo tiempo un bajo nivel de participación de sus socios comunitarios en roles de implementación e impulso de las actividades.

2.5 Dimensión 5. Apoyo institucional al aprendizaje-servicio solidario

El equipo directivo de la OrquestaEscuela de Chascomús se constituye como la entidad coordinadora que abarca toda la organización, y no solo se dedica a coordinar exclusivamente actividades de aprendizaje-servicio, esto genera que los servicios solo se provean a algunos actores o a parte reducida de la organización. En este sentido si bien la coordinación toma decisiones que reconocen el aprendizaje-servicio como un objetivo educacional esencial para la organización, todavía no se han desarrollado políticas oficiales direccionadas en este sentido. Además si bien el equipo administrativo de la organización posee un claro entendimiento acerca del aprendizajeservicio, todavía no ha realizado el esfuerzo suficiente para que el aprendizaje-servicio se visibilice y vuelva a una parte importante de la organización.

Existe un número apropiado de personas en el equipo de trabajo que comprenden completamente el aprendizaje-servicio y que poseen cargos apropiados desde los cuales pueden influenciar el impulso y la institucionalización dentro de la Orquesta. Sin embargo su involucramiento es temporal o está financiado a través de fondos de corto plazo o externos a la organización. Esto genera ciertas inconsistencias en cuanto al esfuerzo y la participación de sus miembros, haciendo que la cultura organizacional dificulte la continuidad del proceso de institucionalización del aprendizaje-servicio. Por otro lado existen todavía muy pocas orquestas en el país que reconozcan al aprendizajeservicio como una parte de sus programas musicales.

Finalmente en cuanto al aspecto de evaluación que se plantea en la quinta dimensión, se considera que gran parte de este trabajo representa un esfuerzo sistemático y vigente para desarrollar una propuesta de seguimiento acerca del número y la calidad de las actividades de aprendizaje-servicio que desarrolla la Orquesta-Escuela de Chascomús actualmente.

\section{Reflexiones finales}

Algunas experiencias demostraron que

Daguerre, G. (2020). La institucionalización del aprendizaje-servicio solidario en la Orquesta-Escuela de Chascomús. RIDAS, Revista Iberoamericana de Aprendizaje Servicio, 9, 155-161. 
muchas veces no se tuvieron en cuenta las alianzas territoriales, ni la colaboración de ciertas instituciones, haciendo que la vinculación con el aprendizaje-servicio fuera bilateral. Con alguna escuela la responsabilidad era desproporcionada, ya que la desvinculación con el resto de las organizaciones comunitarias, generó un sentido negativo en cuanto a la pertenencia de este proyecto.

Si las actividades en una escuela finalizaban se terminaba el proyecto de servicio comunitario y frente a esto, en ocasiones la escuela no terminaba de constituirse en un agente activo que propicie las tareas de promoción humana. En otros casos, no hubo entre el aprendizaje-servicio y la tarea áulica; ya que el planteo pareciera ser totalmente extracurricular, con lo que se afectaba la inserción del aprendizaje-servicio en la escuela.

En los proyectos que tuvieron como objetivo fortalecer los compromisos del alumnado con la escuela, el aprendizaje-servicio entraba en juego sólo en forma tangencial, ya que los esfuerzos se dirigieron a apuntalar el compromiso escolar y el sentido de pertenencia de los alumnos con la escuela. En estos casos, la relación horizontal de la Orquesta-Escuela de Chascomús con la escuela y la comunidad se vio comprometida, ya que la escuela tiende a asumir una posición central, intentando absorber al espacio comunitario.

En general se vio que los organismos de la comunidad local trabajan aspectos educativos a través del apoyo escolar, trabajando en el marco de la contención y fomentando la reinserción de niños y jóvenes en el sistema educativo desde el aprendizaje-servicio desarrollado en la Orquesta-Escuela de Chascomús.

\section{Referencias bibliográficas}

Furco, A. (2005). Impacto de los proyectos de aprendizaje servicio. Aprendizaje y servicio solidario en la Educación Superior y en los sistemas educativos latinoamericanos. Actas del 70 Seminario Internacional Aprendizaje y Servicio Solidario, Buenos Aires (Argentina), 19-26. Recuperado de http://www.ucv.ve/fileadmin/user_uplo ad/facultad_ciencias_juridicas/cservicio cominitario/AprendizajeyservicioenlaEd ucaciOnSuperior_y_en_sistemaseducati voslatinoamericanos.pdf

Daguerre, G. (2020). La institucionalización del aprendizaje-servicio solidario en la Orquesta-Escuela de Chascomús. RIDAS, Revista Iberoamericana de Aprendizaje Servicio, 9, 155-161. 